Portland State University

PDXScholar

Spring 6-6-2018

\title{
Flexural Strength, Ductility, and Serviceability of Beams that Contain High-Strength Steel Reinforcement and High-Grade Concrete
}

Anas Yosefani

Portland State University

Follow this and additional works at: https://pdxscholar.library.pdx.edu/open_access_etds

Part of the Civil and Environmental Engineering Commons Let us know how access to this document benefits you.

Recommended Citation

Yosefani, Anas, "Flexural Strength, Ductility, and Serviceability of Beams that Contain High-Strength Steel Reinforcement and High-Grade Concrete" (2018). Dissertations and Theses. Paper 4402.

https://doi.org/10.15760/etd.6286

This Dissertation is brought to you for free and open access. It has been accepted for inclusion in Dissertations and Theses by an authorized administrator of PDXScholar. Please contact us if we can make this document more accessible: pdxscholar@pdx.edu. 
Flexural Strength, Ductility, and Serviceability of Beams that Contain High-Strength Steel Reinforcement and High-Grade Concrete

by

Anas Yosefani

A dissertation submitted in partial fulfillment of the requirements for the degree of

\section{Doctor of Philosophy}

in

Civil and Environmental Engineering

Dissertation Committee:

Franz Rad, Chair

Peter Dusicka

Thomas Schumacher

Hormoz Zareh

Portland State University

2018 
(C) 2018 Anas Yosefani 


\begin{abstract}
Utilizing the higher capacity steel in design can provide additional advantages to the concrete construction industry including a reduction of congestion, improved concrete placement, reduction in the required reinforcement and cross sections which would lead to savings in materials, shipping, and placement costs. Using high-strength reinforcement is expected to impact the design provisions of ACI 318 code and other related codes.

The Applied Technology Council (ATC-115) report "Roadmap for the Use of HighStrength Reinforcement in Reinforced Concrete Design" has identified key design issues that are affected by the use of high-strength reinforcement. Also, ACI ITG-6, "Design Guide for the Use of ASTM A1035 Grade 100 Steel Bars for Structural Concrete" and NCHRP Report 679, "Design of Concrete Structures Using High-Strength Steel Reinforcement" have made progress towards identifying how code provisions in ACI 318 and AASHTO could be changed to incorporate high-strength reinforcement.
\end{abstract}

The current research aims to provide a closer investigation of the behavior of beams reinforced with high-strength steel bars (including ASTM A615 Grade 100 and ASTM A1035 Grades 100 and 120) and high-strength concrete up to 12000 psi. Focus of the research is on key design issues including: ductility, stiffness, deflection, and cracking. The research includes an extensive review of current literature, an analytical study and conforming experimental tests, and is directed to provide a number of recommendations and design guidelines for design of beams reinforced with high-strength concrete and high-strength steel. Topics investigated include: strain limits (tension-controlled and compression-controlled, and minimum strain in steel); possible change for strength 
reduction factor equation for transition zone $(\phi)$; evaluation of the minimum reinforcement ratio $\left(\rho_{\min }\right)$; recommendations regarding limiting the maximum stress for the high-strength reinforcement; and prediction of deflection and crack width at service load levels. Moreover, this research includes long-term deflection test of a beam made with high grade concrete and high-strength steel under sustained load for twelve months to evaluate the creep deflection and to insure the appropriateness of the current ACI 318 time-dependent factor, $\lambda$, which does not consider the yield strength of reinforcement and the concrete grade. 


\section{Acknowledgments}

First and foremost, praises and thanks to God for His blessing throughout this research work and for granting me the capability to complete it successfully. I would like to express the deepest appreciation to my advisor and committee chair Dr. Franz Rad, for his thoughtful guidance, encouragement, and persistent help throughout my $\mathrm{PhD}$ journey. Moreover, I would like to thank my committee members, Dr. Peter Dusicka, Dr. Thomas Schumacher, and Dr. Hormoz Zareh for their time reviewing my dissertation and for their valuable comments and suggestions. I would also like to acknowledge the Higher Committee of Education Development in Iraq (HCED) for sponsoring my $\mathrm{PhD}$ program at Portland State University. My gratitude also goes to Cascade Steel Rolling Mills Inc. for donating the reinforcing bars used in this research. My sincere thanks also go to Dr. William Wood and Mr. Robert Turpin for their help with manufacturing and installing the loading frame for the long-term deflection test at OMSI lab. I would also like extend my thanks to Mr. Tom Bennett for his help with the instrumentation setup of the experiments. Special thanks to my friends of the graduate students who helped a lot with the experiment part of this research, especially Hayder Al-Khafaji, Hosam Al-Azzawi, Ali Hafiz, Anwer Mohammed, Wisam Aules, Yasir Saeed, Aqeel Al-Bahadily, Salih Mahmood, Naowar Al-Abbas, and Ranj Rafeeq. Finally, I would like to thank my parents and siblings for their prayers, and supporting me spiritually throughout my life. Most importantly, I wish to thank my loving and supportive wife, Rana, and my three wonderful children, Lourd, Lara, and Andrew. My parents, wife, children are the most important people in my world and I dedicate this dissertation to them. 


\section{Table of Contents}

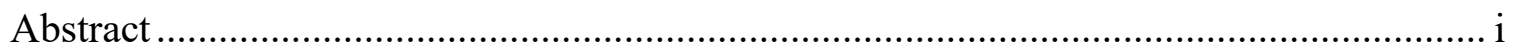

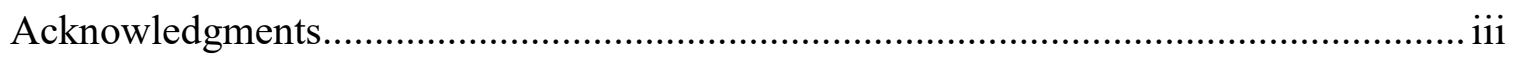

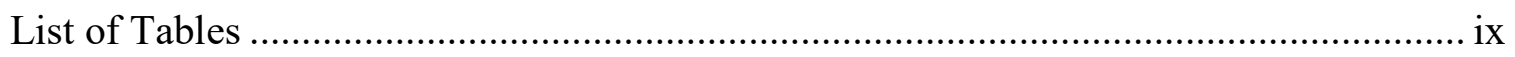

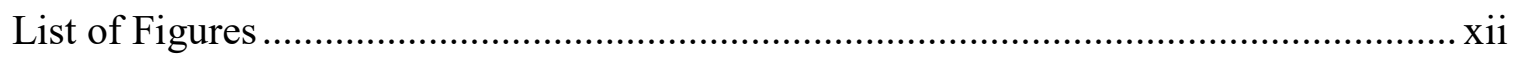

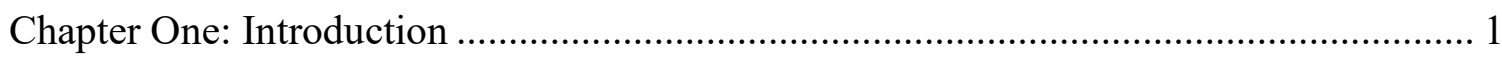

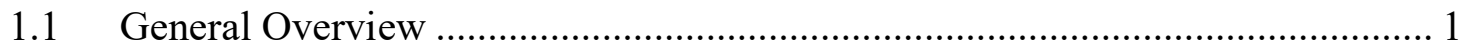

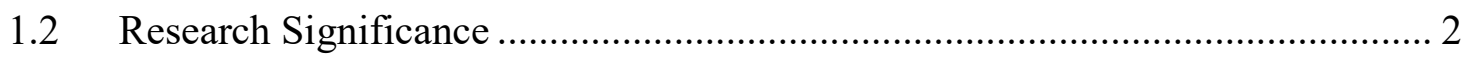

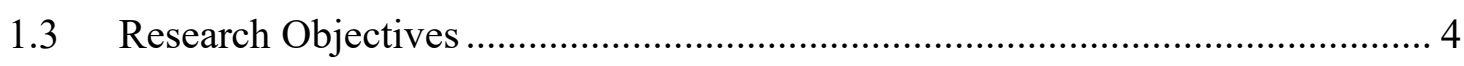

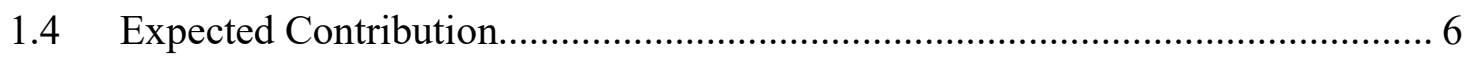

1.5 Dissertation Outline .................................................................................

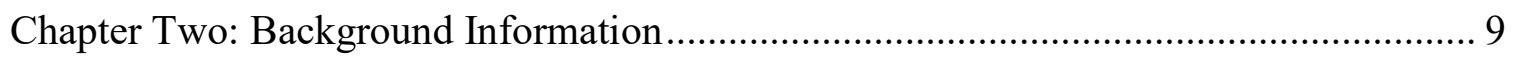

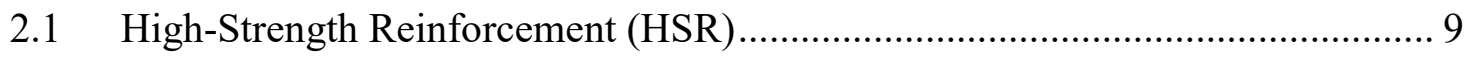

2.1.1 HSR Type ASTM A615 Gr. 100 vs. ASTM A1035 Gr. 100 and 120 Tensile

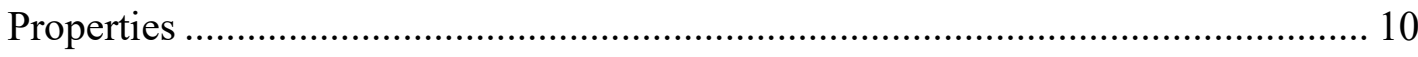

2.1.2 ASTM Specifications for Defining Yield Strength of the Reinforcing Bars 11

2.1.3 Uniform Strain vs. Total Strain of the Reinforcing Bars ............................. 13

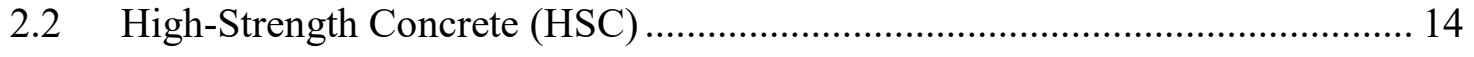


2.3 Stress-Strain Curves for Unconfined Concrete in Compression. 15

2.4 Rectangular Stress Block for Concrete ………........................................... 19

2.5 Reinforcement Ratio Limit vs. Strain Limits ..................................................... 20

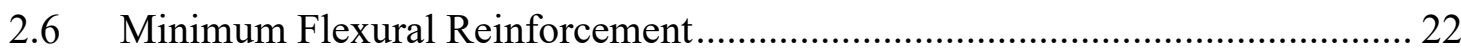

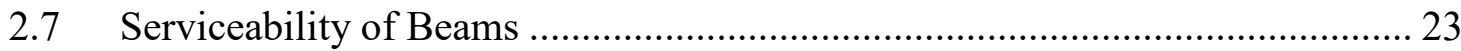

2.7.1 Short-Term Deflection (Immediate Deflection) …………….................... 24

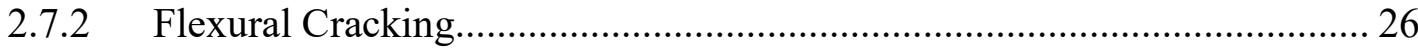

2.7.3 Long-Term Deflection (Time-Dependent Deflection)................................. 27

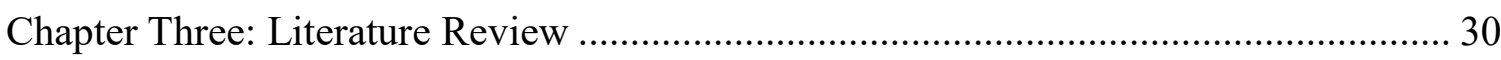

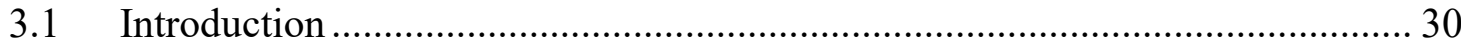

3.2 Flexural Behavior of Beams Made with High-Strength Reinforcement (HSR) 30

3.3 Flexural Behavior of Beams Made with High-Strength Concrete (HSC).......... 38

3.4 Deflection at Service Load Level..................................................................... 42

3.4.1 Immediate Deflection of Beams Reinforced with HSR ............................... 42

3.4.2 Long-Term Deflection of HSC Beams ……………………................... 44

3.5 Flexural Crack Widths and Crack Control of Beams Reinforced with HSR ..... 47

Chapter Four: Theoretical Investigation of Load-Deflection Response ........................... 49

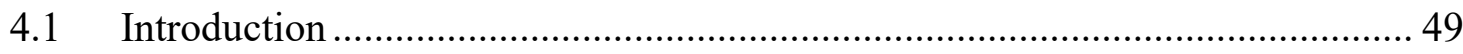

4.2 Nonlinear Flexural Analysis ........................................................................ 49 
4.2.1 Moment-Curvature Response 50

4.2.2 Modeling the Stress-Strain Relationship for Concrete and Reinforcing Steel 52

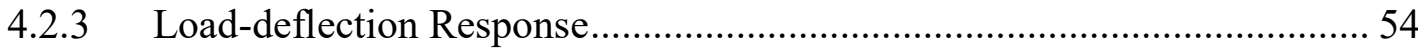

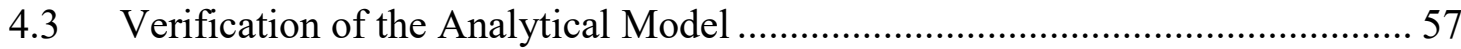

4.4 Flexural Behavior of Beams Made with HSC and HSR ............................... 60

Chapter Five: Experimental Assessment of Beams Made with HSC \& HSR ................. 63

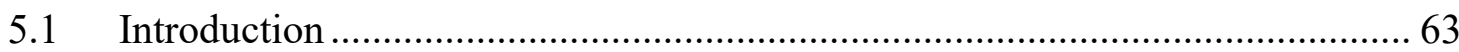

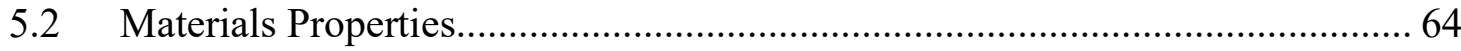

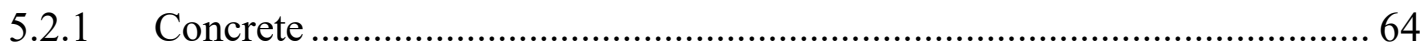

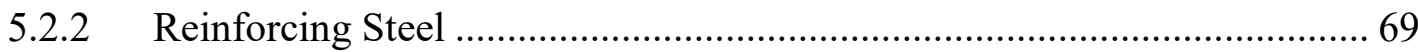

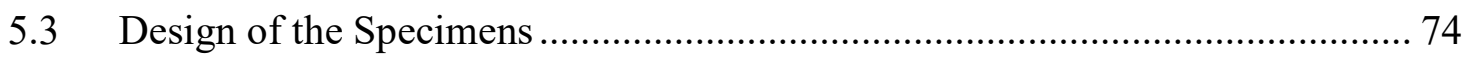

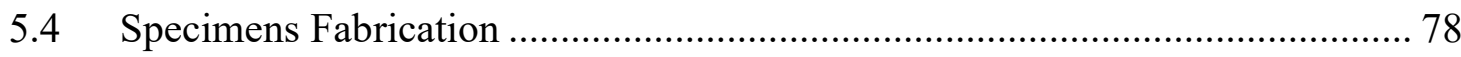

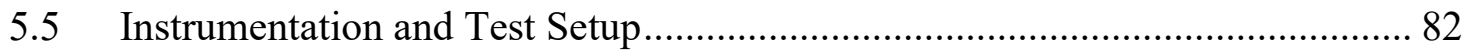

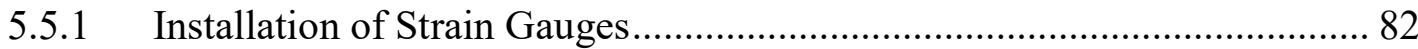

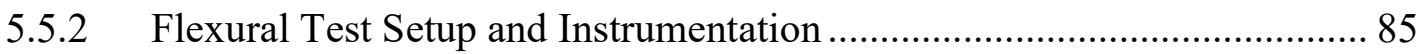

5.5.3 Long-Term Deflection Test Setup .................................................... 86

5.6 Beams Flexural Test Results and Discussion............................................ 89

5.6.1 Load-Deflection Behavior of Test Beams ............................................. 89 
5.6.2 Discussion of Results 105

5.7 Long-Term Deflection Test Results and Discussion........................................... 115

Chapter Six: A Parametric Study on the Key Design Issues with HSR and HSC 118

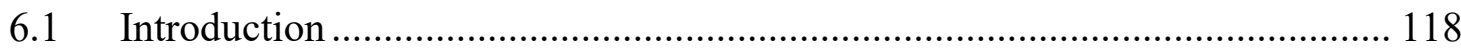

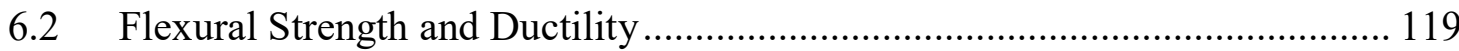

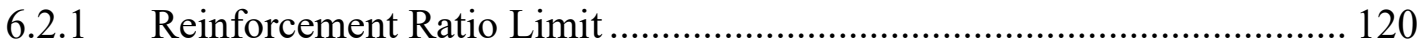

6.2.2 Tension Reinforcement Strain Limits ...................................................... 123

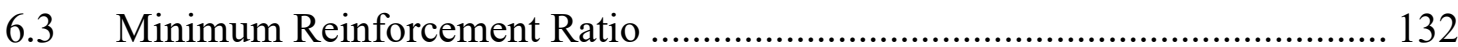

6.4 Effect of Using Simplified Elastic-Plastic vs. Actual Roundhouse Stress-Strain for HSR Type A1035 on Flexural Design of Beams ............................................... 138

6.5 Flexural Design with HSR, Limiting the Maximum Stress .............................. 141

6.6 Design Flexural Strength vs. Reinforcement Ratio Charts for HSR ………...... 144

6.7 Short-Term Deflection at Service Load Level ................................................. 146

Chapter Seven: Summary, Conclusions, and Recommendations for Future Research .. 162

7.1 Summary and Conclusions........................................................................... 162

7.1.1 Strength and Ductility ………………………........................................ 162

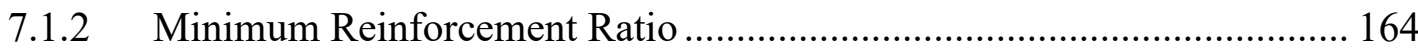

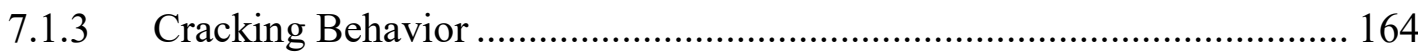

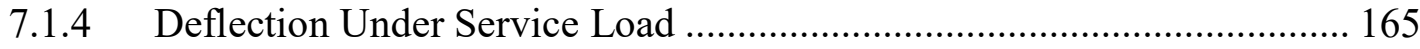


7.2 Recommendations for Future Research (Keep the sentence structure parallel)166

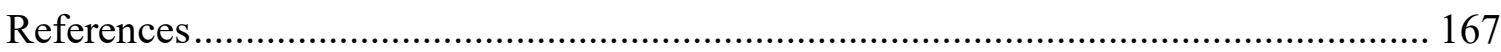

Appendix A: MATLAB Coding to Predict Load-Deflection Behavior.......................... 172

Appendix B: Design Charts for Beams Reinforced with HSR and Based on Materials

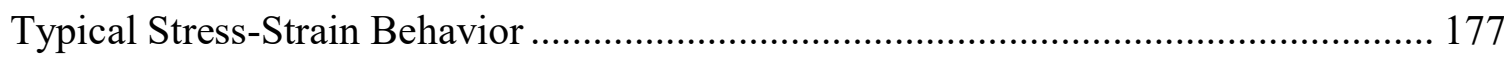

Appendix C: Service Load Level Evaluation ......................................................... 191 


\section{List of Tables}

Table 2-1: Tensile properties requirements ............................................................ 12

Table 2-2: Existing stress-strain models for HSC (Shafiq et al., 2014).......................... 18

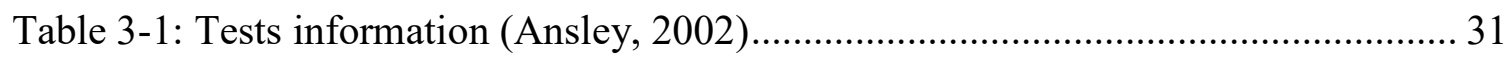

Table 3-2: Comparison of design methods (Mast et al., 2008) ....................................... 34

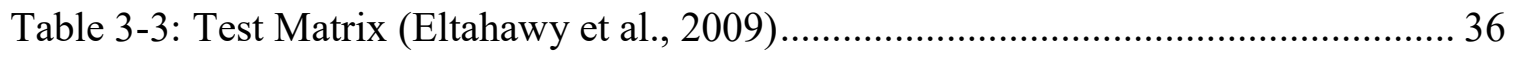

Table 3-4: Test Specimens and Results (Shahrooz et al., 2010).................................. 38

Table 3-5: Comparison of experimental and calculated deflections at service load levels

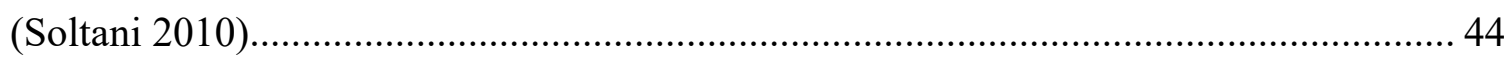

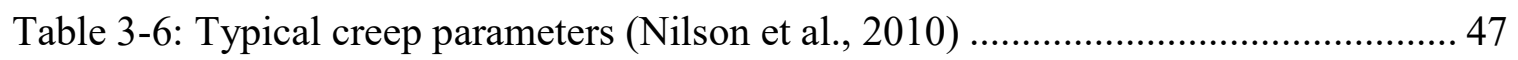

Table 4-1: Typical reinforcement stress-strain parameters used in the analytical

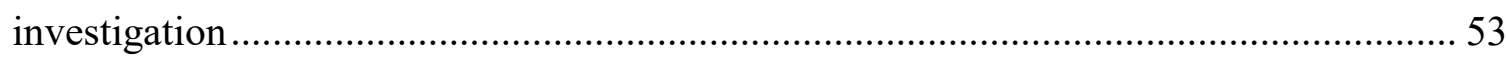

Table 4-2: Details of the selected beams from the literature to verify the analystical model

Table 4-3: Effect of using HSC for beams reinforced with HSR ................................. 60

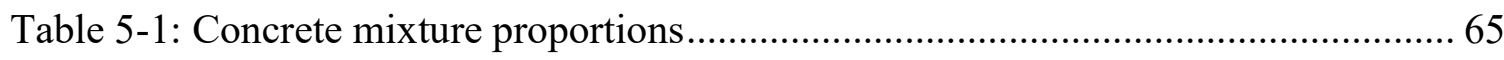

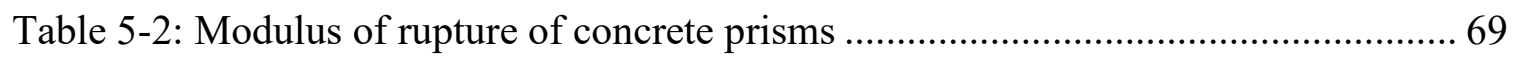

Table 5-3: Reinforcement tensile test results summary ......................................... 70

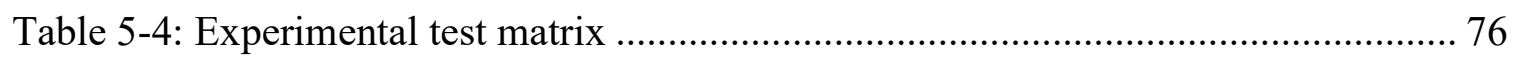

Table 5-5: Test beams experimental flexural test results summary ............................ 100

Table 5-6: Prediction of maximum crack width for test beams at service load level..... 103

Table 5-7: Prediction of maximum deflection at service load level for the test beams.. 104 
Table 5-8: Comparison of predicted and measured time-dependent beam deflections .. 116

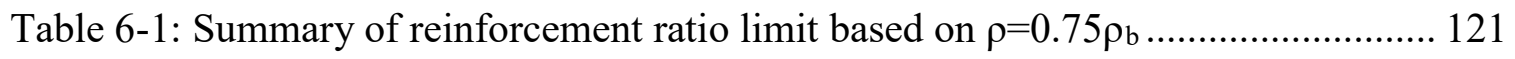

Table 6-2: Comparable strain limits based on curvature ductility $\left(\mu=\varphi_{\mathrm{u}} / \varphi_{\mathrm{y}}\right) \ldots \ldots \ldots \ldots \ldots . . . .130$

Table 6-3: Comparable strain limits based on energy absorption $(\mu=$ Area under P- $\Delta) 130$

Table 6-4: Comparison of minimum strain limits for HSR from different approaches.. 130

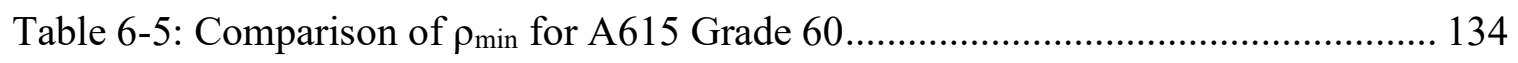

Table 6-6: Comparison of $\rho_{\min }$ for A615 \& A1035 Grade 100 ..................................... 134

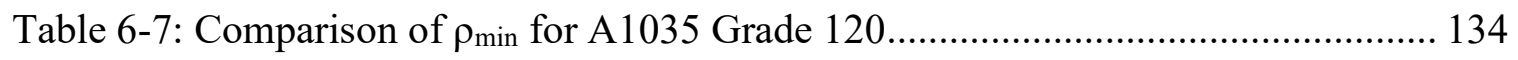

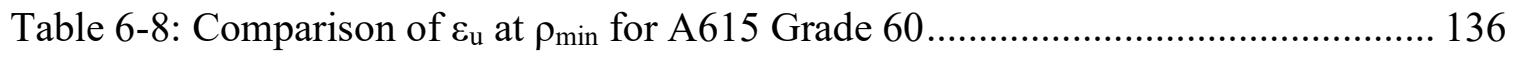

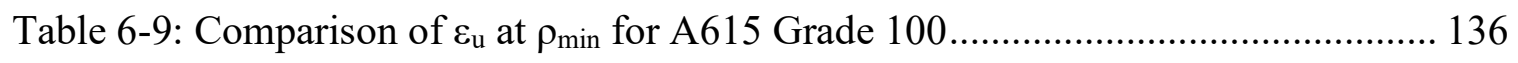

Table 6-10: Comparison of $\varepsilon_{\mathrm{u}}$ at $\rho_{\min }$ for A1035 Grade 100...................................... 137

Table 6-11: Comparison of $\varepsilon_{\mathrm{u}}$ at $\rho_{\mathrm{min}}$ for A1035 Grade 120..................................... 137

Table 6-12: Comparison of using elastic-plastic model vs. actual roundhouse to model

A1035-100 reinforcement on moment capacity and curvature ductility ...................... 139

Table 6-13: Allowable stress in prestressed reinforcement for $\mathrm{f}_{\mathrm{c}}=4000 \mathrm{psi}$.............. 143

Table 6-14: Allowable stress in prestressed reinforcement for $\mathrm{f}_{\mathrm{c}}=12000 \mathrm{psi} \ldots \ldots \ldots \ldots . . . .143$

Table 6-15: Comparison of analytical and calculated deflections at service load level for

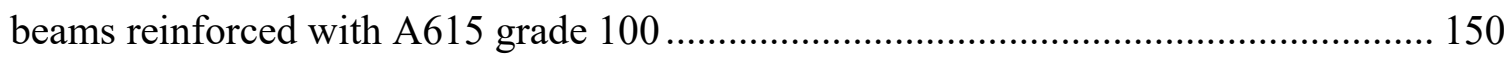

Table 6-16: Comparison of analytical and calculated deflections at service load level for beams reinforced with A1035 grade 100 .......................................................... 151 Table 6-17: Comparison of analytical and calculated deflections at service load level for

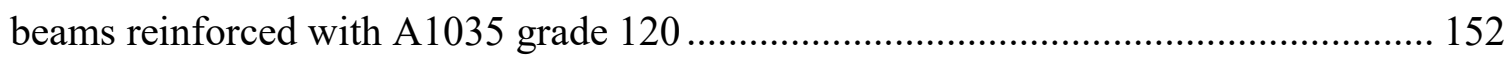


Table 6-18: Modified immediate deflections calculated using the suggested modified Bischoff effective moment of inertia for beams reinforced with A615 grade 100........ 159 Table 6-19: Modified immediate deflections calculated using the suggested modified Bischoff effective moment of inertia for beams reinforced with A1035 grade $100 \ldots \ldots .160$ Table 6-20: Modified immediate deflections calculated using the suggested modified Bischoff effective moment of inertia for beams reinforced with A1035 grade 120 ...... 161 


\section{List of Figures}

Figure 2-1: Representative stress-strain relationships for Grade 60, Grade 80, and Grade

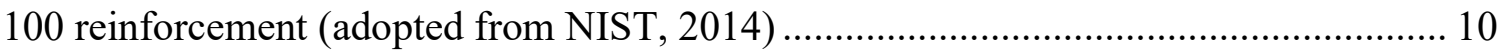

Figure 2-2: Determination of yield strength by offset method .................................. 12

Figure 2-3: Uniform strain vs. total strain (NIST GCR 14-917-30) .............................. 14

Figure 2-4: Carreira and Chu (1985) concrete stress-strain model................................ 17

Figure 2-5: Typical compressive stress-strain curves for normal weight concrete (Nilson

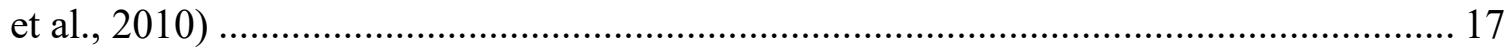

Figure 2-6: Stress and strain distribution across beam depth: (a) beam cross-section;

(b)strains; (c) actual stress block; (d) assumed equivalent stress block (Nawy, 2010) .... 19

Figure 2-7: Strength reduction factor, $\phi$, based on strain limit approach ...................... 21

Figure 2-8: Beam load-deflection and moment-deflection relationships (Nawy, 2010) .. 25

Figure 2-9: ACI 318 multipliers for long-term deflection ........................................ 28

Figure 3-1: Design guidelines for the design with MMFX reinforcement (Dawood et al.

$2004)$

Figure 3-2: Sectional analysis procedure (Mast et al. 2008) …................................... 33

Figure 3-3: Proposed variation of resistance factor $\phi$ (Mast et al. 2008)........................ 35

Figure 3-4: Strain limits for the design with MMFX reinforcement (Eltahawy et al. 2009)

Figure 3-5: Effect of $\mathrm{f}^{\prime}{ }_{\mathrm{c}}$ on displacement ductility, $\mu \mathrm{d}$ (Ashour, 2000) ........................... 39

Figure 3-6: Beam ductility as influenced by concrete strength: (a) test data; and (b)

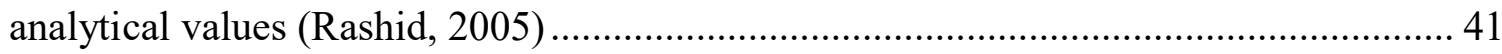


Figure 3-7: Creep and shrinkage deflection of beams (Paulson et al., 1991) .................. 46

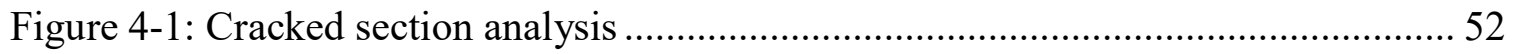

Figure 4-2: Typical stress-strain curves for reinforcing bars ..................................... 54

Figure 4-3: Calculation of the mid-span deflection based on the numerical integration for

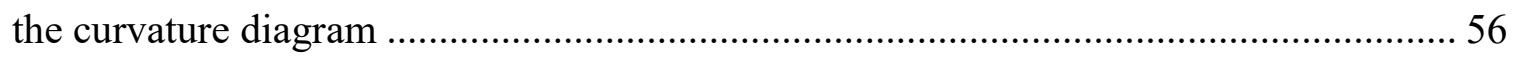

Figure 4-4: Comparison of experimental beams results of Ansley (2002) and analytical

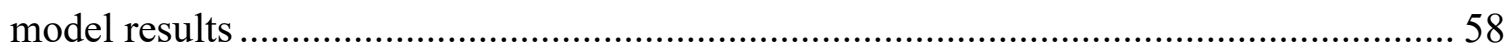

Figure 4-5: Comparison of experimental beams results of Yutakhong (2003) and

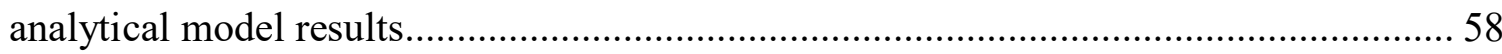

Figure 4-6: Comparison of experimental beams results of Shahrooz et al. (2010) and

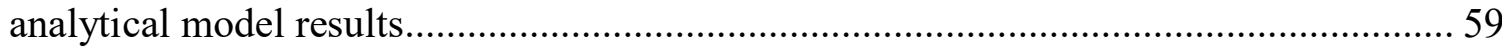

Figure 4-7: Behavior of beam designed with NSC \& grade 60 steel vs. beams designed

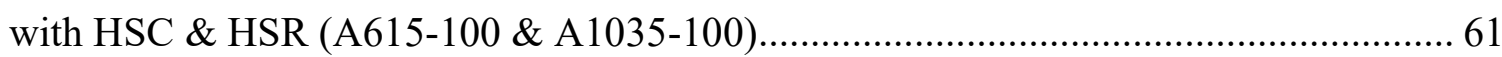

Figure 5-1: Cylinder compression stress-strain test set up .................................... 66

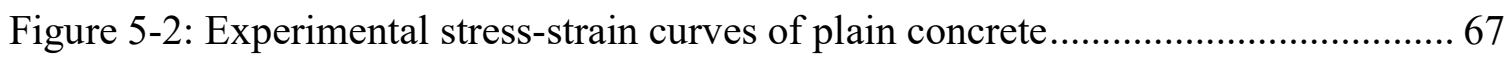

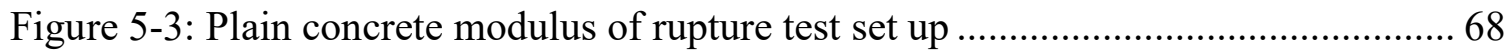

Figure 5-4: Reinforcement tensile stress-strain test set up .................................... 70

Figure 5-5: Tension stress-strain test results for rebar type A615 grade 60 ................... 71

Figure 5-6: Tension stress-strain test results for rebar type A615 grade 100 ................ 72

Figure 5-7: Tension stress-strain test results for rebar type A1035 grade $120 \ldots \ldots \ldots \ldots \ldots . . . .73$

Figure 5-8: Tension stress-strain test results for no. 2 wire used for shear reinforcement 74

Figure 5-9: Experimental program test beams details ............................................ 77 


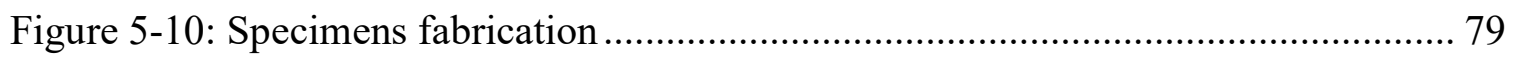

Figure 5-11: Concrete mixing and casting process of the specimens ............................... 80

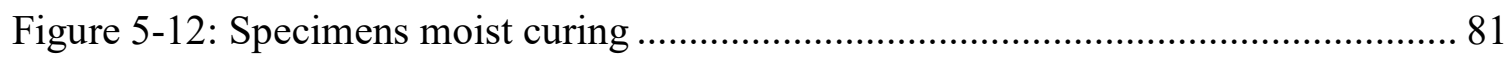

Figure 5-13: Installation steps of concrete strain gauges.............................................. 83

Figure 5-14: Installation steps of reinforcement strain gauges ....................................... 84

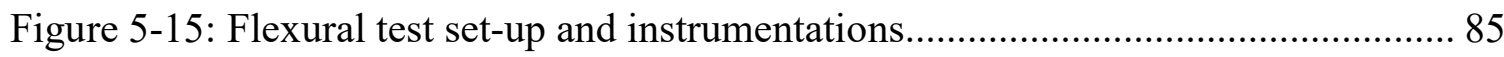

Figure 5-16: Typical flexural test setup of reinforced concrete beam specimens ............ 86

Figure 5-17: Schematic drawing for the test setup of the long-term deflection ............... 87

Figure 5-18: Fabrication of the loading frame for flexural long-term deflection test ...... 88

Figure 5-19: Experimental results of beam 5/A615-60 (1.1\%) ……………………...... 90

Figure 5-20: Experimental results of beam 8/A615-100 (0.62\%) ................................... 91

Figure 5-21: Experimental results of beam 8/A1035-120 (0.41\%) ………………….... 92

Figure 5-22: Experimental results of beam 13/A615-100 (0.62\%) ................................ 93

Figure 5-23: Experimental results of beam 11/A1035-120 (0.41\%) ................................ 94

Figure 5-24: Experimental results of beam 5/A615-60 (2.29\%) ……………………..... 95

Figure 5-25: Experimental results of beam 10/A1035-120 (0.74\%) …………….......... 96

Figure 5-26: Experimental results of beam 14/A1035-120 (0.74\%) ………………….... 97

Figure 5-27: Crack pattern and failure mode of the first group of the test beams.......... 101

Figure 5-28: Crack pattern and failure mode of the second group of the test beams ..... 102

Figure 5-29: Load-deflection response of tested beams ................................................ 113

Figure 5-30: Stress level in the tension reinforcement at service loading state for the tested beams reinforced with steel type A1035 Grade 120......................................... 114 
Figure 5-31: Time-dependent deflection of beam 14/A1035-120 (0.41\%) .................. 115

Figure 5-32: Crack pattern and maximum crack width measurement of the beam 14/A1035-120 (0.41\%) tested under long-term period.

Figure 5-33: Crack pattern and maximum crack width measurement of the beam 14/A1035-120 (0.41\%) tested under long-term period. 117

Figure 6-1: Moment-curvature responses for beams reinforced with conventional grade 60 steel and HSR based on $\rho=0.75 \rho b$ 122

Figure 6-2: M- $\phi$ response for a beam with $\mathrm{f}_{\mathrm{c}}=4000$ psi \& Grade 60 steel with $\rho=0.0195$ 125

Figure 6-3: Effect of $\rho$ on the moment capacity and tension reinforcement strain........ 125 Figure 6-4: HSR comparable tension-control strain limits based on curvature ductility 126 Figure 6-5: HSR comparable tension-control strain limits based on energy absorption (area under $\mathrm{P}-\Delta$ ) 127

Figure 6-6: HSR comparable minimum strain limits based on curvature ductility ........ 128 Figure 6-7: HSR comparable minimum strain limits based on energy absorption (area under $\mathrm{P}-\Delta)$ 129

Figure 6-8: Relationship between strength reduction factor, $\phi$, and strain limits 131

Figure 6-9: Comparison of $\rho_{\min }$ for A615 Grade 60 135

Figure 6-10: Comparison of $\rho_{\min }$ for A615 \& A1035 Grade 100 135

Figure 6-11: Comparison of $\rho_{\min }$ for A1035 Grade 120 136 Figure 6-12: Effect of using simplified elastic-plastic model to idealize the behavior of A1035 reinforcement on moment capacity and curvature ductility.... 140 
Figure 6-13: Flexural design chart for beams with $\mathrm{f}_{\mathrm{c}}=8000$ psi \& reinforced with A1035 grade 100 rebar 145

Figure 6-14: Flexural design chart for beams with $\mathrm{f}_{\mathrm{c}}=8000$ psi \& reinforced with A615 grade 100 rebar 145

Figure 6-15: Flexural design chart for beams with $\mathrm{f}_{\mathrm{c}}=8000$ psi \& reinforced with A1035 grade 120 rebar 146

From the moment-curvature analysis, the immediate deflection at service load is extracted from the load-deflection relationship when the load is equal to $60 \%$ of the maximum load. The cross section of the beams is assumed 6 in. x10 in. with a simple span of $8 \mathrm{ft}$, and the reinforcement ratio is varied from $\rho \min$ to $\rho \max$. Figure 6-16 shows the relationship between $\rho$ and $\mathrm{M}_{\mathrm{cr}} / \mathrm{M}_{\mathrm{a}}$ ratio for the example beam. 148

Figure 6-17: Relationship between $\rho$ and $\mathrm{M}_{\mathrm{cr}} / \mathrm{M}_{\mathrm{a}}$ ratio for an example beam 149

Figure 6-18: Immediate deflection prediction using M- $\phi$ analysis and $I_{e}$ method for beams reinforced with A615 grade 100 rebar..... 153

Figure 6-19: Immediate deflection prediction using M- $\phi$ analysis and $I_{e}$ method for beams reinforced with A1035 grade 100 rebar 154

Figure 6-20: Immediate deflection prediction using M- $\phi$ analysis and $I_{e}$ method for beams reinforced with A1035 grade 120 rebar. 155

Figure 6-21: Relationship between immediate deflection calculated using M- $\phi$ analysis and $I_{e}$ of Bischoff method for beams reinforced with HSR 158 


\section{Chapter One: Introduction}

\subsection{General Overview}

For many years, the design of reinforced concrete in the United States was dominated by the use of reinforcing steel of Grades 40 and 60 that have a well-defined yield strength and yield plateau. Design for flexural members with higher strength reinforcement has been permitted in the current ACI 318-14 code but is limited to $80 \mathrm{ksi}$ for non-seismic systems. The limits to the yield strength are mainly related to the prescribed limit on the concrete ultimate strain of 0.003 , and to the control of crack widths at service level loads. Crack width is related to the strain developed in the tension reinforcement and consequently to the steel stress at the service load. Therefore, the limit to the steel stress is needed to prevent the cracks from affecting the serviceability of the structure. However, recent improvements in concrete properties have made it possible to use reinforcements of higher strength.

Currently, high-strength reinforcement (HSR) with yield strength exceeding $80 \mathrm{ksi}$ is commercially available in the United States up to Grade 120. It is expected that utilizing the higher capacity steel in design can provide additional advantages to the concrete construction industry including reduction of congestion in heavily reinforced members, improved concrete placement, potential reduction in the amount of reinforcement needed for design and reducing member cross sections which would lead to savings in materials, shipping, and placement costs. Moreover, using high-strength concrete (HSC) coupled with HSR is expected to result in more efficient structural designs, longer spans, shallower sections, and higher load-carrying capacities. 
High-Strength Concrete (HSC) can be obtained by minimizing the water-cement ratio with the aid of superplasticizers, and by carefully selecting reasonable doses and types of pozzolanic admixtures such as silica fume. Currently, HSC can be produced up to a strength of $20 \mathrm{ksi}$.

In spite of the fact that many advantages are expected in using high strength steel, ductility is expected to be reduced due to the potential lowering of the steel strain at failure. Therefore, using high-strength reinforcement is expected to impact the design provisions of ACI 318 and other codes related to reinforced concrete structures.

However, combining HSR with HSC may improve the reduction in the ductility when using HSR. Based on the current code provisions, and if everything else remains the same, it can be analytically shown that an increase in concrete strength leads to higher ductility. Therefore, this study is focusing on the use of both high strength materials.

\subsection{Research Significance}

There are many issues associated with the use of high-strength reinforcement that need to be addressed, and many sections of the ACI 318 code may require new or revised provisions in order to incorporate the use of high-strength reinforcement. The Applied Technology Council (ATC-115) report 2014 "Roadmap for the use of high-strength reinforcement in reinforced concrete design", identified the key design issues that are affected by the use of high-strength reinforcement, which are related to the provisions of strength and ductility, serviceability, reinforcement limits, analysis, detailing, and seismic systems. Also, documents such as the ACI ITG-6, "Design Guide for the Use of ASTM 
A1035 Grade 100 Steel Bars for Structural Concrete" (ACI, 2010a) and the NCHRP Report 679, "Design of Concrete Structures Using High-Strength Steel Reinforcement" (Shahrooz et al., 2011) have made progress towards identifying how some code provisions in ACI 318 and AASHTO could be changed to incorporate high-strength reinforcement. However, a challenge for the design process will involve integration of high-strength reinforcement into concrete structures in ways that optimize and fully utilize the higher yield strength of the bars. Therefore, further research is needed to better understand the effects of using higher strength reinforcement in concrete members and to provide answers for the identified key design issues.

This research represents a closer investigation of the ductility and the behavior of beams made with different grades of concrete (4000 psi - $12000 \mathrm{psi})$, and reinforced with different types and grades of HSR, which include ASTM A615 Grade 100 and ASTM A1035 Grades 100 and 120 . The research focus is on the key design issues related to the use of high-strength steel bars as flexural reinforcement for beams that contain normal strength concrete (NSC) and high strength concrete (HSC). Analytical and experimental studies will be conducted to investigate and overcome the deficiencies in the existing knowledge base, and to support an update to ACI 318 to incorporate the use of reinforcement in excess of $80 \mathrm{ksi}$. 


\subsection{Research Objectives}

The flexural behavior of concrete beams that contain a range of concrete capacities and are reinforced with high-strength steel reinforcement will be investigated analytically and experimentally.

The analytical study is intended to address the following issues:

1. Investigate the strength and ductility of flexural concrete beams reinforced with two different types of high-strength reinforcement that has a defined yield stress and yield plateau (A615 grade 100), as well as other types without well-defined yield stress and lack for yield plateau (A1035 grades $100 \& 120$ ), and those made with a range of concrete strengths (4000 to $12000 \mathrm{psi}$ ).

2. Based on ductility requirement, evaluate the previous approach of ACI 318 to determine the maximum reinforcement ratio as a fraction of the balanced ratio $\left(\rho_{\max }=0.75 \rho_{b}\right)$ versus the current approach that is based on tensile reinforcement strain limits (tension-controlled strain limit, minimum tensile strain limit, and compression-controlled strain limit) for beams reinforced with HRS. Depending on the grade and the shape of the stress-strain relationship for high-strength reinforcement, ACI Code strain limits may need to be modified.

3. Explore the possible revisions to the strength reduction factors for flexural beams reinforced with HSR. This critical ratio is required to protect against sudden collapse of flexural members in the event of loading beyond the cracking moment. 
4. Evaluate the minimum reinforcement ratio for the use of high-strength reinforcement. This study will attempt to determine the minimum flexural reinforcement required to provide an acceptable ratio of cracked section flexural strength to "gross" uncracked section strength in beams with high-strength reinforcement.

5. Evaluate whether the traditional ACI 318 design assumption of using a simplified elastic-plastic stress-strain relationship for modeling the reinforcement is adequate when using high-strength reinforcement type A1035 that lacks the well-defined yield point and yield plateau.

6. Evaluate the current ACI 318 provisions for predicting the deflection at service load level when beams are designed using HSC \& HSR.

7. Explore the effectiveness of combining high-strength concrete (HSC) with highstrength reinforcement (HSR) for flexural beams through comparing the design with the current practice.

The experimental testing will be performed to determine the load-deflection behavior of the beams made with high-strength concrete and reinforced with high-strength reinforcement grades $100 \& 120$. The tests will consider the actual tensile-to-yield strength ratios and elongations that are likely to be achieved in the production of highstrength reinforcement. The experimental tests are mainly to confirm the results of the analytical studies. Tests will attempt to:

- Track bar elongations and concrete strains as the beam is loaded to failure. 
- Track deflections at service load levels, as well as near failure.

- Observe the cracking behavior and evaluate the crack width.

Moreover, the experimental program included an investigation of the long-term deflection of a beam made with HSC (14000 psi) and HSR (A1035 grade 120) to evaluate the current ACI 318 time-dependent factor $(\lambda)$ for the use of both high strength materials as the current factor does not take into account the yield strength of reinforcement and the concrete grade.

\subsection{Expected Contribution}

This research represents a broader study for the use of high-strength bars as a flexural reinforcement in RC beams. It will compromise of a range of steel and concrete grades, and it is expected to contribute in providing further study to allow the general use of steel reinforcement in excess of Grade 80 for gravity load applications, and ultimately, encouraging the integration of high-strength reinforcing steel into the ACI 318 code and

other building codes. The main contributions can be summarized in the following points:

a) Evaluating analytically and experimentally the use of steel that conforms to ASTM 1035 Grade 120 bars as a flexural reinforcement for concrete beams.

b) Evaluating analytically and experimentally the use of the new bar type ASTM A615 Grade 100 and compare the behavior with beams reinforced with bars type ASTM A1035 Grade 100. 
c) Evaluating the current ACI 318 design provisions regarding strain limits, flexural strength, ductility, and service load deflection prediction for beams reinforced with high-strength bars and provide recommendations for changes, if necessary.

d) Propose a new approach for determining the minimum reinforcement ratio for the use of HSR based on the minimum ultimate uniform strain $\left(\varepsilon_{u}\right)$ that can be achieved by the high-strength reinforcement.

e) Evaluating experimentally the effectiveness of coupling high-strength concrete with high-strength reinforcement on the flexural behavior of beams.

f) Evaluating experimentally the long-term (creep) deflection of a beam made with HSC and HSR.

\subsection{Dissertation Outline}

This dissertation consists of six chapters, as following:

Chapter One presents a general overview, significance, objectives, and the expected contribution of the research.

Chapter Two gives a background information about the materials and the parameters studied in this research, and the current provisions of the ACI 318 code that are related to the flexural behavior and serviceability of the reinforced concrete beams.

Chapter Three presents a review about the available research in the literature that is related to the use of high-strength reinforcement and high-strength concrete for beams in flexure. 
Chapter Four discusses the creation of a computer model to predict the flexural behavior of concrete beams of different concrete strengths and reinforced with Grade 60 as well as high-strength reinforcing bars. Also, this chapter includes a theoretical investigation for beams made with HSC \& HSR.

Chapter Five presents an experimental program conducted to validate the theoretical results, and to compare the design using the current practice that includes the use of normal-strength concrete and conventional grade 60 steel versus the design using high strength materials.

Chapter Six summarizes the results of a parametric study on the key design issues with HSR and HSC for the objective of developing guidelines for design that are compatible with current practice.

Chapter Seven summarizes the observations and conclusions drawn based on both the analytical and the experimental results of this research. 


\section{Chapter Two: Background Information}

\subsection{High-Strength Reinforcement (HSR)}

The terminology high-strength reinforcement (HSR) is used for the bars that have a defined yield strength of $75 \mathrm{ksi}$ and higher. A number of high-strength reinforcing steels are currently available in the United States such as ASTM A1035 Grades 100 \& 120, ASTM A615 Grades 75, 80 \& 100, ASTM A706 Grade 80, SAS 670 Grade 97. As shown in Figure 2-1, three distinct shapes of stress-strain relationships for high-strength reinforcing steels are possible:

(1) A rounded curve (designated as S1) defined by a gradual reduction in stiffness that becomes nonlinear before reaching a yield strength that is defined by the $0.2 \%$ offset

method, followed by gradual softening until the tensile strength is reached (also called a "roundhouse" curve).

(2) A curve defined by two segments (designated as S2) consisting of linear-elastic behavior to the yield strength, followed by linear strain hardening behavior until the tensile strength is reached.

(3) A curve defined by three segments (designated as S3) consisting of linear-elastic behavior to a well-defined yield strength, a relatively flat yield plateau, and a rounded strain-hardening region.

Different stress-strain relationships are expected to impact the force-displacement behavior of reinforced concrete beams in different ways including strain limits, flexural 
strength and corresponding maximum deflection, and the spread of plasticity as the beam is loaded monotonically to failure (ductility).

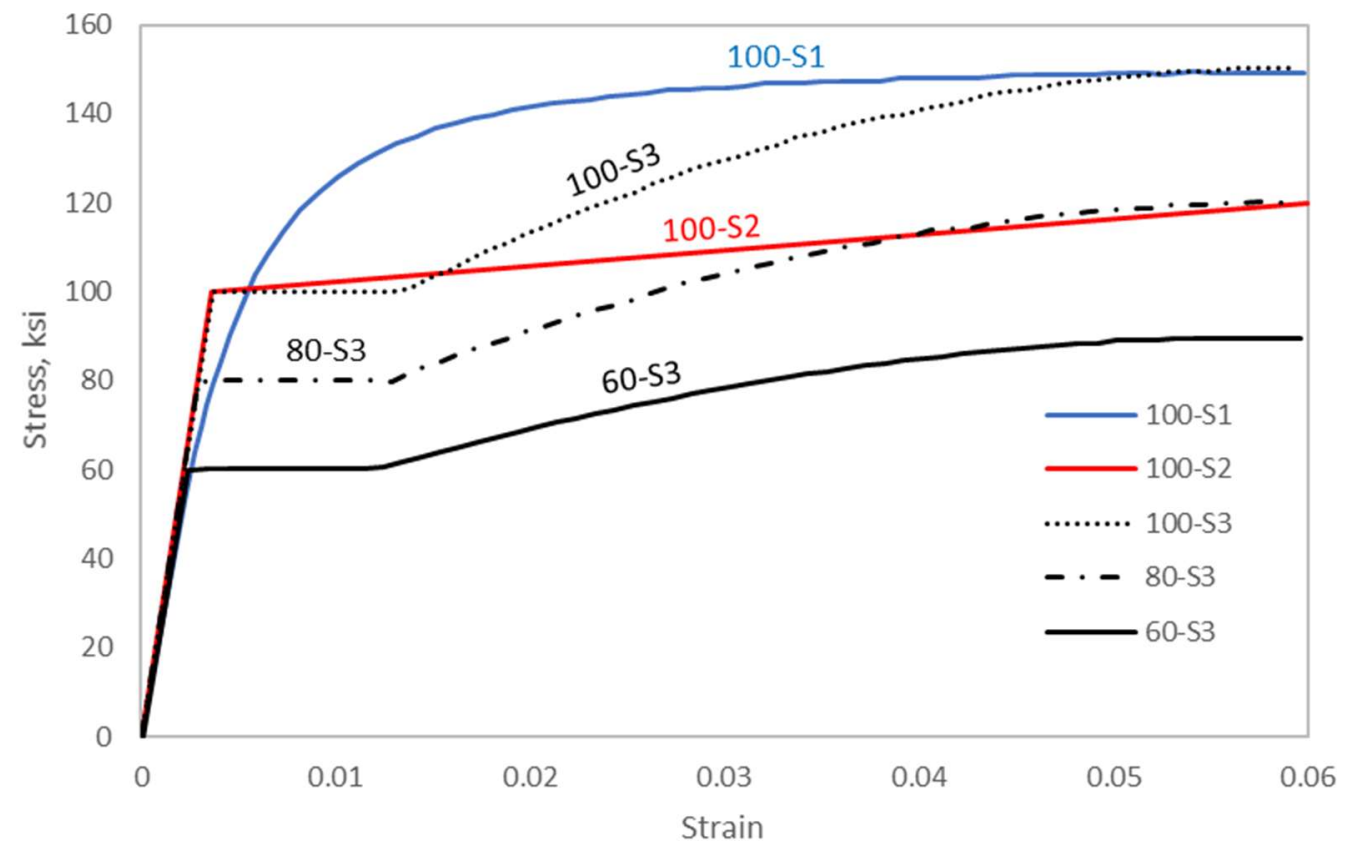

Figure 2-1: Representative stress-strain relationships for Grade 60, Grade 80, and Grade 100 reinforcement (adopted from NIST, 2014)

\subsubsection{HSR Type ASTM A615 Gr. 100 vs. ASTM A1035 Gr. 100 and 120 Tensile Properties}

Two types of HSR bars are investigated in this research, ASTM A615 Grade 100 and ASTM A1035 Grades 100 and 120. ASTM A1035 reinforcing steel is characterized by a low carbon content (maximum of $0.15 \%$ ) and a high chromium content (minimum $8 \%$ and maximum 10.9\%), which results in a much higher tensile strength than ASTM A615 steel, however, the maximum strain that can be achieved before rupture is lower than that of ASTM A615. The stress-strain curve for HSR bar type A615 mostly contains a welldefined yield point and yield plateau up to the onset of rounded strain hardening segment, 
while HSR type A1035 exhibits a roundhouse stress-strain behavior, as shown in Figure 2-1.

\subsubsection{ASTM Specifications for Defining Yield Strength of the Reinforcing Bars}

ASTM specifications require that the yield strength of the reinforcing bars shall be determined by the drop or halt of the gauge of the tensile testing machine when the steel tested has a sharp-knee or well-defined yield point. However, for the steel that lacks for a well-defined yield point, all ASTM reinforcing bar standards in 2014 and later required that the yield strength shall be determined by the $0.2 \%$ offset method described in ASTM A370 and shown here in Figure 2-2. First, a strain is located on the strain axis 0.002 in./in. from the origin, then a line is drawn from that point parallel to the initial linear portion of the stress-strain curve. The point where this line intersects the stress-strain curve is defined as $f_{y}$. A study in 2016 about defining yield strength for the nonprestressed reinforcement (Paulson et al., 2016) supported that the use of the $0.2 \%$ offset method to define the yield strength for reinforcement of roundhouse stress-strain curves is safe and realistic.

ASTM specifications also require that the reinforcing bars must satisfy the minimum tensile properties for each bar type and size, as specified in Table 2-1. 


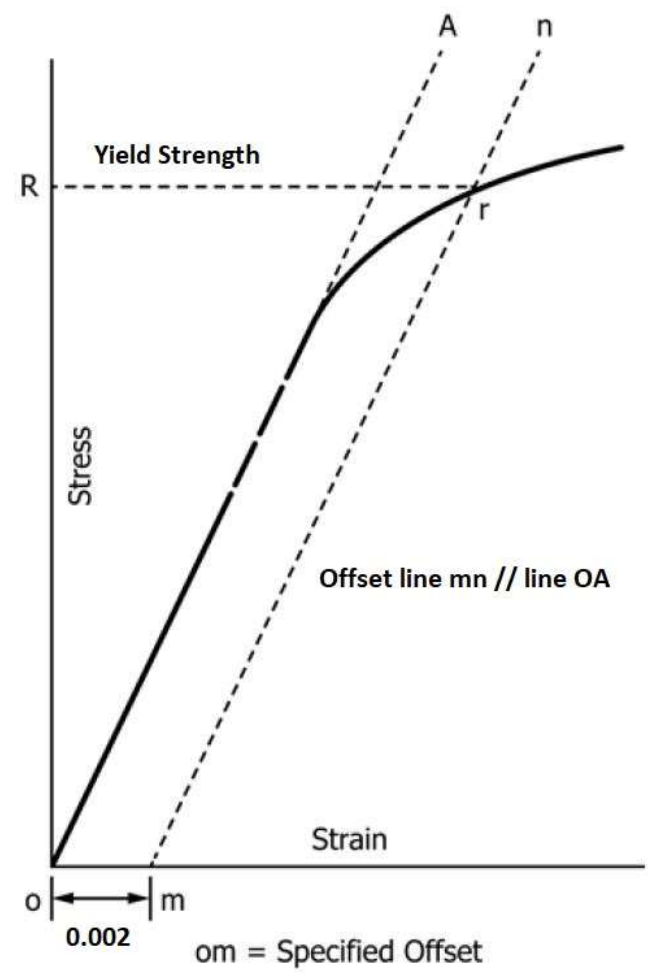

Figure 2-2: Determination of yield strength by offset method

Table 2-1: Tensile properties requirements

\begin{tabular}{|c|c|c|c|c|}
\hline Steel Type - Grade & A615-60 & A615-100 & A1035-100 & A1035-120 \\
\hline Minimum tensile strength, psi & 90,000 & 115,000 & 150,000 & 150,000 \\
\hline Minimum yield strength, psi & 60,000 & 100,000 & 100,000 & 120,000 \\
\hline \multicolumn{5}{|c|}{ Minimum elongation in 8", \% } \\
\hline Bar Designation No. & & 7 & 7 & 7 \\
\hline 3 through 6 & 9 & 7 & 7 & 7 \\
\hline 7,8 & 8 & 7 & 7 & 7 \\
\hline 9 through 18 & 7 & 7 &
\end{tabular}




\subsubsection{Uniform Strain vs. Total Strain of the Reinforcing Bars}

Uniform strain or elongation $\left(\varepsilon_{u}\right)$ is defined as the largest elongation in the bar for which the tensile strains are uniform throughout the length of the bar, and this generally occurs before the onset of necking. The uniform elongation can be measured experimentally for the tensile test of a rebar by first marking the rebar every two inches along the length between the machine grips. After the rebar fractures, then $\varepsilon_{u}$ is the change in the length of an 8-inch gauge distance between any two gauge marks that are away from necking and fracture zone. The term $\varepsilon_{\mathrm{u}}$ is useful in seismic design.

Total strain $\left(\varepsilon_{f}\right)$ is defined as the total elongation over a prescribed gauge length $(8 \mathrm{in}$. that extends across the fracture of a bar (the ends of the fractured bar should fit together to measure the distance between the gauge marks). $\varepsilon_{f}$ is useful for monotonic load design. Figure 2-3 depicts both the uniform and the total strains.

For strains larger than $\varepsilon_{u}$, the strain becomes localized around the necking zone and the other portions of the bar that are sufficiently away from the necking zone gradually stop elongating. As the bar necks down, its cross-sectional area decreases to be less than the original area making the apparent stress in the bar decrease as the stress is calculated based on the original cross-sectional area. This stress-strain curve is called the engineering curve and not a true stress-strain. If the stress-strain curve is plotted in terms of true stress and true strain, the stress will continue to increase until failure. 

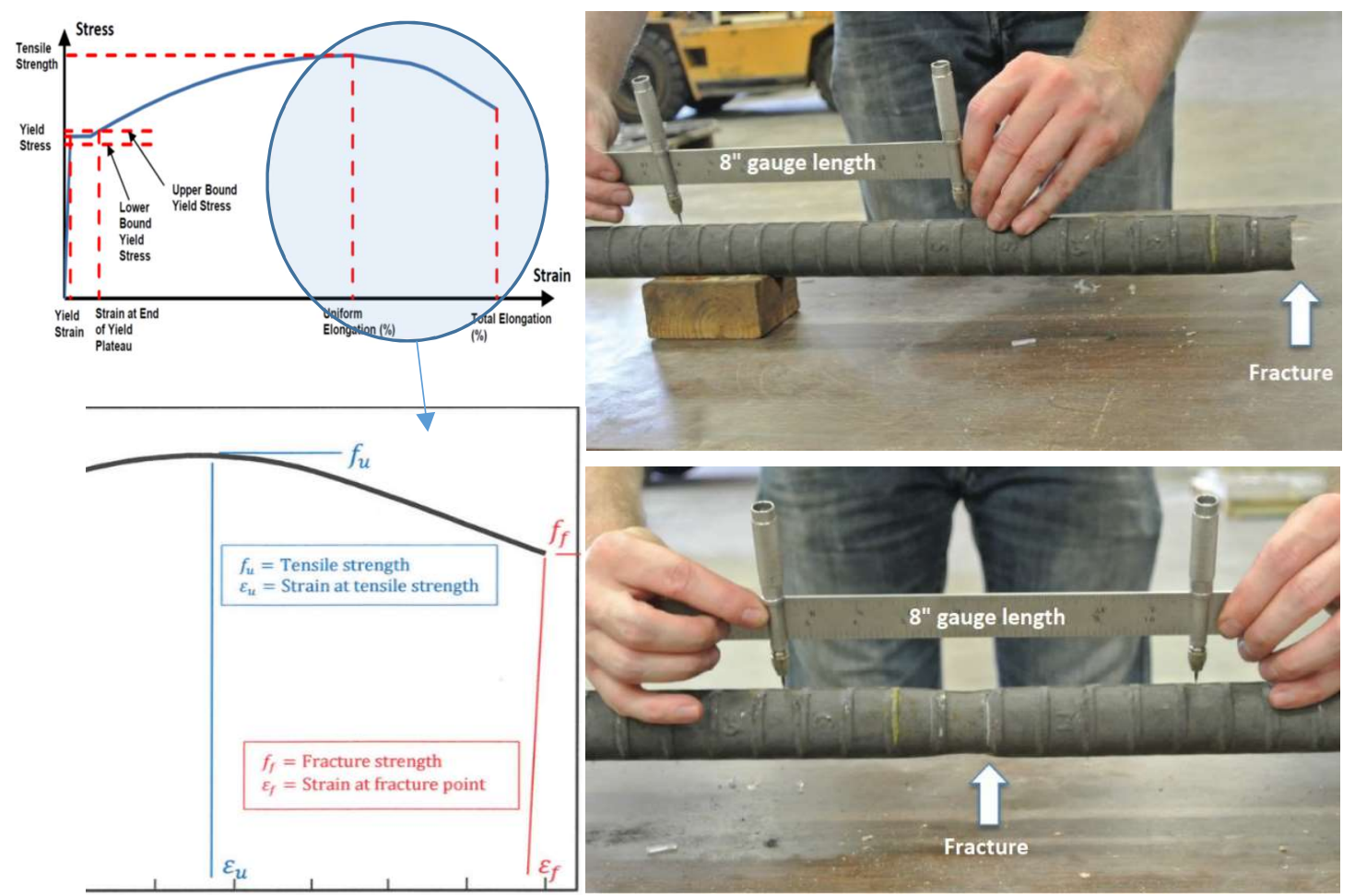

Figure 2-3: Uniform strain vs. total strain (NIST GCR 14-917-30)

\subsection{High-Strength Concrete (HSC)}

According to the American Concrete Institute (ACI), high strength concrete is defined as concrete that is over 6000 psi compressive strength. Nowadays, HSC is being widely used all over the world in different applications such as high-rise buildings and long span bridges. The use of HSC in structures would result in both technical and economic advantages. It is usually produced using high strength aggregate, cement, and water, with the addition of mineral and chemical admixtures. Generally, superplasticizers or highrange water-reducer admixtures are used as the chemical admixtures, and Silica fume, fly ash, ground slag, and slag cement are used as mineral admixtures. ACI 211.4R-08 presents a guide for selecting mixture proportions and optimizing these mixture 
proportions on the basis of trial batches. Concrete mixtures for HSC typically contain 600 to $850 \mathrm{lb} / \mathrm{yd}^{3}$ of cementitious materials plus $5 \%$ to $15 \%$ silica fume by weight of cement with a $w / \mathrm{cm}$ as low as 0.2 . Silica fume increases the concrete strength largely because it increases the strength of the bond between the aggregate particles and the cement paste, and reduces the permeability. The use of the mineral admixtures will improve the strength, however, it will increase the water demand. Therefore to maintain the desired w/cm ratio, water-reducing admixtures, high-range water-reducing admixtures, or both should be used to obtain the required workability as they help in dispersing cement particles. Many trial batches are often required to obtain the required HSC properties.

\subsection{Stress-Strain Curves for Unconfined Concrete in Compression}

Knowledge of concrete stress-strain relationship is essential for developing analysis and design terms of concrete structures. The stress-strain curve of concrete under uniaxial compression load is highly affected by the testing conditions used and varies depending on many factors, among which are: (a) strength of concrete, (b) confinement, (c) rate of loading, and (d) different mix proportions and material properties. Therefore, defining just one valid curve for each concrete strength is not possible. Typical stress-strain curves of various strengths are shown in Figure 2-5. All stress-strain curves have an ascending part that reaches maximum stress at a strain between 0.0015 and 0.003 followed by a descending branch. Frequently, an axially tested concrete cylinder fails explosively at the point of maximum stress and the descending branch of the curve may not be captured. 
The strain at maximum stress, $\varepsilon_{o}$, increases as the concrete strength increases, while the maximum strain, $\varepsilon_{c u}$, decreases with an increase in concrete strength.

A complete stress-strain curve for concrete is necessary for the nonlinear analysis of structural members. To describe the behavior of unconfined concrete, many models have been proposed by researchers for both normal and high strength concretes. Some research suggested two different equations to model the ascending and the descending branches, while others proposed only one equation to simulate the entire curve. In 2014, Shafiq et al. conducted a study to assess different predictive models for HSC available in the literature. Table 2-2 is adopted from Shafiq et al. (2014) study to show some of the existing stress-strain models for HSC.

For the purpose of this research, Carreira and Chu (1985) model is deemed appropriate for nonlinear analysis to model the concrete behavior in compression because of its applicability for both normal and high strength concrete as shown in Figure 2-4.

$f_{c}=f_{c}^{\prime}\left[\frac{\beta\left(\frac{\varepsilon}{\varepsilon_{o}}\right)}{\beta-1+\left(\frac{\varepsilon}{\varepsilon_{o}}\right)^{\beta}}\right] \ldots \ldots \ldots \ldots . \quad$ (Carreira and Chu equation) where: $\beta=\frac{1}{1-\left(\frac{f_{c}^{\prime}}{\varepsilon_{o} E_{i t}}\right)} \quad$ (material parameter)

$E_{i t}=\frac{f_{c}^{\prime}(p s i)}{\varepsilon_{o}}\left(\frac{24.82}{f_{c}^{\prime}(p s i)}+0.006343\right) \quad$ (Initial tangent modulus of elasticity)

$\varepsilon_{o}=\left(1680+0.04895 f_{c}^{\prime}(p s i)\right) \times 10^{-6}$ (Strain corresponding to the peak compressive strength of plain concrete) 


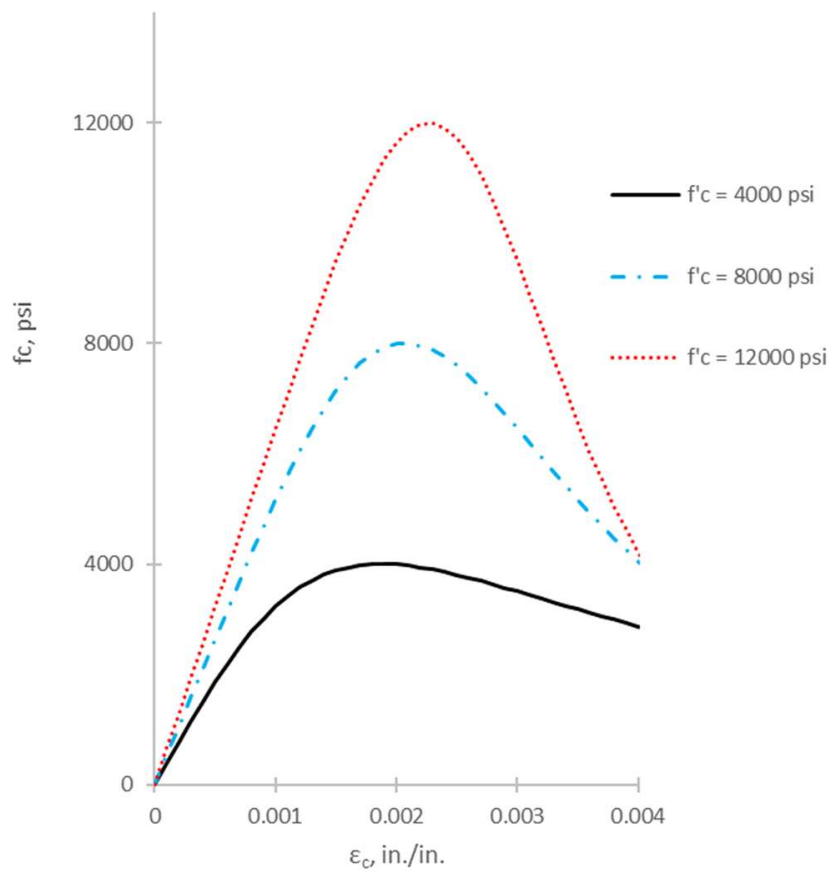

Figure 2-4: Carreira and Chu (1985) concrete stress-strain model

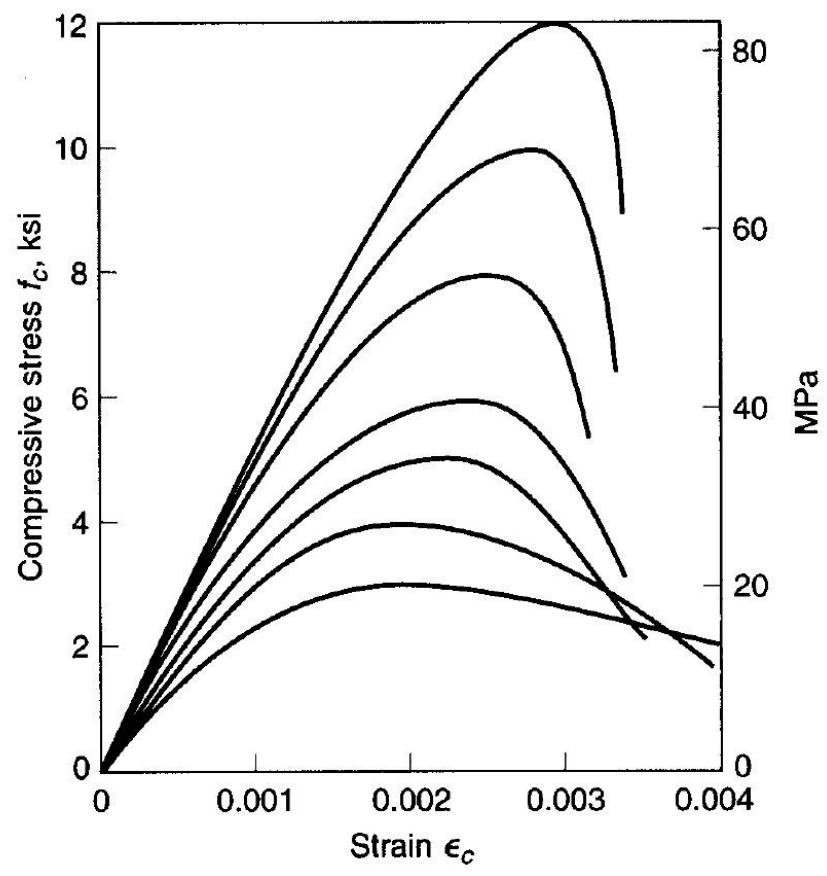

Figure 2-5: Typical compressive stress-strain curves for normal weight concrete (Nilson et al., 2010) 
Table 2-2: Existing stress-strain models for HSC (Shafiq et al., 2014)

\begin{tabular}{|c|c|c|c|c|}
\hline Authors (Year) & Model description & Parameter description & $\begin{array}{l}\text { Valid compressive } \\
\text { strength range }\end{array}$ & Authors Remarks \\
\hline \multicolumn{5}{|c|}{ Single model capable of predicting stress-strain response from origin to ultimate (i.e. $0<\varepsilon \leq \varepsilon_{u}$ ). } \\
\hline $\begin{array}{l}\text { Sargin \& Handa } \\
\text { (1969) }\end{array}$ & $\frac{f_{c}}{f_{c}^{\prime}}=k_{3} \frac{A\left(\frac{\varepsilon_{c}}{\varepsilon_{c}^{\prime}}\right)+(D-1)\left(\frac{\varepsilon_{c}}{\varepsilon_{c}^{c}}\right)^{2}}{1+(A-2)\left(\frac{\varepsilon_{c}}{\varepsilon_{c}^{\prime}}\right)+D\left(\frac{\varepsilon_{c}}{\varepsilon_{c}^{\prime}}\right)^{2}}$ & $\begin{array}{c}A=\frac{E_{i t}}{E_{c}} ; D=0.65-7.25 f_{c}^{\prime} \times 10^{-3} \\
E_{i t}=5979 \sqrt{f_{c}^{t}} ; \varepsilon_{c}^{\prime}=0.0021\end{array}$ & & \\
\hline Popovics (1973) & $\frac{f_{c}}{f_{c}^{\prime}}=\frac{\beta\left(\frac{\varepsilon_{c}}{\varepsilon_{c}^{\prime}}\right)}{\beta-1+\left(\frac{\varepsilon_{c}}{\varepsilon_{c}^{\prime}}\right)^{\beta}}$ & $\beta=.058 f_{c}^{\prime}+1$ & Up to $51 \mathrm{MPa}$ & \\
\hline $\begin{array}{l}\text { Wang et al. } \\
\text { (1978) }\end{array}$ & $\frac{f_{c}}{f_{c}^{\prime}}=\frac{A\left(\varepsilon_{c} / \varepsilon_{c}^{\prime}\right)+B\left(\varepsilon_{c} / \varepsilon_{c}^{\prime}\right)^{2}}{1+C\left(\varepsilon_{c} / \varepsilon_{c}^{\prime}\right)+D\left(\varepsilon_{c} / \varepsilon_{c}^{\prime}\right)^{2}}$ & 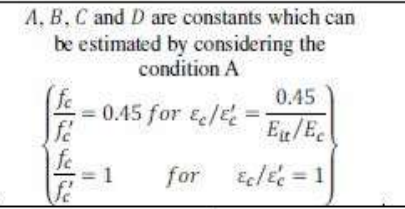 & Up to $76 \mathrm{MPa}$ & \\
\hline $\begin{array}{l}\text { Carriera \& Chu } \\
\quad(1985)\end{array}$ & $\frac{f_{c}}{f_{c}^{\prime}}=\frac{\beta\left(\varepsilon_{c} / \varepsilon_{c}^{\prime}\right)}{\beta-1+\left(\varepsilon_{c} / \varepsilon_{c}^{\prime}\right)^{\beta}}$ & $\begin{array}{c}\beta=\frac{1}{1-\left(\frac{f_{c}^{\prime}}{\varepsilon_{c}^{\prime} E_{i t}}\right)} \\
E_{i t}=\frac{f_{c}^{\prime}}{\varepsilon_{c}^{\prime}}\left(\frac{24.82}{f_{c}^{\prime}}+0.92\right) \\
\varepsilon_{c}^{\prime}=\left(1,680+7.1 f_{c}^{\prime}\right) \times 10^{-6}\end{array}$ & 23 to $80 \mathrm{MPa}$ & $\begin{array}{l}\text { Does not fit on current } \\
\text { data due to negative value } \\
\text { of } \beta\end{array}$ \\
\hline \multicolumn{5}{|c|}{$\begin{array}{l}\text { Two models, one for combine prediction of the behavior of rising branch and falling branch up to the limiting strain (i.e. } 0<\varepsilon \leq \varepsilon_{\text {clim }} \text { ), while second model } \\
\text { predicts the behavior of the depressing branch frem limiting strain up to ultimate strain (i.e. } \varepsilon_{\text {clim }}<\varepsilon \leq \varepsilon_{u} \text {. }\end{array}$} \\
\hline CEB-FIP (1993) & $\begin{array}{l}\text { For } 0 \leq \varepsilon \leq \varepsilon_{c, \text { lim }} \\
\qquad f_{c}=f_{c}^{\prime} \frac{\left(\frac{\varepsilon_{t_{t}}}{E_{c}}\right)\left(\frac{\varepsilon_{c}}{\varepsilon_{c}^{\prime}}\right)-\left(\frac{\varepsilon_{c}^{\prime}}{\varepsilon_{c}^{\prime}}\right)^{2}}{1+\left(\frac{E_{t i}}{E_{c}}-2\right)\left(\frac{\varepsilon_{c}}{\varepsilon_{c}^{\prime}}\right)} \\
\text { For } \varepsilon>\varepsilon_{c, \text { lim }} \\
\qquad f_{c}=\frac{f_{c}^{\prime}}{\left(\frac{\xi}{\eta_{2}}-\frac{2}{\eta_{2}^{2}}\right)\left(\frac{\varepsilon_{c}}{\varepsilon_{c}^{\prime}}\right)^{2}+\left(\frac{4}{\eta_{2}}-\xi\right)\left(\frac{\varepsilon_{c}}{\varepsilon_{c}^{c}}\right)}\end{array}$ & $\begin{array}{c}\frac{\varepsilon_{c . i m m}}{\varepsilon_{c}^{\prime}}=\frac{1}{2}\left[\left(\frac{E_{i t}}{2 E_{c}}+1\right)+\sqrt{\left(\frac{E_{i t}}{2 E_{c}}+1\right)^{2}-2}\right] \\
\eta_{2}=\frac{\varepsilon_{c . l i m}}{\varepsilon_{c}^{\prime}} \\
\xi=4 \frac{\eta / 2\left(\frac{E_{i t}}{E_{c}}-2\right)+2 \eta_{2}-\frac{E_{i t}}{2 E_{c}}}{\left[\eta_{2}\left(\frac{E_{i t}}{2 E_{c}}-2\right)+1\right]^{2}}\end{array}$ & & $\begin{array}{l}\text { Modified form of Sargin } \\
\text { and Handa (1969) }\end{array}$ \\
\hline $\begin{array}{l}\text { Hsu \& Hsu } \\
\text { (1994) }\end{array}$ & $\begin{array}{l}\text { For } 0 \leq \varepsilon \leq \varepsilon_{c, l i m} \\
\qquad \frac{f_{c}}{f_{c}^{\prime}}=\frac{n \beta\left(\varepsilon_{c} / \varepsilon_{c}^{\prime}\right)}{n \beta-1+\left(\varepsilon_{c} / \varepsilon_{c}^{\prime}\right)^{n \beta}} \\
\text { For } \varepsilon>\varepsilon_{c, l i m} \\
\qquad f_{c}=0.3 f_{c}^{\prime} e^{-0.8\left(\frac{\varepsilon_{c}}{\varepsilon_{c}} \frac{\varepsilon_{c}, l l m}{\varepsilon_{c}}\right)^{2 s}}\end{array}$ & $\begin{array}{l}\qquad \beta=\left(\frac{f_{c}^{\prime}}{65.23}\right)^{3}+2.59 \\
\text { Where, } E_{i t}=0.0736 w^{151}\left(f_{c}^{\prime}\right)^{0.3}, \\
\qquad \varepsilon_{o}=\left(1680+7.1 f_{c}^{\prime}\right) \times 10^{-6} \\
\text { For } 0 \leq \varepsilon \leq \varepsilon_{c}^{\prime} ; n=1 \\
\text { For } \varepsilon_{c}^{\prime} \leq \varepsilon \leq \varepsilon_{d} ; \\
n=1 \text { if } f_{c}^{\prime}<62 M P a \\
n=2 \text { if } 62 \mathrm{MPa}<f_{c}^{\prime}<76 \mathrm{MPa} \\
n=3 \text { if } 76 \mathrm{MPa}<f_{c}^{\prime}<90 \mathrm{MPa} \\
n=5 \text { if } f_{c}^{\prime} \geq 90 \mathrm{MPa} \\
\varepsilon_{c, l i m} \text { is the strain at } 0.3 f_{c}^{\prime} \text { in the falling } \\
\text { branch of stress-strain curve. }\end{array}$ & $>69 \mathrm{MPa}$ & \\
\hline $\begin{array}{l}\text { Van Gysel \& } \\
\text { Taerwe (1996) }\end{array}$ & $\begin{array}{l}\text { For } 0 \leq \varepsilon \leq \varepsilon_{c, \text { tim }} \\
\qquad f_{c}=f_{c}^{\prime} \frac{\left(\frac{\varepsilon_{\varepsilon}}{E_{0}}\right)\left(\frac{\varepsilon_{c}}{\varepsilon_{0}}\right)-\left(\frac{\varepsilon_{c}}{\varepsilon_{0}}\right)^{2}}{1+\left(\frac{\varepsilon_{u t}}{\varepsilon_{0}}-2\right)\left(\frac{\varepsilon_{c}}{\varepsilon_{0}}\right)} \\
\text { For } \varepsilon>\varepsilon_{c, \text { lim }} \\
\qquad f_{c}=\frac{f_{c}^{\prime}}{\left(\frac{\xi}{\eta_{12}}-\frac{2}{\eta_{2}^{2}}\right)\left(\frac{\varepsilon_{c}}{\varepsilon_{0}}\right)^{2}+\left(\frac{4}{\eta_{2}}-\xi\right)\left(\frac{\varepsilon_{c}}{\varepsilon_{0}}\right)}\end{array}$ & $\begin{array}{c}\frac{\varepsilon_{c, l i m}}{E_{c}^{t}}=\frac{1}{2}\left[\left(\frac{E_{i t}}{2 E_{c}}+1\right)+\sqrt{\left.\left(\frac{E_{i t}}{2 E_{c}}+1\right)^{2}-2\right]}\right. \\
\eta_{2}=\frac{\varepsilon_{c, i l i m}}{\varepsilon_{c}^{\prime}} \\
\xi=4 \frac{\eta_{2}^{2}\left(\frac{E_{i t}}{E_{c}}-2\right)+2 \eta_{2}-\frac{E_{u}}{2 E_{c}}}{\left[\eta_{2}\left(\frac{E_{u}}{2 E_{c}}-2\right)+1\right]^{2}}\end{array}$ & & \\
\hline $\begin{array}{l}\text { Lu \& Zhao } \\
\text { (2010) }\end{array}$ & $\begin{array}{c}\text { For } 0 \leq \varepsilon \leq \varepsilon_{\varepsilon_{1}} \\
\frac{f_{c}}{f_{c}^{\prime}}=\left[\frac{\left(E_{i t} / E_{c}\right)\left(\varepsilon_{c} / \varepsilon_{c}^{\prime}\right)-\left(\varepsilon_{c} / \varepsilon_{c}^{\prime}\right)^{2}}{1+\left(E_{i t} / E_{c}-2\right)\left(\varepsilon_{c} / \varepsilon_{c}^{\prime}\right)}\right] \\
\frac{f_{c}}{f_{c}^{\prime}}=\frac{\text { For } \varepsilon>\varepsilon_{d}}{1+\lambda\left[\left(\varepsilon_{c} / \varepsilon_{c}^{\prime}\right)-1 /\left(\varepsilon_{d} / \varepsilon_{c}^{\prime}\right)-1\right]^{2(1-\lambda)}}\end{array}$ & $=\varepsilon_{c}^{\prime}\left[\left(\frac{1}{10} \frac{E_{i t}}{E_{c}}+\frac{4}{5}\right)+\sqrt{\left(\frac{1}{10} \frac{E_{i t}}{E_{c}}+\frac{4}{5}\right)^{2}-\frac{4}{5}}\right]$ & $50-140 \mathrm{MPa}$ & $\begin{array}{c}\left.\text { For } 0 \leq \varepsilon \leq \varepsilon_{L}\right) \text {, modified } \\
\text { form of Sargin \&Handa } \\
\text { (1969)\& } \\
\text { for } \varepsilon>\varepsilon_{L} \text {, the model of } \\
\text { Van Gysel \& Taerwe } \\
\text { (1996) are used }\end{array}$ \\
\hline \multicolumn{5}{|c|}{$\begin{array}{l}\text { Two models, one for predicting the behavior of rising branch up to the peak point (i.e. } 0<\varepsilon \leq \varepsilon_{c}^{\prime} \text { ), while second model for predicting the behavior of falling } \\
\text { branch from peak point to the ultimate (i.e. } \varepsilon_{\mathrm{c}}<\varepsilon \leq \varepsilon_{\mathrm{u}} \text { ). }\end{array}$} \\
\hline $\begin{array}{l}\text { Wee et al. } \\
\text { (1996) }\end{array}$ & $\begin{aligned} \text { For } f_{c}^{\prime} & \leq 50 \mathrm{MPa} \\
& \frac{f_{c}}{f_{c}^{\prime}}=\frac{\beta\left(\varepsilon_{c} / \varepsilon_{c}^{\prime}\right)}{\beta-1+\left(\varepsilon_{c} / \varepsilon_{c}^{\prime}\right)^{\beta}} \\
\text { For } 50<f_{c}^{\prime} & \leq 120 \mathrm{MPa} \\
\frac{f_{c}}{f_{c}^{\prime}} & =\frac{k_{1} \beta\left(\varepsilon_{c} / \varepsilon_{c}^{\prime}\right)}{k_{1} \beta-1+\left(\varepsilon_{c} / \varepsilon_{c}^{\prime}\right)^{k_{2} \beta}}\end{aligned}$ & $\begin{array}{c}\beta=\frac{1}{1-\left(\frac{f_{c}^{\prime}}{\varepsilon_{c}^{\prime} E_{l t}}\right)} \\
\text { Where, } E_{l t}=10,200\left(f_{c}^{\prime}\right)^{1 / 3} \\
k_{1}=\left(\frac{50}{f_{c}^{\prime}}\right)^{3.0} ; k_{2}=\left(\frac{50}{f_{c}^{\prime}}\right)^{1.3}\end{array}$ & $50-120 \mathrm{MPa}$ & \\
\hline
\end{tabular}

$f_{c}^{\prime}$ is the maximum compressive strength in $M P a, \varepsilon_{c}^{\prime}$ is the corresponding strains. $\beta$ is the parameter that controls the descending branch. $w$ is the unit weigh of the concrete in $\mathrm{kg} / \mathrm{m}^{3}$ 


\subsection{Rectangular Stress Block for Concrete}

The actual stress-strain of concrete in compression has a parabolic shape as shown in Figure 2-5, and it is known that the real stress distribution of a concrete section in the compression zone is the same as the stress-strain curve in compression. However in design, it is time consuming to find the area and the centroid of the parabolic distribution of the compression stress. Whitney proposed an equivalent rectangular stress block to make the calculations of the flexural strength easier without an excessive loss of accuracy. The equivalent stress block is derived such that both the area under the actual stress distribution and the centroid of this area correspond closely to those of the rectangular stress block. ACI 318 has adopted the use of the stress block for the design of reinforced concrete elements with no stated limit on the concrete strength. However, the limit is specified by ACI 318 for a maximum allowable strain of $0.003 \mathrm{in} / \mathrm{in}$ based on exhaustive experimental tests. Figure 2-6, shows the stress and strain distribution across beam depth.
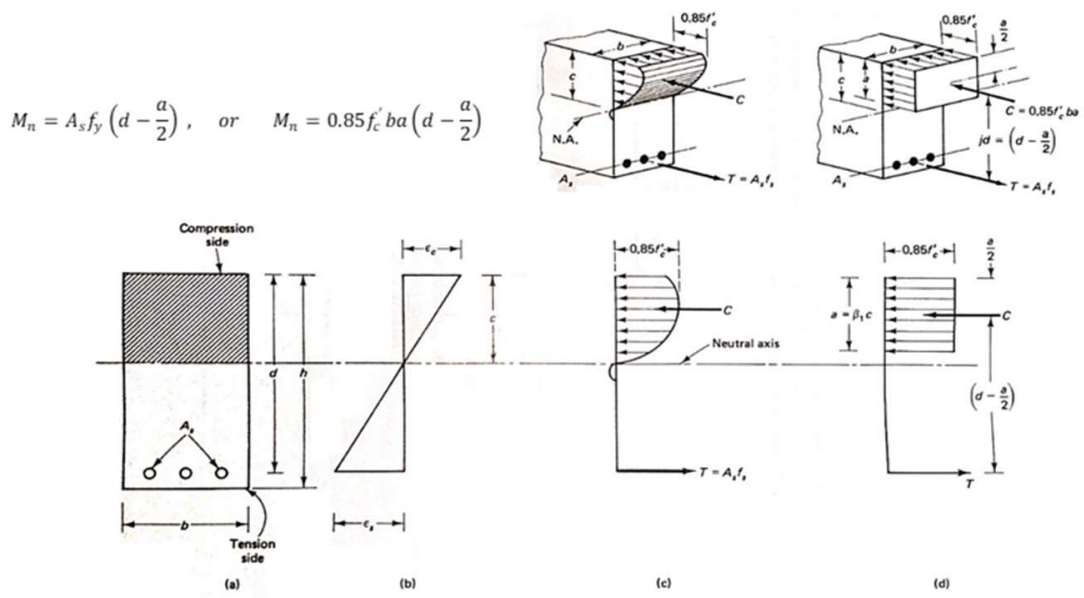

Figure 2-6: Stress and strain distribution across beam depth: (a) beam cross-section; (b)strains; (c) actual stress block; (d) assumed equivalent stress block (Nawy, 2010) 


\subsection{Reinforcement Ratio Limit vs. Strain Limits}

For many years, in the design of flexural members, the maximum reinforcement ratio was limited to $0.75 \rho_{b}$ for ductility purposes. This maximum reinforcement ratio assures that the reinforcement yields before the concrete crushes so that a member shows visible warnings such as obvious deflection and cracks before it fails. In 2002, the ACI 318 code introduced a new approach for designing concrete members under flexure that depends on the outmost tensile reinforcement layer strain limits. This approach was due to the attempts to find a unified design approach for both reinforced and prestressed concrete flexural and compression members. Three strain limit zones were introduced: Tensioncontrolled, transition-zone, and compression-controlled beam sections. The concrete sections for which $\varepsilon_{t}<\varepsilon_{t y}$, such as column sections, are classified as compressioncontrolled sections. A strain value of 0.005 in./in. is required for tension-controlled beam sections. This value is approximately 2.5 times the yield strain of about 0.002 for ASTM A615 Grade 60 reinforcement, and is higher than what was required in ACI 318 prior to 2002.

ACI 318 code also requires for flexural members that the minimum strain in the reinforcement should not be less than 0.004 in./in. This limit determines the maximum reinforcement ratio based on the new approach. Figure 2-7 shows the current strain limits

of the ACI 318 code (that correspond to the use of grade 60 reinforcing steel) along with the strength reduction factor. 
To compare the reinforcement ratio approach with the strain limit approach in terms of $\rho_{\max }$ from the strain compatibility and section equilibrium, the following equation is obtained for $\rho$ :

$$
\rho=\frac{0.85 \beta_{1} f_{c}^{\prime}}{f_{s}}\left(\frac{\varepsilon_{c u}}{\varepsilon_{c u}+\varepsilon_{t}}\right)
$$

In order to find $\rho_{b}$ in Grade 60 steel, substitute $\varepsilon_{c u}=0.003$ and $\varepsilon_{t}=\varepsilon_{t y}=0.00207$ in the above equation. Then to find $\rho_{\max }$, substitute $\varepsilon_{c u}=0.003$ and $\varepsilon_{t}=0.004$. Dividing $\rho_{\max }$ over $\rho_{b}$ yields to: $\rho_{\max } \approx 0.72 \rho_{b}$, which is slightly less than $0.75 \rho_{b}$ based on ACI 318 prior to 2002 . Therefore, the new approach should lead to a slightly better ductility.

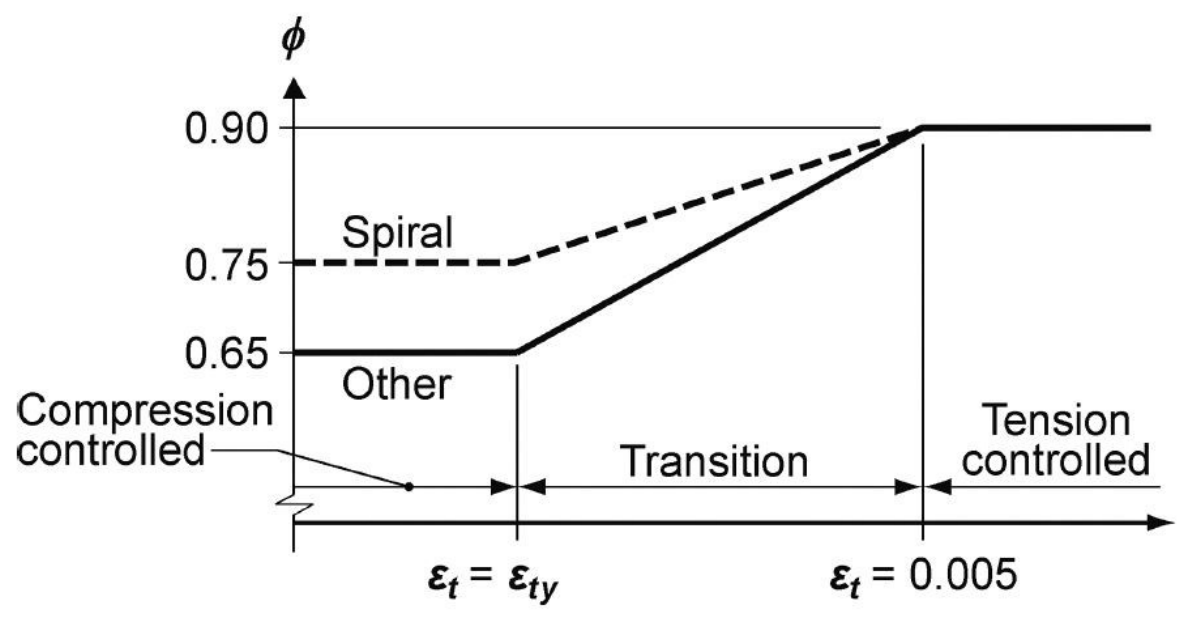

Figure 2-7: Strength reduction factor, $\phi$, based on strain limit approach 


\subsection{Minimum Flexural Reinforcement}

In beams, minimum reinforcement is usually required when sections are larger than required for strength, such as for architectural or other reasons. The minimum flexural reinforcement is provided to avoid sudden and brittle failure in case of accidental overload, or additional tensile forces due to shrinkage, temperature, or creep. The concept of providing minimum reinforcement is to assure that the strength of the member (computed using cracked section analysis) is greater than the corresponding strength of an unreinforced concrete section (computed using modulus of rupture, $f_{r}$ ) to prevent a sudden and brittle failure. The current provision of ACI 318 code for minimum reinforcement ratio is written in terms of geometric and material properties of the section. For rectangular beam section, $\rho_{\min }$ is determined using the following equation:

$$
\rho_{\text {min }}=\text { maximum of }\left(\frac{3 \sqrt{f_{c}^{\prime}}}{f y}, \frac{200}{f y}\right)
$$

The term, $\frac{200}{f y}$, was derived by equating the ultimate strength of the section without reinforcement to the ultimate strength of the section with reinforcement and solving for $\rho_{\min }$ (ACI 318-63). While the term, $\frac{3 \sqrt{f_{c}^{\prime}}}{f y}$, is derived from equating the design flexural capacity, $\varnothing M_{n}$, to the cracking capacity, $M_{c r}$ and solving for $\rho_{\text {min }}$, then the resulted constant was rounded up to 3 to provide a margin of safety, $\varnothing M_{n} / M_{c r}$, (ACI 318-95). A parametric study conducted by Seguirant et al. (2010) demonstrated the variability of the safety margin provided by the ACI $318 \rho_{\min }$ for non-prestressed rectangular sections 
from slightly under-conservative to extremely over-conservative $\left(\varnothing M_{n} / M_{c r}=1.42\right.$ to 3.19).

Although the current equation for ACI $318 \rho_{\min }$ already addresses reinforcement with variable yield strength, its application to the use of HSR of different stress-strain shapes and grades needs to be verified. The ATC-115 (2014) stated that the current ACI 318 provision of $\rho_{\min }$ for prestressed members $\left(\varnothing M_{n} / M_{c r}=1.2\right)$ inherently includes and considers HSR in the limit state. Therefore in this research, a study on $\rho_{\min }$ for beams made with HSR is included to examine the applicability of the current ACI 318 provisions for non-prestressed and prestressed members on those beams, and to propose new requirements when they provide more-consistent results than existing provisions.

\subsection{Serviceability of Beams}

When designing a reinforced concrete beam, the designer must ensure that it is both safe and serviceable. Serviceability means that the member should satisfy its intended function throughout its working life. Serviceability consideration is making reliable predictions for the instantaneous and time-dependent deflections and crack widths. Both excessive deflection and crack width can affect the serviceability negatively, for this reason building codes, including ACI 318, specify limits for deflections and crack widths at service load level. Serviceability problems may become more prevalent with the use of higher strength materials as they lead to smaller sections and/or less amount of reinforcement. 


\subsubsection{Short-Term Deflection (Immediate Deflection)}

The load-deflection relationship of a reinforced concrete beam is idealized to be composed of three regions prior to failure: Pre-cracking stage, post-cracking stage, and post-serviceability cracking stage (steel yield), as shown in Figure 2-8.

In the pre-cracking stage, the flexural stiffness $(E I)$ can be estimated using a modulus of elasticity of concrete $\left(E_{c}=57000 \sqrt{f_{c}^{\prime}}\right)$ and the transformed moment of inertia $\left(I_{g t}\right)$ or the gross moment of inertia $\left(I_{g}\right)$. This stage ends at the initiation of the first crack. Then the post-cracking stage starts in which the flexural cracks develop, and the contribution of concrete in tension zone reduces substantially, which in turn decreases the beam stiffness. The stiffness at this stage is estimated as $\left(E_{c} I_{c r}\right)$ as indicated in Figure 2-8. However, only portions of the beam are cracked, and the uncracked segments still have a higher degree of stiffness. The actual stiffness of the beam lies between $\left(E_{c} I_{g}\right)$ and $\left(E_{c} I_{c r}\right)$. The ACI code uses the effective moment of inertia $\left(I_{e}\right)$ to account for the reduced stiffness $\left(E_{c} I_{e}\right)$ at this stage. At the last stage, the member stiffness will decrease considerably due to extensive cracking. As the load increases, the cracks will continue to open until the maximum compressive strain in the concrete is reached leading to a total crushing of the concrete in the maximum moment region, then possibly followed by rupture of reinforcement. For the serviceability limit state, the ACI 318 code specifies service load deflection control limits as a fraction of the member span to maintain serviceability of the structure.

To predict deflections at service load level, ACI 318-14 uses the effective moment of inertia $I_{e}$ (equation 24.2.3.5a) with the elastic beam deflection equations. However, the use of high-strength bars would result in lower reinforcement ratios, and for low 
reinforcement ratios it has been shown (Bischoff, 2007) that Eq. 24.2.3.5a overestimates the stiffness, and as a result underestimates the deflection. A different expression may be needed to compute $I_{e}$ when using high-strength reinforcement. The equation developed by Bischoff (2007) has been shown to provide accurate results with low reinforcement ratios $(\rho<1 \%)$ for beams reinforced with fiber reinforced polymer bars (FRP), however, the application of Bischoff's equation needs to be verified for the use of the higher strength reinforcement.

$$
\begin{aligned}
& I_{e}=\left(\frac{M_{c r}}{M_{a}}\right)^{3} I_{g}+\left[1-\left(\frac{M_{c r}}{M_{a}}\right)^{3}\right] I_{c r} \leq I_{g} \quad \ldots \ldots \ldots \text { ACI } 318-14 \text { Eq. (24.2.3.5a) } \\
& I_{e}=\frac{I_{c r}}{1-\left(1-\frac{I_{c r}}{I_{g}}\right)\left(\frac{M_{c r}}{M_{a}}\right)^{2}} \leq I_{g} \quad \ldots \ldots \ldots \text { Bischoff }(2007) \text { Eqaution }
\end{aligned}
$$

where: $\quad M_{c r}=\frac{f_{r} I_{e}}{y_{t}} \quad$ and $f_{r}=7.5 \sqrt{f_{c}^{\prime}}$
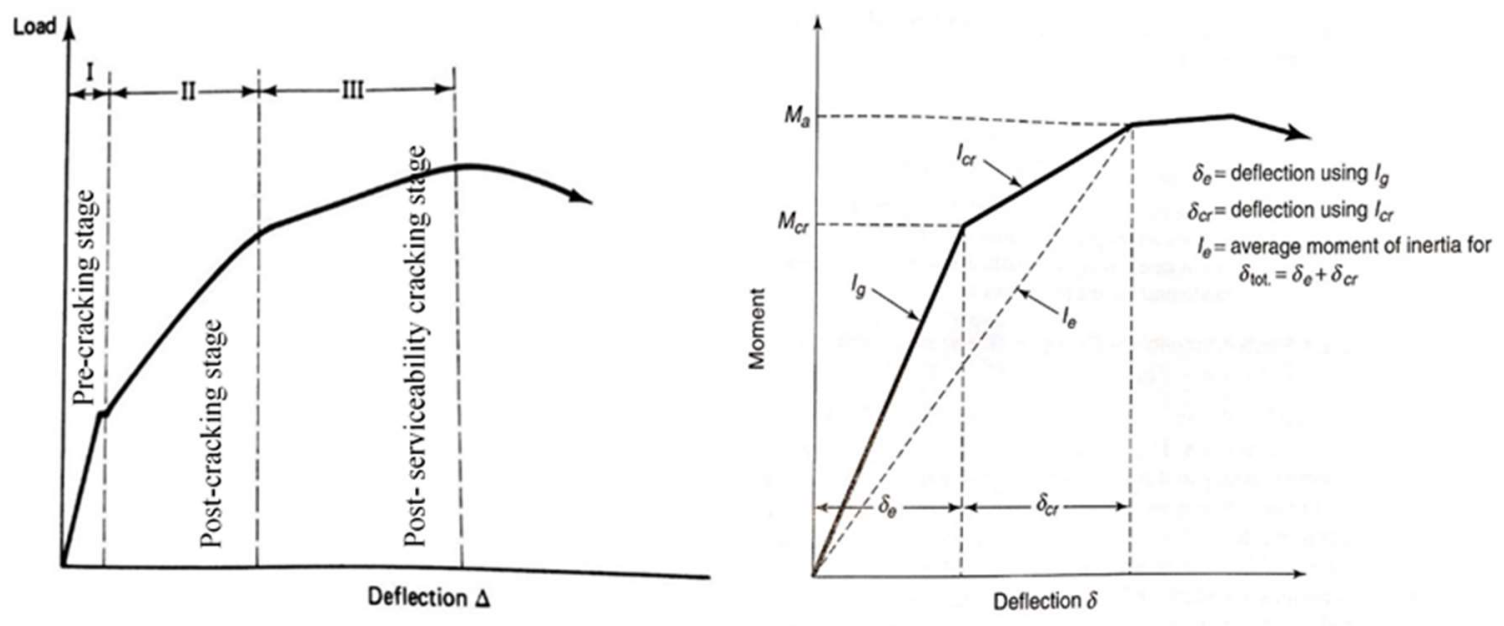

Figure 2-8: Beam load-deflection and moment-deflection relationships (Nawy, 2010) 


\subsubsection{Flexural Cracking}

It is well known that concrete is weak in tension and it cracks at an early stage of its loading history. Cracking can contribute to the deterioration of concrete surface and corrosion of the reinforcement. Therefore, it is important to predict and control the crack widths to prevent cracking from affecting the serviceability performance under long-term loading. Crack width is a function of steel strain and consequently steel stress, therefore, the stress in the reinforcement needs to be limited to some extent to control cracking. The ACI 318 code prior to 1999 adopted Gergely-Lutz's (1968) approach, known as the “zfactor approach", to estimate crack widths. This approach was based on a statistical evaluation of experimental cracking data. However, it was found that with the use of thicker covers, the z-factor method became unworkable. In 1999, ACI 318 adopted a simplified version of the approach proposed by Frosch $(1999,2001)$, which is based on a physical model for cracking. Based on the physical model, the equation for calculating maximum crack width is:

$$
w_{c}=2 \varepsilon_{s} \beta \sqrt{d_{c}^{2}+\left(\frac{s}{2}\right)^{2}}
$$

Where: $w_{c}=$ limiting crack width, in

$\beta=1.0+0.08 \mathrm{~d}_{\mathrm{c}}$

$\mathrm{dc}=$ bottom cover measured from the center of lowest bar, in

$\mathrm{s}=$ maximum permissible bar spacing, in 
The ACI 318 version of the Frosch equation prescribes spacing limits for longitudinal reinforcing bars, thereby indirectly controls cracks width, as shown in the following equation:

$s \leq 15\left(\frac{40,000}{f_{s}}\right)-2.5 d_{c} \leq 12\left(\frac{40,000}{f_{s}}\right) \quad\left(f_{s}\right.$ in psi $)$

ACI 318 implicitly assumes a maximum crack width of 0.018 in.

\subsubsection{Long-Term Deflection (Time-Dependent Deflection)}

Long-term deflection under a sustained load also needs to be evaluated as part of the serviceability limit state by checking to make sure its value also satisfies the maximum permissible limits specified by the building design codes. The additional increasing deflection under sustained load with time is mainly caused by the creep, shrinkage, and temperature strains, however, the calculation of these strains is a complex process. For more practical solution, the additional deflection from long-term loading is often based on an empirical approach. The ACI 318 procedure to calculate the time-dependent deflection due to the combined effects of creep and shrinkage is based on computing the short-term deflection and taking some multiple of this initial value to calculate the additional deflection $\left(\lambda \Delta_{i}\right)$. The total deflection can then be determined by adding the two:

$$
\Delta_{T}=\Delta_{i}+\lambda \Delta_{i}
$$

The multiplier, $\lambda$, is calculated from the following equation: $\quad \lambda=\frac{\xi}{1+50 \rho^{\prime}}$ 
where: $\xi=$ time dependent factor from Figure 2-9

$\xi=1$ for three months, 1.2 for six months, 1.4 for twelve months, or 2 for five years or more.

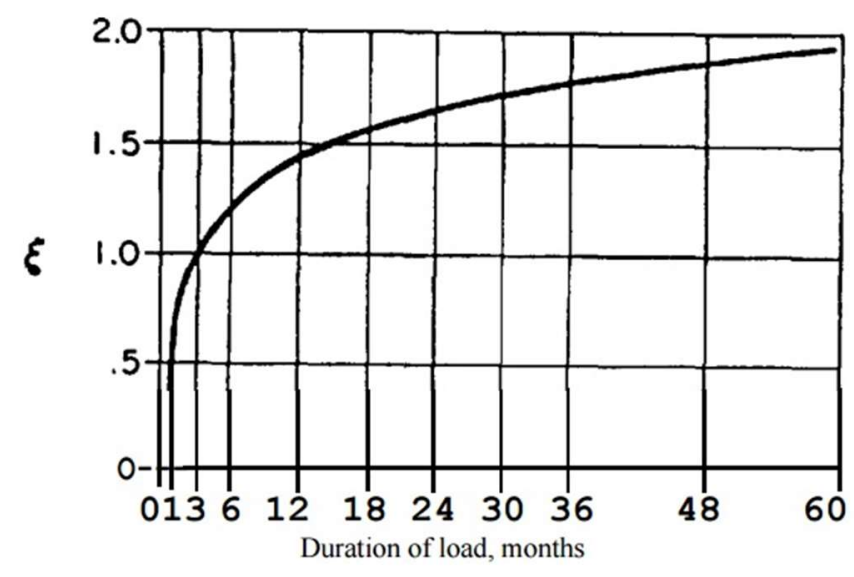

Figure 2-9: ACI 318 multipliers for long-term deflection

Research has shown that high strength concrete members exhibit significantly less sustained load deflections than low strength concrete members (Luebkeman et al, 1985; Nilson, 1985). This behavior is mainly due to lower creep strain characteristics. Studies have shown that a modifier, $\mu$, can be used to account satisfactorily for HSC, leading to the following simplified equation:

$$
\lambda=\frac{\mu \xi}{1+50 \mu \rho^{\prime}}
$$

where: $\quad 0.7 \leq \mu=1.3-0.00005 f^{\prime} c \leq 1.0$.

However, according to the ACI 435R-95 report, more data are needed, particularly for concrete strengths between 9000 to 12,000 psi and beyond before a definitive statement 
can be made. Moreover, the appropriateness of the use of time dependent factor, $\lambda$, needs to be verified for the use of high-strength reinforcement because of the potential use of lower reinforcement ratio that can lead to higher curvatures, and result in higher overall creep deflections. 


\section{Chapter Three: Literature Review}

\subsection{Introduction}

Recently, the use of high-strength reinforcing steel in concrete construction is gaining more interest for the benefits that it can add to concrete industry. High-strength steel rebar is now available with deferent types and grades, and each type is good for specific applications depending on its mechanical properties. For instance, some types are good for gravity applications (A615 and A1035) and other are good for seismic application (A706). Research on the use of high-strength steel as reinforcement for concrete members has been ongoing for some time, and the flexural behavior of concrete beams reinforced with high-strength reinforcing bars has been investigated by a number of researchers. Most of the available research papers are mainly focused on the use of the Micro-Composite Multi-Structural Formable reinforcing steel, commercially known as MMFX, which is a type of high-strength reinforcement that meets or exceeds the requirement of ASTM A1035 with the normal strength concrete. In this chapter, relevant literature related to the aspects investigated in this research is presented including: Flexural behavior of beams reinforced with high-strength steel, flexural behavior of beams made with high-strength concrete, immediate and long-term deflections at service load levels, crack width, and minimum reinforcement ratio.

\subsection{Flexural Behavior of Beams Made with High-Strength Reinforcement (HSR)}

Ansley (2002) investigated the possibility of substituting Grade 60 reinforcing with MMFX bars for concrete beams. The study included experimental program on a series of 
four beam tests to compare the behavior of MMFX bars with that of Grade 60 bars. Each test series consisted of two similar beams except in the reinforcing type. Table 3-1 summarizes the experimental program details. Examining the test results, it was concluded that MMFX led to a higher strength capacity. However, when utilizing the MMFX reinforcing additional consideration should be given to the detailing because of its higher strength and the lack of a well-defined yield stress.

Table 3-1: Tests information (Ansley, 2002)

\begin{tabular}{|c|c|c|c|c|c|}
\hline $\begin{array}{c}\text { Test } \\
\text { Number }\end{array}$ & Test Type & $\begin{array}{c}\text { Cross } \\
\text { section }\end{array}$ & $\begin{array}{c}\text { Clear } \\
\text { Span }\end{array}$ & $f_{\text {cos }}(\mathrm{psi})$ & $\rho$ \\
\hline 1 & Flexural test with continuous reinforcing & $12^{\prime \prime} \times 18^{\prime \prime}$ & $14^{\prime}$ & 6,683 & 0.0045 \\
\hline 2 & Flexural test with reinforcing lapped 10" & $12^{\prime \prime} \times 18^{\prime \prime}$ & $14^{\prime}$ & 6,034 & 0.0045 \\
\hline 3 & Flexural test with reinforcing lapped 30.5" & $12^{\prime \prime} \times 18^{\prime \prime}$ & $14^{\prime}$ & 5,420 & 0.0045 \\
\hline 4 & Shear test & $12 " \times 18^{\prime \prime}$ & $8^{\prime}$ & 4,943 & 0.0197 \\
\hline
\end{tabular}

Dawood et al. (2004) conducted an analytical study on the behavior of high-strength bars (MMFX) as a flexural reinforcement for concrete beams, and proposed a design guideline represented by a design chart for a common range of concrete strengths used for design $(3000,5000,8000 \mathrm{psi})$. The analysis was conducted using a cracked section analysis, and aimed to represent the behavior of the MMFX bars. Three models of stress-strain for the high-strength bars were examined: (1) the actual behavior (2) elastic-plastic behavior with $E_{s}=29,000 \mathrm{ksi}$ and $f_{y}=100 \mathrm{ksi}$ (3) elastic-plastic behavior with a yield strength of $80 \mathrm{ksi}$. The relationship between the moment capacity and the reinforcement ratio for each of the three models were compared, and it was shown that using the actual stressstrain behavior for MMFX could closely approximate the experimental behavior 
conducted by others, while both models 2 and 3 significantly underestimated the flexural strength of the beams. Moreover, the elastic-plastic model may result in inaccurate failure mode and inaccurate prediction of ductility. Therefore, the actual behavior of MMFX bars was used to establish the design chart shown in Figure 3-1a. It was also indicated that sections reinforced with MMFX steel exhibit significantly lower ductility than the sections reinforced with Grade 60 steel for the same reinforcement ratio. New strain limits for designs with MMFX bars were proposed to ensure sufficient ductility prior to failure, Figure 3-1b.

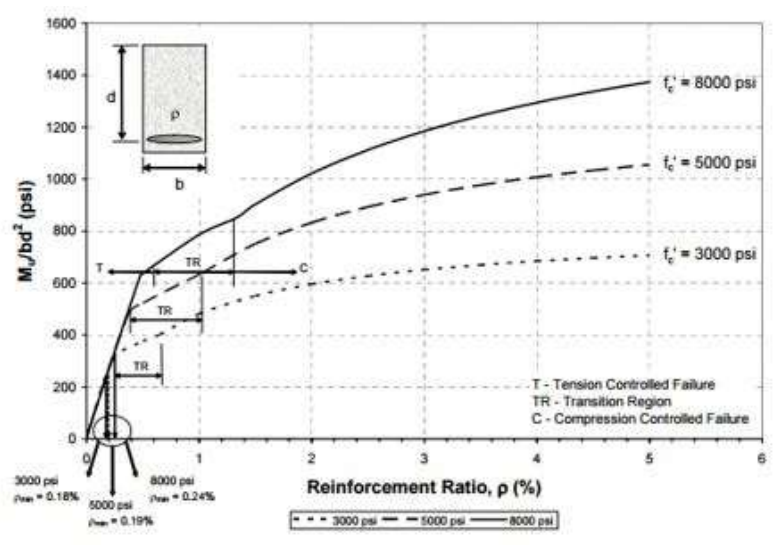

a) Design chart for MMFX reinforced concrete flexural members

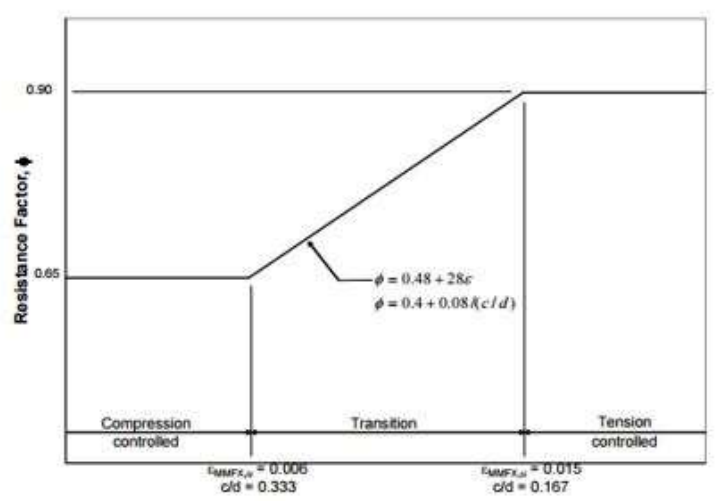

b) Strength resistance factors and proposed strain limits for MMFX reinforced concrete flexural

Figure 3-1: Design guidelines for the design with MMFX reinforcement (Dawood et al. 2004) 
Mast et al. (2008) presented a methodology for the flexural strength design of concrete beams reinforced with high-strength steel bars (MMFX) conforming ASTM A1035-07. A simplified elastic-plastic stress-strain relationship with elastic modulus of $29000 \mathrm{ksi}$ and yield strength of $100 \mathrm{ksi}$ was proposed for the high-strength steel bars to simplify the design. In the research, it was also proposed to increase the allowable yield strength for the tension steel only, and to maintain the current $\mathrm{ACI}$ limitation of $80 \mathrm{ksi}$ for compression steel because the strain of the compression steel is controlled by the ACI limitation for the maximum strain in concrete of 0.003 . An analytical investigation was performed to assess the adequacy of the proposed 100 ksi yield stress using cracked section analysis satisfying section equilibrium and strain compatibility at both service and nominal levels, as shown in Figure 3-2.

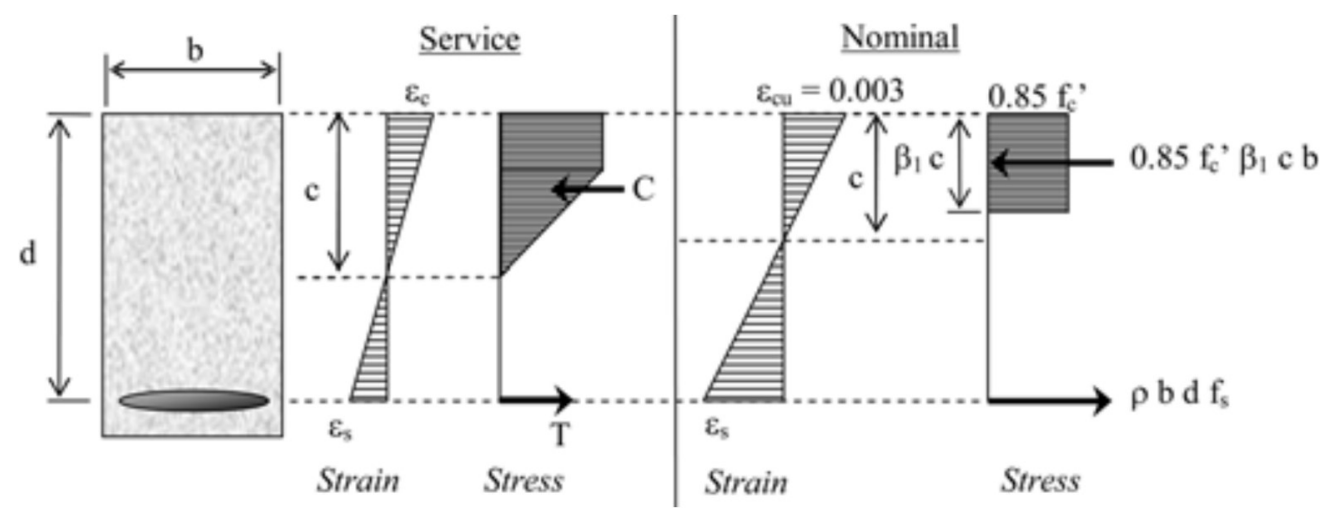

Figure 3-2: Sectional analysis procedure (Mast et al. 2008)

Three different models to represent the high-strength steel behavior were examined to validate the proposed bilinear model: (1) the actual behavior of the reinforcing steel, (2) elastic-perfectly plastic behavior with the current ACI limitation of $\mathrm{f}_{\mathrm{y}}=80 \mathrm{ksi}$, (3) the proposed simplified model (elastic-perfectly plastic behavior with $\mathrm{f}_{\mathrm{y}}=100 \mathrm{ksi}$ ). It was 
shown that the proposed model under predicts the nominal moment capacity when $\rho$ is less than $1.75 \%$ (which is the typical reinforcement ratio for the majority of beams), and over predicts the capacity when $\rho$ is between $1.75 \%$ and $2.7 \%$.

Also in this research, eight concrete beams of 12 " $\times 30$ " cross section, 28 " effective depth, and $40^{\prime}$ span were considered for the moment-curvature analysis to establish suitable design limits for tension-controlled and compression controlled sections. The results showed that when using high-strength reinforcement represented by the actual behavior that the tension-controlled limit of 0.0066 gives comparable deformability ratios (strain, curvature, and deflection ratios) to that when using Grade 60 steel. However, when using the proposed bilinear behavior to represent the high-strength steel, the tension-controlled strain limit was increased to 0.009 in order to get the same deformability ratios. The compression-controlled strain limit for the beams designed at compression-strain limit was proposed to be limited to 0.004 to-insure the beams exhibit elastic behavior under service loading conditions. The comparison of design methods is summarized in Table 3-2 and the proposed variation of resistance factor $\phi$ for the proposed simplified design procedure is shown in Figure 3-3.

Table 3-2: Comparison of design methods (Mast et al., 2008)

\begin{tabular}{|c|c|c|}
\hline & Actual behavior & Simplified method \\
\hline Tension-controlled strain & 0.0066 & 0.009 \\
\hline Neutral axis depth $c$ & $0.3125 d$ & $0.25 d$ \\
\hline Stress block depth $a=\beta_{1} c$ & $0.3125 \beta_{1} d$ & $0.25 \beta_{1} d$ \\
\hline Compressive force $C$ & $0.85 f^{\prime}{ }_{c} a b$ & $0.85 f^{\prime}{ }_{c} a b$ \\
\hline Steel area $A_{s}=C / f_{s}$ & $0.85 f^{\prime}{ }_{c}\left(0.3125 \beta_{1} d\right) b / 125\left(\mathrm{in}^{2}\right)$ & $0.85 f^{\prime}{ }_{c}\left(0.25 \beta_{1} d\right) b / 100\left(\mathrm{in}^{2}\right)$ \\
\hline Reinforcement ratio $\rho=A_{s} / b d$ & $0.002125 f^{\prime}{ }_{c} \beta_{1}$ & $0.002125 f^{\prime}{ }_{c} \beta_{1}$ \\
\hline
\end{tabular}




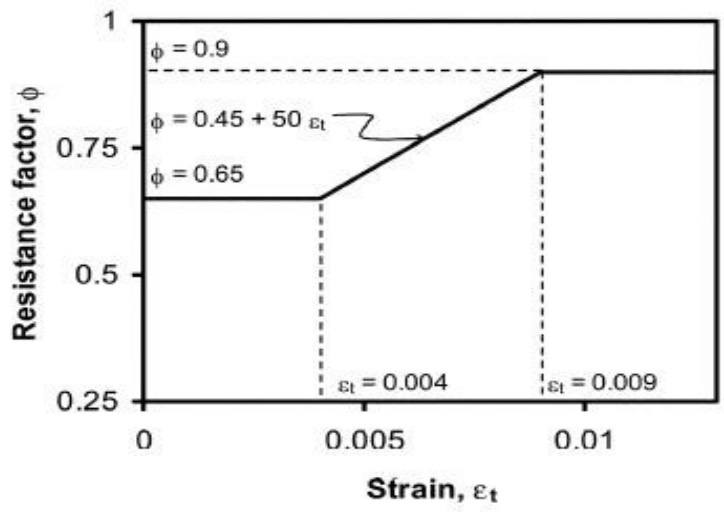

Figure 3-3: Proposed variation of resistance factor $\phi$ (Mast et al. 2008)

Eltahawy et al. (2009) examined the mechanical characteristics of the high-strength reinforcing bars (MMFX), and evaluated their corrosion resistance and their structural performance as the main flexural reinforcement. The mechanical characteristics for the MMFX bars are represented by modulus of elasticity $\left(E_{s}\right)$, and the strain and strength at yield, ultimate, and failure were tested and compared to that of the conventional steel bars for a set of three different bar sizes. The stress-strain behaviors for both MMFX and conventional steel bars were examined before and after the exposure to wet/dry cycles for one year to study the effect of corrosion. It was found that the MMFX bars have a high corrosion resistance; the measured decrease in the yield strength using $0.2 \%$ offset method was less than $10 \%$ compared to about $20 \%$ decrease for conventional steel. The structural performance of MMFX bars as the main reinforcement was evaluated through experimental and analytical study. A total of eight T-beams were designed so that the reinforcement ratio satisfies the minimum and maximum values of ECP-07 (Egyptian building code) and ACI 318-05 provisions. The varying parameters of the eight beams 
were the type of reinforcement, reinforcement ratio, and concrete compressive strength, as indicated in

Table 3-3. The resulted failure mode of the tested beams are also included in table 3-3.

The experimental tests showed that all beams with MMFX reinforcement exhibited a comparable ductile flexural failure and higher ultimate strength compared to the beams with conventional reinforcement. The analytical study to predict the behavior of the concrete beams reinforced with MMFX was conducted using strain compatibility and the section equilibrium approach to obtain the moment-curvature relationships and determine the mid-span deflections. Based on the results of the analytical study, the researchers proposed new strain limits for the design with MMFX bars as shown in Figure 3-4, and recommended that the minimum reinforcement ratio to be used with MMFX is 0.0067 to prevent rupture of the reinforcement.

Table 3-3: Test Matrix (Eltahawy et al., 2009)

\begin{tabular}{|c|c|c|c|c|}
\hline Beam Label & Steel Type & $\rho$ & $f^{\prime}$, psi & Experimental Failure Mode \\
\hline XC1-1 & MMFX & $0.0026(2 \# 4)$ & 3,553 & Rupture of tensile reinforcement \\
\hline XC1-2 & MMFX & $0.0046(2 \# 5)$ & 3,553 & Rupture of tensile reinforcement \\
\hline XC1-3 & MMFX & $0.0065(2 \# 6)$ & 3,118 & Tension-controlled failure \\
\hline XC1-4 & MMFX & $0.013(4 \# 6)$ & 3,481 & Shear failure \\
\hline XC2-3 & MMFX & $0.0065(2 \# 6)$ & 6,091 & Tension-controlled failure \\
\hline XC3-3 & MMFX & $0.0065(2 \# 6)$ & 8,267 & Tension-controlled failure \\
\hline SC1-1 & $40 / 60$ & $0.0026(2 \# 4)$ & 3,771 & Tension-controlled failure \\
\hline SC1-3 & $40 / 60$ & $0.0065(2 \# 6)$ & 3,771 & Tension-controlled failure \\
\hline
\end{tabular}




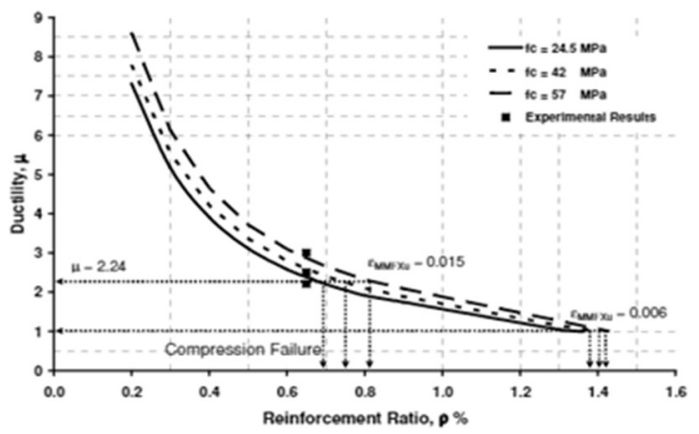

a) Effect of reinforcement ratios with various concrete strength on ductilitv

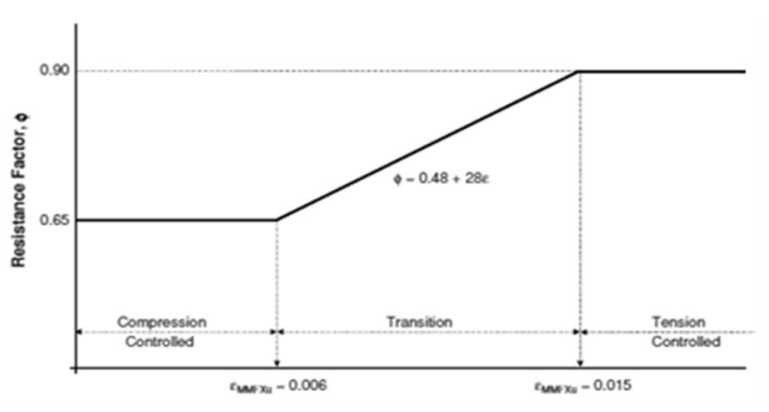

b) Resistance factor for MMFX reinforced concrete flexural members

Figure 3-4: Strain limits for the design with MMFX reinforcement (Eltahawy et al. 2009)

Shahrooz et al. (2010) presented a study on concrete members reinforced with highstrength bars that lack the well-defined yield stress. The focus of the study was on the determination of flexural capacity and strain limits for tension-controlled and compression-controlled failure modes. The study included both theoretical analysis and experimental tests. In the theoretical study, different models for the high-strength reinforcing stress-strain relationship were examined for the purpose of finding an acceptable method to predict the flexural capacity of the members designed with highstrength reinforcement. The models they examined were:

- Elastic-perfectly plastic with yield stress found from $0.2 \%$ offset method

- Elastic-perfectly plastic with yield stress corresponds to 0.0035 strain

- Elastic-perfectly plastic with yield stress corresponds to 0.005 strain

- Actual stress-strain behavior 
The analytical results considering the elastic-perfectly plastic models with yield stress corresponding to either of the three methods showed conservative flexural capacity for the range of reinforcement ratios and concrete compressive strength encountered in practice. The recommended strain limits for the members reinforced with ASTM A1035 steel are:

$$
\begin{aligned}
& \varepsilon_{t} \geq 0.008 \text { for tension-controlled failure and } \\
& \varepsilon_{t} \leq 0.004 \text { for compression-controlled failure. }
\end{aligned}
$$

The experimental program included testing three flexural beams of 12 in. x 16 in. cross section and $20 \mathrm{ft}$ simple span with the average concrete compressive strength of $13.3 \mathrm{ksi}$. The tested beams with high-strength steel showed adequate ductility compared to those reinforced with conventional steel. The test variables and results are summarized in Table $3-4$.

\begin{tabular}{|c|c|c|c|c|c|}
\hline \multirow[b]{2}{*}{$\begin{array}{c}\text { Specimen } \\
\text { Label }\end{array}$} & \multirow[b]{2}{*}{$\begin{array}{c}\rho \\
\text { (A1035) }\end{array}$} & \multirow[b]{2}{*}{$\begin{array}{c}\text { Target } \\
\varepsilon_{\mathrm{t}}\end{array}$} & \multirow[b]{2}{*}{ Comment } & \multicolumn{2}{|c|}{ Measured/Predicted } \\
\hline & & & & $\begin{array}{c}\text { Elastic-perfectly } \\
\text { plastic, } f_{y} \text { based on } \\
\text { strain }=0.0035\end{array}$ & $\begin{array}{l}\text { Actual behavior } \\
\text { (Ramberg- } \\
\text { Osgood function) }\end{array}$ \\
\hline F1 & 0.0128 & 0.008 & Tension controlled & 1.47 & 1.07 \\
\hline F2 & 0.0183 & 0.006 & Transition & 1.31 & 1.08 \\
\hline F3 & 0.00784 & 0.0115 & $\begin{array}{c}\text { Tension controlled } \\
\text { with small } \rho\end{array}$ & 1.54 & 1.01 \\
\hline
\end{tabular}

Table 3-4: Test Specimens and Results (Shahrooz et al., 2010)

\subsection{Flexural Behavior of Beams Made with High-Strength Concrete (HSC)}

Ashour (2000) investigated the effect of concrete compressive strength and reinforcement ratio on the load-deflection behavior, and displacement ductility of 
reinforced concrete beams made with high strength concrete. Nine beams were tested experimentally with different compressive strengths $(6900,11300$, and $14800 \mathrm{psi})$ and different tensile reinforcement ratios $(1.18,1.77$, and $2.37 \%)$. The results showed that for the same reinforcement ratio, the displacement ductility increases slightly as the concrete compressive strength $\left(f^{\prime}\right)$ increases to some limit and thereafter decreases as $f_{c}^{\prime}$ increases, as shown in Figure 3-5.

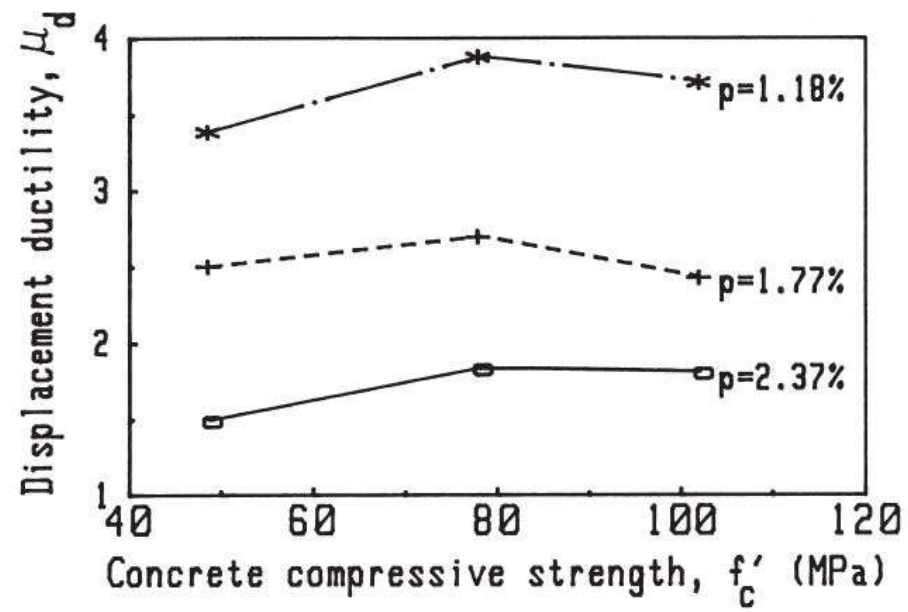

Figure 3-5: Effect of $\mathrm{f}_{\mathrm{c}}$ on displacement ductility, $\mu \mathrm{d}$ (Ashour, 2000)

Three important parameters that control the serviceability and deflection calculation were evaluated experimentally and compared with the theoretical values. These parameters are: Cracking moment $\left(M_{c r}\right)$, modulus of elasticity $\left(E_{c}\right)$, and cracked moment of inertia $\left(I_{c r}\right)$. It was found that the experimental $M_{c r}$ is about 50 to $60 \%$ of the theoretical $M_{c r}$ calculated using the modus of rupture value $\left(f_{r}\right)$. Therefore, it was concluded that the modulus of rupture is not a true indicator for the cracking moment. Also, the experimental $I_{c r}$ is about 75 to $93 \%$ of the theoretical $I_{c r}$. Because of the overestimation of these critical parameters for the deflection at service load levels, the previously proposed 
formula in the literature for the estimation of the effective moment of inertia was modified to consider the effect of reinforcement ratio and concrete compressive strength, as the following formula:

$I_{e}=\left(\frac{M_{c r}}{M_{a}}\right)^{m} I_{u t}+\left[1-\left(\frac{M_{c r}}{M_{a}}\right)^{m}\right] I_{c r}$

Where:

$m=3-0.8 \rho \sqrt{\frac{4786.25}{f_{c}^{\prime}}}, \quad\left(\right.$ where $\left.f_{c}^{\prime}>4786.25 \mathrm{psi}\right)$

$M_{a}=$ maximum bending moment

$I_{u t}=$ moment of inertia of uncracked transformed section

Rashid et al. (2005) tested sixteen reinforced high-strength concrete beams under flexure to investigate the effect of concrete compressive strength, ratio of tensile and compressive reinforcements, and spacing of lateral ties on ductility. The used concrete compressive strength ranged from 5800 to 18000 psi. Particular emphasis was given to the issues of deflection at service load and ductility. It was shown that the use of ACI Code expressions for $f_{r}$ and $E_{c}$ leads to highly unconservative predictions for the deflection at service load, and the effect of shrinkage of concrete and the resulting creep effect, which modify both $E_{c}$ and $M_{c r}$, should be included for reasonable predictions. To include the effect of shrinkage of concrete, a reduced tensile strength of concrete equal to $f_{r}-f_{s h}\left(f_{s h}\right.$ is the shrinkage-induced tension stress at the extreme fiber) should be used in the calculations of $M_{c r}$; and to include the effect of the resulting creep, a reduced 
modulus, $\bar{E}_{c}=\frac{E_{c}}{2}$, along with the gross section properties should be used. Regarding the influence of concrete strength on ductility, it was shown that keeping everything else the same, an increase in concrete strength, but up to certain level $\left(f_{c}^{\prime} \approx 15000 \mathrm{psi}\right)$, leads to higher ductility. Thereafter, any increase in $f_{c}{ }_{c}$ leads to decrease in ductility, as shown in Figure 3-6. Moreover, it was observed that the maximum crack width at service load increased as $f^{\prime}$ is increased.
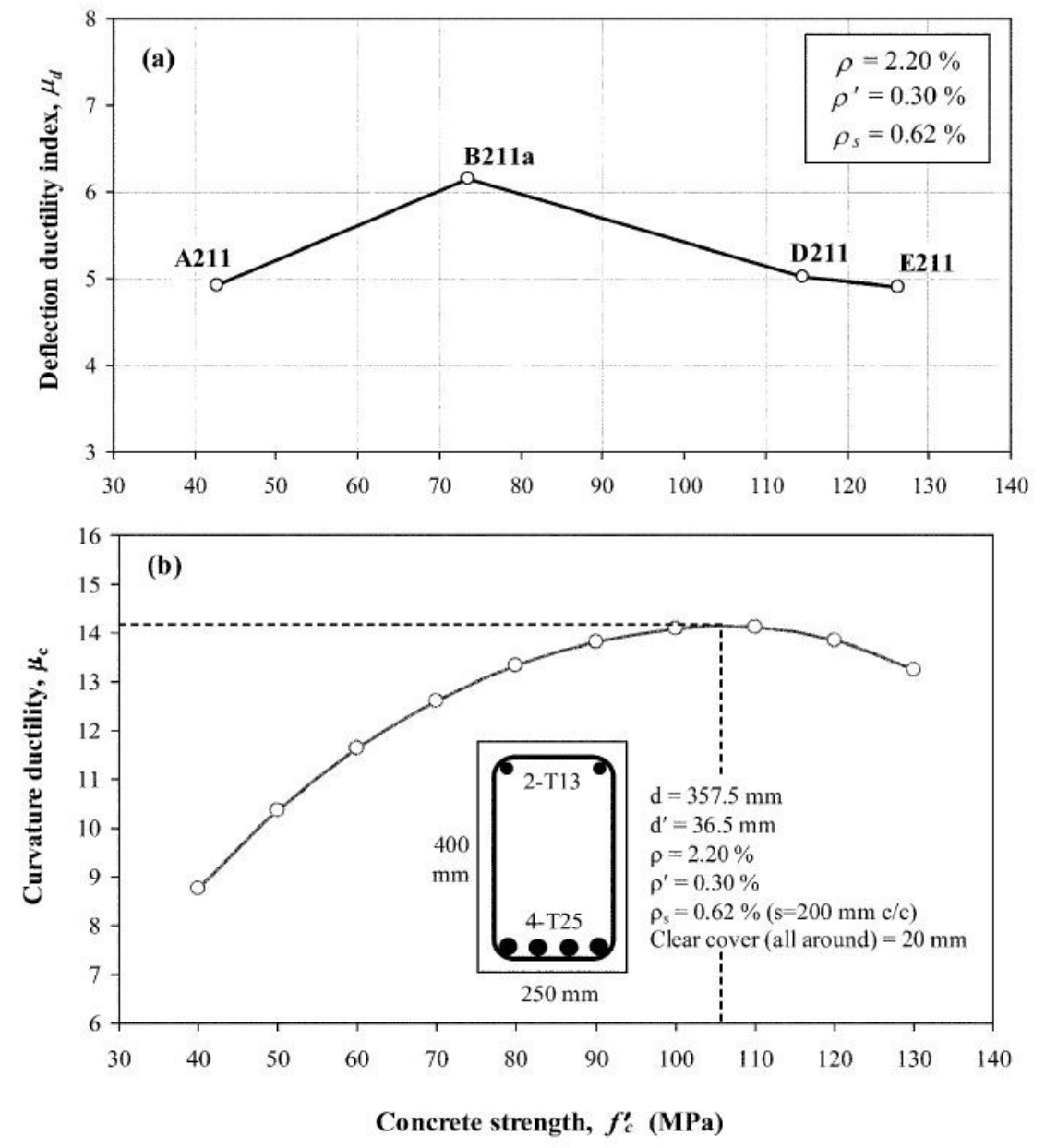

Figure 3-6: Beam ductility as influenced by concrete strength: (a) test data; and (b) analytical values (Rashid, 2005) 
Sharifi et al (2014) performed an experimental study on the flexural behavior of heavily reinforced beams made with high-strength concrete. Six beams were tested with three different steel ratios: $4.81 \%, 5.38 \%$, and $6.8 \%$. The compressive strength ranged from 9,700 to 11,280 psi. Based on the obtained results, it was found that the prediction of the ultimate moment of the tested beams using the classical ACI 318-11 code provisions were in good agreement with the tests results. However, the prediction for the deflection at service load level (ultimate load divided by a factor of 1.7) using ACI 318-11 code provisions for serviceability requirements was found to underestimate the deflection of high-strength concrete beams at service load. The researchers indicated that the use of ACI 318-11 code expressions for $f_{r}$ and $E_{c}$ leads to highly unconservative predictions for deflection at service load. It was also shown that the theoretical cracking moment $M_{c r}$, and the cracked moment of inertia $I_{c r}$ are greater than the experimental values of these two parameters for the use of high-strength concrete.

\subsection{Deflection at Service Load Level}

\subsubsection{Immediate Deflection of Beams Reinforced with HSR}

Soltani (2010) evaluated the immediate deflection of reinforced concrete beams made with high-strength concrete and high-strength steel reinforcement type ASTM A1035 Grade 100. The results of six beams tested at the University of Cincinnati as part of the NCHRP 12-77 study (Shahrooz et al. 2010) were used for the comparison. The evaluation included comparing the experimental midspan deflection results at service load levels with the AASHTO's approach to predict the deflection using the effective 
modulus of elasticity, $I_{e}$. The service load levels considered in this study were at steel stress equal to 36,60 , and $72 \mathrm{ksi}$, which are corresponding to $0.6 f_{y}$ for steel Grades 60 , 100 , and 120 steels respectively. The effective moment of inertia was calculated using Branson's and Bischoff's equations.

$$
\begin{aligned}
& I_{e}=\left(\frac{M_{c r}}{M_{a}}\right)^{3} I_{g}+\left[1-\left(\frac{M_{c r}}{M_{a}}\right)^{3}\right] I_{c r} \leq I_{g} \quad \text { (Branson's Equation, 1963) } \\
& I_{e}=\frac{I_{c r}}{1-\left(1-\frac{I_{c r}}{I_{g}}\right)\left(\frac{M_{c r}}{M_{a}}\right)^{2}} \leq I_{g} \quad \text { (Bischoff's Equation, 2005 \& 2007) }
\end{aligned}
$$

The results of this study are summarized in Table 3-5. It was shown that both Branson's and Bischoff's formulations yielded to very similar results for the tested specimens, and both underestimated the deflection by an average ratio of calculated to experimental deflection of (0.487). However, it was indicated that Bischoff's approach may be applied to for any type of elastic reinforcing material because it is based on fundamental mechanics and not empirical calibration for only mild steel as Branson's Equation. 
Table 3-5: Comparison of experimental and calculated deflections at service load levels (Soltani 2010)

\begin{tabular}{|c|c|c|c|c|c|c|c|c|c|}
\hline \multirow{3}{*}{ Beam and bar stress } & \multirow{3}{*}{$f_{c}^{\prime}(\mathrm{ksi})$} & \multirow{3}{*}{$f_{y}(0.2 \%)$} & \multirow{3}{*}{$\rho$} & \multirow{3}{*}{ Ma (k-in) } & \multicolumn{5}{|c|}{ Deflection (in) } \\
\hline & & & & & \multirow[t]{2}{*}{ experimental } & \multicolumn{2}{|c|}{ Branson } & \multicolumn{2}{|c|}{ Bischoff } \\
\hline & & & & & & calculated & calc/exp & calculated & calc/exp \\
\hline F1@36 ksi & 12.9 & 130.2 & $1.2 \%$ & 899.1 & 0.582 & 0.372 & 0.639 & 0.365 & 0.627 \\
\hline F1@60 ksi & 12.9 & 130.2 & $1.2 \%$ & 1319.8 & 1.145 & 0.6 & 0.524 & 0.59 & 0.515 \\
\hline F1@72 ksi & 12.9 & 130.2 & $1.2 \%$ & 1554.4 & 1.4 & 0.723 & 0.517 & 0.713 & 0.509 \\
\hline F2@36 ksi & 12.9 & 121.8 & $1.6 \%$ & 1041.7 & 0.527 & 0.318 & 0.604 & 0.312 & 0.592 \\
\hline F2@60 ksi & 12.9 & 121.8 & $1.6 \%$ & 1730.2 & 1.145 & 0.567 & 0.496 & 0.561 & 0.49 \\
\hline F2@72 ksi & 12.9 & 121.8 & $1.6 \%$ & 2087.2 & 1.45 & 0.695 & 0.479 & 0.689 & 0.476 \\
\hline F3@36 ksi & 12.9 & 130.2 & $0.7 \%$ & 648.5 & 0.527 & 0.27 & 0.513 & 0.288 & 0.547 \\
\hline F3@60 ksi & 12.9 & 130.2 & $0.7 \%$ & 903.5 & 0.855 & 0.479 & 0.56 & 0.483 & 0.565 \\
\hline F3@72 ksi & 12.9 & 130.2 & $0.7 \%$ & 1102.4 & 1.182 & 0.633 & 0.536 & 0.629 & 0.533 \\
\hline F4@36 ksi & 16.5 & 129.2 & $1.6 \%$ & 896.5 & 0.625 & 0.286 & 0.458 & 0.28 & 0.448 \\
\hline F4@60 ksi & 16.5 & 129.2 & $1.6 \%$ & 1406.5 & 1.146 & 0.501 & 0.437 & 0.492 & 0.429 \\
\hline F4@72 ksi & 16.5 & 129.2 & $1.6 \%$ & 1651.3 & 1.354 & 0.601 & 0.444 & 0.592 & 0.437 \\
\hline F5@36 ksi & 16.3 & 134.4 & $2.3 \%$ & 1315.4 & 0.688 & 0.33 & 0.48 & 0.326 & 0.474 \\
\hline F5@60 ksi & 16.3 & 134.4 & $2.3 \%$ & 2098.2 & 1.271 & 0.551 & 0.434 & 0.547 & 0.431 \\
\hline F5@72 ksi & 16.3 & 134.4 & $2.3 \%$ & 2519.0 & 1.583 & 0.669 & 0.423 & 0.666 & 0.421 \\
\hline F6@36 ksi & 16.9 & 129.2 & $1.2 \%$ & 569.2 & 0.458 & 0.156 & 0.341 & 0.166 & 0.363 \\
\hline F6@60 ksi & 16.9 & 129.2 & $1.2 \%$ & 1012.9 & 0.938 & 0.429 & 0.458 & 0.424 & 0.453 \\
\hline F6@72 ksi & 16.9 & 129.2 & $1.2 \%$ & 1242.4 & 1.229 & 0 . & 0.456 & 0.552 & 0.449 \\
\hline
\end{tabular}

\subsubsection{Long-Term Deflection of HSC Beams}

Paulson et al. (1991) conducted a study on the long-term deflection of high-strength concrete beams. The study intended to provide an experimental basis for improved equations for predicting long-term deflections of high-strength concrete beams with tensile reinforcement, and with or without compression reinforcement. Three different concrete grades were included in this study: 6000, 10000, and 12000 psi. One 4 x 16 in. concrete cylinder of each strength was tested under sustained load of approximately $45 \%$ of its strength to determine the creep coefficient through the relationship between the 
measured strains with time. Nine beams, all of the same cross section ( 5 " x 10"), same span (18 feet), and same amount of tension steel (2-\#5 bars, $\rho=1.5 \%)$, were divided into three groups of different concrete compressive strength. Within each group, the compression steel was varied: $A_{s}{ }^{\prime}=$ zero, $A_{s}{ }^{\prime}=1 / 2 A_{s}$, and $A_{s}{ }^{\prime}=A_{s}$. All of the beams were tested under sustained load for twelve months. Initial elastic deflections were measured for the nine tested beams and compared with the calculated values using the effective moment of inertia $I_{e}$ of the ACI 318 Code. The comparison indicated that the ratio of predicted/measured deflections ranged from 0.79 to 0.89 , and that this ratio did not depend on concrete strength or the presence of the compression reinforcement. The main conclusion of this research was that long-term deflections can be reduced significantly either through use of compression reinforcement or high-strength concrete and the use of both is redundant. Also, the prediction of long-term deflection for highstrength concrete beams can be greatly improved by using the authors' proposed multiplier through modifying ACI Building Code multiplier:

$\lambda=\frac{\mu . \xi}{1+50 . \mu . \rho^{\prime}} \quad$ (where $\quad \mu=1.4-\frac{f_{c}^{\prime}}{10,000} \quad$, and $\quad 0.4 \leq \mu \leq 1.0$ )

The results of the long-term deflections for the tested beams are shown in Figure 3-7. 

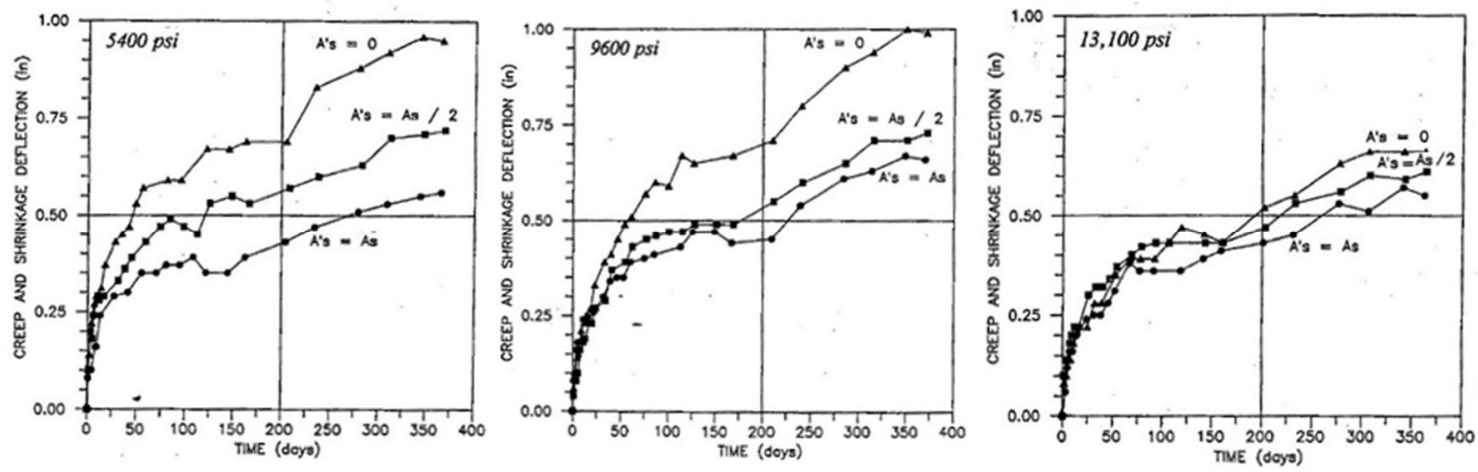

Figure 3-7: Creep and shrinkage deflection of beams (Paulson et al., 1991)

Muhaisin (2012) conducted a theoretical study to propose a new form to calculate the long-term deflection coefficient, $\lambda$, for reinforced concrete beams made with normal and high strength concretes. The proposed form considered concrete compressive strength, compressive steel ratio, cross section dimensions, and span length. The author compared the results from the proposed form with experimental results of other researchers, and a good agreement was obtained. After validating the new form, a parametric study was performed to examine the effect of $f^{\prime} c, \rho ' \rho$, and span/cross section perimeter ratio on long-term deflection. Among the conclusions drawn, the long-term deflections are highly reduced by increasing $f_{c}^{\prime}$ (the long-term deflection is reduced by about $50 \%$ when $f_{c}^{\prime}$ is increased from 2,900 to 14,500 psi). In addition, the effectiveness of using compression steel to reduce the long-term deflection is much less when high-strength concrete is used due to low creep coefficient. The proposed form equation is shown below:

$\Delta_{\text {total }}=(1+\lambda) \Delta$ instantaneous

Where: 
$\lambda=2.7 \times \alpha_{1} \times \alpha_{2} \times C_{c u} \times \frac{T^{0.3}}{10+T^{0.3}}, \quad \alpha_{1}=0.7+\left(\frac{L}{13 \times P}\right)^{2} \leq 1.0, \quad \alpha_{2}=\frac{1}{1+\left(\frac{16}{f_{c}^{\prime}} \times \frac{\rho^{\prime}}{\rho}\right)}$

$C_{c u}$ : ultimate creep coefficient from Table 3-6 or the best fit equation for the table values

$$
C_{c u}=4.1-0.05 f_{c}^{\prime}+0.00022 f_{c}^{\prime 2}
$$

$\alpha 1$ : Factor to take the effect of span to perimeter ratio

$\alpha 2$ : Factor to take the effect of compressive steel

$f^{\prime}$ : : Concrete compressive strength $(\mathrm{MPa})$

$\mathrm{T}$ : Time of loading (months)

P: Perimeter of the cross section $(\mathrm{mm})$

L: Span length (mm)

Table 3-6: Typical creep parameters (Nilson et al., 2010)

\begin{tabular}{|c|c|}
\hline Compressive strength, $f^{\prime}, \mathrm{MPa}(\mathrm{psi})$ & Creep coefficient, $C_{c u}$ \\
\hline $21(3000)$ & 3.1 \\
\hline $28(4000)$ & 2.9 \\
\hline $41(6000)$ & 2.4 \\
\hline $55(8000)$ & 2.0 \\
\hline $69(10000)$ & 1.6 \\
\hline $83(12000)$ & 1.4 \\
\hline
\end{tabular}

\subsection{Flexural Crack Widths and Crack Control of Beams Reinforced with HSR}

Harries et al. (2012) presented a study of flexural crack widths at service load levels (i.e., 0.6 $\mathrm{f}_{\mathrm{y}}$ ) for beams reinforced with high-strength ASTM 1035 reinforcing steel.

AASHTO (2007) provisions for crack control were evaluated for a series of flexural 
beams with reinforcement ratios between 0.007 and 0.023 , and for loads corresponding to longitudinal reinforcing bar stresses of 36,60 , and $72 \mathrm{ksi}$ for steel having $\mathrm{f}_{\mathrm{y}}=60,100$, 120 ksi respectively. The average measured crack widths were found to be below the AASHTO limits for Class 1 and Class 2 exposure. It was concluded that the conservativeness of the AASHTO crack control provisions allows extending them to higher service level stresses associated with the use of high-strength reinforcing bars. Moreover, the application of the provisions must be limited to steel strains up to the proportional limit where the stress-strain relationship is linear and $E_{s}=29000 \mathrm{ksi}$. 


\section{Chapter Four: Theoretical Investigation of Load-Deflection Response}

\subsection{Introduction}

This chapter discusses the creation of a computer model to predict the flexural behavior

of concrete beams of different concrete strengths ranging from normal to high strength (4 ksi to $12 \mathrm{ksi}$ ), and reinforced with conventional as well as high-strength bars of two different stress-strain behaviors (A615 Grade100 \& A1035 Grades 100 and 120). Different stress-strain relationships are expected to impact the force-displacement behavior of reinforced concrete beams in different ways including strain limits, flexural strength and corresponding maximum deflection as the beam is loaded monotonically to failure.

\subsection{Nonlinear Flexural Analysis}

To predict the flexural behavior of reinforced concrete beams, an analytical computer program was written by the author using MATLAB software. It is based on strain compatibility and the section equilibrium approach and utilizes concrete and reinforcement stress-strain relationships to obtain moment-curvature relationship at the mid-span section. The model performs numerical integration for the moment-curvature relationship to obtain load-deflection behavior for the mid-span section (critical section). 


\subsubsection{Moment-Curvature Response}

Un-cracked and cracked section analysis is conducted using a MATLAB coding developed to determine the moment curvature behavior before and after cracking with the following assumptions:

1. Plane sections remain plane after loading.

2. Reinforcing bars are fully bonded with concrete and no slippage is permitted.

3. No tension stiffening is considered after the initiation of the first crack, i.e. the tensile stress in concrete is assumed equal zero.

4. The strains are uniform over the section width and the section is only subjected to axial strains.

5. Failure is assumed to occur when either the concrete or the reinforcement reaches its ultimate strain.

The following steps are used for the determination of the moment-curvature response:

1. A strain at the extreme compression fiber of the concrete section is increased incrementally from zero to $\varepsilon_{c u}$. The maximum strain in concrete is taken as 0.003 to be consistent with ACI 318 requirement.

2. For each increment, the strain compatibility and section equilibrium are applied to determine the neutral axis depth, c, as shown in Figure 4-1. All the variables are set in terms of c. $\left(T+C_{c}=0\right)$ 
3. The concrete compression force, $C_{c}$, is determined from integrating the Carreira and Chu (1985) stress-strain equation:

$$
\begin{aligned}
& C_{c}=\int f_{c} \cdot b \cdot d z, \quad \text { where: } d z=\frac{c}{\varepsilon_{c z}} d \varepsilon_{c z} \\
& C_{c}=\frac{f_{c}^{\prime} \cdot b \cdot c}{\varepsilon_{c}} \int_{0}^{\varepsilon_{c}} \frac{\beta\left(\frac{\varepsilon_{c z}}{\varepsilon_{o}}\right)}{\beta-1+\left(\frac{\varepsilon_{c z}}{\varepsilon_{o}}\right)^{\beta}} d \varepsilon_{c z}
\end{aligned}
$$

4. The tension force in the steel, $\mathrm{T}$, is calculated from the product of area of steel by the stress in the steel, which is determined from the equations shown in section

\subsection{2.}

5. The moment capacity of the section, $M_{n}$, is determined by summing the moment of $\mathrm{Cc}$ and $\mathrm{T}$ forces around the neutral axis:

$$
M_{n}=T \cdot(d-c)+\int_{0}^{\varepsilon_{c}} f_{c} \cdot b \cdot z \cdot d z, \quad \text { where: } z=\frac{c}{\varepsilon_{c z}} \varepsilon_{c}
$$

6. The curvature is determined as: $\varphi=\frac{\varepsilon_{c}}{c}$

7. A new increment for $\varepsilon_{c}$ is applied, and the steps from 2 to 6 are repeated for each increment until either $\varepsilon_{c u}$ or $\varepsilon_{s u}$ is reached. 


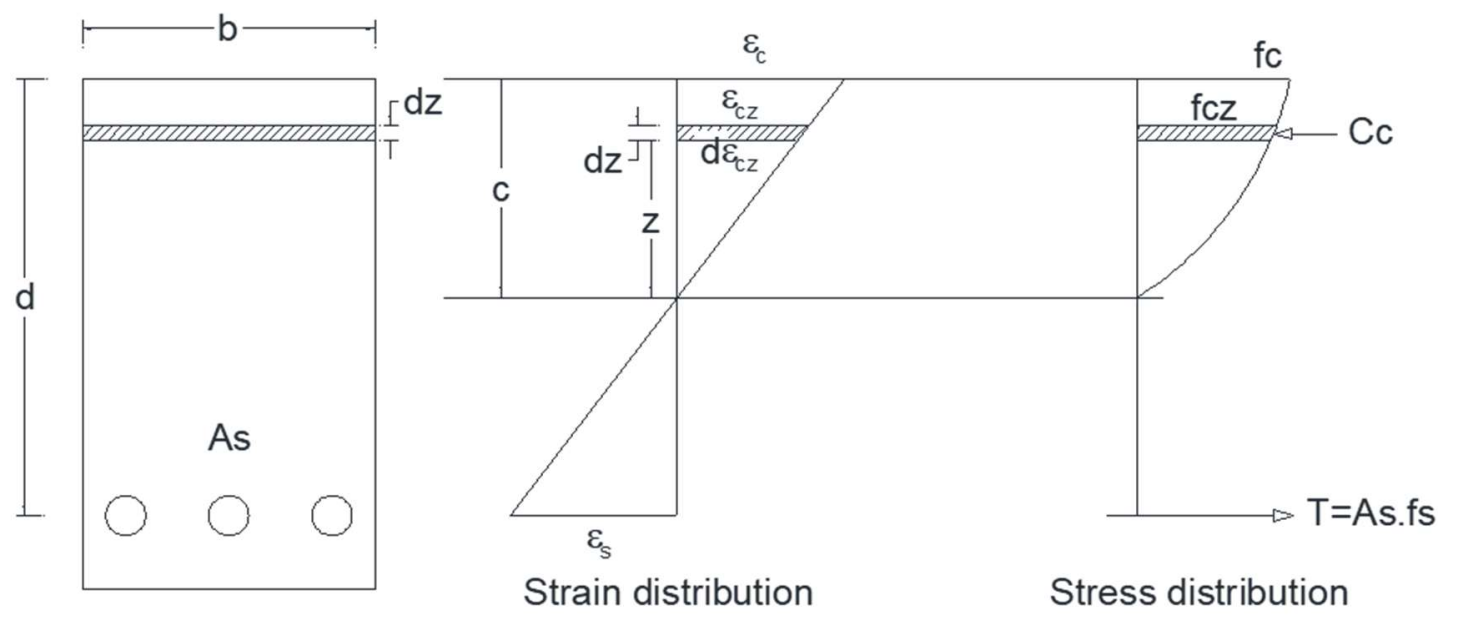

Figure 4-1: Cracked section analysis

\subsubsection{Modeling the Stress-Strain Relationship for Concrete and Reinforcing Steel}

Concrete behavior is modeled using Carreira and Chu (1985) stress-strain equation mentioned in section 2.3 for both normal and high strength concretes. Reinforcing steel is modeled using different formulas found from the literature to best fit the typical stressstrain behavior for each steel grade and type, as shown in Table 4-1 and Figure 4-2.

A615 Grade 60: A curve defined by three segments (designated as S3)

$$
\begin{array}{ll}
f_{s}=29000 * \varepsilon_{s} & \text { for } \quad 0 \leq \varepsilon_{s} \leq \varepsilon_{y}(0.002) \\
f_{s}=f_{y}(60 k s i) & \text { for } \quad \varepsilon_{y} \leq \varepsilon_{s} \leq \varepsilon_{s h}(0.0055) \\
f_{s}=f_{y}+\left(f_{s u}-f_{y}\right) \sqrt{\frac{\varepsilon_{s}-\varepsilon_{s h}}{\varepsilon_{s u}-\varepsilon_{s h}}} & \text { for } \quad \varepsilon_{s h} \leq \varepsilon_{s} \leq \varepsilon_{s u}(0.05), f_{s u}=90 k s i
\end{array}
$$

A615 Grade 100: A curve defined by three segments (designated as S3)

$$
f_{s}=29000 * \varepsilon_{s} \quad \text { for } \quad 0 \leq \varepsilon_{s} \leq \varepsilon_{y}(0.003448)
$$




$$
\begin{array}{cc}
f_{s}=f_{y}(60 \mathrm{ksi}) & \text { for } \quad \varepsilon_{y} \leq \varepsilon_{s} \leq \varepsilon_{s h}(0.014) \\
f_{s}=f_{y}\left[1.5-0.5\left(\frac{\varepsilon_{s u}-\varepsilon_{s}}{\varepsilon_{s u}-\varepsilon_{s h}}\right)^{2}\right] & \text { for } \quad \varepsilon_{s h} \leq \varepsilon_{s} \leq \varepsilon_{s u}(0.05)
\end{array}
$$

A1035 Grades 100\& 120: A rounded curve (designated as S1)

$$
\begin{aligned}
& f_{s}=29000 * \varepsilon_{s}\left\{A+\frac{1-A}{\left[1+\left(B \varepsilon_{s}\right)^{c}\right]^{1 / c}}\right\} \leq f_{s u} \\
& \text { where } A=0, B=165, C=1.5 \quad \text { for Grade } 100 \\
& \text { and } A=0, B=165, C=1.841 \text { for Grade } 120
\end{aligned}
$$

(A, B, and C are calibrated to best fit the typical curve for Grade $100 \& 120$ )

Table 4-1: Typical reinforcement stress-strain parameters used in the analytical investigation

\begin{tabular}{|c|c|c|c|c|c|c|}
\hline Reinforcement Type & $\mathrm{f}_{\mathrm{y}}(\mathrm{ksi})$ & $\mathrm{f}_{\mathrm{u}}(\mathrm{ksi})$ & $\varepsilon_{\mathrm{y}}$ & $\varepsilon_{\text {sh }}$ & $\varepsilon_{\mathrm{su}}$ & $\mathrm{f}_{\mathrm{u}} / \mathrm{f}_{\mathrm{y}}$ \\
\hline A615-60 & 60 & 90 & 0.00207 & 0.0055 & 0.05 & 1.5 \\
\hline A615-100 & 100 & 148 & 0.00345 & 0.014 & 0.05 & 1.48 \\
\hline A1035-100 & 100 & 171 & 0.005 & - & 0.05 & 1.71 \\
\hline A1035-120 & 120 & 174 & 0.006 & - & 0.05 & 1.45 \\
\hline
\end{tabular}




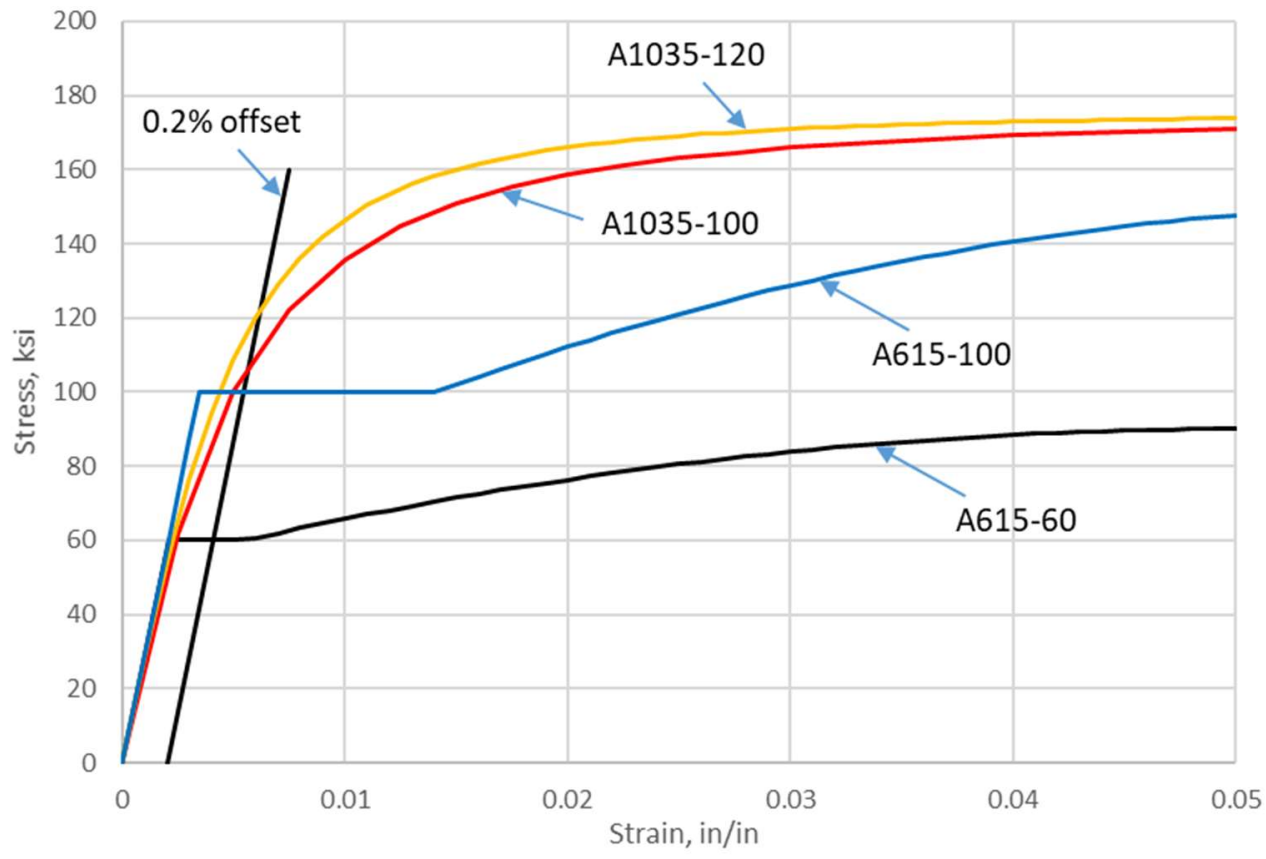

Figure 4-2: Typical stress-strain curves for reinforcing bars

\subsubsection{Load-deflection Response}

The load-deflection response for the beams is determined at the midspan section as it represent the maximum deflection along the beam span. The load results are determined directly from the moment value for each $\varepsilon_{c}$ increment. The corresponding deflection then is determined from the numerical integration of the curvature distribution up to the midspan. The numerical integration is performed according to the following equation:

$$
\Delta=\sum\left(\frac{\varphi_{i} x_{i}+\varphi_{i+1} x_{i+1}}{2}\right) \Delta x_{i}
$$

Where:

$\Delta=$ Deflection at mid-span section 
$x_{i}=$ Distance from the support to point $x_{i}$

$x_{i+1}=$ Distance from the support to point $x_{i+1}$

$\varphi_{i}=$ Curvature corresponding to $x_{i}$

$\varphi_{i+1}=$ Curvature corresponding to $x_{i+1}$

$\Delta x_{i}=x_{i+1}-x_{i}$

In the following a brief description of the process given for the case of beam with 2-point loading. The number of divisions from the support to the point load was a variable at each moment stage and was determined according to the following procedure: 1) moment at the point load was increased sequentially 30 times, from 1 to 30 stages of loading, 2) this was accomplished by increasing the concrete strain $\varepsilon_{c}$ from 0 to 0.003 with an increment of $1 \times 10^{-4}$ for the maximum moment section, which is at the point load, 3) for each $\varepsilon_{c}$ the corresponding curvature and moment were determined, which defined the stage of loading for that particular $\left.\varepsilon_{c}, 4\right)$ the distance from the support to the position of the point load was divided into (n-1) divisions where $\mathrm{n}=$ number of the sequence, i.e., $1,2,3,4, \ldots \mathrm{n}, 5)$ the moment and curvature between point load and mid-span were kept constant.

This process continues until concrete strain reaches 0.003 , which occurs at sequence $=$ 30, which defines the ultimate section capacity. In this ultimate loading stage the number of divisions was $n-1=30-1=29$ between the support and the point load, which represented a high level of accuracy of the variation in the curvature. Then the area of each division was calculated as a trapezoidal area and the distance from the centroid of 
each area to the support was determined. To determine the deflection at any stage of moment, the moment area method was applied, i.e., the deflection is equal to the summation of the moments of incremental areas about the support point, which consists of the area from the support to the mid-span.

Figure 4-3 illustrates the numerical integration for the curvature diagram to calculate the mid-span deflection for a simply supported beam.

The accuracy of the calculated load-deflection response is verified with experimental results for beams tested by others as discussed in the following section.

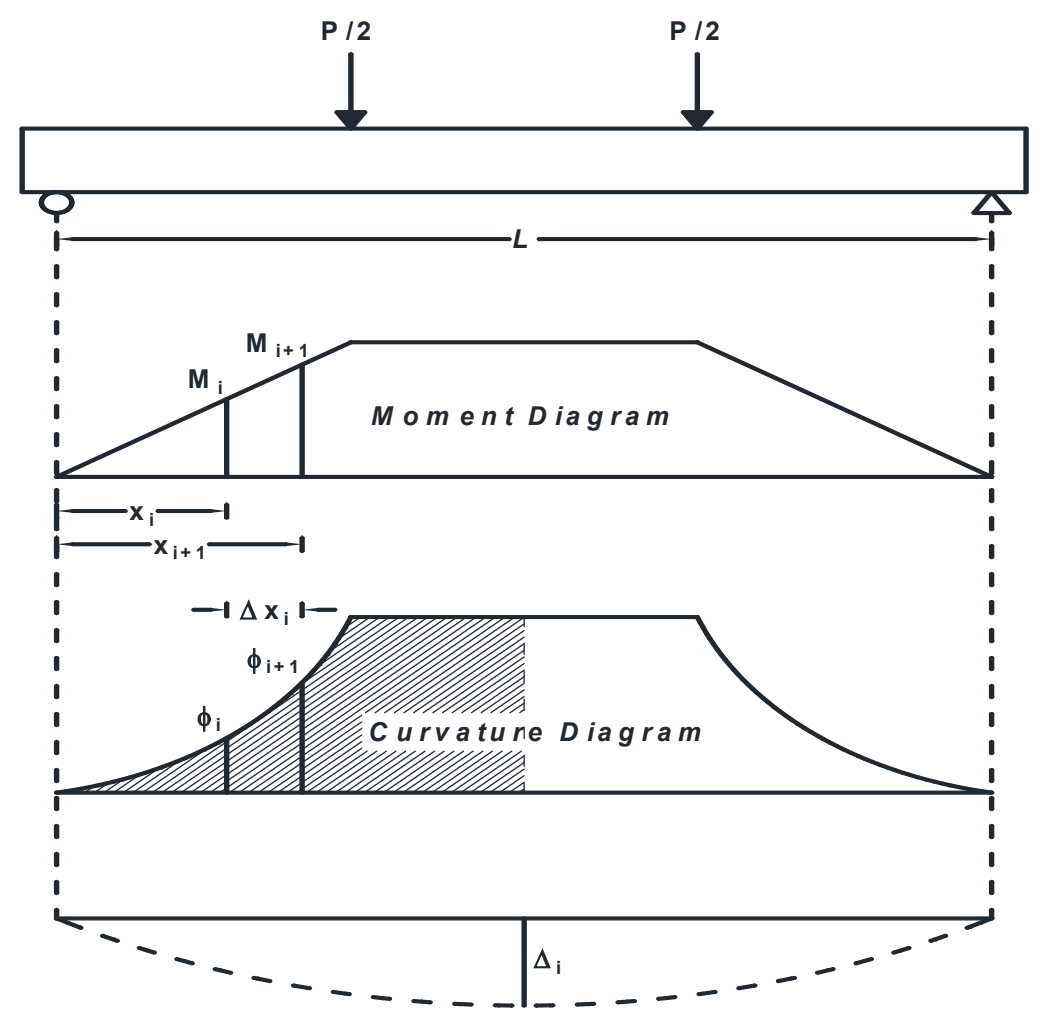

Figure 4-3: Calculation of the mid-span deflection based on the numerical integration for the curvature diagram 


\subsection{Verification of the Analytical Model}

To validate the written program and to verify its accuracy, eight of the experimentally tested beams by other researchers were modeled. The verification contained beams of different concrete capacities and reinforced with both conventional Grade 60 steel and high-strength reinforcement. All beams were tested under two-point load configuration. Table 4-2 presents the beams dimensions, details, and properties of materials. The best fit for the actual tensile test stress-strain results of the reinforcement rather than the typical representative curves were used for modeling the reinforcing bars.

Table 4-2: Details of the selected beams from the literature to verify the analystical model

\begin{tabular}{|c|c|c|c|c|c|c|c|c|}
\hline $\begin{array}{c}\text { Reference } \\
\text { (designation) }\end{array}$ & Steel type & $\begin{array}{l}\mathrm{bxh} \\
\text { (in.) }\end{array}$ & $\begin{array}{c}d \\
\text { (in.) }\end{array}$ & $\begin{array}{l}\mathrm{L}_{\mathrm{n}} \\
\text { (ft) }\end{array}$ & $\begin{array}{l}\mathrm{a}^{*} \\
(\mathrm{ft})\end{array}$ & $\rho$ & $\begin{array}{l}\mathrm{f}_{\mathrm{c}}^{\prime} \\
(\mathrm{psi})\end{array}$ & $\begin{array}{c}\mathrm{f}_{\mathrm{y}} \\
(\mathrm{ksi})\end{array}$ \\
\hline $\begin{array}{l}\text { Ansley, } 2002 \\
\text { (Test } 1)\end{array}$ & A615 & $12 \times 18$ & 16.125 & 14 & 10 & $\begin{array}{c}0.00455 \\
(2-\# 6)\end{array}$ & 6,683 & 60 \\
\hline $\begin{array}{l}\text { Ansley, } 2002 \\
\text { (Test } 1)\end{array}$ & $\begin{array}{c}\text { A1035 } \\
\text { (MMFX) }\end{array}$ & $12 \times 18$ & 16.125 & 14 & 10 & $\begin{array}{c}0.00455 \\
(2-\# 6)\end{array}$ & 6,683 & 135 \\
\hline $\begin{array}{l}\text { Yutakhong, } 2003 \\
\text { (B1) }\end{array}$ & A615 & $12 \times 18$ & 15.625 & 16 & 6 & $\begin{array}{c}0.00704 \\
(3-\# 6)\end{array}$ & 5000 & 60 \\
\hline $\begin{array}{c}\text { Yutakhong, } 2003 \\
\text { (B2) }\end{array}$ & $\begin{array}{c}\text { A1035 } \\
\text { (MMFX) }\end{array}$ & $12 \times 18$ & 15.625 & 16 & 6 & $\begin{array}{c}0.00469 \\
(2-\# 6)\end{array}$ & 6000 & 123 \\
\hline $\begin{array}{c}\text { Yutakhong, } 2003 \\
\text { (B3) }\end{array}$ & $\begin{array}{c}\text { A1035 } \\
\text { (MMFX) }\end{array}$ & $12 \times 18$ & 15.625 & 16 & 6 & $\begin{array}{c}0.00704 \\
(3-\# 6)\end{array}$ & 6000 & 123 \\
\hline $\begin{array}{c}\text { Shahrooz et al., } 2010 \\
\text { (F1) }\end{array}$ & $\begin{array}{c}\text { A1035 } \\
\text { (MMFX) }\end{array}$ & $12 \times 16$ & 12.125 & 20 & 8.25 & $\begin{array}{l}0.0126 \\
(6-\# 5)\end{array}$ & 12,900 & 130.2 \\
\hline $\begin{array}{c}\text { Shahrooz et al., } 2010 \\
\text { (F2) }\end{array}$ & $\begin{array}{c}\text { A1035 } \\
\text { (MMFX) }\end{array}$ & $12 \times 16$ & 12 & 20 & 8.25 & $\begin{array}{l}0.018 \\
(6-\# 6)\end{array}$ & 12,900 & 121.8 \\
\hline $\begin{array}{c}\text { Shahrooz et al., } 2010 \\
\text { (F3) }\end{array}$ & $\begin{array}{c}\text { A1035 } \\
\text { (MMFX) }\end{array}$ & $12 \times 16$ & 13.1875 & 20 & 8.25 & $\begin{array}{l}0.0078 \\
(4-\# 5)\end{array}$ & 12,900 & 130.2 \\
\hline
\end{tabular}

$*$ a is the distance from support to the location of the point load 
The results of the analytical load-deflection are shown in Figure 4-4 to Figure 4-6 and reflect very good agreement with the experimental results.

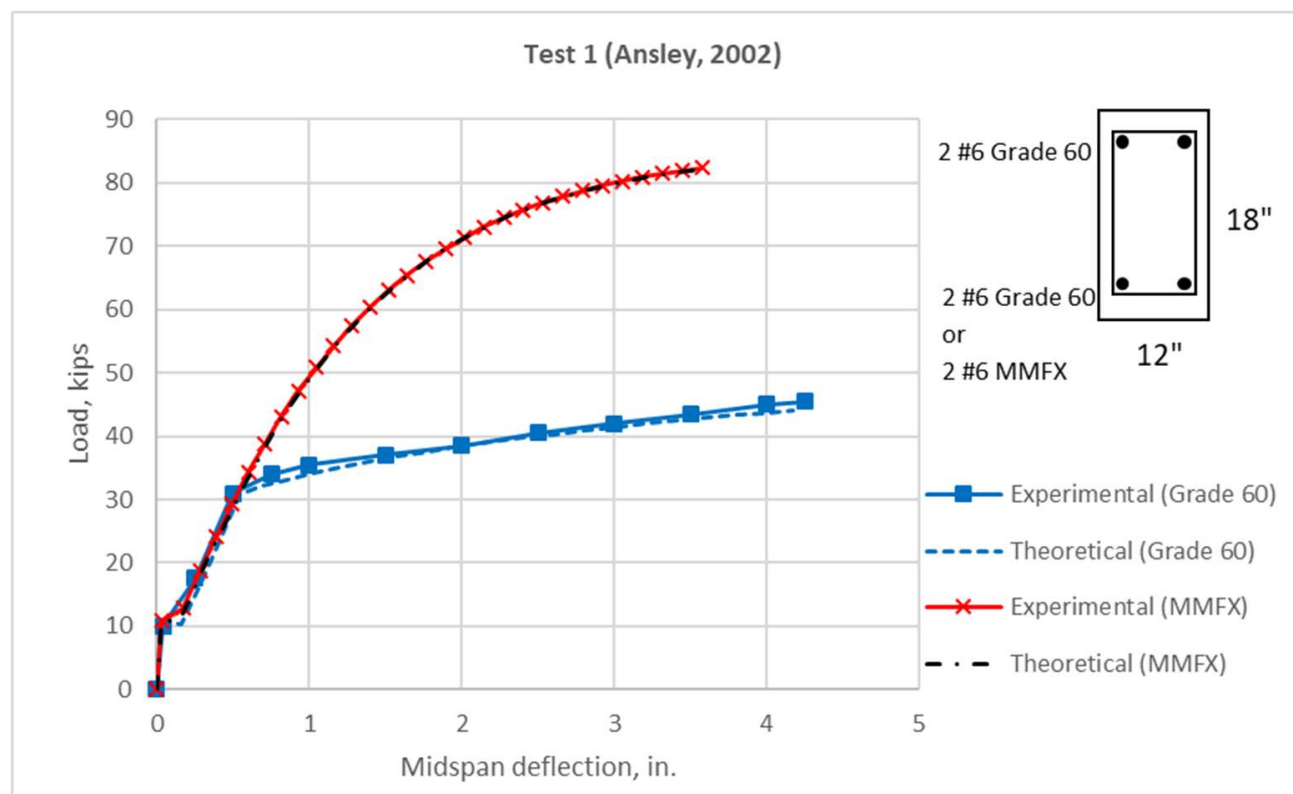

Figure 4-4: Comparison of experimental beams results of Ansley (2002) and analytical model results

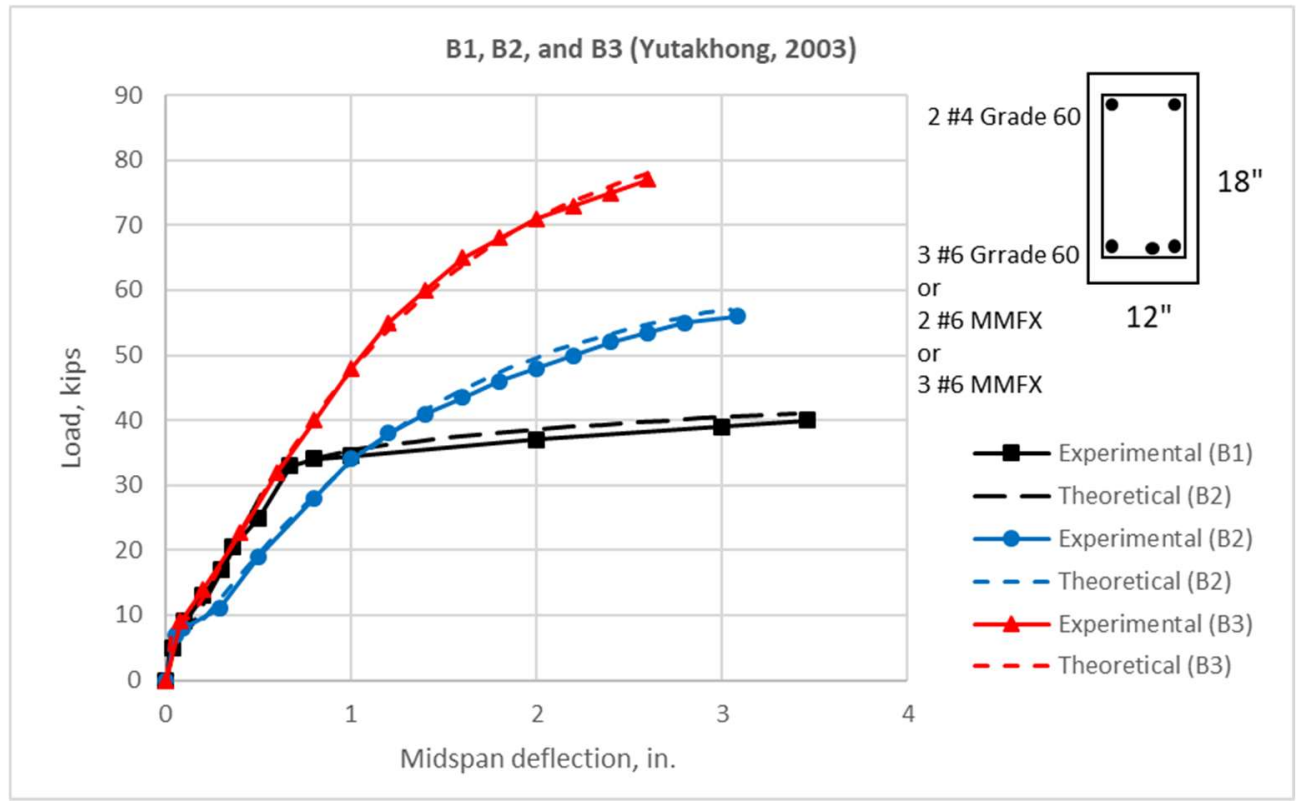

Figure 4-5: Comparison of experimental beams results of Yutakhong (2003) and analytical model results 


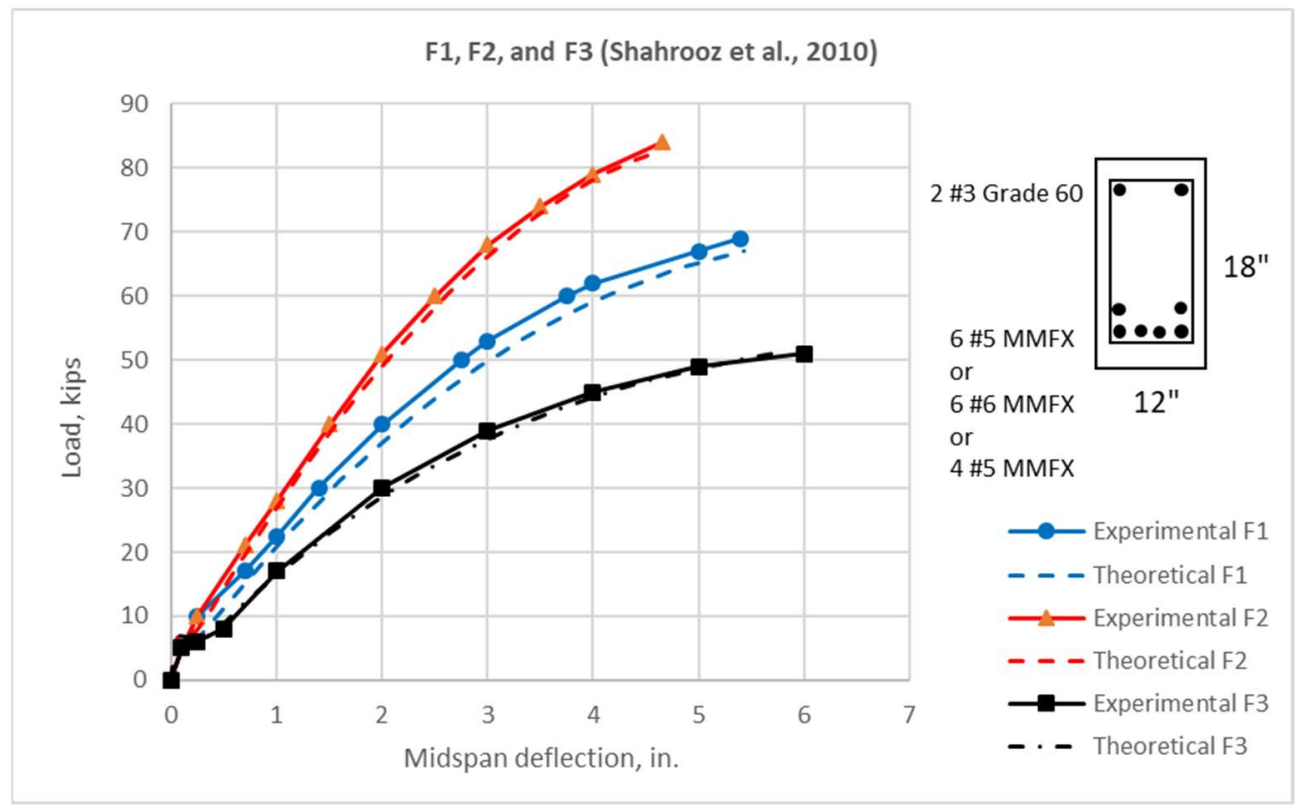

Figure 4-6: Comparison of experimental beams results of Shahrooz et al. (2010) and analytical model results

The load-deflection response can show the ductility of the section as determined by the ratio of the curvature at maximum load to the curvature at yielding of the reinforcement $\left(\mu=\phi_{\mathrm{u}} / \phi_{\mathrm{y}}\right)$. Also, the area under the load-deflection curve may be considered to examine the energy absorption, which is another indication of ductility. These properties, as well as other important issues related to flexural behavior of beams that contain HSR and HSC are further discussed in Chapter 6. 


\subsection{Flexural Behavior of Beams Made with HSC and HSR}

In this section, a study is conducted to compare the design of beams reinforced with HSR with varying concrete compressive strength (4000, 8000, and 12000 psi). An example beam that has a 6 in. $x 10$ in. cross-section and $8 \mathrm{ft}$ span is first designed with 4000 psi concrete strength and Grade 60 steel with a reinforcement ratio of $1 / 2 \rho_{\max }$ (control beam), which represents a reasonable (average) ratio of reinforcement for beams designed with conventional Grade 60 steel. Then the same beam is designed for the same moment capacity with HSR and various concrete strengths to compare the design with the current practice, and to investigate the effect of increasing concrete strength on ductility and deflection at service load. Two point-loads are applied on third points of the beam's span. The summary of the results is given in Table 4-3 and Figure 4-7.

Table 4-3: Effect of using HSC for beams reinforced with HSR

\begin{tabular}{|c|c|c|c|c|c|c|c|}
\hline $\begin{array}{c}\text { Steel Type- } \\
\text { Grade }\end{array}$ & $\begin{array}{c}\mathrm{f}^{\prime}{ }_{\mathrm{c}} \\
(\mathrm{ksi})\end{array}$ & $\rho$ & $\begin{array}{c}\mathrm{M}_{\mathrm{n}} \\
(\mathrm{k} . \mathrm{ft})\end{array}$ & $\varepsilon_{\mathrm{s}}$ & $\mu 1=\phi_{\mathrm{u}} / \phi_{\mathrm{y}}$ & $\begin{array}{c}\mu 2=\text { Area Under } \\
\mathrm{P}-\Delta \\
(\mathrm{k} . \mathrm{ft})\end{array}$ & $\begin{array}{c}\Delta_{\text {service }} \\
\text { load } \\
\text { (in.) }\end{array}$ \\
\hline $\begin{array}{c}\text { A615-60 } \\
\text { (control beam) }\end{array}$ & $\mathbf{4}$ & $\mathbf{0 . 0 1 1 1}$ & $\mathbf{2 4 . 7}$ & $\mathbf{0 . 0 0 9 3}$ & $\mathbf{3 . 8 7}$ & $\mathbf{1 . 7 2}$ & $\mathbf{0 . 2 5}$ \\
\hline A615-100 & 4 & 0.0076 & 24.7 & 0.0093 & 2.54 & 1.70 & 0.34 \\
\hline $\mathrm{A} 615-100$ & 8 & 0.0067 & 24.7 & 0.0207 & 5.63 & 3.46 & 0.35 \\
\hline $\mathrm{A} 615-100$ & 12 & 0.0057 & 24.8 & 0.0306 & 8.48 & 4.66 & 0.39 \\
\hline $\mathrm{A} 1035-100$ & 4 & 0.0057 & 24.6 & 0.0093 & 1.93 & 1.47 & 0.51 \\
\hline $\mathrm{A} 1035-100$ & 8 & 0.0045 & 24.7 & 0.0207 & 4.02 & 3.11 & 0.65 \\
\hline $\mathrm{A} 1035-100$ & 12 & 0.0042 & 24.5 & 0.0310 & 6.46 & 4.63 & 0.69 \\
\hline
\end{tabular}



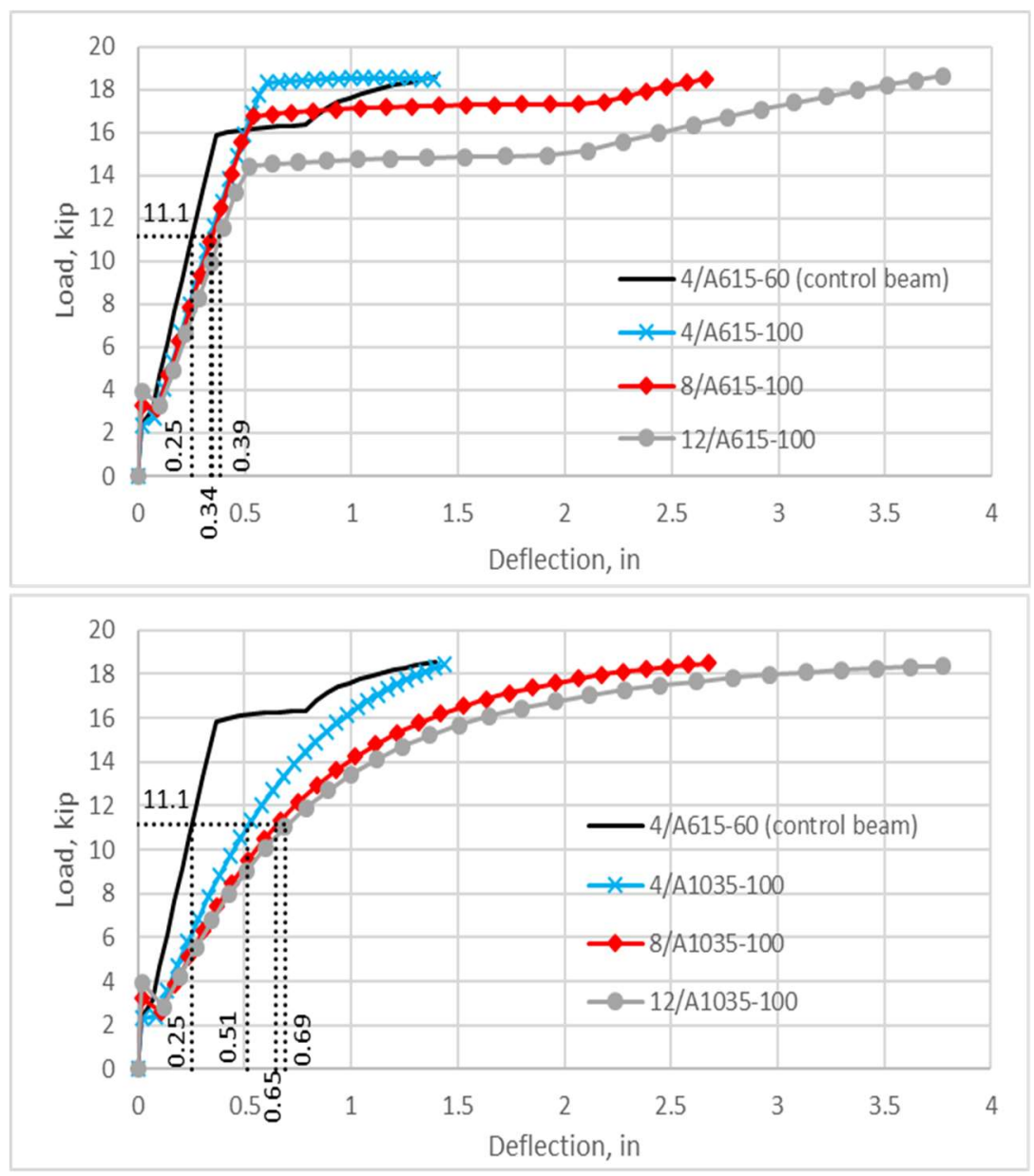

Figure 4-7: Behavior of beam designed with NSC \& grade 60 steel vs. beams designed with HSC \& HSR (A615-100 \& A1035-100)

The results of this study indicated that the use of high-strength concrete will significantly improve the deformation capacity of the beams as they will have a lesser area of steel, higher bar tensile strain, more curvature, and hence, improved ductility. However, the reduction in the required area of steel for design will reduce the member stiffness, which in turn will result in more deflection at service load level. Therefore, serviceability considerations are more likely to control the design of members made with HSC \& HSR 
than members made with normal strength concrete (NSC) and reinforced with Grade 60 reinforcement.

This study was chosen for experimental investigation in chapter five to compare the flexural behavior (load-midspan deflection, ductility, deflection at service load level and near failure, and crack widths at service load level) of beams made with conventional materials versus that of beams made with high strength materials for the same load capacity. 


\section{Chapter Five: Experimental Assessment of Beams Made with HSC \& HSR}

\subsection{Introduction}

The main objective of the experimental tests is to investigate the flexural behavior of concrete beams made with high grade concrete up to 14000 psi and reinforced with highstrength reinforcement of two different types where one has a well-defined yield point and yield plateau (A615 Grade 100) and the other has a roundhouse curve (A1035 Grade 120). The second main objective is to confirm the results of the analytical study. The third is to compare the design of beams made with HSC and HSR with the design using normal strength concrete and conventional Grade 60 rebar. A total of eight beams were designed, tested, and evaluated under short term monotonic loading, and one beam was tested under constant long-term loading. The tests tracked bar elongations and concrete strains as the beams were loaded to failure, tracked deflections at service load levels, as well as near failure, and observed the cracking behavior and maximum crack width. This chapter presents the details of the tested beams, materials properties, and description of instrumentation, tests setup, and the experimental tests results and discussion. 


\subsection{Materials Properties}

\subsubsection{Concrete}

Four different target strengths of concrete $(5000,8000,10000,12000)$ were designed for and prepared in the laboratory to use in this research. ACI 211.1-91 was followed as a guideline for the mix proportions of normal-strength concrete (5000 psi) that was used for the control beams. ACI 211.4R-08 was used as a guideline for selecting the proportions for the high-strength concrete that was used for the beams reinforced with high-strength steel bars. Silica Fume was used as a cementitious material for the batch of target strength 12000 psi to improve the strength, and superplasticizer was added to the low water/cementitious ratio to increase the workability of the material. For all of the four target strengths, and before casting the beams, several trial batches were mixed and cast in ASTM standard cylinders (6 in. x 12 in. for normal strength concrete and 4 in. $x 8$ in. for high-strength concrete) and tested after 28 days to assure that they developed the required compressive strengths. However, when preparing a large sized cast for beam B5 with a target strength of 12000 psi, the mixture was not workable compared to the trial batch. Therefore, water was added to improve the workability, which led to a reduction of strength compared to the targeted beam. This problem was solved for the other beams (B4, B8, and B9) of the same target strength of 12000 psi through using a mixer with a faster mixing speed, which helped the superplasticizer to react faster and improve the workability without adding additional water. A sufficient mixing time was allowed to produce a uniform and homogenous concrete. 
The coarse aggregates (CA) used were pea gravel with a maximum size of 3/8 in. Natural river sand was used as fine aggregates (FA). The cement (C) was Type I/II. Both $100 \%$ pure densified silica fume (SF) and a powder superplasticizer (SP) were added to the mixture of target strength $12000 \mathrm{psi}$ as a percentage by weight of cement. Table 5-1 illustrates the mix proportions used in the experimental program.

Table 5-1: Concrete mixture proportions

\begin{tabular}{|c|c|c|c|c|c|c|c|c|c|}
\hline \multirow{2}{*}{$\begin{array}{l}\text { Beam } \\
\text { No. }\end{array}$} & \multirow{2}{*}{$\begin{array}{l}\text { Target } \\
\mathrm{f}_{\mathrm{c}}(\mathrm{psi})\end{array}$} & \multicolumn{6}{|c|}{ Mixture Proportions $\left(\mathrm{lb} / \mathrm{ft}^{3}\right)$} & \multirow{2}{*}{$\begin{array}{c}\mathrm{W} / \mathrm{C} \text { or } \\
\mathrm{W} /(\mathrm{C}+\mathrm{SF})\end{array}$} & \multirow{2}{*}{$\begin{array}{l}\text { Slump } \\
\text { (in.) }\end{array}$} \\
\hline & & CA & FA & $\mathrm{C}$ & SF & W & SP & & \\
\hline $\begin{array}{c}\text { B1\& } \\
\text { B6 }\end{array}$ & 5000 & 45.68 & 60.19 & 25.02 & - & 11.35 & - & 0.45 & 3.5 \\
\hline $\begin{array}{c}\text { B2 \& } \\
\text { B3 }\end{array}$ & 8000 & 65.98 & 37 & 34.95 & - & 11.52 & - & 0.33 & 3.5 \\
\hline B7 & 10000 & 65.98 & 37 & 34.95 & - & 10.61 & - & 0.3 & 2.5 \\
\hline B5 & 12000 & 65.98 & 23.88 & 42.47 & 7.49 & 12.92 & 0.45 & 0.26 & 5 \\
\hline $\begin{array}{c}\text { B4, B8, } \\
\text { \& B9 }\end{array}$ & 12000 & 65.98 & 23.88 & 42.47 & 7.49 & 11.14 & 0.45 & 0.22 & 3.5 \\
\hline
\end{tabular}

\subsubsection{Concrete Cylinder Compression Test}

At least two concrete cylinders were tested at 28 days to check the design strength as required by ASTM standards, and at least three cylinders were tested to obtain the compressive strength at the time of testing of the specimens. The cylinders were cast and moist cured for 28 days with the beams in the laboratory. Also, one cylinder for each specimen was tested for stress-strain using a hand-controlled hydraulic load, a compressometer with two Leaner Variable Displacement Transducers (LVDT), and 
gauge length of 6 in. as shown in Figure 5-1. The load was measured using a pressure sensor, and then converted to stress by dividing over the cross-sectional area of the cylinder. The strain was calculated by dividing the LVDTs readings by the gage length. Figure 5-2 presents the test results compared to the Carreira and Chu equation. As it can be seen, only the ascending branch of the stress-strain curve up to the maximum load was captured as the descending branch needs a special technique to capture, especially with high-strength concrete, which is more brittle than the normal strength concrete. Also, the cylinder brakes (explodes) suddenly and it is hard to control the applied load manually.

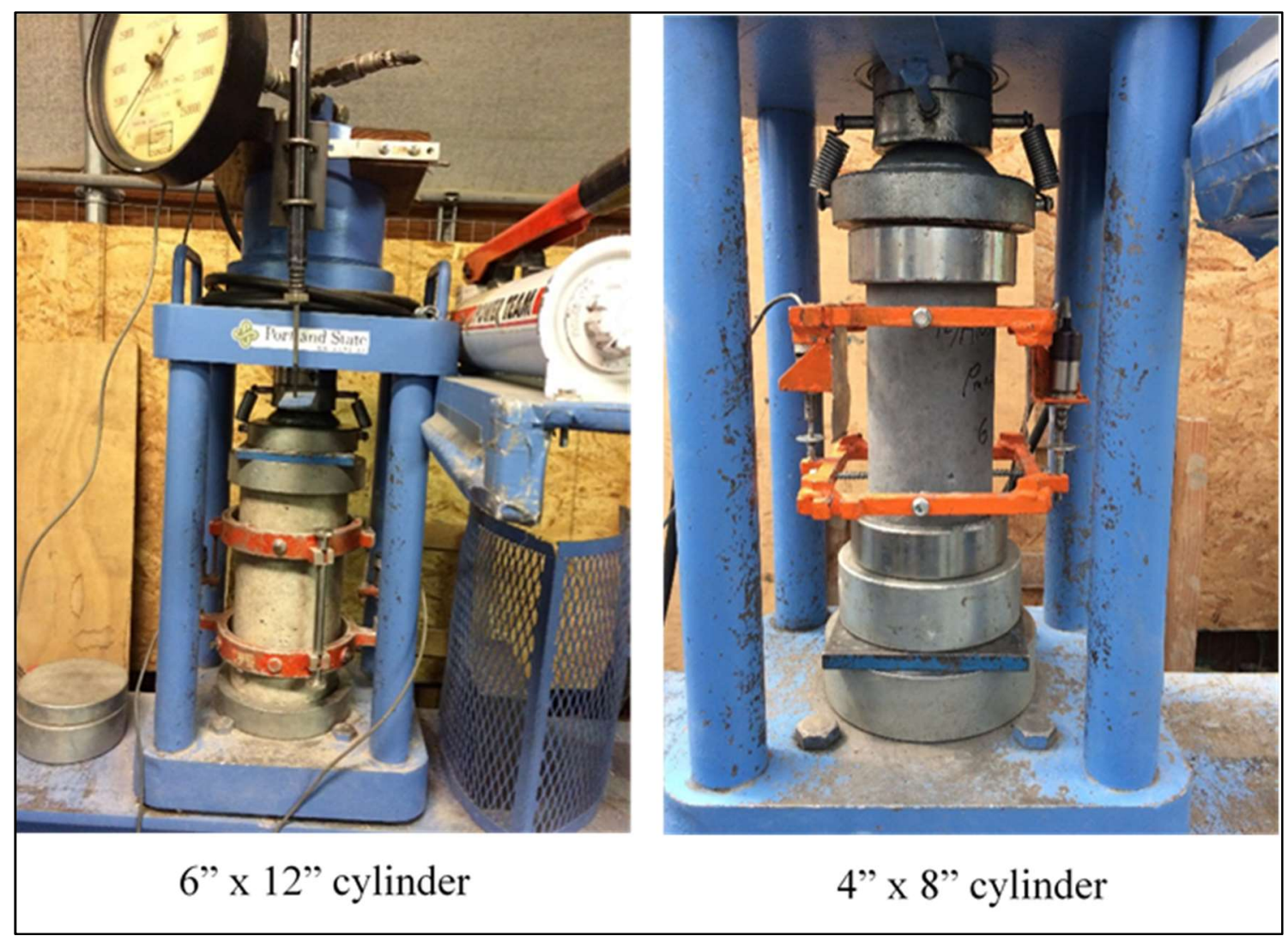

Figure 5-1: Cylinder compression stress-strain test set up 

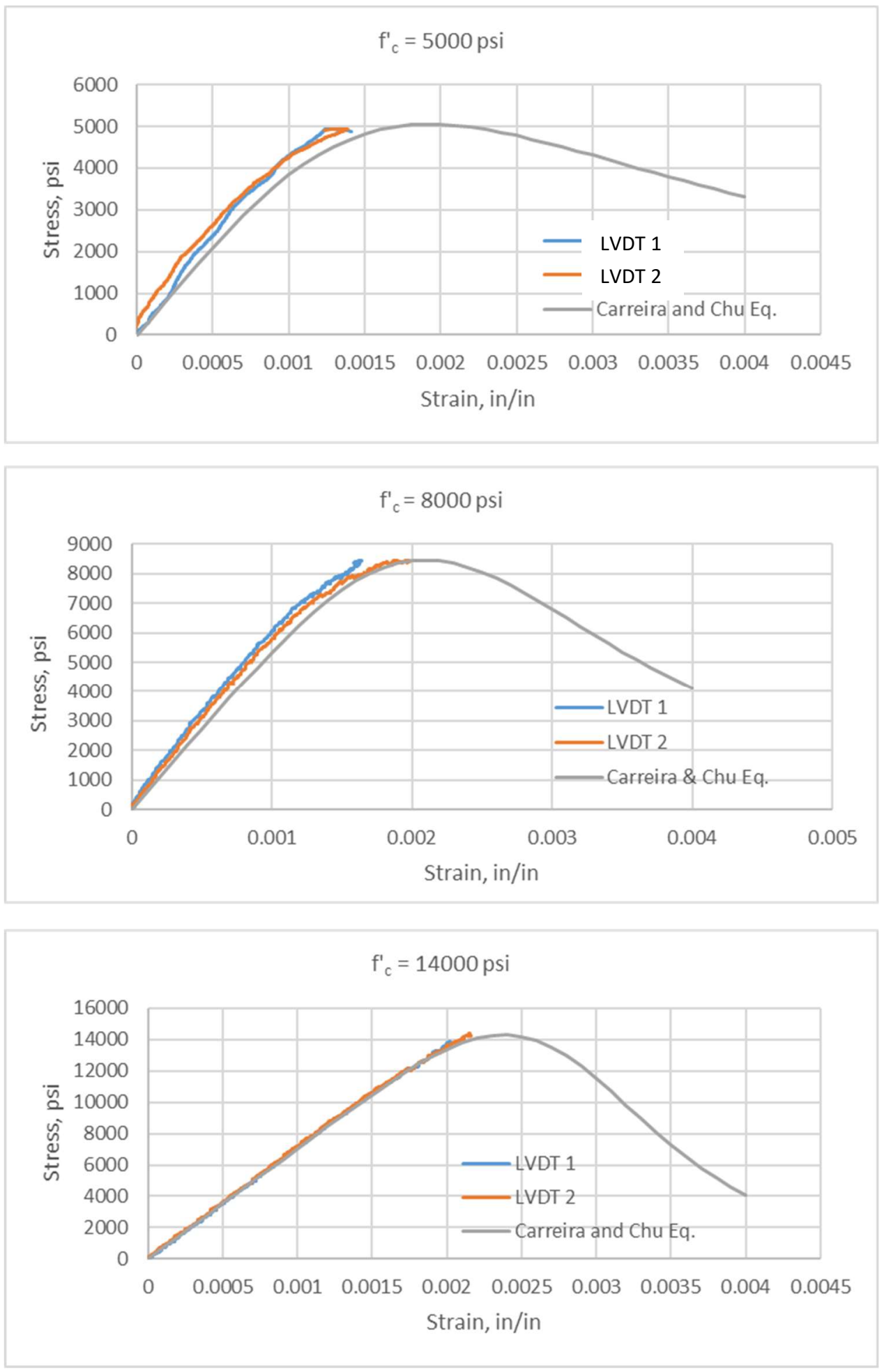

Figure 5-2: Experimental stress-strain curves of plain concrete 


\subsubsection{Modulus of Rupture of Concrete (Flexural Strength)}

Three concrete prisms ( 6 in. $\mathrm{x} 6$ in. $\mathrm{x} 18$ in.) were cast with each beam to determine the experimental modulus of rupture $\left(f_{r}\right)$ in terms of average value. ASTM C78 was followed for test guidance. The prisms were placed in the testing frame, oriented in such a way that the specimen was turned on its side with respect to its molded position. Figure 5-3 shows the test setup, and Table 5-2 presents the experimental results and the values using ACI 318 equation of modulus of rupture $\left(f_{r}=7.5 \sqrt{f_{c}^{\prime}}\right.$, psi). Comparing the two, ACI 318 equation overestimates $f_{r}$. The experimental modulus of rupture is calculated after determining the breaking load $(\mathrm{P})$ as following:

$f_{r}=\frac{M \cdot C}{I}$

where: $\quad M=\frac{P . L}{6} ; C=\frac{h}{2} ; I=\frac{b h^{3}}{12} ; \quad(b=h=6 ") \&\left(L=18^{\prime \prime}\right)$

After substituting the above parameters: $\quad f_{r}=\frac{P}{12}$
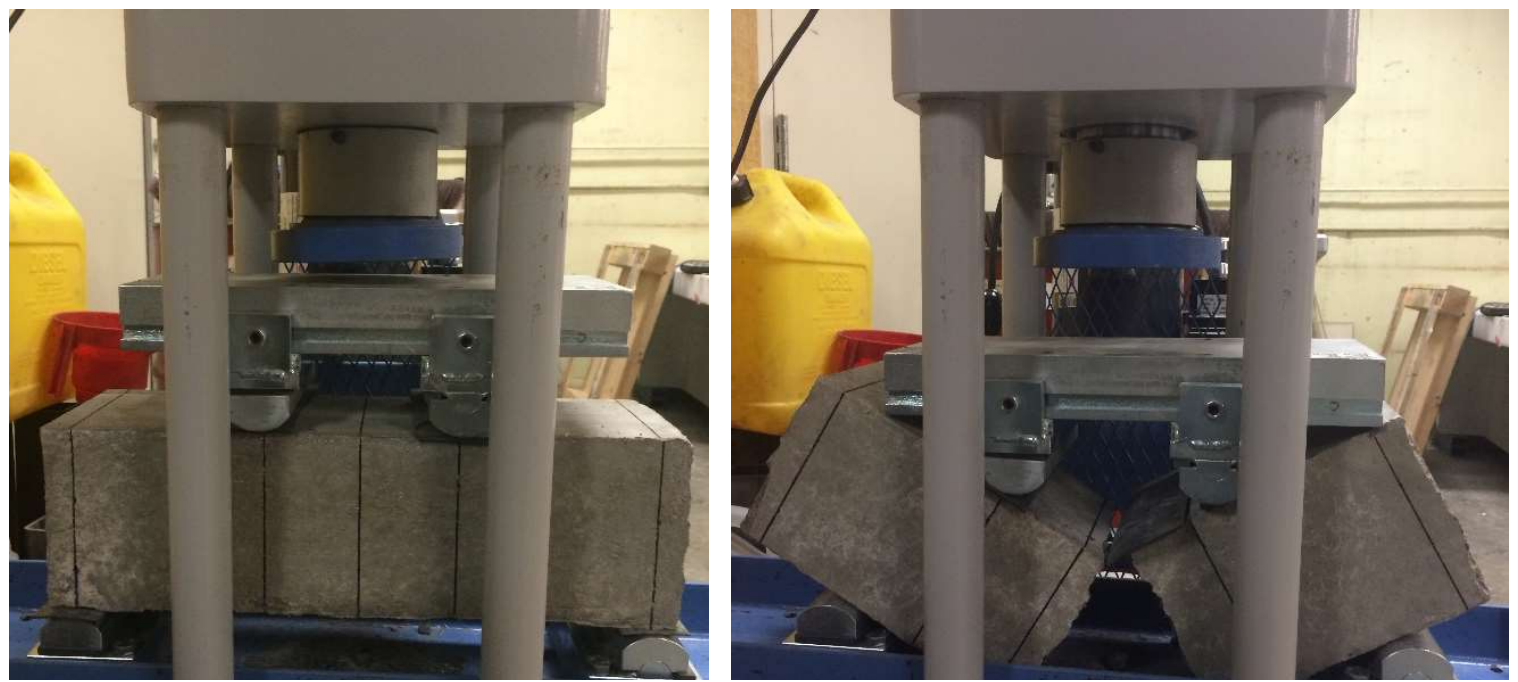

Figure 5-3: Plain concrete modulus of rupture test set up 
Table 5-2: Modulus of rupture of concrete prisms

\begin{tabular}{|c|c|c|c|c|}
\hline Beam No. & $\mathrm{f}_{\mathrm{c}}^{\prime}, \mathrm{psi}$ & $\mathrm{f}_{\mathrm{r} \text { experimental, }} \mathrm{psi}$ & $\mathrm{f}_{\mathrm{r}}$ ACI 318, $\mathrm{psi}$ & $\mathrm{f}_{\mathrm{r} \text { experimental }} / \mathrm{f}_{\mathrm{r}}$ ACI 318 \\
\hline B1 & 5,600 & 444.6 & 561.2 & 0.79 \\
\hline B2 & 8,100 & 622.5 & 670.8 & 0.93 \\
\hline B3 & 8,100 & 666.3 & 670.8 & 0.99 \\
\hline B4 & 13,500 & 623.6 & 871.4 & 0.72 \\
\hline B5 & 11,100 & 550.6 & 786.6 & 0.70 \\
\hline B6 & 5,800 & 510.0 & 571.2 & 0.89 \\
\hline B7 & 10,700 & 518.3 & 775.8 & 0.67 \\
\hline B8 & 14,300 & 731.4 & 896.9 & 0.82 \\
\hline B9 & 14,600 & 726.5 & 908.1 & 0.80 \\
\hline
\end{tabular}

\subsubsection{Reinforcing Steel}

ASTM A615 Grades 60 and 100, and ASTM A1035 Grade 120 reinforcing steel of bar sizes no. $3 \& 4$ were provided by Cascade Steel Rolling Mills Inc.

(www.cascadesteel.com) and were used as longitudinal tension reinforcement in the construction of the specimens. No. 2 smooth wire was used to make stirrups for shear reinforcement. Tension tests were performed according to ASTM A370-15 to determine the stress-strain characteristics of the reinforcing bars. Two coupons of $30 \mathrm{in}$. length for each bar type and size were tested as shown in Figure 5-4. A clip-on extensometer was used to record the elongation in the bar. However, the extensometer was removed before the expected failure load was reached to protect it from any possible damage, and hence, the failure strain was not recorded. The summary of the reinforcement tension tests is given in Table 5-3, and the measured stress-strain curves are presented in Figure 5-5 to Figure 5-8. 
Table 5-3: Reinforcement tensile test results summary

\begin{tabular}{|c|c|c|c|c|}
\hline Steel Type & Bar Size & $\begin{array}{l}\text { Yield Strength } \\
\text { (ksi) }\end{array}$ & $\begin{array}{c}\text { Tensile Strength } \\
\text { (ksi) }\end{array}$ & $\begin{array}{c}\text { Elongation in } 8 " \\
(\%)\end{array}$ \\
\hline \multirow{4}{*}{ A615-60 } & \multirow{2}{*}{$\# 3$} & 71.9 & 111.0 & 13.5 \\
\hline & & 71.2 & 110.8 & 15.0 \\
\hline & \multirow{2}{*}{$\# 4$} & 70.4 & 108.0 & 13.5 \\
\hline & & 68.6 & 108.0 & 13.0 \\
\hline \multirow{4}{*}{ A615-100 } & \multirow{2}{*}{$\# 3$} & 121.4 & 147.5 & 17.0 \\
\hline & & 121.6 & 147.5 & 10.0 \\
\hline & \multirow{2}{*}{$\# 4$} & 117.0 & 149.3 & 11.0 \\
\hline & & 117.1 & 149.1 & 11.0 \\
\hline \multirow{4}{*}{ A1035-120 } & \multirow{2}{*}{$\# 3$} & $154.0^{*}$ & 188.6 & 7.0 \\
\hline & & $151.8^{*}$ & 189.8 & 6.5 \\
\hline & \multirow{2}{*}{$\# 4$} & $137.2^{*}$ & 169.2 & 7.5 \\
\hline & & $136.1^{*}$ & 172.6 & 7.5 \\
\hline \multirow{2}{*}{ Smooth wire } & \multirow{2}{*}{$\# 2$} & 58.3 & 74.2 & 21.0 \\
\hline & & 57.4 & 74.8 & 17.5 \\
\hline
\end{tabular}

$* 0.2 \%$ offset method
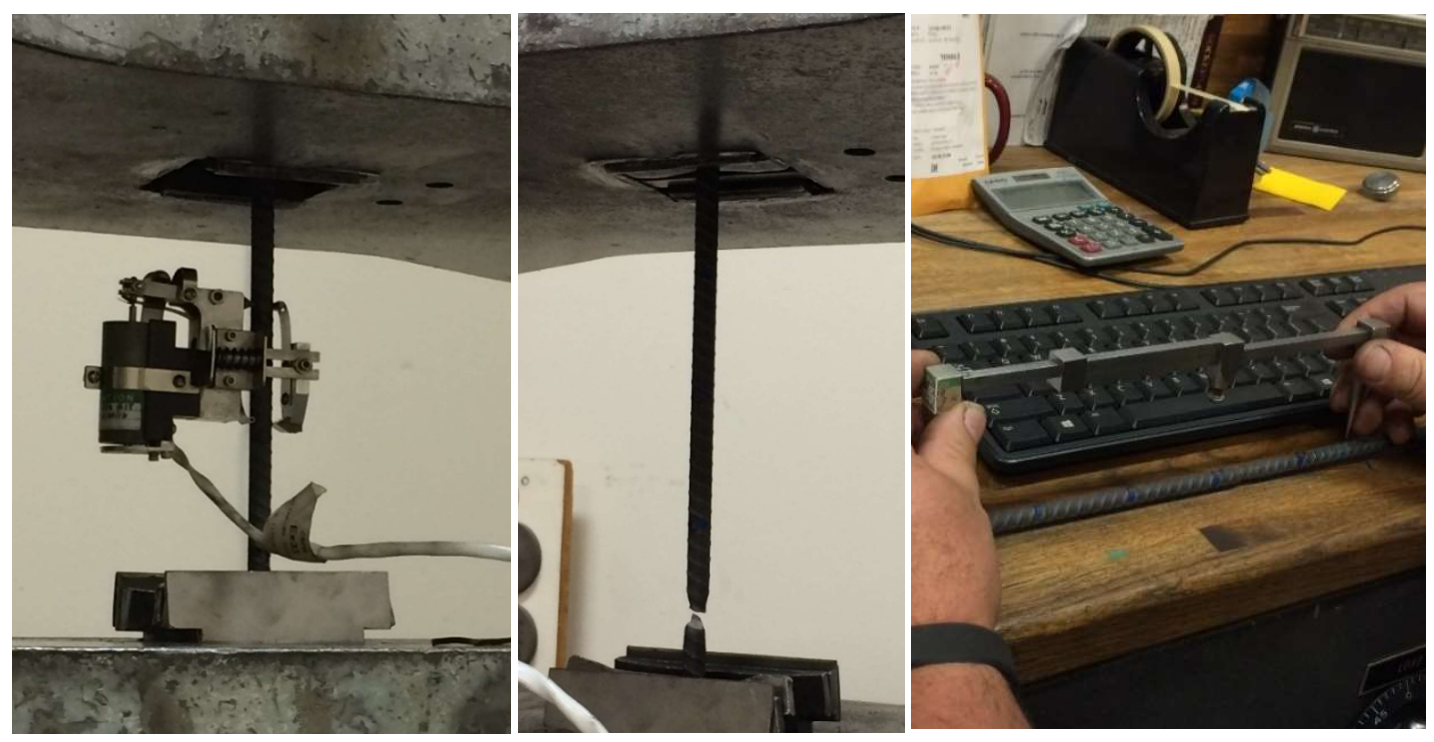

Figure 5-4: Reinforcement tensile stress-strain test set up 

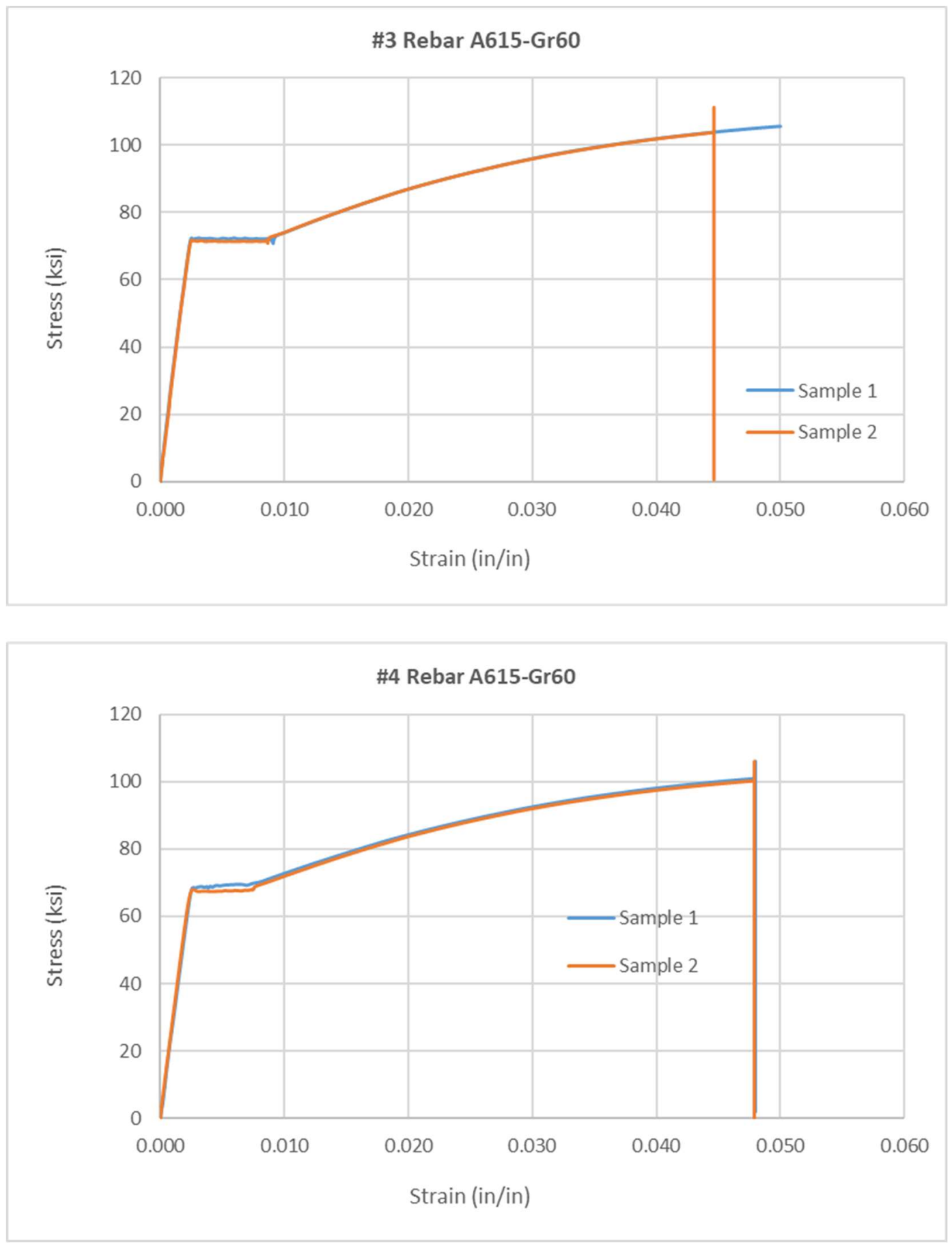

Figure 5-5: Tension stress-strain test results for rebar type A615 grade 60 

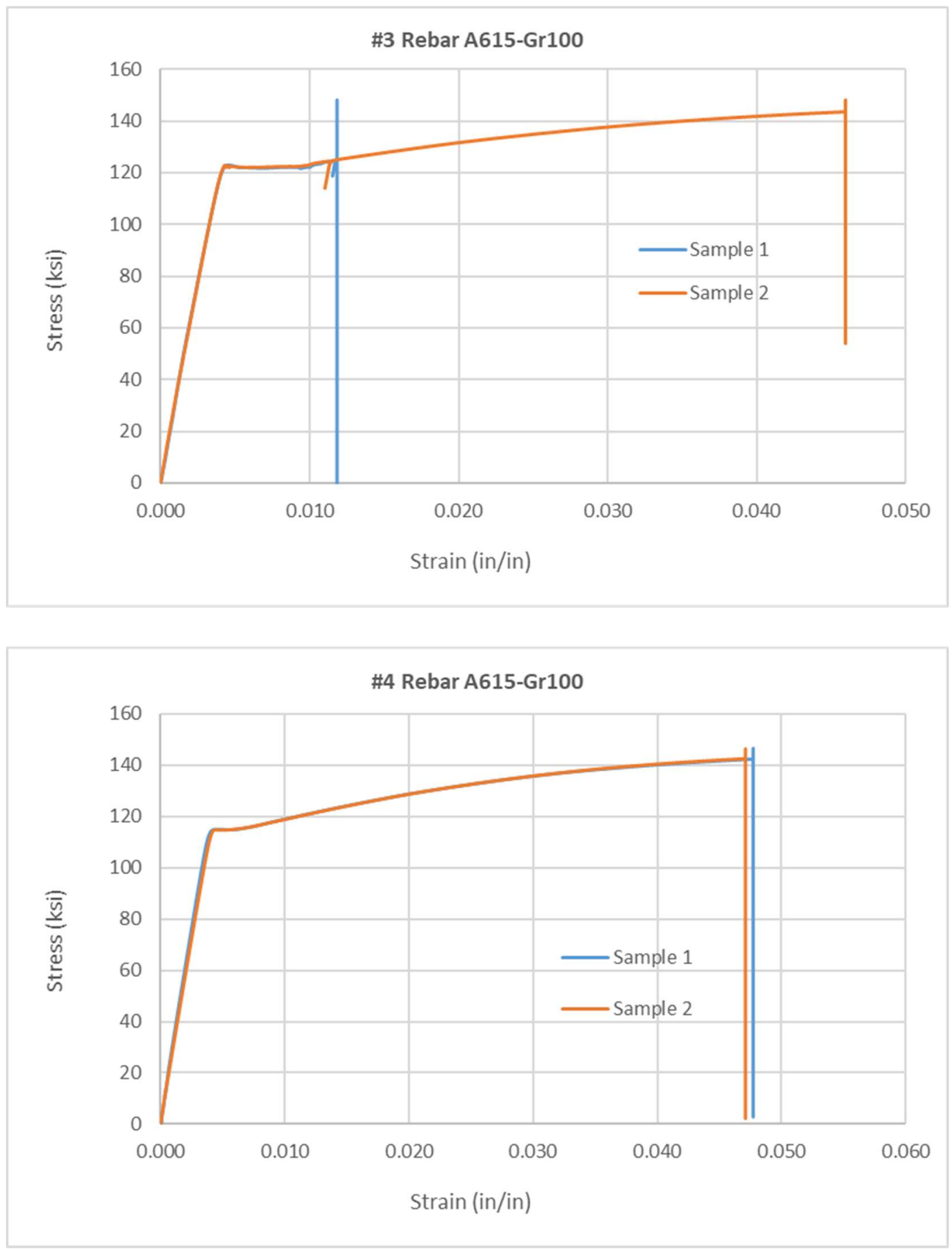

Figure 5-6: Tension stress-strain test results for rebar type A615 grade 100 

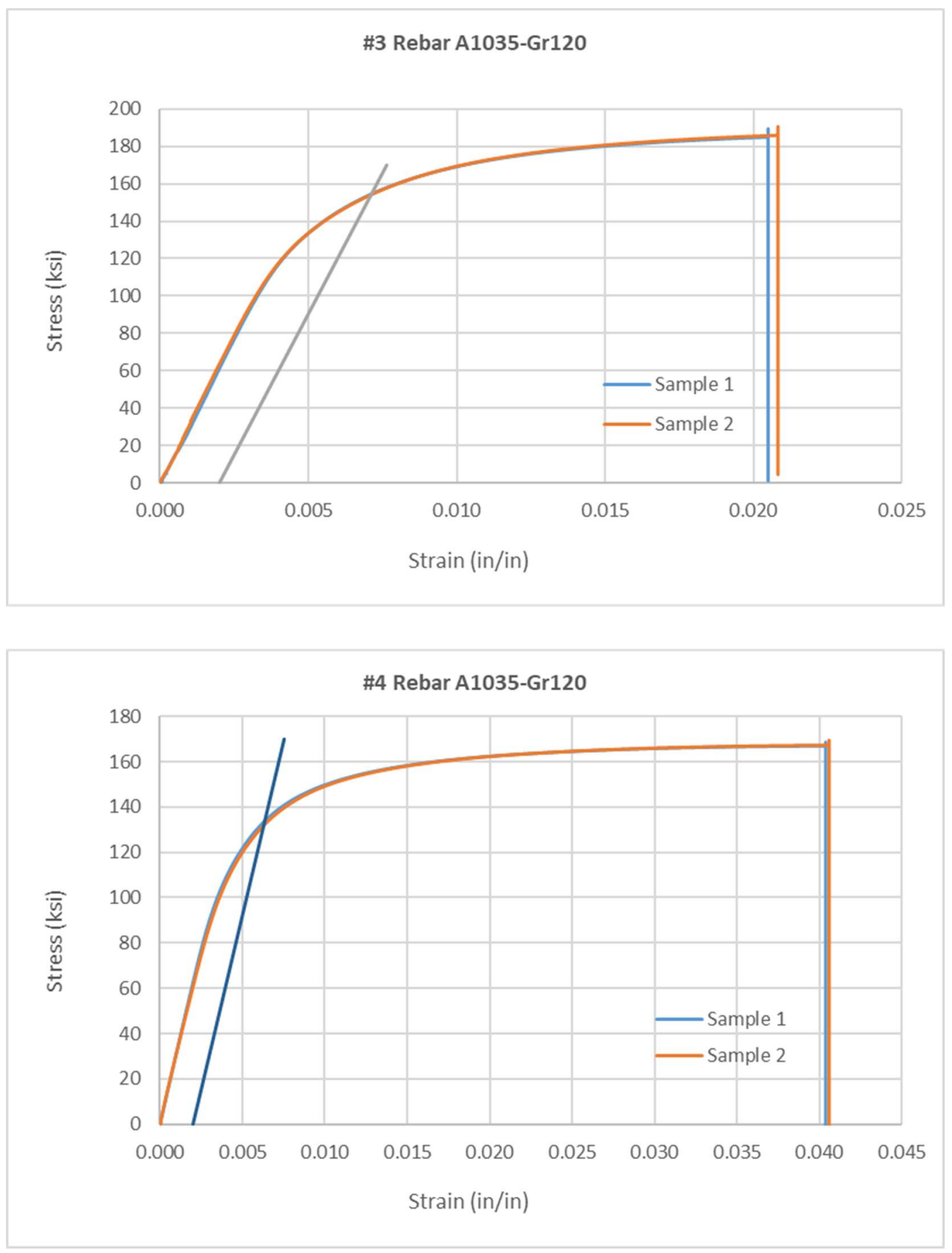

Figure 5-7: Tension stress-strain test results for rebar type A1035 grade 120 


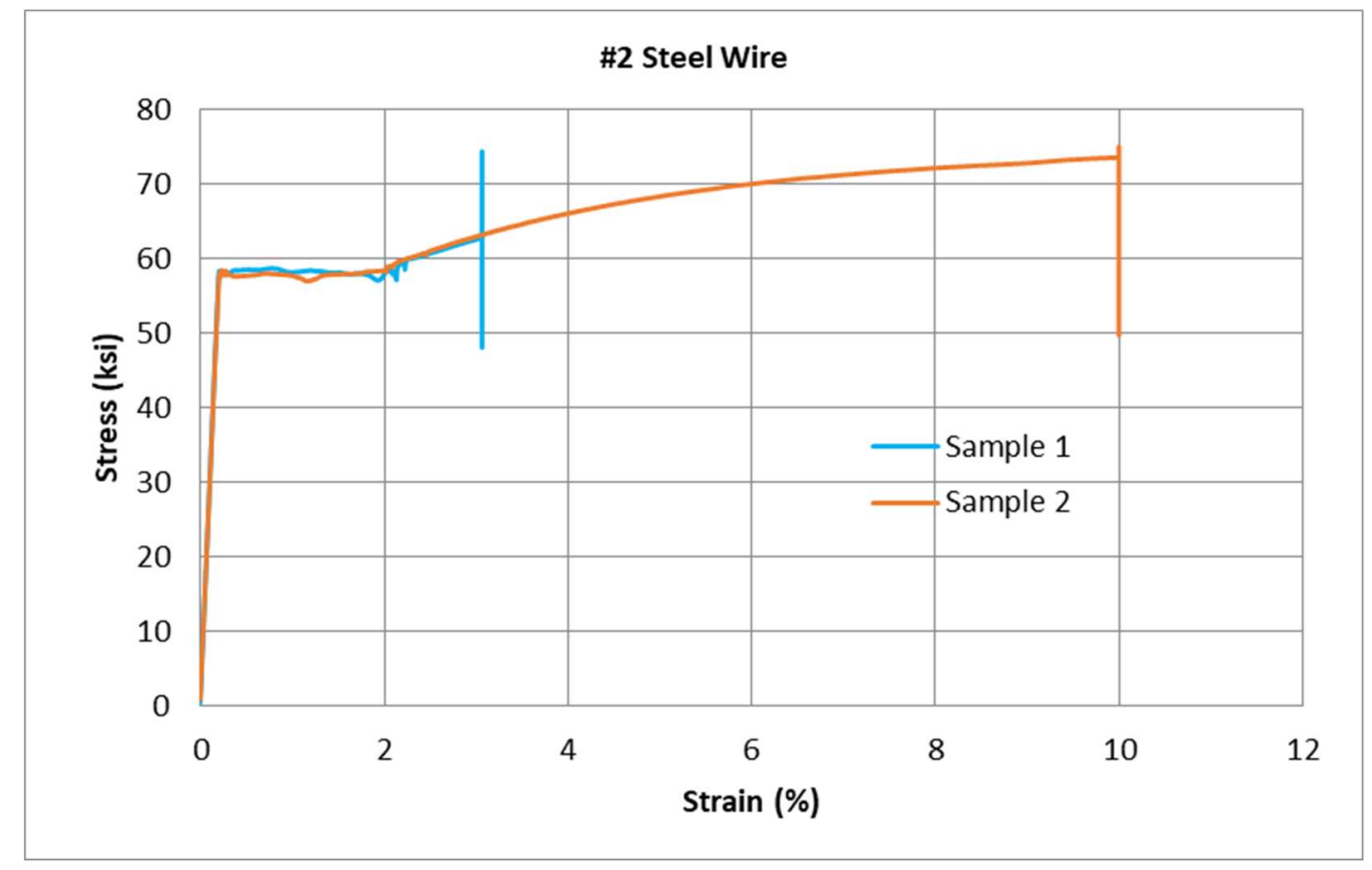

Figure 5-8: Tension stress-strain test results for no.2 wire used for shear reinforcement

\subsection{Design of the Specimens}

All specimens were designed to fit the capacity of the loading frame; therefore, a thirdscale modeling was used to simulate the typical field behavior of a concrete beam. All the tested beams were 6 in. wide x 10 in. deep, and were tested over an 8-ft simple span in a four-point loading arrangement that had a constant moment region of $32 \mathrm{in}$. Two control beams were designed with 5000 psi concrete and Grade 60 steel with a reinforcement ratio equal to $1 / 2 \rho_{\max }$ and $\rho_{\max }$ to observe and assess the flexural performance when these two beams are designed using HSC and HSR. 
The beams tested under short-term monotonic loading were categorized into two groups. The first group consisted of five beams including the control beam that was designed for $1 / 2 \rho_{\max }(\rho \approx 1 \%)$, which represents most cases encountered in practice. Four beams were designed to achieve approximately the same load carrying capacity of the control beam using different combinations of HSC and HSR. In designing the beams with HSR, the steel stress at LRFD load level was assumed as $f_{u}$, i.e., the ultimate stress.

The provided area of steel of two beams in the first group, beam 8/A1035-120 (0.42\%) and beam 11/A1035-120 (0.42\%), was slightly less than what was required by design to achieve the same loading capacity of the control beam due to bar size limitation. The required area of steel is $0.253 \mathrm{in}^{2}$, therefore, $2-\# 3$ bars were used to provide a slightly less area of steel equal to $0.22 \mathrm{in}^{2}$. Thus, the load carrying capacity is slightly less than that of the control beam.

In the same way, the second group consisted of a control beam designed for $\rho_{\max }(\rho \approx$ $2 \%$ ), and two beams were designed with HSC and HSR for approximately the same loading capacity. In addition to these two groups, one beam that was designed with HSC \& HSR was tested under a long-term sustained load. The details of the tested beams are presented in Table 5-4 and Figure 5-9.

The beams were designated according to their concrete compressive strength, reinforcement type, grade, and ratio. For example, beam "10/A1035-120 (0.74\%)" has a concrete nominal compressive strength equal to $10 \mathrm{ksi}$ and is reinforced with rebar type A1035, which satisfies the requirement for Grade 120 bars with a reinforcement ratio of $0.74 \%$. 
In order to verify the accuracy of the written MATLAB code with the tested beams, the actual stress-strain curves obtained from rebar coupons tensile test were modeled and used for the beams' design to determine the required reinforcement ratios that give the same load capacity as the control beams. To prevent the possibility of shear failure in the beams, \#2 Grade 60 stirrups were provided throughout the span, as shown in Figure 5-9. All beams were singly-reinforced, and two \#2 Grade 60 smooth wire were used in the compression zone of the section for framing purposes.

Table 5-4: Experimental test matrix

\begin{tabular}{c|ccccccc}
\hline $\begin{array}{c}\text { Beam } \\
\text { No. }\end{array}$ & $\begin{array}{c}\text { Beam } \\
\text { Designation }\end{array}$ & $\mathbf{f}^{\prime}$ ', psi & Steel Type & $\begin{array}{c}\text { Bottom } \\
\text { Reinf. }\end{array}$ & $\boldsymbol{\rho}$ & $\boldsymbol{f}_{\boldsymbol{y}}$, ksi & $\begin{array}{c}\text { Loading } \\
\text { Type }\end{array}$ \\
\hline B1 & $\begin{array}{c}5 / \mathrm{A} 615-60 \\
(1.1 \%)\end{array}$ & 5,600 & $\mathrm{~A} 615-60$ & $3-\# 4$ & $\begin{array}{c}0.011 \\
(1 / 2\end{array}$ & 69.5 & Short-term \\
(control) & $\begin{array}{c}8 / \mathrm{A} 615-100 \\
(0.62 \%)\end{array}$ & 8,100 & $\mathrm{~A} 615-100$ & $3-\# 3$ & 0.0062 & 121.5 & Short-term \\
\hline B3 & $\begin{array}{c}8 / \mathrm{A} 1035-120 \\
(0.41 \%)\end{array}$ & 8,100 & $\mathrm{~A} 1035-120$ & $2-\# 3$ & 0.0041 & 152.9 & Short-term \\
\hline B4 & $\begin{array}{c}13 / \mathrm{A} 615-100 \\
(0.62 \%)\end{array}$ & 13,500 & $\mathrm{~A} 615-100$ & $3-\# 3$ & 0.0062 & 121.5 & Short-term \\
\hline B5 & $\begin{array}{c}11 / \mathrm{A} 1035-120 \\
(0.41 \%)\end{array}$ & 11,100 & $\mathrm{~A} 1035-120$ & $2-\# 3$ & 0.0041 & 152.9 & Short-term \\
\hline B6 & $\begin{array}{c}5 / \mathrm{A} 615-60 \\
(2.29 \%)\end{array}$ & 5,800 & $\mathrm{~A} 615-60$ & $5-\# 4+1-\# 3$ & 0.0229 & 69.5 & Short-term \\
\hline B7 $\left.\rho_{m a x}\right)$ & $\begin{array}{c}10 / \mathrm{A} 1035-120 \\
(0.74 \%)\end{array}$ & 10,700 & $\mathrm{~A} 1035-120$ & $2-\# 4$ & 0.0074 & 136.7 & Short-term \\
\hline B8 & $\begin{array}{c}14 / \mathrm{A} 1035-120 \\
(0.74 \%)\end{array}$ & 14,300 & $\mathrm{~A} 1035-120$ & $2-\# 4$ & 0.0074 & 136.7 & Short-term \\
\hline B9 & $\begin{array}{c}14 / \mathrm{A} 1035-120 \\
(0.41 \%)\end{array}$ & 14,600 & $\mathrm{~A} 1035-120$ & $2-\# 3$ & 0.0041 & 152.9 & Long-term \\
\hline
\end{tabular}


Group 1, Beams are designed to carry the same load of the control beam 5/A615-60 ( $\left.1 \frac{1}{2} \rho_{\max }\right)$
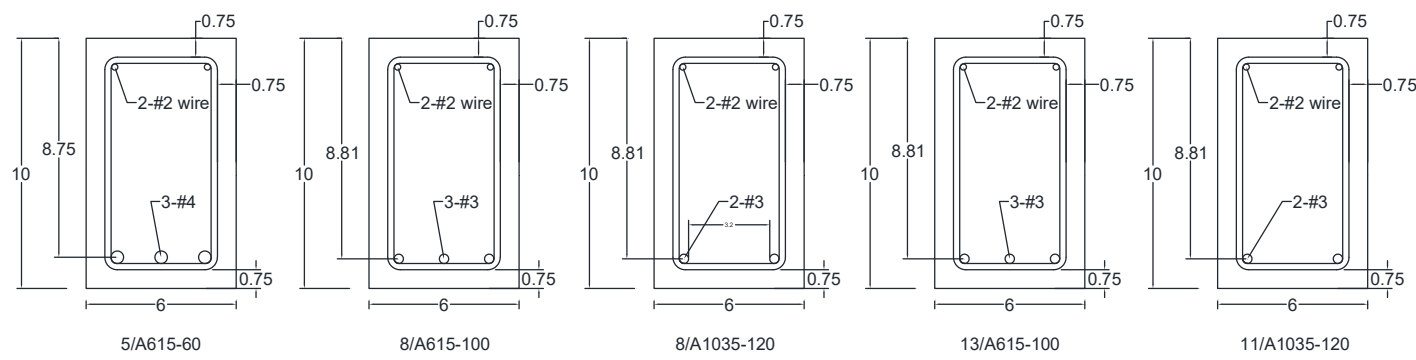

Group 2, Beams are designed to carry the same load of the control beam 5/A615-60 ( $\left.\rho_{\max }\right)$
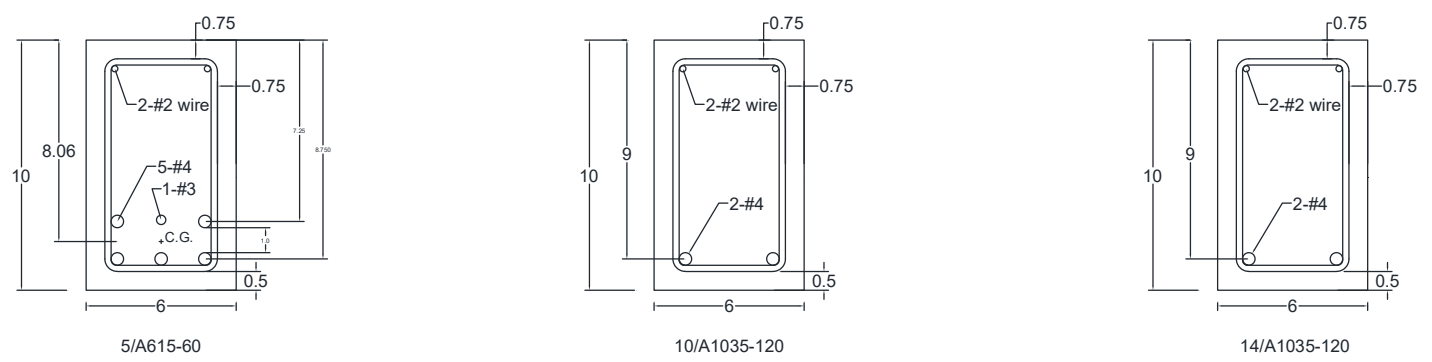

\section{$\underline{\text { Long-term loading }}$}
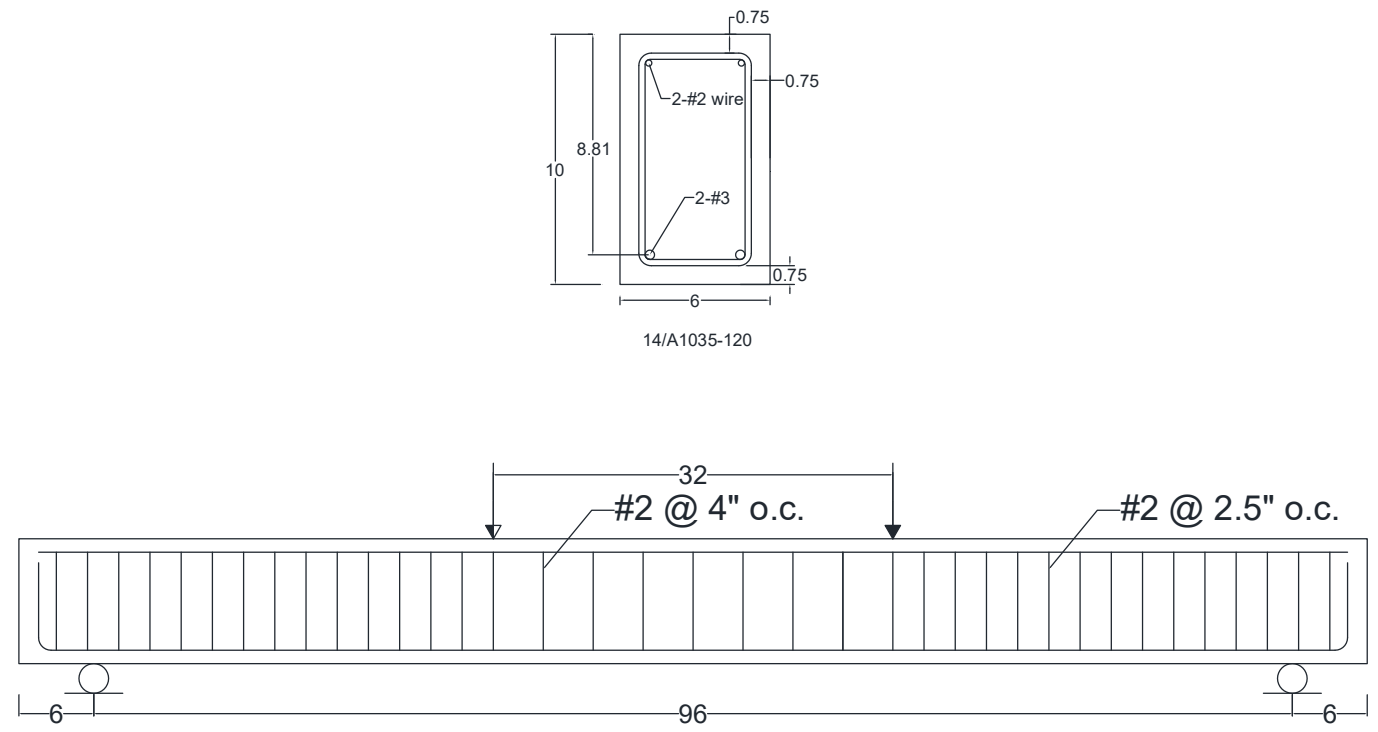

Figure 5-9: Experimental program test beams details 


\subsection{Specimens Fabrication}

All beams were fabricated and constructed at the South Greenhouse Laboratory at Portland State University. Framing lumber pieces of $1 \frac{1 / 2}{2}$ in. thickness were used to make the formwork. The stirrups were formed in the laboratory with the proper dimensions using a hand-made steel wire bender, and then the reinforcing cage was assembled according to the specimen design. The longitudinal HRS were hooked to $90^{\circ}$ to prevent any possible debonding between the reinforcement and the concrete. Then the formwork was oiled to simplify removal efforts, and the reinforcement cage was placed in the form on plastic chairs to provide the required cover. Then the form was moved to the casting place.

Concrete was mixed in the laboratory, and the slump test was performed to check the workability of the mixture before pouring the concrete in the beam form and its ancillary cylinders and prisms. A vibrator was used for compaction and to let the concrete fill the gaps. Twenty-four hours after casting the specimens, the form sides were removed, and the specimens were covered with wet burlap and plastic sheets for moist curing for 28 days. Figure 5-10 to Figure 5-12 illustrate the fabrication, casting, and curing process of the beams. 

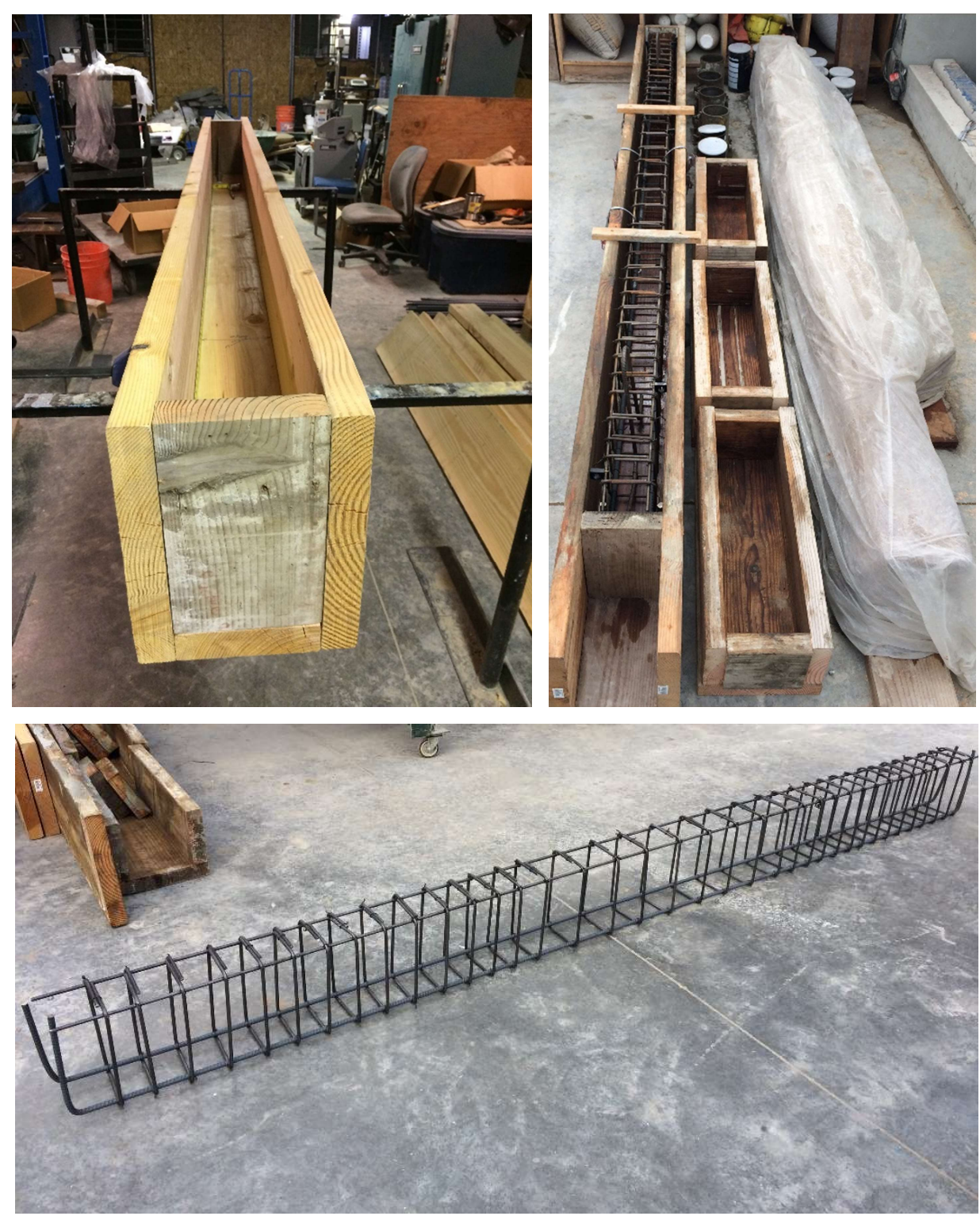

Figure 5-10: Specimens fabrication 


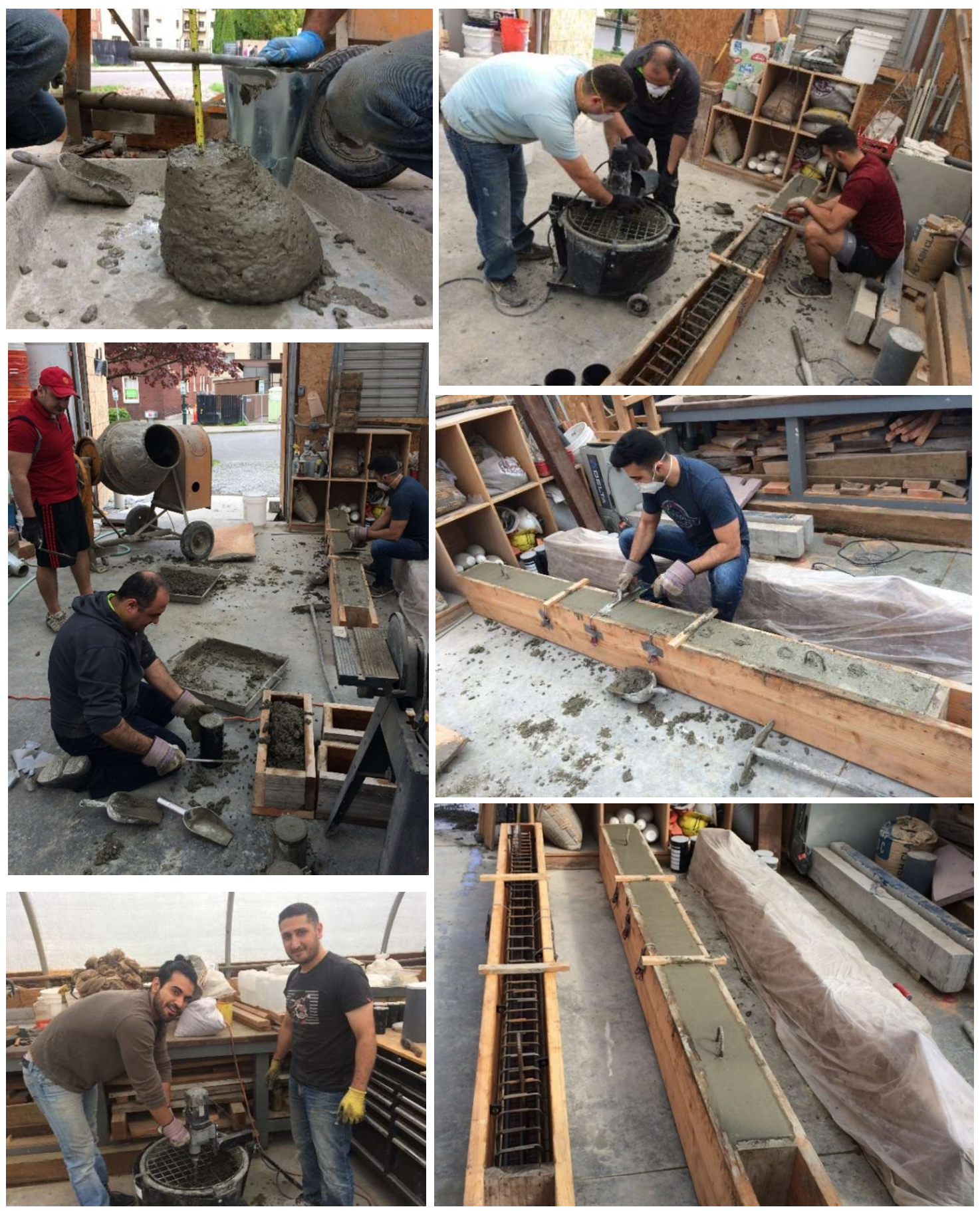

Figure 5-11: Concrete mixing and casting process of the specimens 


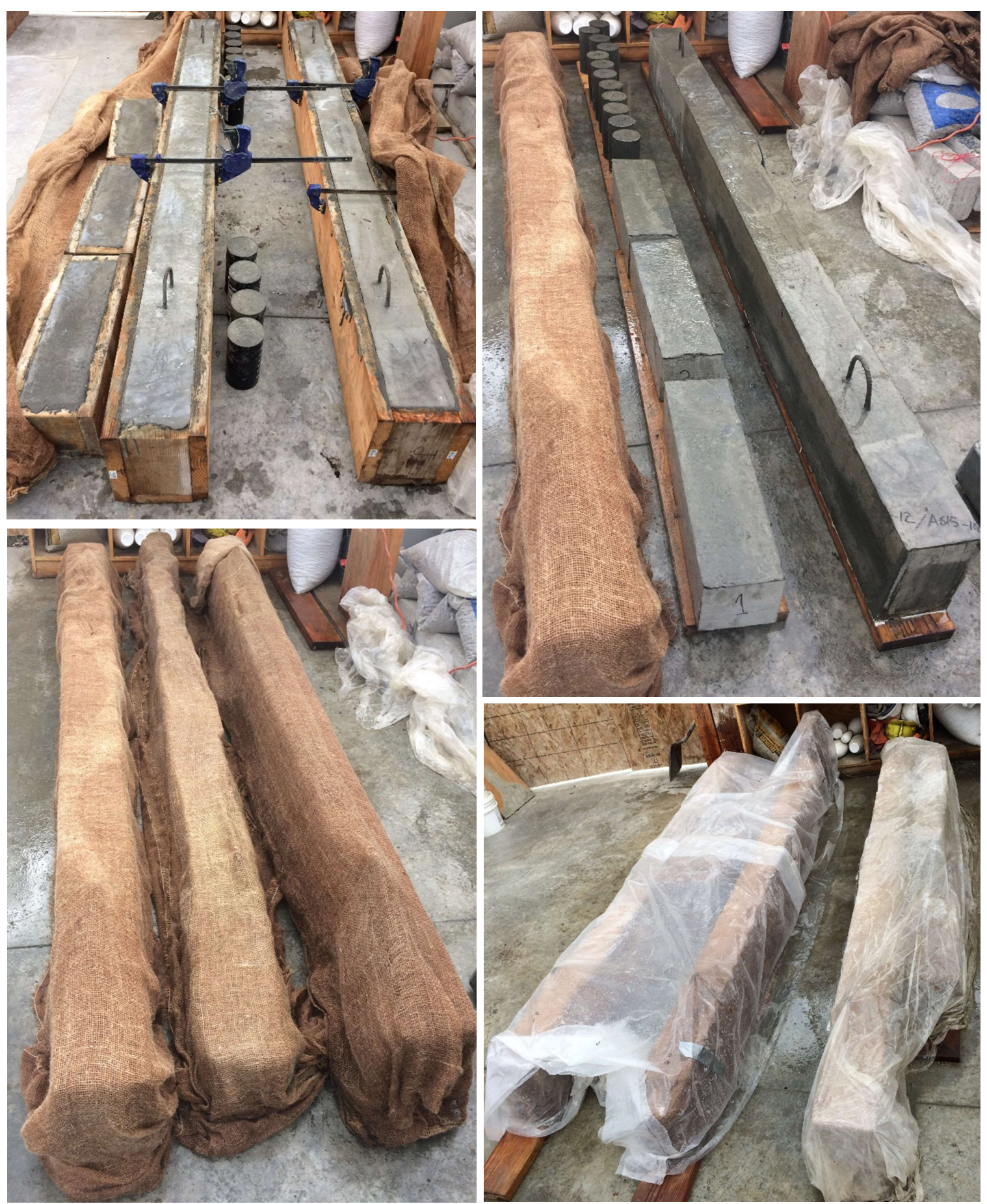

Figure 5-12: Specimens moist curing 


\subsection{Instrumentation and Test Setup}

\subsubsection{Installation of Strain Gauges}

Strain gauges were used to measure the strains in the concrete and the reinforcement in the constant moment zone (location of maximum stresses) of the beams span subjected to two-point loading during the flexural tests of the beams. In order to measure the strain in the concrete, three pre-wired strain gauges (PL-120-11-1L) of $120 \mathrm{~mm}$ (4.7 in.) gauge length were installed on the side face and close to the top edge of each beam to measure the compression strain in the concrete. The strain gauges for the concrete were ordered from Texas Measurement (www.straingage.com). The installation process started by grinding the concrete surface, cleaning it, and covering it with a very thin layer of epoxy to fill in the voids. The thin layer of epoxy was ground down using sand paper to get a leveled smooth surface, and the strain gauge was installed using a special adhesive. Figure 5-13 shows the installation steps.

For reinforcement, pre-wired strain gauges (KFH-20-120-C1-11L1M2R) of $20 \mathrm{~mm}$ (0.787 in.), were ordered from OMEGA Engineering Inc. (www.omega.com), and installed on each of the bottom longitudinal reinforcing bars to measure the tension strain in the reinforcement within the constant moment zone. The process of installing the strain gauges on the steel bars was also started by grinding the surface of the bar at the desired point in order to get a leveled smooth surface, and then installing the strain gauge. After that, the strain gauge was glued to the bar using a special adhesive recommended by the manufacture. Duct-tape was wrapped around the strain gauge to protect it from any 
damage during the casting process of the specimens. The process of placing the strain gauges is illustrated in Figure 5-14.
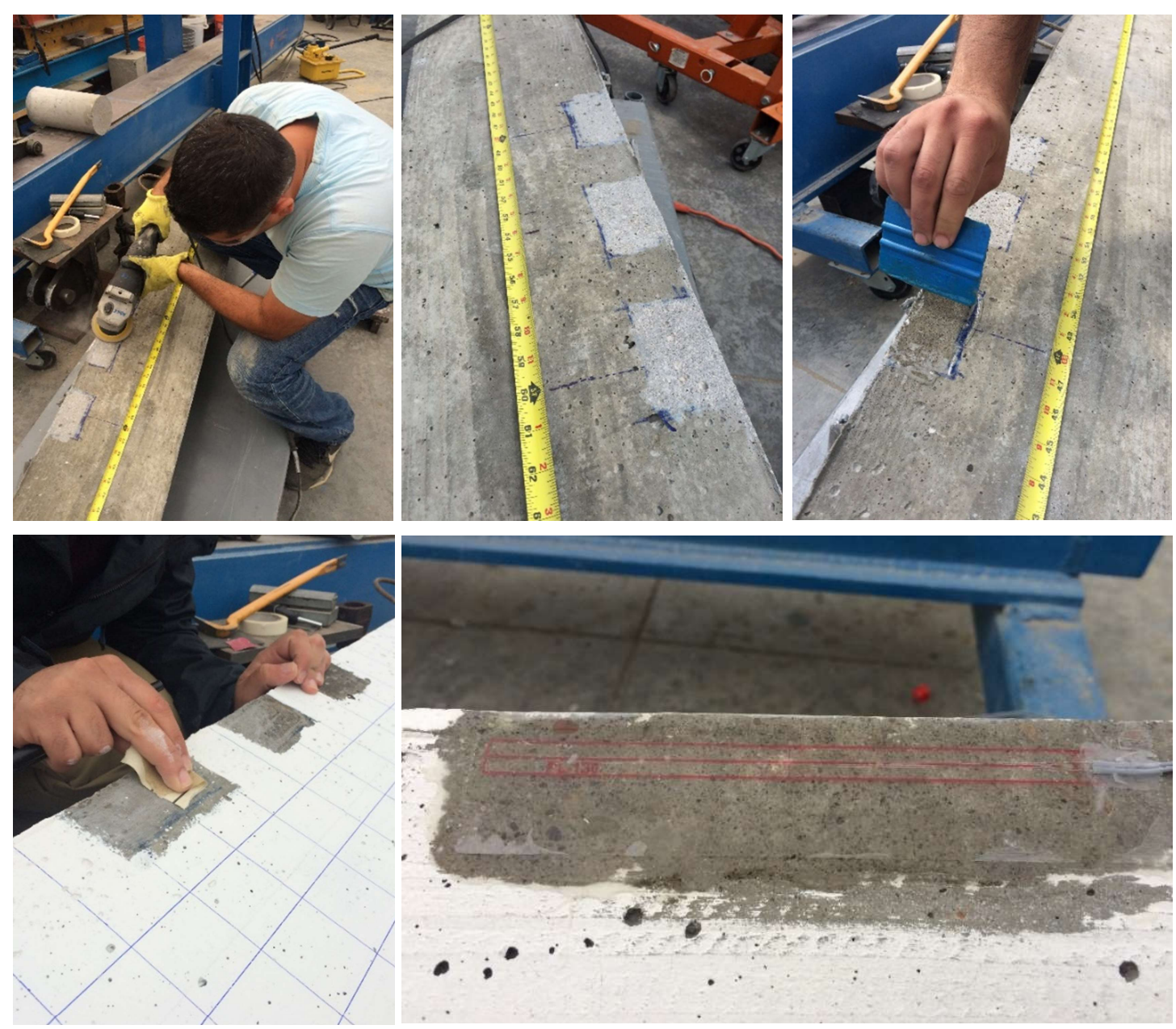

Figure 5-13: Installation steps of concrete strain gauges 

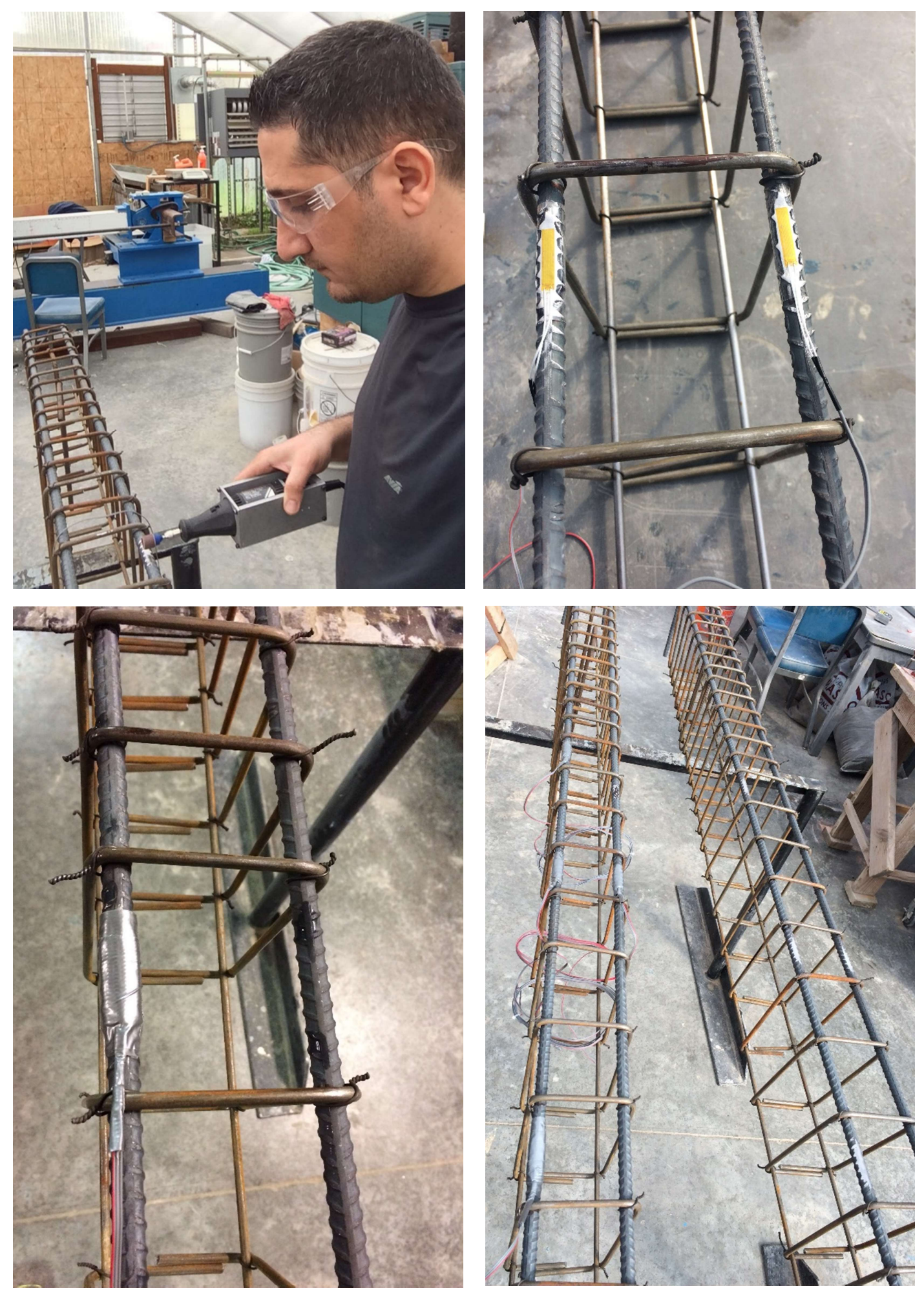

Figure 5-14: Installation steps of reinforcement strain gauges 


\subsubsection{Flexural Test Setup and Instrumentation}

The flexural test for the beams was performed by using a self-sustained load frame because the floor of the laboratory is not a rigid floor. The beam was placed on the frame bed, and the load that was applied to the beam was transferred to the load frame through two steel straps. All beams were simply supported on the frame bed. The load was applied using a hydraulic cylinder of 50 kips capacity. To measure the applied load, a 100 kips load cell was placed between the hydraulic cylinder and the distributer steel beam that was used to distribute the central load into two-point load. An 8-inch stroke linear variable differential transformer (LVDT) was used to measure the mid-span deflection. Figure 5-15 and Figure 5-16 illustrate the typical beam flexural test setup. All beams were tested under monotonic incrementally increased load up to the failure of the specimens. The data from the load cell, central LVDT, and strain gauges were recorded to the computer using a data acquisition system (DATAQ USB data loggers and Signal Conditioning Amplifier boxes).

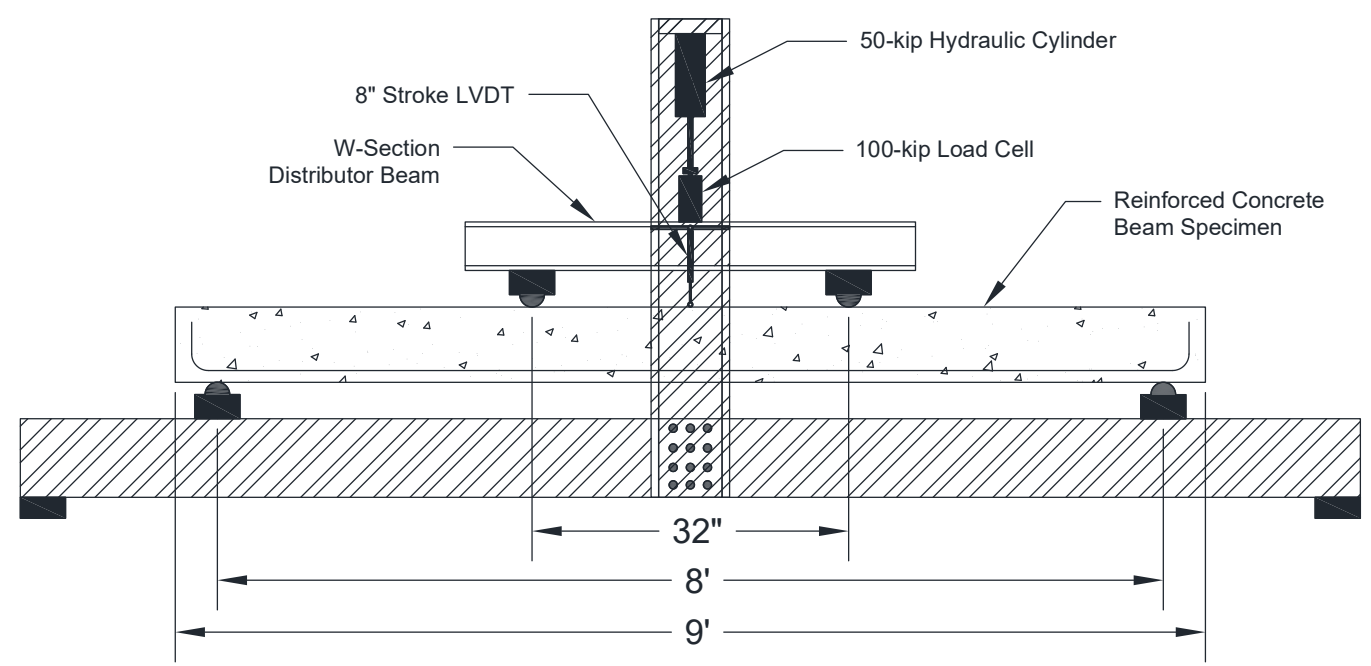

Figure 5-15: Flexural test set-up and instrumentations 


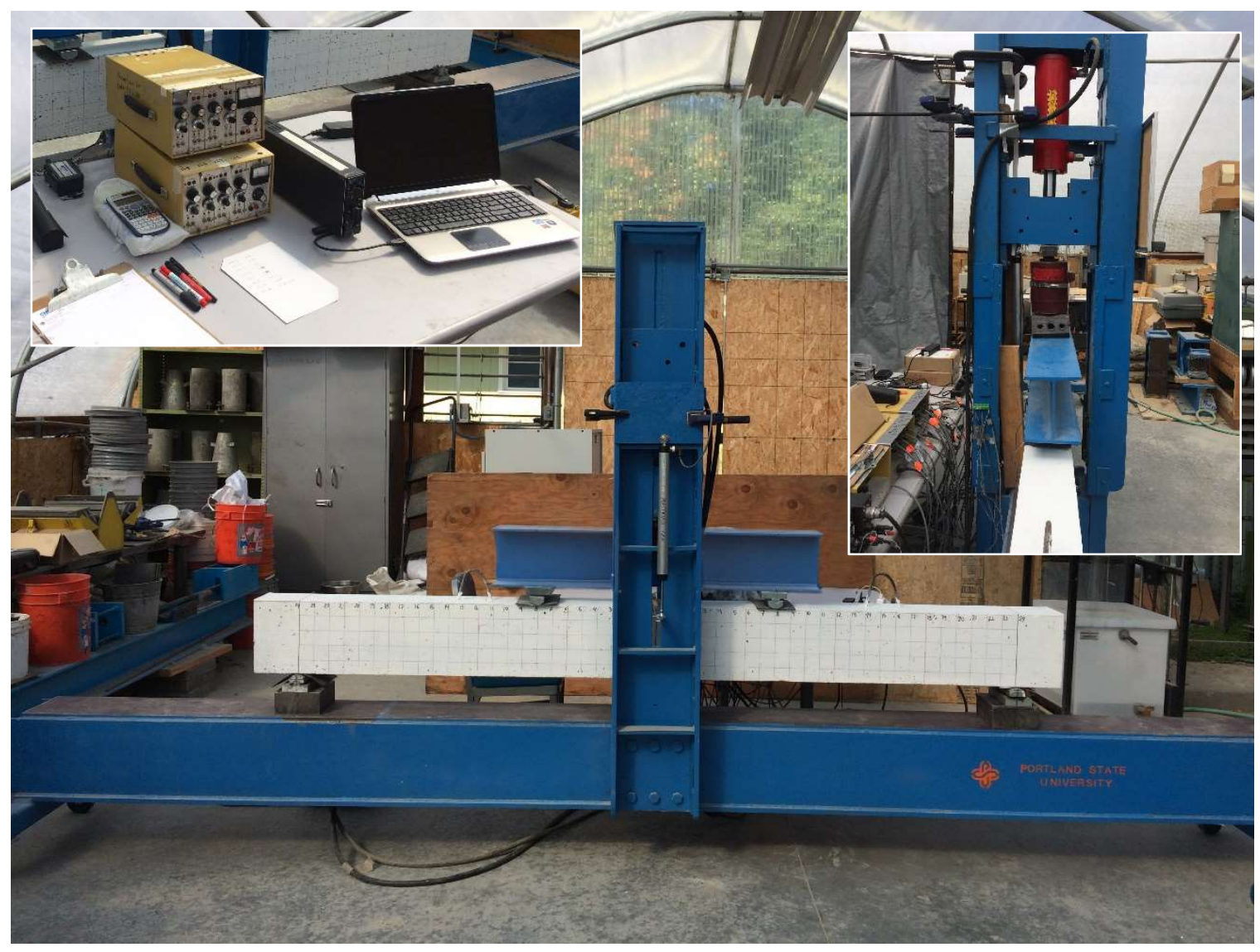

Figure 5-16: Typical flexural test setup of reinforced concrete beam specimens

\subsubsection{Long-Term Deflection Test Setup}

The experimental program included the investigation of one beam made with highstrength concrete $\left(f^{\prime}{ }_{c}=14600 \mathrm{psi}\right)$ and reinforced with high-strength reinforcement type A1035 Grade 120 with reinforcement ratio of $0.41 \%$ to evaluate the long-term deflection factor $(\lambda)$ of the current ACI 318 code. This study required designing a load frame that could be used to apply a constant sustained load. A mechanical loading frame was designed by the author to perform a long-term flexural test for simply supported reinforced concrete beams, as illustrated in Figure 5-17. The test was performed at the 
Mechanical Engineering lab at PSU. The load was applied using hanging weights, and an aluminum beam was used as a lever arm to magnify the load by ten times applied at the midpoint of the spreader beam. In order to place the reinforced concrete specimen and to transfer the load within the loading frame, a base beam of the HSS steel section was added to the loading frame. The beam specimen was oriented with the tension side up as the load was applied upward. To assure no loading transferred to the beam before applying the required sustained load, the weight of the loading system parts was subtracted by placing an equivalent weight to the other side of the pivot point of the lever arm to satisfy the equilibrium condition. The midspan deflection was monitored using an electronic dial gauge with 0.001 in. precision. The applied sustained load (13.8 kip) was about $60 \%$ of the failure load. Figure 5-17 shows the schematic drawing for the long-term deflection test loading frame, and Figure 5-18 shows some of the fabrication work done for the modification of the loading frame.

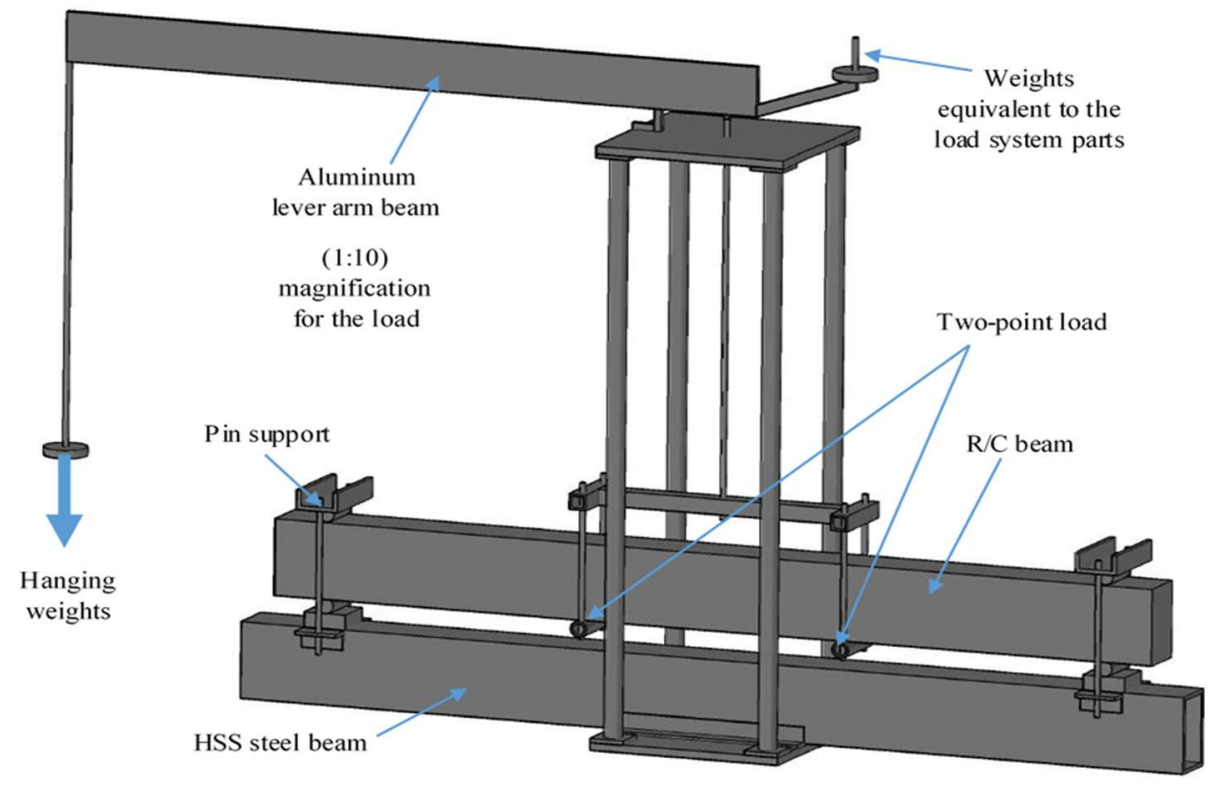

Figure 5-17: Schematic drawing for the test setup of the long-term deflection 


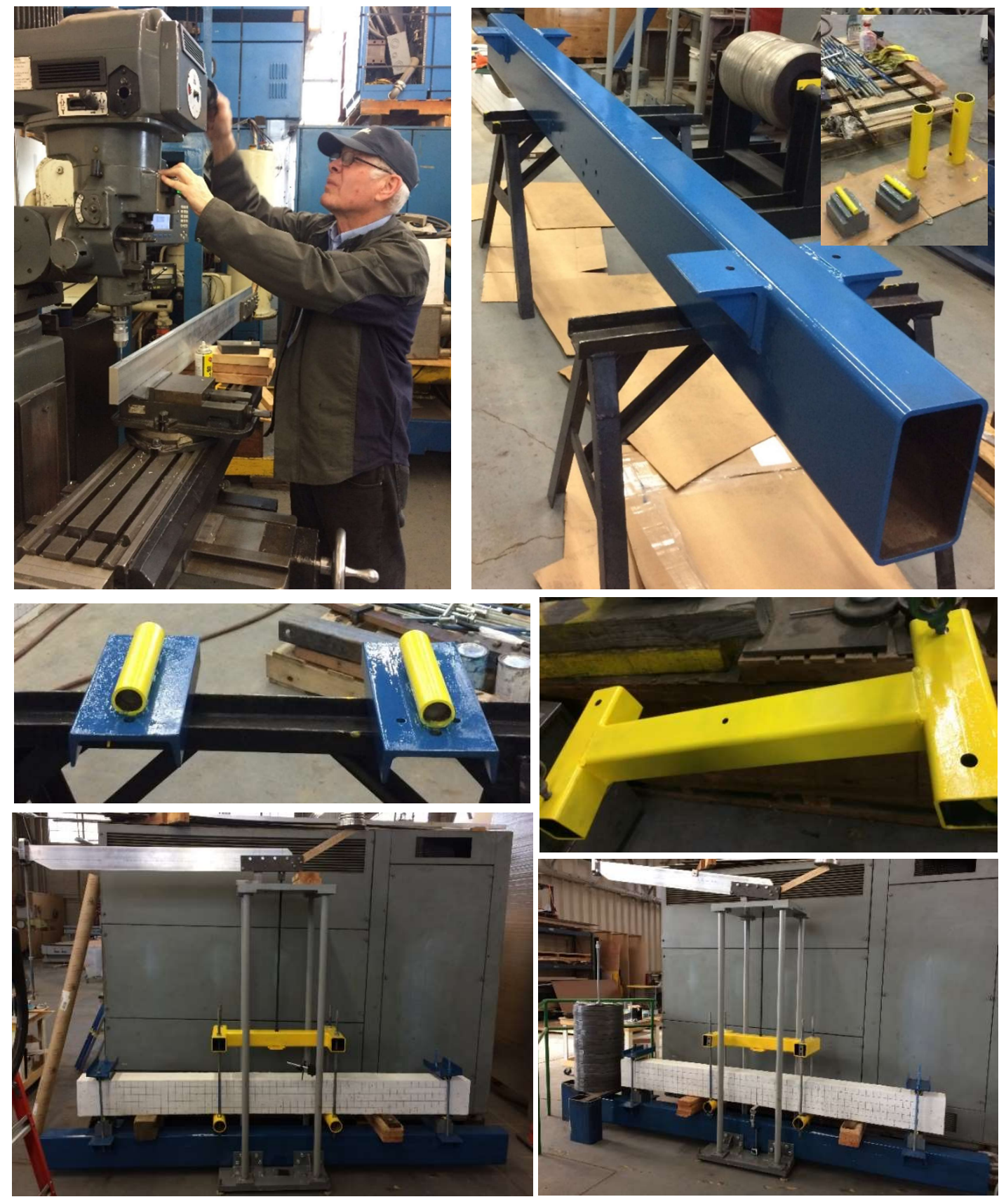

Figure 5-18: Fabrication of the loading frame for flexural long-term deflection test 


\subsection{Beams Flexural Test Results and Discussion}

All eight beams were tested under a monotonic two-point load until failure. The load versus midspan deflection behavior, strain in concrete at the top fiber, and strain in the reinforcing bars were recorded. The cracking behavior was observed, and the maximum crack width at service load level (60\% of the maximum load) was measured using a crack width gauge. The predicted behaviors and the expected capacities were computed using the MATLB code created by the author, which was based on a strain compatibility and section equilibrium concept, and that utilized the actual stress-strain curves.

The test beams were divided into two groups based on the design load capacity. The first group included five beams: A control beam that was designed with conventional materials (NSC and Grade 60 steel) with a reinforcement ratio $\approx 1 \%$, which represented a common or average case in practice; and four beams made of two different types of HSC and HSR (A615-100 and A1035-120), and designed to achieve the same load carrying capacity as the control beam. The second group included three beams: A control beam made with NSC and Grade 60 steel bars and designed with maximum reinforcement ratio permissible by ACI, $\rho \approx 2 \%$; and two beams made with HSC and HSR type A1035-120. The objective was to compare the behavior of beams using conventional materials with those using the combination of high strength materials.

\subsubsection{Load-Deflection Behavior of Test Beams}

The experimental load-deflection behaviors along with the predicted theoretical behaviors for each beam are shown in Figure 5-19a to Figure 5-26a. The strain in the concrete at the top fibers and the strain in the tension reinforcement were also recorded 
during the tests and plotted versus the applied load and compared with the results of the computer model, as illustrated in Figure 5-19 b and c through Figure 5-26 b and c.

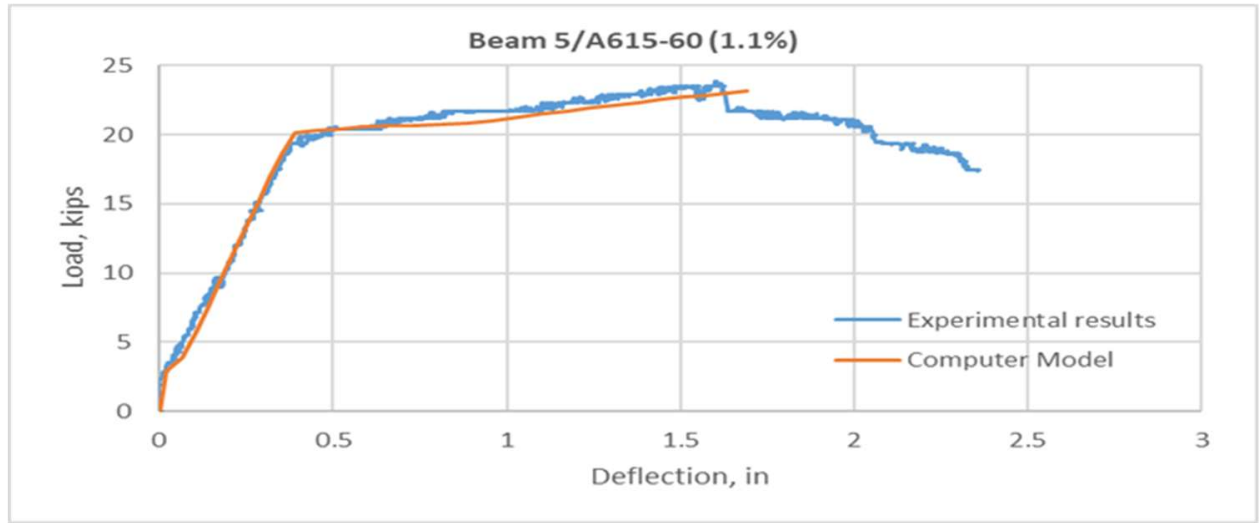

a) Load-midspan deflection

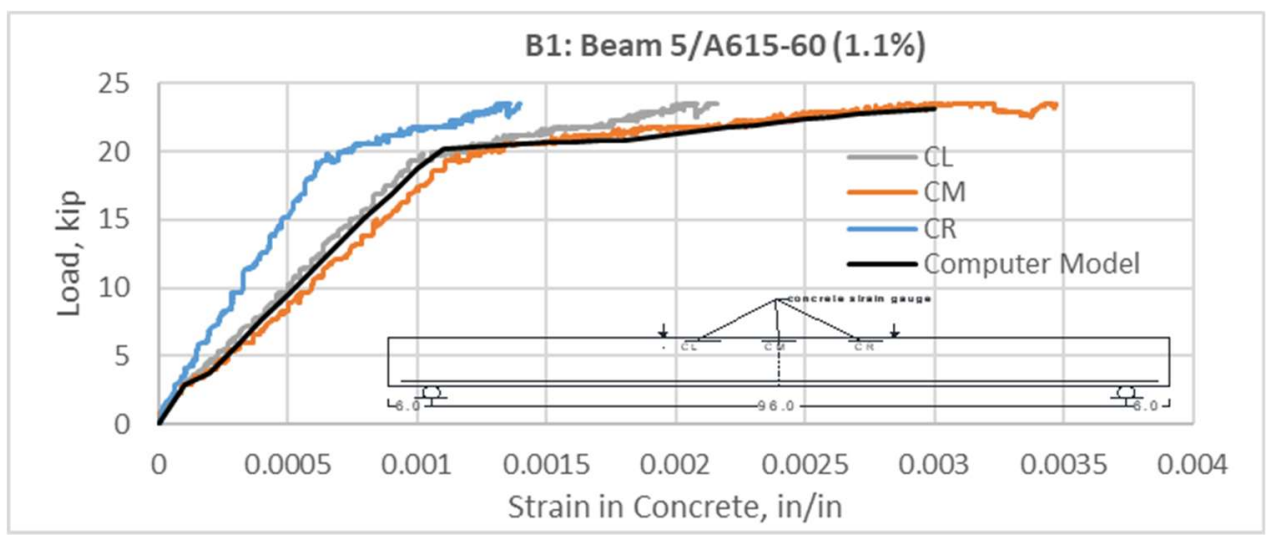

b) Load-concrete strain

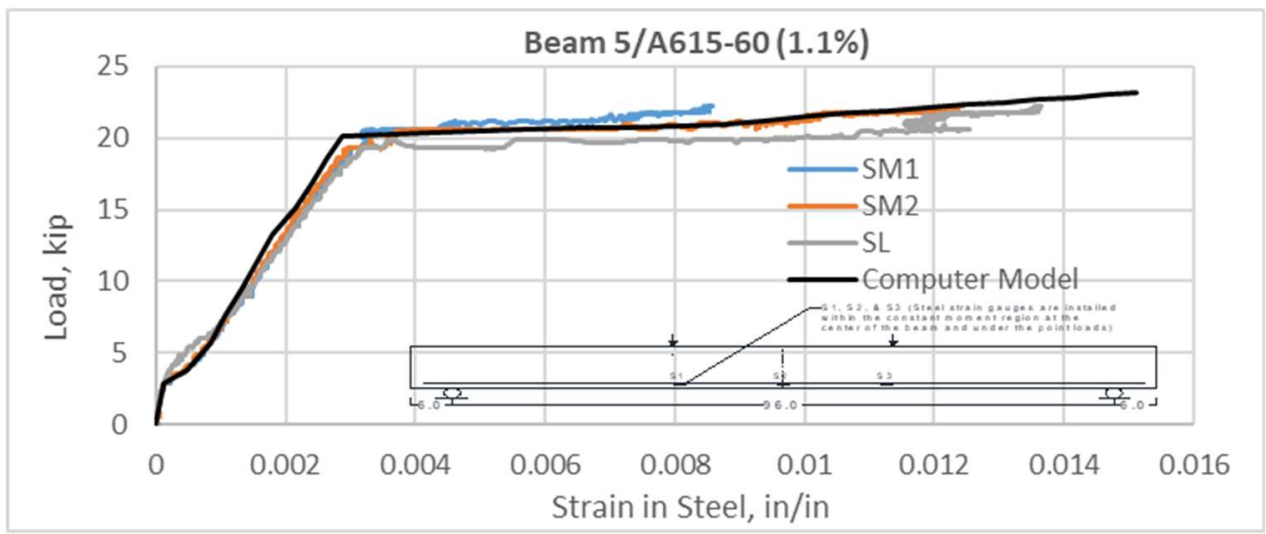

c) Load-steel strain

Figure 5-19: Experimental results of beam 5/A615-60 (1.1\%) 


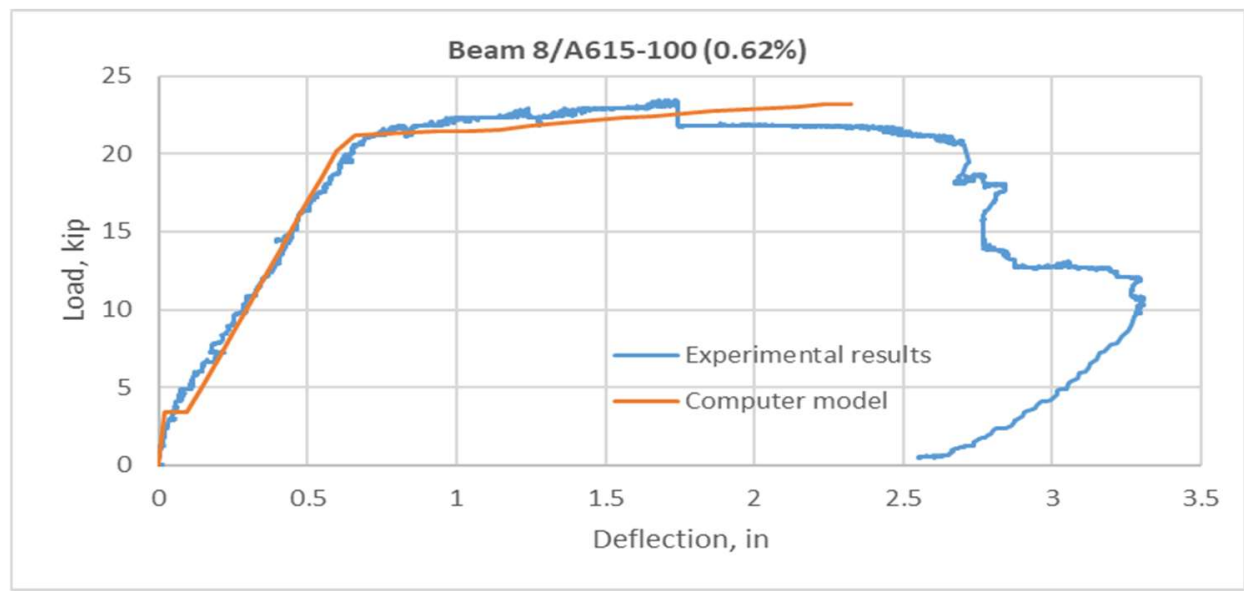

a) Load-midspan deflection

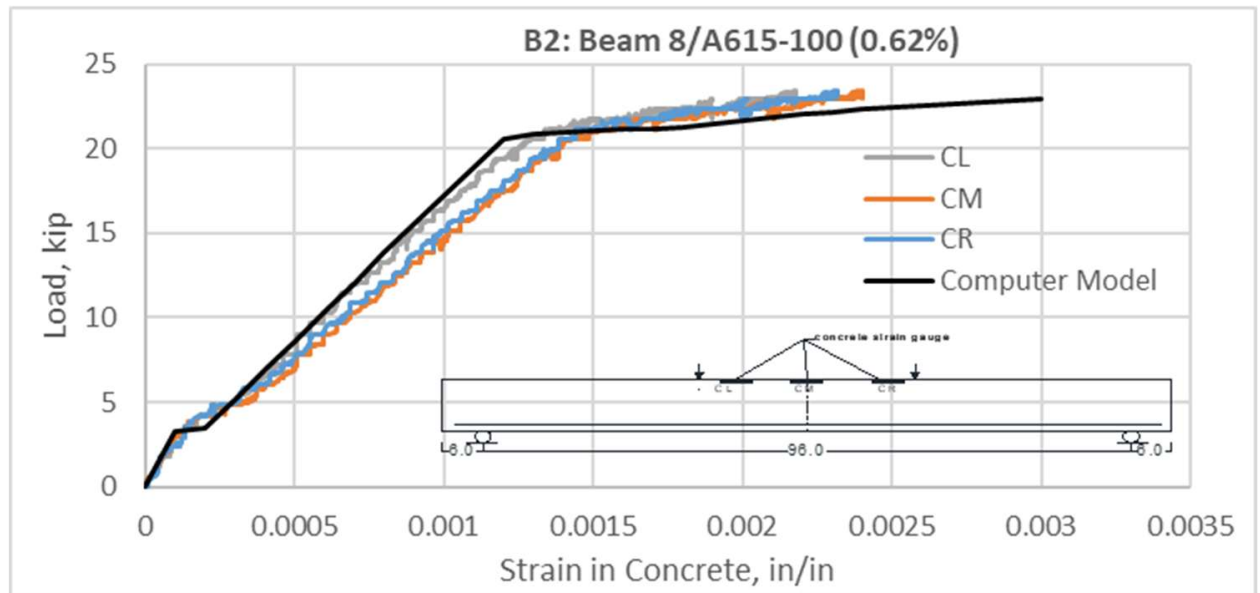

b) Load-concrete strain

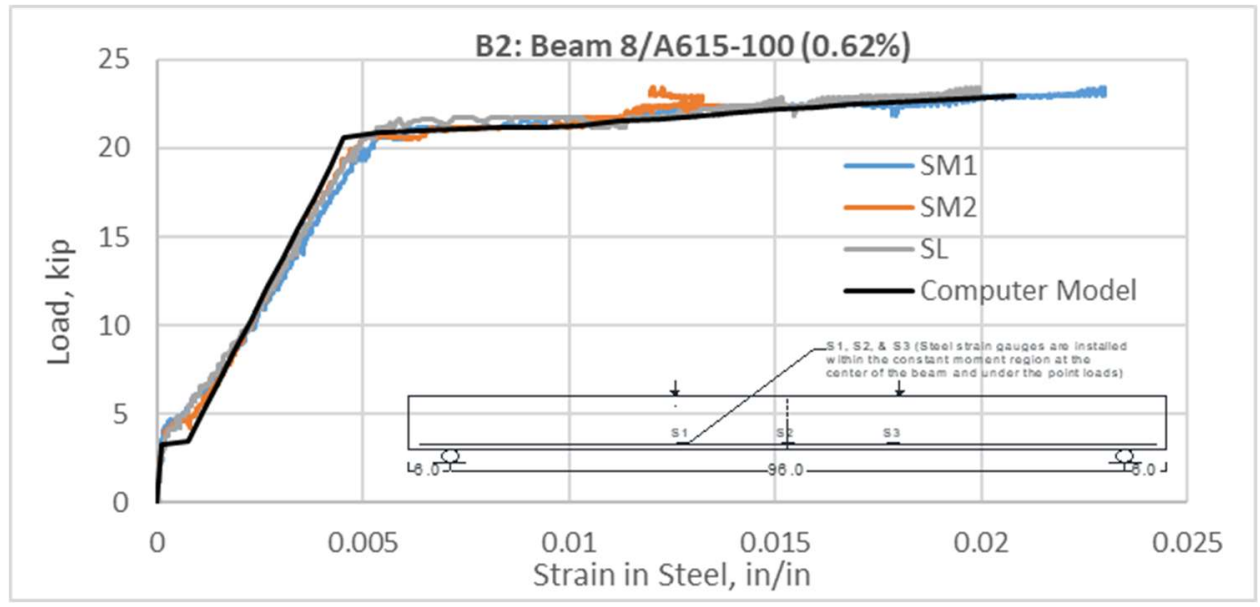

c) Load-steel strain

Figure 5-20: Experimental results of beam 8/A615-100 (0.62\%) 


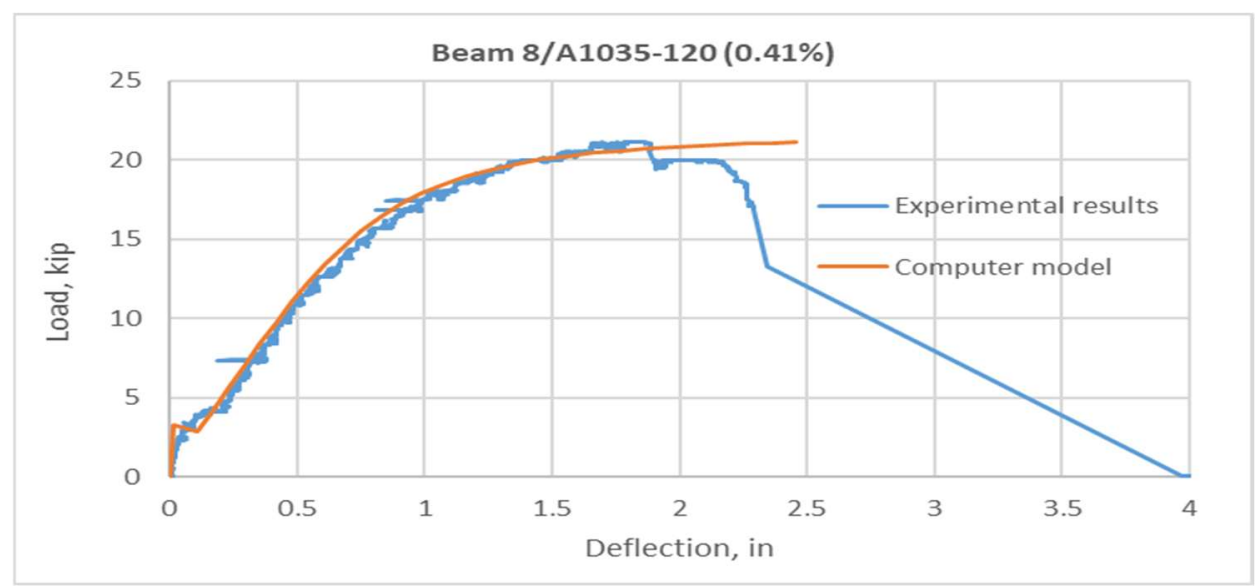

a) Load-midspan deflection

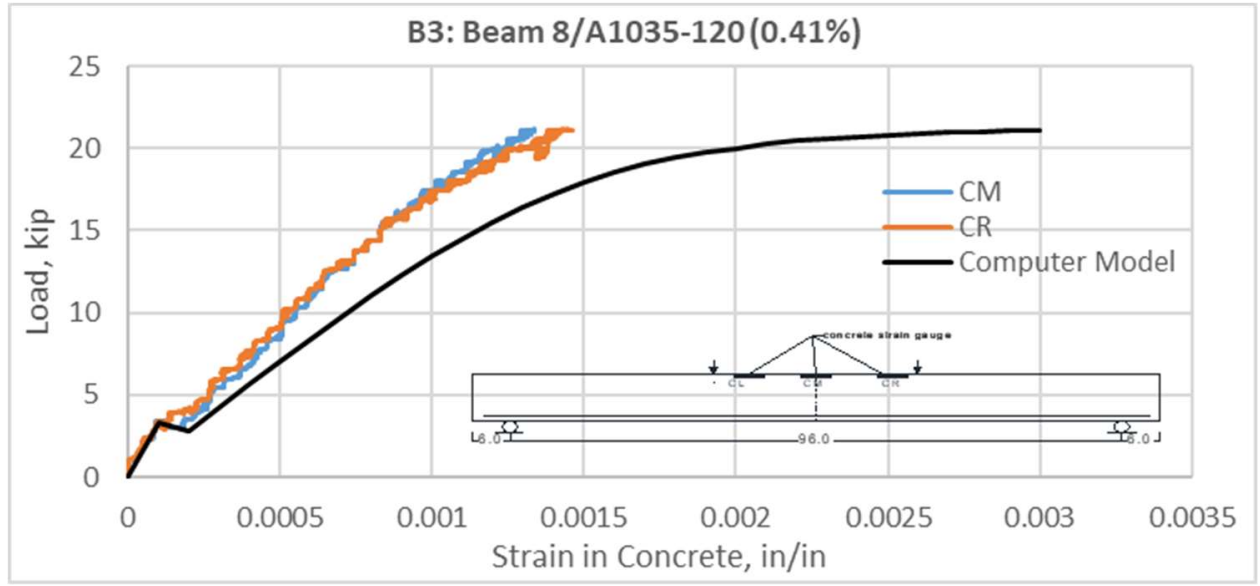

b) Load-concrete strain

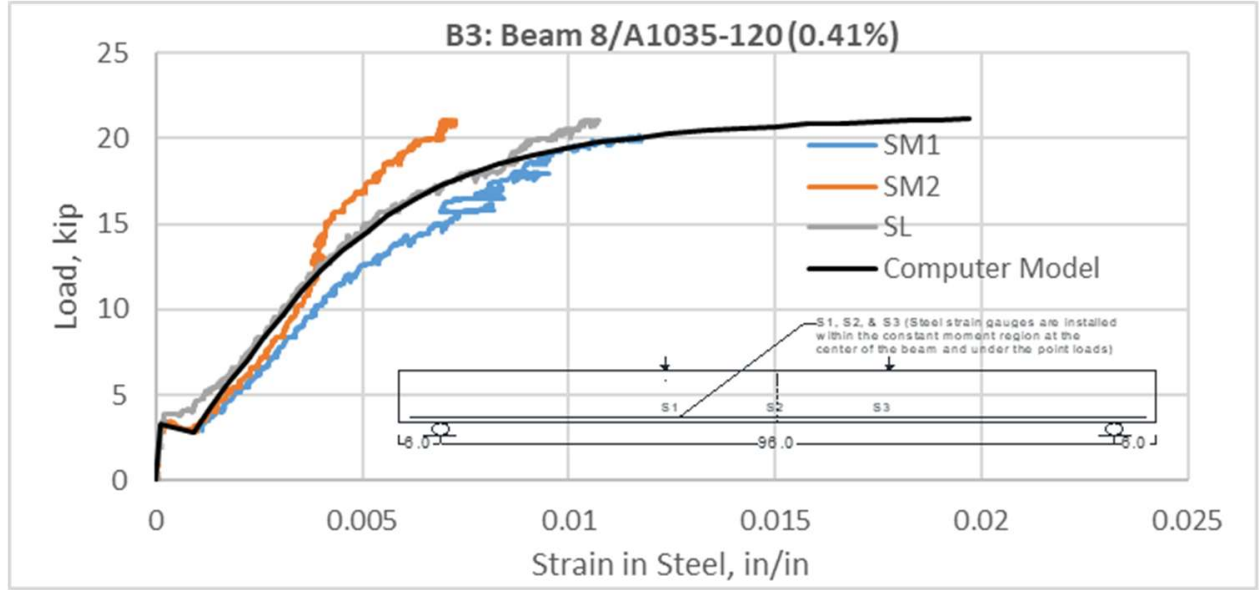

c) Load-steel strain

Figure 5-21: Experimental results of beam 8/A1035-120 (0.41\%) 


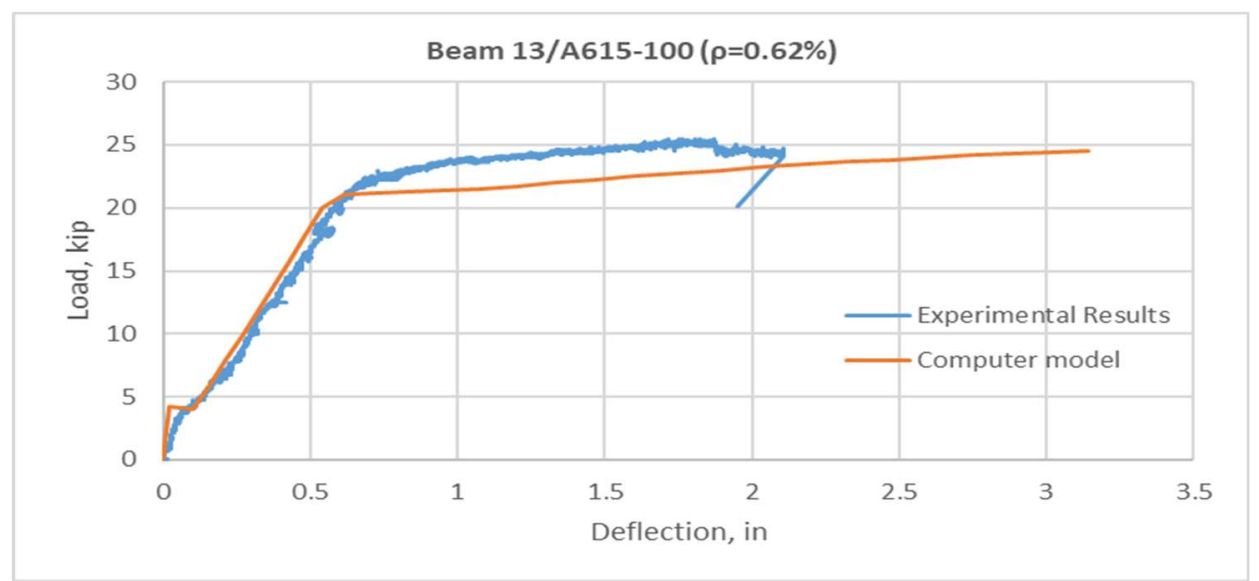

a) Load-midspan deflection

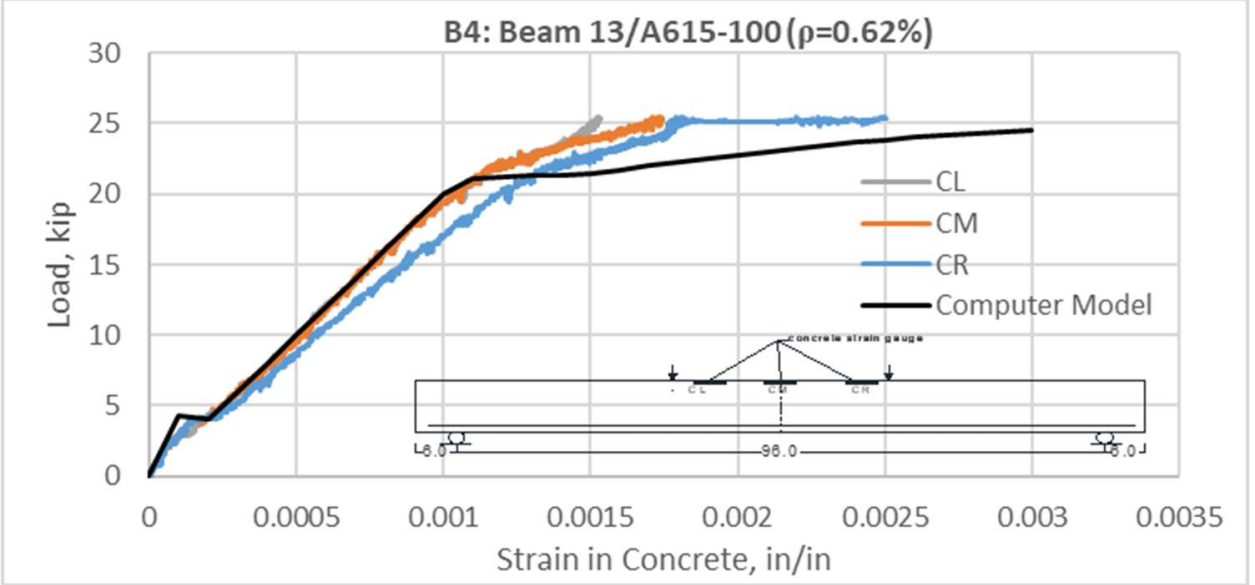

b) Load-concrete strain

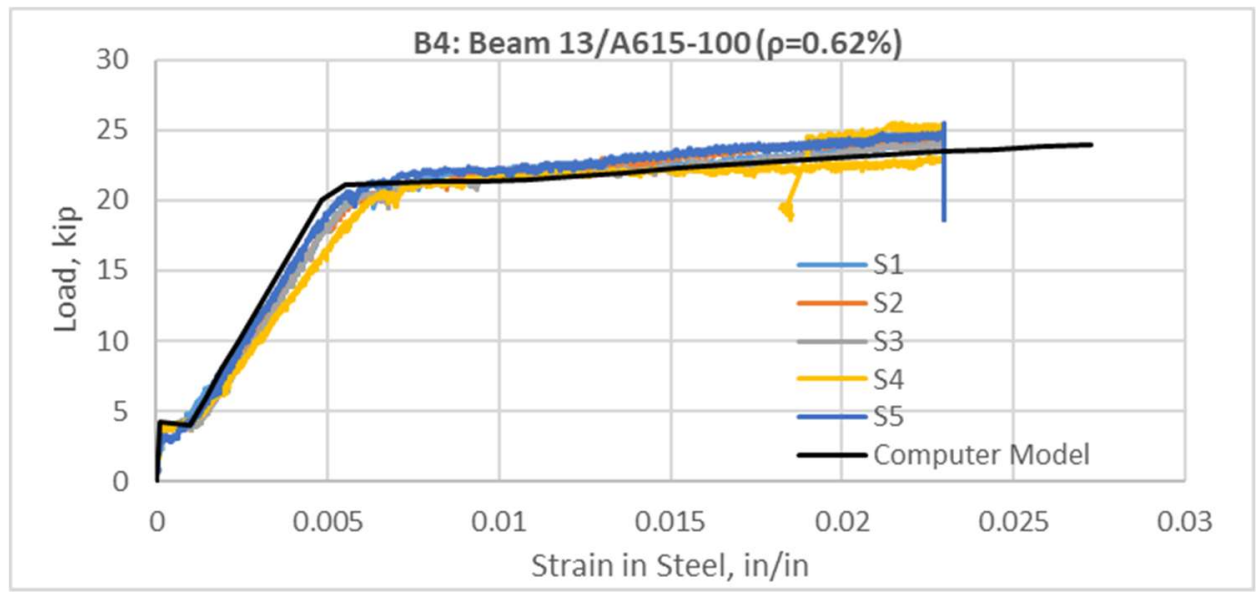

c) Load-steel strain

Figure 5-22: Experimental results of beam 13/A615-100 (0.62\%) 


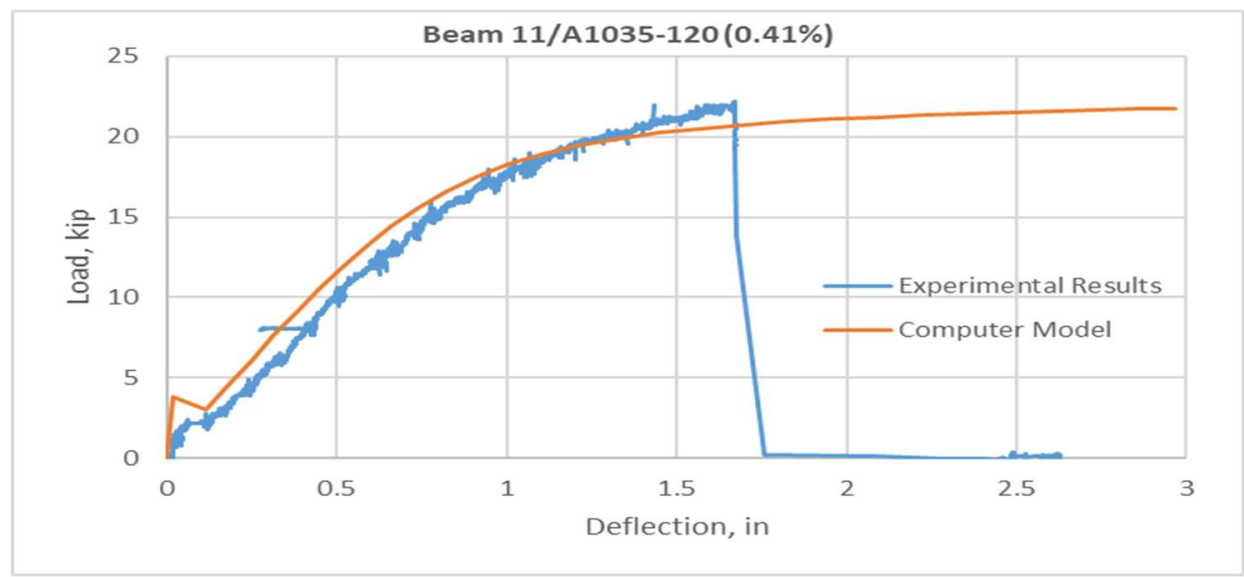

a) Load-midspan deflection

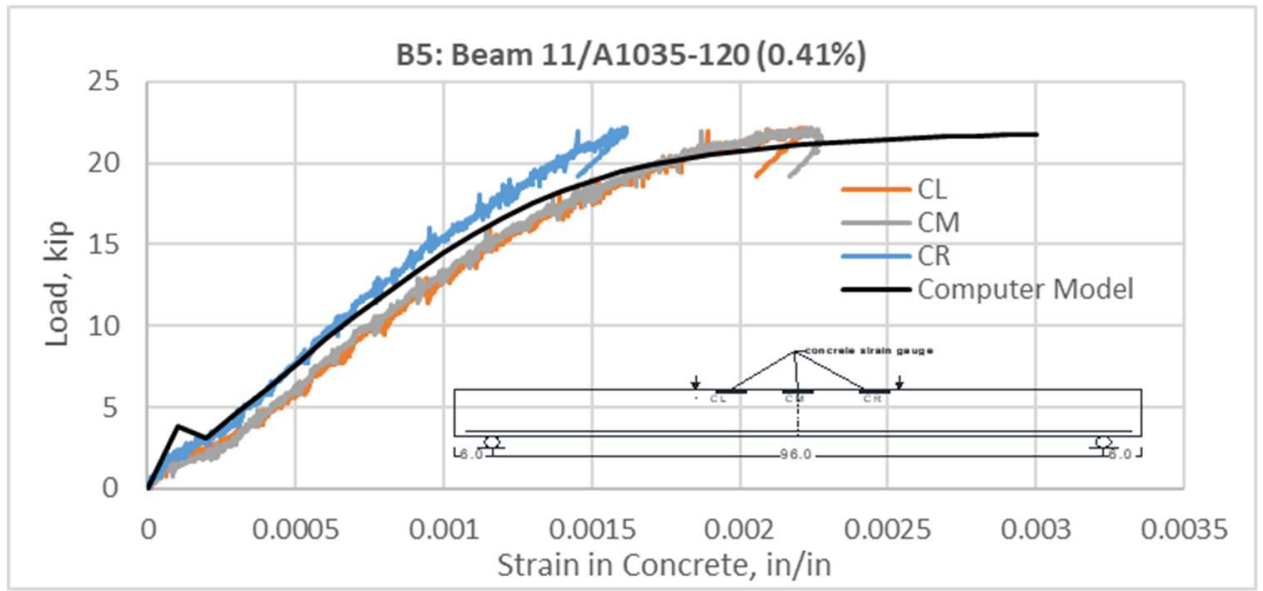

b) Load-concrete strain

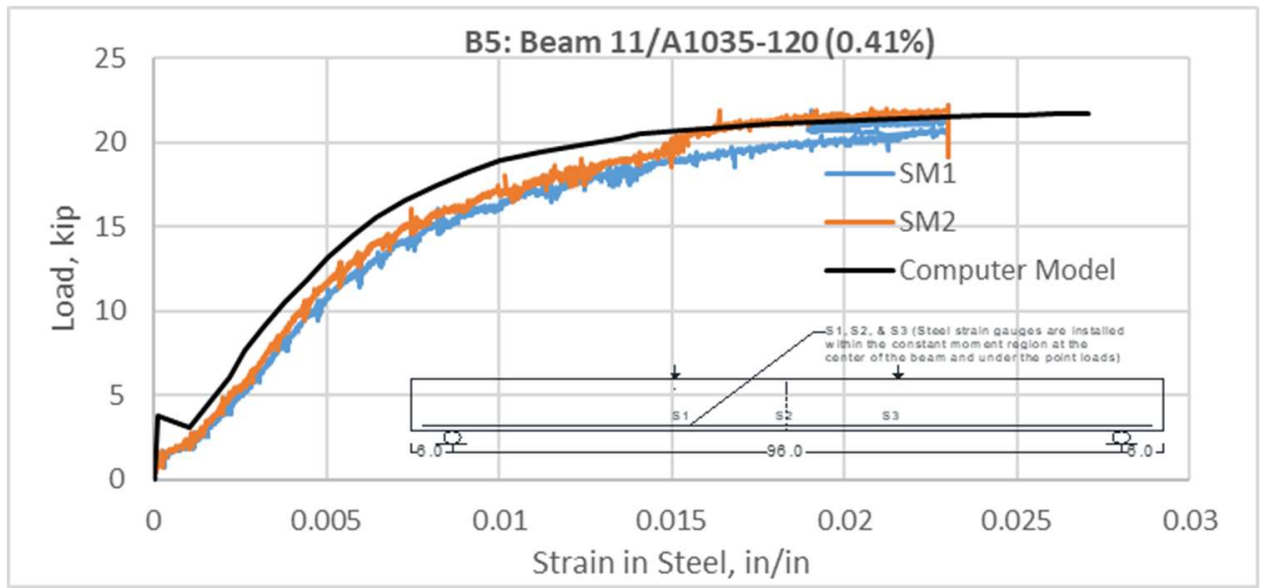

c) Load-steel strain

Figure 5-23: Experimental results of beam 11/A1035-120 (0.41\%) 


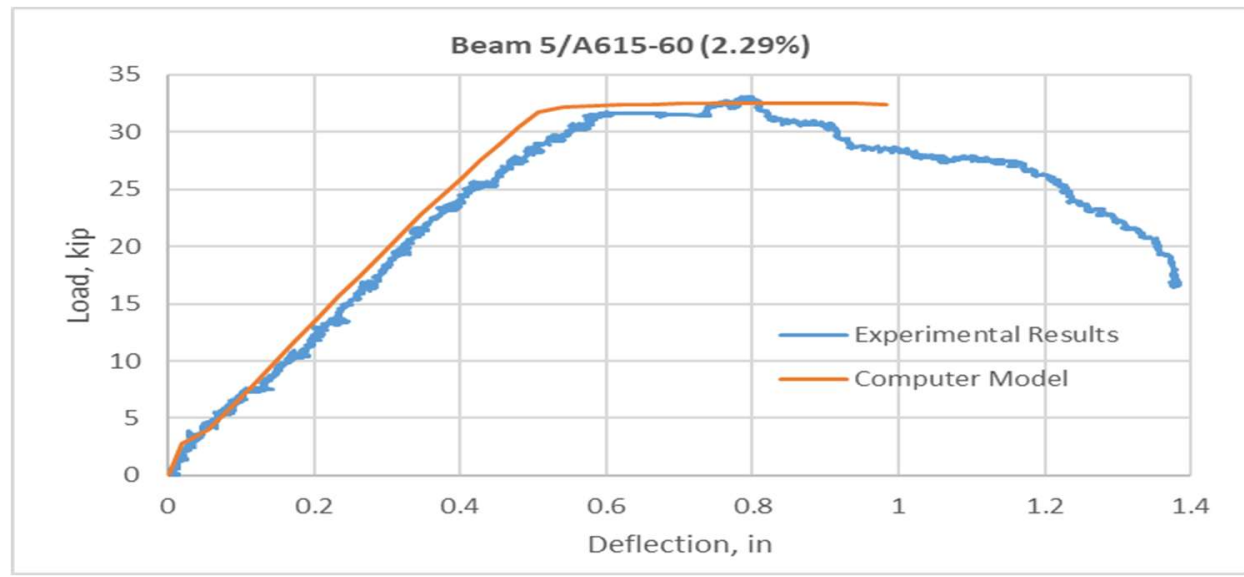

a) Load-midspan deflection

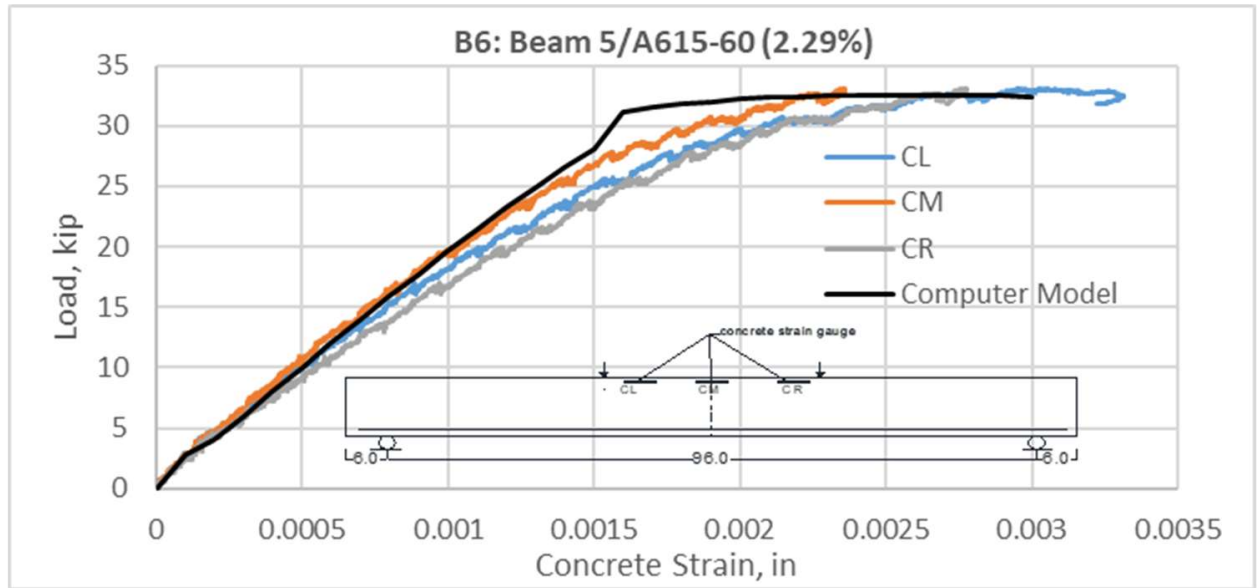

b) Load-concrete strain

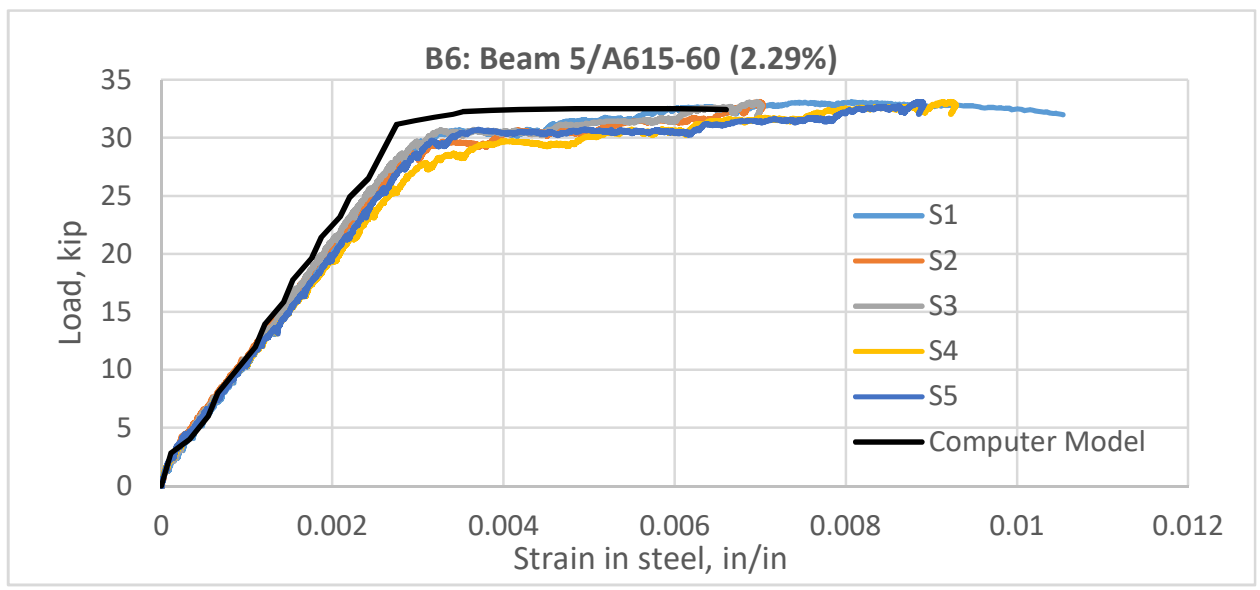

c) Load-steel strain

Figure 5-24: Experimental results of beam 5/A615-60 (2.29\%) 


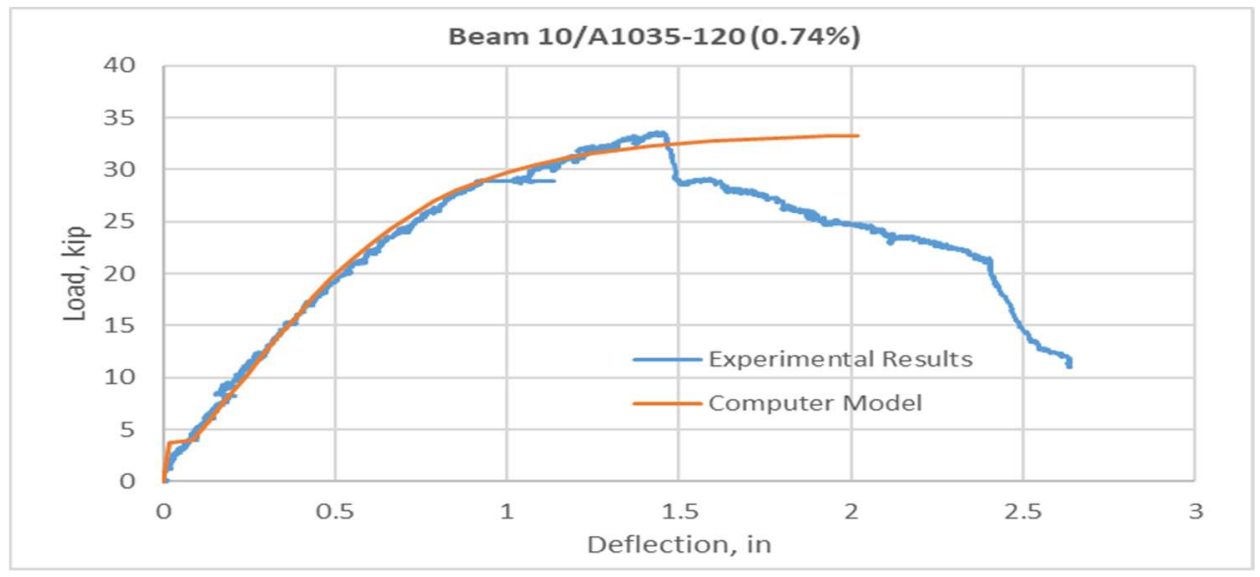

a) Load-midspan deflection

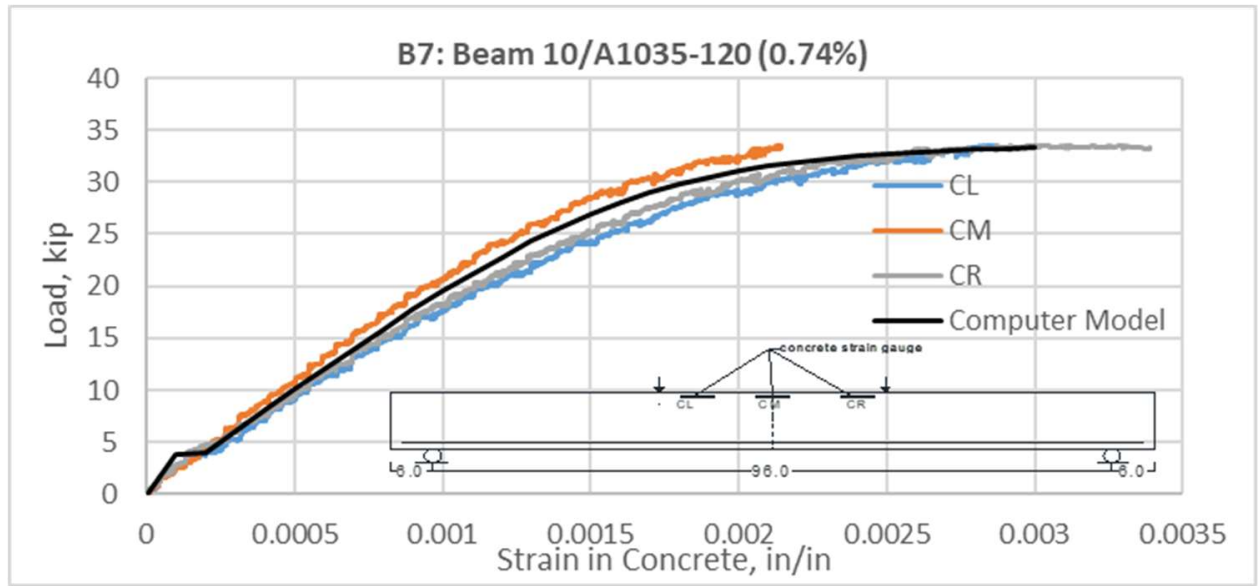

b) Load-concrete strain

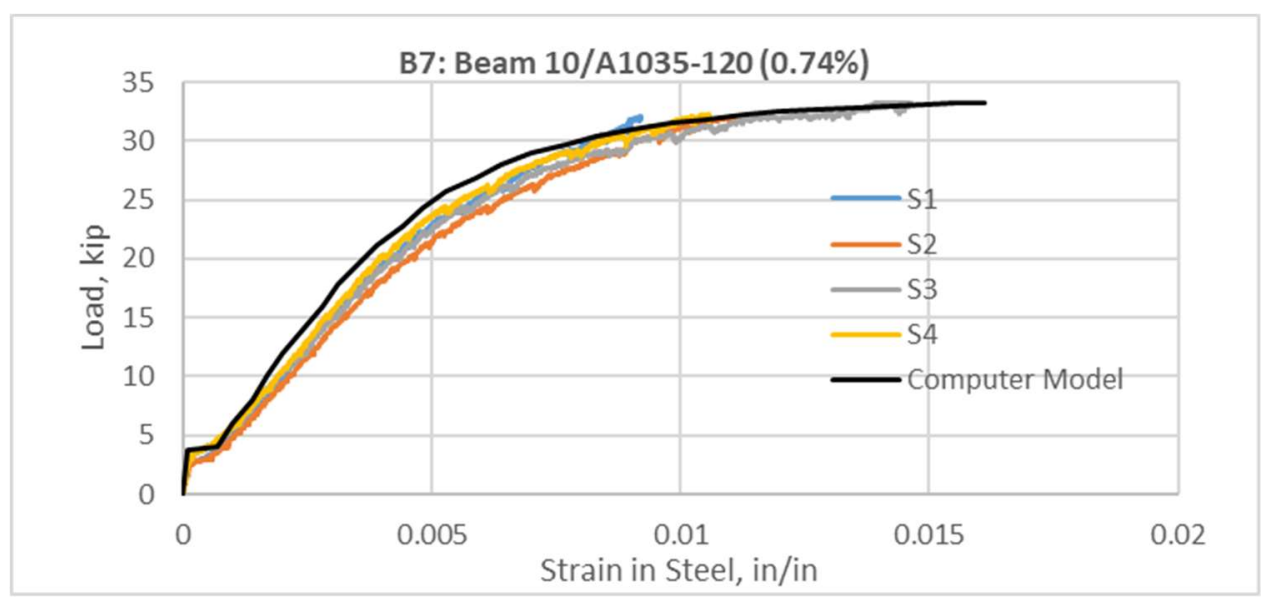

c) Load-steel strain

Figure 5-25: Experimental results of beam 10/A1035-120 (0.74\%) 


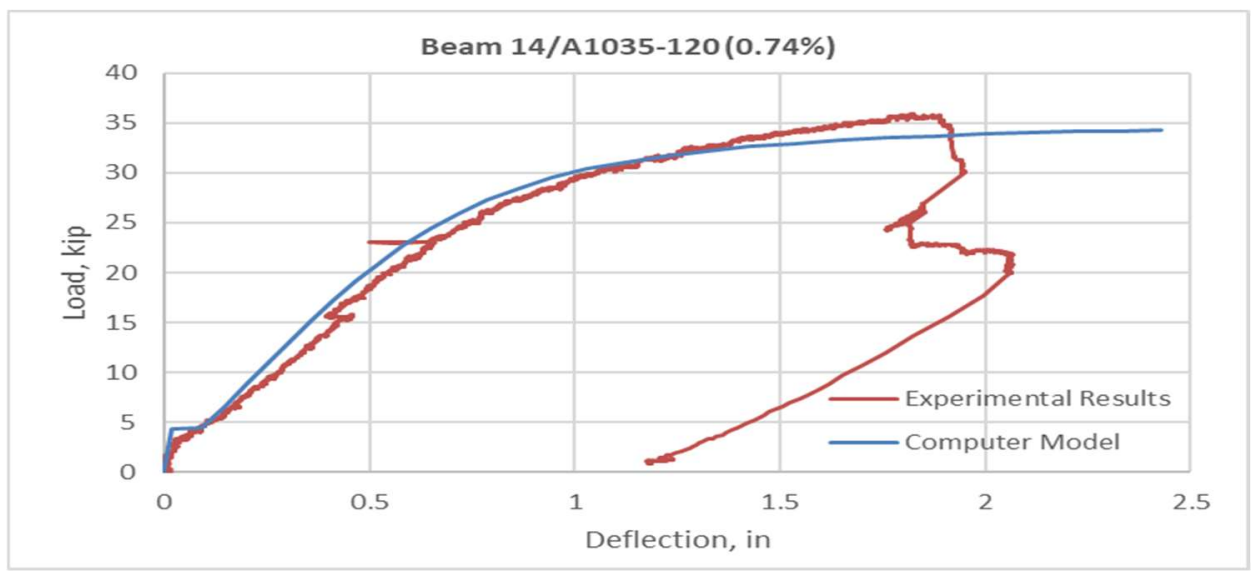

a) Load-midspan deflection

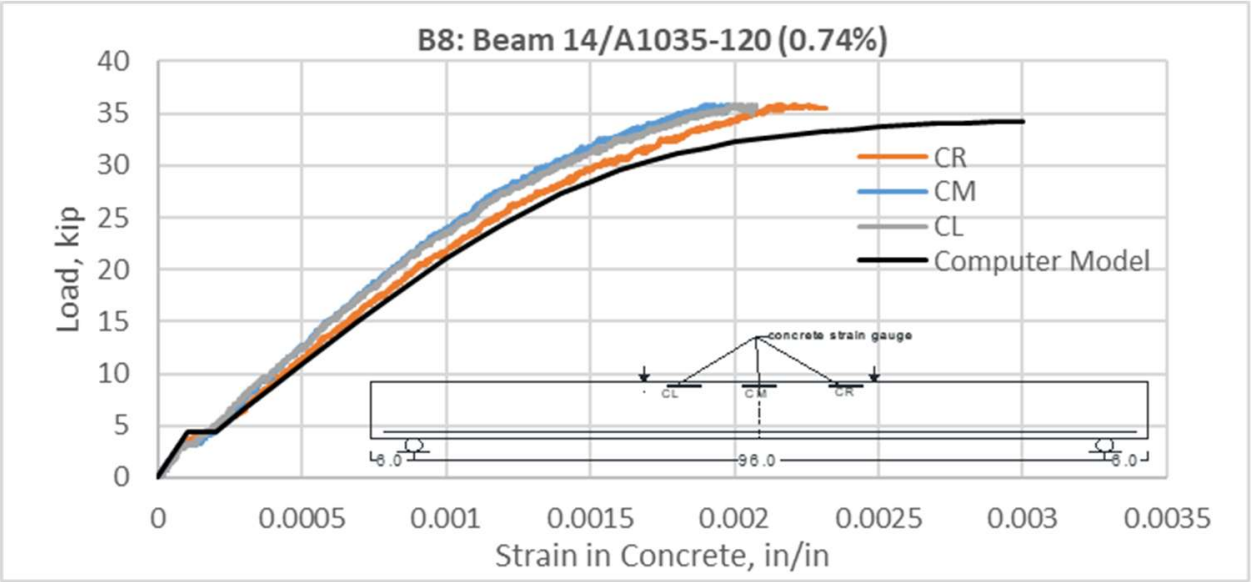

b) Load-concrete strain

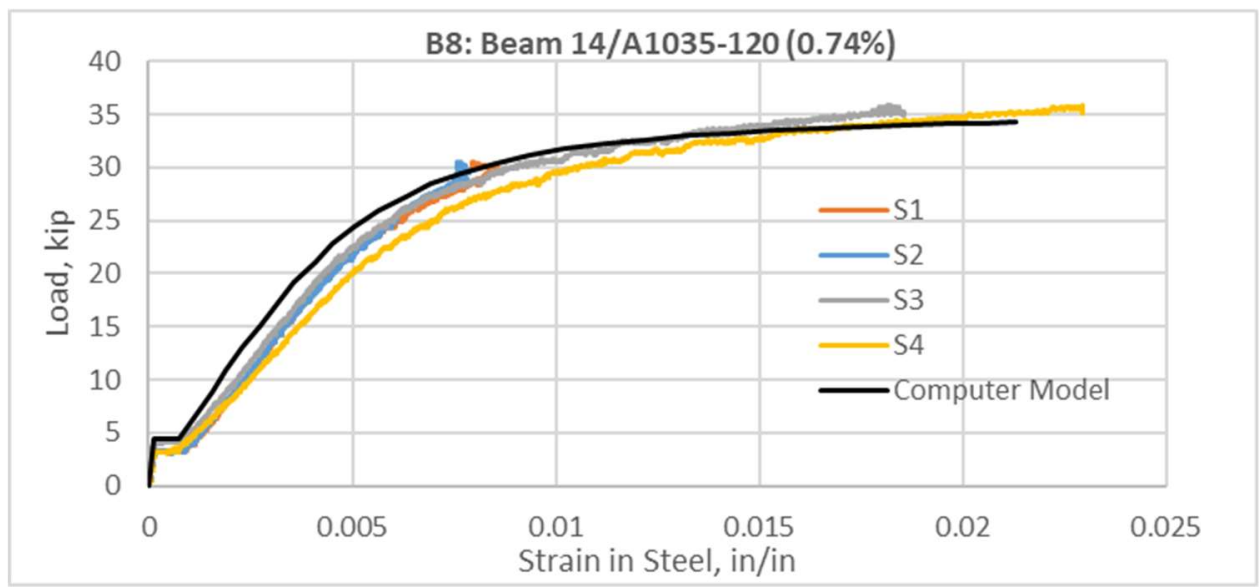

c) Load-steel strain

Figure 5-26: Experimental results of beam 14/A1035-120 (0.74\%) 
For all beams, the predicted analytical load-deflection responses showed a very good agreement with the experimental results, which gives more validity for the written MATLAB code.

It can be noted that for all of the tested specimens reinforced with steel type A615, which has well-defined yield strength and yield plateau, the load-deflection responses started with a linear part until the first crack occurred. The load-deflection responses were then followed by another linear behavior with a reduction in the beam stiffness due to the formation of more cracks until the yielding of tension reinforcement occurred. The latter event was associated with a considerable reduction in the beam stiffness. No more cracks were formed after yielding, however, the existing cracks widened and became deeper due to the shifting of the neutral axis toward the compression face. The specimens continued to maintain the applied load up to failure, which occurred due to the crushing of the concrete near the point load locations.

For the specimens that were reinforced with steel type A1035, the load-deflection responses also started with a linear behavior until the first crack occurred, then a gradual reduction in the stiffness occurred and continued until failure. Two of the tested specimens, beam 8/A1035-120 (0.41\%) and beam 11/A1035-120 (0.41\%), failed due to the rupture of the reinforcement. This type of failure is undesirable, and it could be attributed to the low uniform strain $\left(\varepsilon_{u}=0.0208\right)$ observed from the tensile test of \#3 A1035 Grade 120 bars. Therefore, a minimum allowable uniform strain should be specified for each HSR type to prevent the failure due to reinforcement rapture. However, all test beams reinforced with HSR bars were under-reinforced, therefore, the yielding of 
tensile reinforcement occurred before the crushing of concrete. This was true for all except the two beams reinforced with \#3 A1035 Grade 120 bars, that failed due to rupture of reinforcement.

The maximum recorded strain in the reinforcement for each specimen was compared with the obtained target strains for tension-controlled sections for each type. For all the tested specimens, the target strains were satisfied which attested to the ductile behavior of the beams. The summary of the results is given in Table 5-5. 


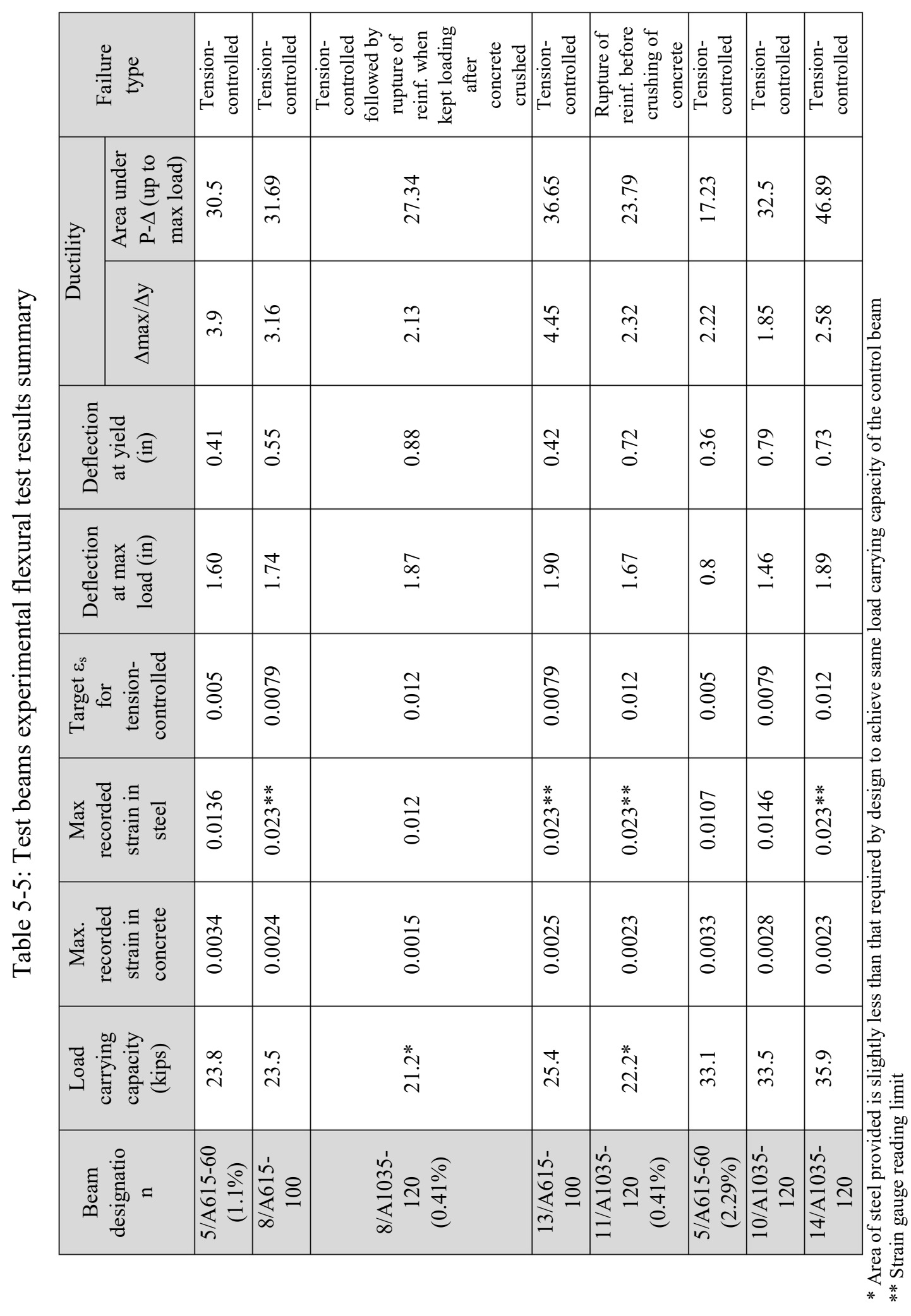


Figure 5-27 and Figure 5-28, show the crack pattern and failure mode for each test beam.
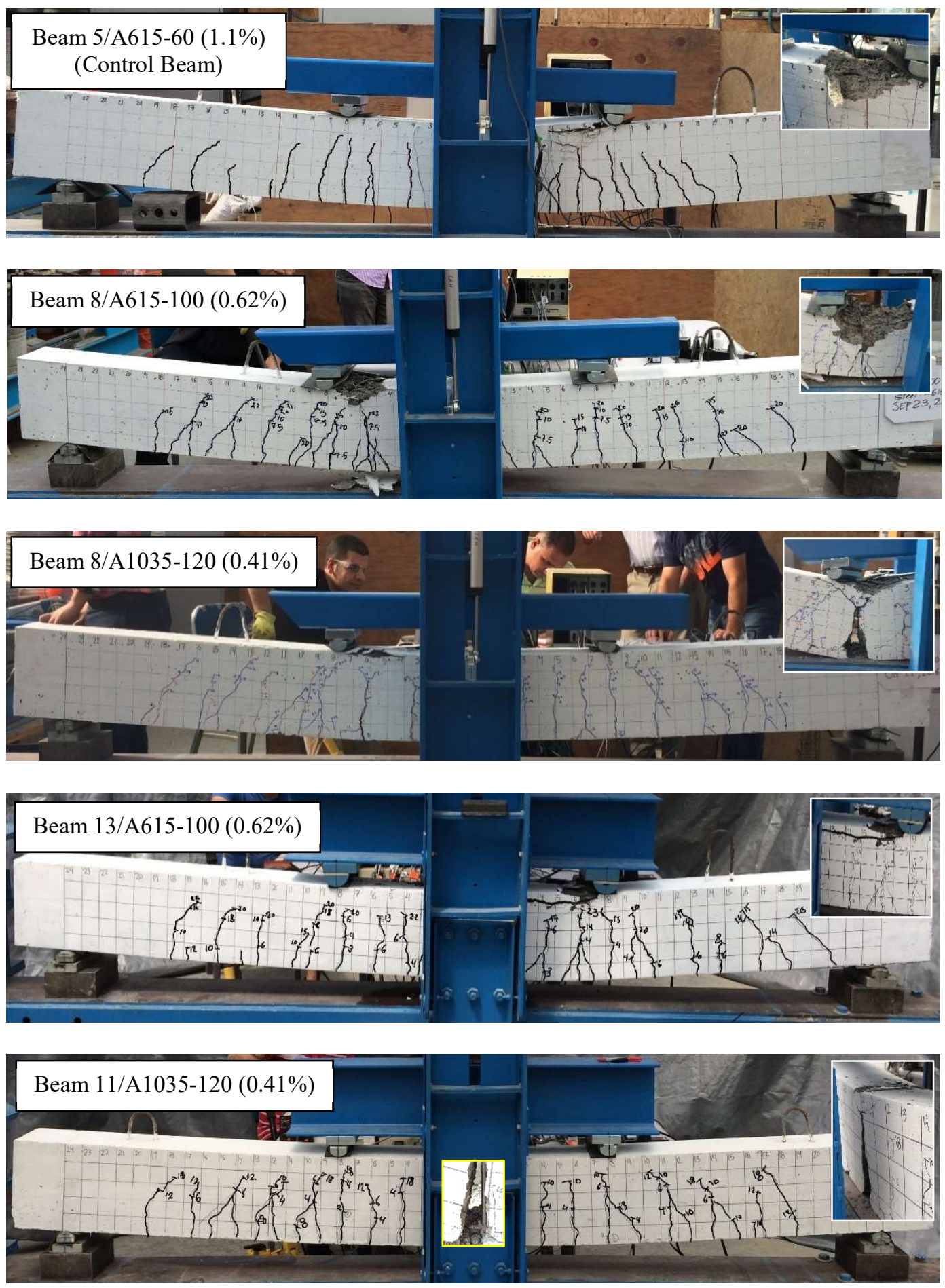

Figure 5-27: Crack pattern and failure mode of the first group of the test beams 

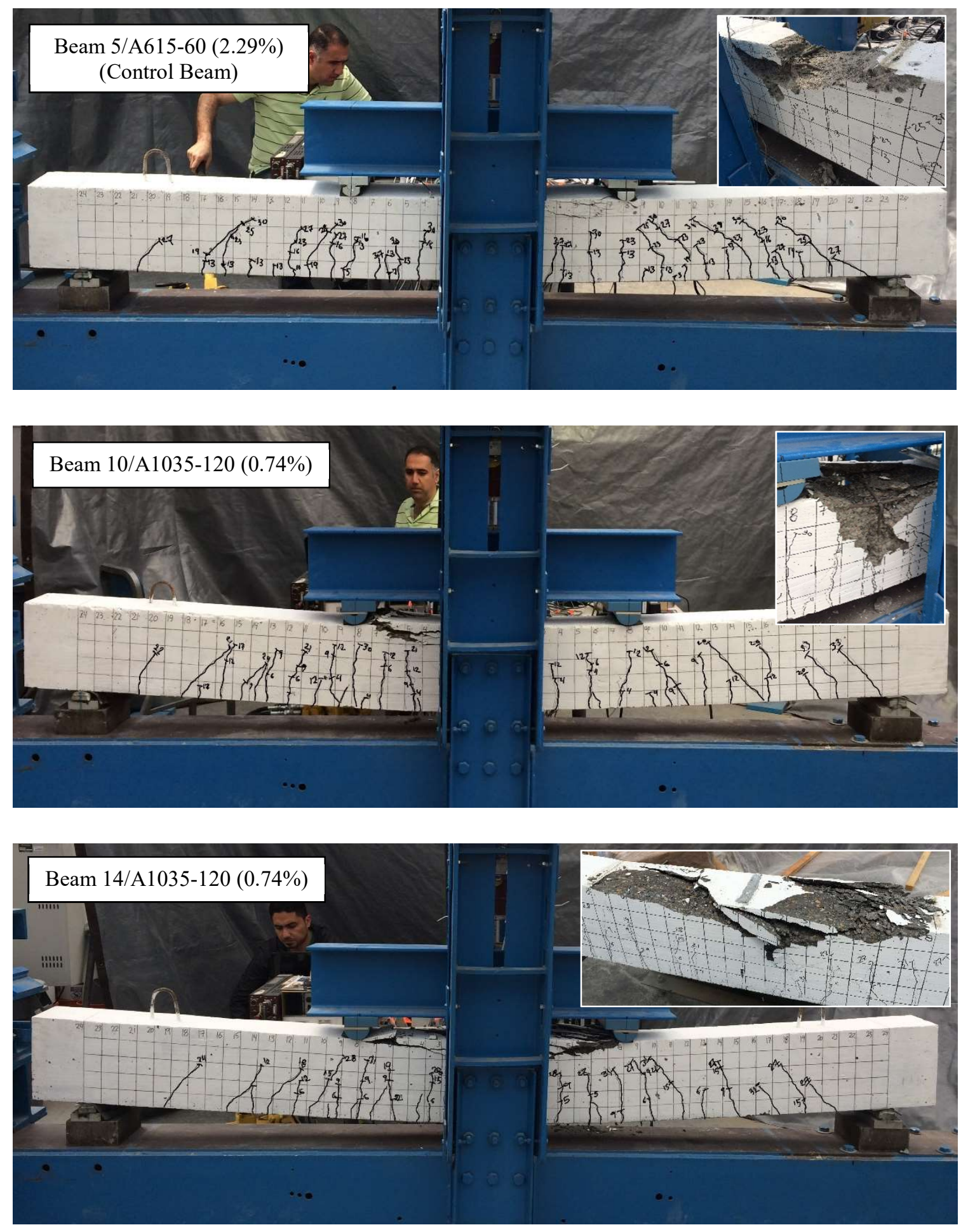

Figure 5-28: Crack pattern and failure mode of the second group of the test beams 
The maximum crack width for each specimen was measured at the service load level, which was assumed to be $60 \%$ of the maximum load. For analytical evaluation, the results were compared with Frosch's (1999) expression for crack width prediction, which is the basis of the current ACI 318 code for limiting crack width. The predictions of maximum crack width for test beams at service loads are presented in Table 5-6.

Table 5-6: Prediction of maximum crack width for test beams at service load level

\begin{tabular}{|c|c|c|c|c|c|c|c|}
\hline Beam designation & $\begin{array}{l}\text { Max } \\
\text { load } \\
\text { (kips) }\end{array}$ & $\begin{array}{c}\text { Service } \\
\text { load } \\
(0.6 * \mathrm{Max} \\
\text { load })\end{array}$ & $\begin{array}{c}\varepsilon_{\mathrm{s}} \text { at } \\
\text { service } \\
\text { load }\end{array}$ & $\begin{array}{c}\mathrm{f}_{\mathrm{s}} \text { at } \\
\text { service } \\
\text { load } \\
(\mathrm{ksi})\end{array}$ & $\begin{array}{c}\text { Maximum } \\
\text { measured } \\
\text { crack } \\
\text { width (in) }\end{array}$ & $\begin{array}{c}\text { Calculated } \\
\text { crack width } \\
\text { using } \\
\text { Frosch's Eq., } \\
1999 \text { (in) }\end{array}$ & $\begin{array}{c}\mathrm{W}_{\text {eq. }} / \mathrm{W} \\
\text { exp. }\end{array}$ \\
\hline 5/A615-60 (1.1\%) & 23.8 & 14.28 & 0.0022 & $\begin{array}{c}58.18 \\
\left(0.83 \mathrm{f}_{\mathrm{y}}\right)\end{array}$ & 0.0073 & 0.0068 & 0.93 \\
\hline $\begin{array}{c}8 / \mathrm{A} 615-100 \\
(0.62 \%)\end{array}$ & 23.5 & 14.1 & 0.0033 & $\begin{array}{c}101 \\
\left(0.83 \mathrm{f}_{\mathrm{y}}\right)\end{array}$ & 0.011 & 0.01 & 0.91 \\
\hline $\begin{array}{l}\text { 8/A1035-120 } \\
\quad(0.41 \%)\end{array}$ & 21.2 & 12.72 & 0.0053 & $\begin{array}{c}137 \\
\left(0.89 f_{y}\right)\end{array}$ & 0.018 & 0.023 & 1.28 \\
\hline $\begin{array}{c}\text { 13/A615-100 } \\
(0.62 \%)\end{array}$ & 25.4 & 15.24 & 0.0042 & $\begin{array}{l}121.6 \\
\left(1.0 \mathrm{f}_{\mathrm{y}}\right)\end{array}$ & 0.0134 & 0.0127 & 0.95 \\
\hline $\begin{array}{c}\text { 11/A } 1035-120 \\
(0.41 \%)\end{array}$ & 22.2 & 13.32 & 0.0064 & $\begin{array}{c}148 \\
\left(0.96 f_{y}\right)\end{array}$ & 0.021 & 0.028 & 1.33 \\
\hline 5/A615-60 (2.29\%) & 33.1 & 19.86 & 0.0021 & $\begin{array}{c}57.7 \\
\left(0.83 \mathrm{f}_{\mathrm{y}}\right)\end{array}$ & 0.0055 & 0.0053 & 0.97 \\
\hline $\begin{array}{c}\text { 10/A } 1035-120 \\
(0.74 \%)\end{array}$ & 33.5 & 20.1 & 0.0042 & $\begin{array}{c}111.7 \\
\left(0.81 f_{y}\right)\end{array}$ & 0.0158 & 0.0152 & 0.96 \\
\hline $\begin{array}{c}\text { 14/A } 1035-120 \\
(0.74 \%)\end{array}$ & 35.9 & 21.54 & 0.0047 & $\begin{array}{c}116.5 \\
\left(0.85 \mathrm{f}_{\mathrm{y}}\right)\end{array}$ & 0.0167 & 0.0183 & 1.10 \\
\hline
\end{tabular}


Additionally, the prediction of the deflection at the service load level was also evaluated for the taking into consideration the effective moment of inertia specified by the current ACI 318 code (Branson's equation), and the expression of Bischoff. Moreover, the deflection resulting from the moment-curvature analysis was included for comparison, as shown in Table 5-7.

Table 5-7: Prediction of maximum deflection at service load level for the test beams

\begin{tabular}{|c|c|c|c|c|c|c|c|c|c|}
\hline \multirow{2}{*}{$\begin{array}{c}\text { Beam } \\
\text { designation }\end{array}$} & \multirow{2}{*}{$\begin{array}{l}\text { Service } \\
\text { load } \\
\text { (kips) }\end{array}$} & \multirow{2}{*}{$\begin{array}{c}\mathrm{f}_{\mathrm{S} \text { at }} \\
\text { service } \\
\text { load } \\
(\mathrm{ksi})\end{array}$} & \multirow{2}{*}{$\begin{array}{l}\Delta_{\text {exp. }} \\
\text { (in) }\end{array}$} & \multicolumn{3}{|c|}{ Calculated deflection (in) } & \multirow{2}{*}{$\begin{array}{c}\Delta_{1} / \Delta \\
\text { exp. }\end{array}$} & \multirow{2}{*}{$\begin{array}{l}\Delta_{2} / \Delta \\
\text { exp. }\end{array}$} & \multirow{2}{*}{$\begin{array}{l}\Delta_{3} / \Delta \\
\text { exp. }\end{array}$} \\
\hline & & & & $\begin{array}{c}I_{e l} \\
\text { (Branson) }\end{array}$ & $\begin{array}{c}I_{e 2} \\
\text { (Bischoff) }\end{array}$ & $\begin{array}{c}M-\varphi \\
\text { analysis }\end{array}$ & & & \\
\hline $\begin{array}{c}\text { 5/A615-60 } \\
(1.1 \%)\end{array}$ & 14.28 & $\begin{array}{c}58.18 \\
\left(0.83 \mathrm{f}_{\mathrm{y}}\right)\end{array}$ & 0.27 & 0.27 & 0.26 & 0.27 & 1.00 & 0.96 & 1.00 \\
\hline $\begin{array}{c}8 / \mathrm{A} 615- \\
100 \\
(0.62 \%) \\
\end{array}$ & 14.1 & $\begin{array}{c}101 \\
\left(0.83 f_{y}\right)\end{array}$ & 0.41 & 0.38 & 0.39 & 0.41 & 0.93 & 0.95 & 1.00 \\
\hline $\begin{array}{c}8 / \mathrm{A} 1035- \\
120 \\
(0.41 \%)\end{array}$ & 12.72 & $\begin{array}{c}137 \\
\left(0.89 f_{\mathrm{y}}\right)\end{array}$ & 0.61 & 0.44 & 0.48 & 0.57 & 0.72 & 0.79 & 0.93 \\
\hline $\begin{array}{c}13 / \mathrm{A} 615- \\
100 \\
(0.62 \%)\end{array}$ & 15.24 & $\begin{array}{c}121.6 \\
\left(1.0 f_{\mathrm{y}}\right)\end{array}$ & 0.44 & 0.36 & 0.39 & 0.41 & 0.82 & 0.89 & 0.93 \\
\hline $\begin{array}{c}11 / \mathrm{A} 1035- \\
120 \\
(0.41 \%)\end{array}$ & 13.32 & $\begin{array}{c}148 \\
\left(0.96 f_{y}\right)\end{array}$ & 0.69 & 0.41 & 0.48 & 0.59 & 0.59 & 0.70 & 0.86 \\
\hline $\begin{array}{c}5 / \mathrm{A} 615-60 \\
(2.29 \%) \\
\end{array}$ & 19.86 & $\begin{array}{c}57.7 \\
\left(0.83 f_{y}\right)\end{array}$ & 0.32 & 0.30 & 0.30 & 0.30 & 0.94 & 0.94 & 0.94 \\
\hline $\begin{array}{c}10 / \mathrm{A} 1035- \\
120 \\
(0.74 \%)\end{array}$ & 20.1 & $\begin{array}{c}111.7 \\
\left(0.81 f_{\mathrm{y}}\right)\end{array}$ & 0.54 & 0.45 & 0.46 & 0.51 & 0.83 & 0.85 & 0.94 \\
\hline $\begin{array}{c}14 / \mathrm{A} 1035- \\
120 \\
(0.74 \%)\end{array}$ & 21.54 & $\begin{array}{c}116.5 \\
\left(0.85 \mathrm{f}_{\mathrm{y}}\right)\end{array}$ & 0.60 & 0.47 & 0.47 & 0.54 & 0.78 & 0.78 & 0.90 \\
\hline
\end{tabular}




\subsubsection{Discussion of Results}

To evaluate the flexural behavior of the tested beams made with HSC and HSR, beams' behavior and results were compared in terms of ductility, maximum crack width at the service load level, and service load deflection.

\subsubsection{Ductility}

The ductility of the test beams was defined based on a deflection index rather than a curvature index, as the midspan deflection was monitored continuously during the tests. Two ductility definitions were explored here: Deflection ductility index $\mu_{\mathrm{d}}$, which is defined as the ratio of the maximum deflection of the beam to the deflection at yielding of the longitudinal tensile reinforcement $\left(\Delta_{\mathrm{u}} / \Delta_{\mathrm{y}}\right)$, and the energy dissipation index, which is defined as the area under the load-deflection curve up to maximum load.

From Table 5-5 showed the results of ductility for beam 8/A615-100 (0.62\%) with the control beam 5/A615-60 (1.1\%). It can be noted that the deflection ductility index and the energy dissipation index for beam 8/A615-100 (0.62\%) is about $81 \%$ and $103 \%$ respectively of that of the control beam. The ductility of this beam was considered comparable to that of the control beam, however, theoretically the ductility for beam 8/A615-100 (0.62\%) was expected to be even higher. The reason for less ductility could be attributed to the mechanical properties of high-strength concrete, which tends to be more sensitive to "load-control" testing procedure, i.e., the ultimate strain may not have reached 0.003 or higher. The maximum recorded strain in the concrete for beam 8/A615- 
$100(0.62 \%)$ was 0.0024 . It has been shown by many researchers that the ultimate concrete strain of HSC varies from 0.002 to 0.004 .

When the same beam 8/A615-100 (0.62\%) was made with a higher concrete strength, which is represented by the behavior of beam 13/A615-100 (0.62\%), the ductility was significantly increased and exceeded that of the control beam 5/A615-60 (1.1\%) by about $114 \%$ and $120 \%$ for the deflection ductility index and the energy dissipation index respectively, even though the maximum recorded concrete strain $(0.0025)$ was also less than 0.003 . Therefore, increasing the concrete strength resulted in increasing the ductility within the range considered as it will allow for more stress to be induced in the reinforcement. This observation can also be made with the second group of beams. The ductility of beams 10/A1035-120 (0.47\%) and 14/A1035-120 (0.74\%) showed comparable ductility to that of the control beam 5/A615-60 (2.29\%). The deflection ductility indexes for beams 10/A1035-120 (0.47\%) and 14/A1035-120 (0.47\%) compared to that of the control beam 5/A615-60 (2.29\%) were $83 \%$ and $116 \%$ respectively, and the energy dissipation indices compared to that of the control beam 5/A615-60 (2.29\%) were $188 \%$ and $272 \%$ respectively. This shows the effectiveness of coupling HSR with HSC for beams designed to improve flexural ductility. Once again, it can be noted that the ductility increased with increasing the concrete strength. The maximum recorded strain in concrete was also less than 0.003 . The strain of 0.0028 and 0.0023 was the maximum recorded strain for beam 10/A1035-120 (0.47\%) and beam 14/A1035-120 (0.74\%) respectively. 
Two of the tested beams, however, did not exhibit the desired ductility. Those were beam 8/A1035-120 (0.41\%) and beam 11/A1035-120 (0.41\%). They failed due to the rupture of their reinforcement. The reason for that could be attributed to the mechanical properties of the reinforcement used for these two beams, which had a low maximum uniform strain of only 0.0208 . This caused the reinforcement to rupture before the concrete crushed.

On the other hand, the strain in the tension reinforcement for all the tested beams exceeded the determined target strains for minimum required ductility, as illustrated in Table 5-5. Furthermore, well before failure, all beams made with HSC and HSR showed visual signs of a ductile behavior by showing a noticeable deflection and a series of extensive cracks. In tested beams, there was no evidence of lack of visible ductility when using HSC in beams with HSR.

Finally, it can be also seen from the results of ductility of the first group of the tested beams (Table 5-4) that use of high strength reinforcement with a defined yield strength and yield plateau (A615 Grade 100) would result in a higher ductility than that of the beams reinforced with high strength reinforcement of a roundhouse behavior (A1035

Grade 120). However, the saving in the reinforcement amount was greater with the use of HSR type A1035.

\subsubsection{Crack Pattern and Maximum Crack Width}

All beams failed in flexure as they were designed to do. The first cracks started at the constant moment region and continued to propagate as the applied load was increased. 
Cracks then started to appear outside of the constant moment region. At high load levels no more flexural cracks were formed, but the existing cracks continued to widen as the beams increasingly deflected, and a few diagonal flexural shear cracks started in the constant shear regions. For the second group of beams, shear cracks began to appear at a 45-degree angle near the supports at approximately $80 \%$ of the ultimate loads. All tested beams in the first and second groups showed a similar crack pattern, as shown in Figure 5-27 and Figure 5-28.

To assess the effect of designing beams with HSC and HSR, crack widths were measured during the tests and the maximum crack widths at service load levels were compared with that of the control beams, as summarized in Figure 5-27 and Figure 5-28, show the crack pattern and failure mode for each test beam.

The maximum crack width for each specimen was measured at the service load level, which was assumed to be $60 \%$ of the maximum load. For analytical evaluation, the results were compared with Frosch's (1999) expression for crack width prediction, which is the basis of the current ACI 318 code for limiting crack width. The predictions of maximum crack width for test beams at service loads are presented in Table 5-6. 
Table 5-6. It may be observed from the results that the crack widths were wider for the beams made with HSC and HSR as compared to the beams made with conventional materials. The reason is that crack width is a function of steel strain and consequently steel stress, and clearly, the stress in the reinforcement at service load level was higher when using HSR.

For beams of same reinforcement type and same reinforcement ratio, the results indicated that the maximum crack width increases as the concrete strength increased. This is basically due to the higher stress level at service load for beams with higher concrete strength.

Most importantly, the measured crack widths for all tested beams with HSR under service load level were within the generally acceptable maximum crack width of 0.018 in. (Harries et at., 2012) except for beam 11/A1035-120 (0.41\%), where the maximum measured crack width was $0.021 \mathrm{in}$. Moreover, the considered service load level of $60 \%$ of the ultimate load (based on $\mathrm{f}_{\mathrm{u}}$ ) for all tested beams resulted in stress level in the reinforcement that was higher than $0.67 f_{y}$, as prescribed by ACI 318 code for conventional steel.

In this study, crack width prediction using Frosch's expression (section 2.7.2) was also evaluated as shown in Figure 5-27 and Figure 5-28, show the crack pattern and failure mode for each test beam. 
The maximum crack width for each specimen was measured at the service load level, which was assumed to be $60 \%$ of the maximum load. For analytical evaluation, the results were compared with Frosch's (1999) expression for crack width prediction, which is the basis of the current ACI 318 code for limiting crack width. The predictions of maximum crack width for test beams at service loads are presented in Table 5-6.

Table 5-6. The results of the maximum crack width prediction agreed very well with the measured ones. The ratio of the predicted to the measured maximum crack width for all beams were within $10 \%$ error except for beam 8/A1035-120 (0.41\%) and beam 11/A1035-120 (0.41\%) where the error was within $25 \%$. The reason could be due to the fact that the stress in the reinforcement exceeded the stress-strain curve proportional limit (i.e., $\varepsilon_{s}=f_{s} / E_{s}$ ) of the reinforcement, and Frosch's expression was derived for reinforcement stress within the proportional limit.

\subsubsection{Immediate Deflection at Service Load Level}

To evaluate the implication of designing beams with HSC and HSR on the immediate deflection at service loading state, the results of the load-deflection behaviors of the tested beams were plotted together for each group as shown in Figure 5-29. It may be seen that the stiffness of the beams made with HSC and HSR was reduced compared to that of the control beams made with conventional materials. The reason is that the design 
with high-strength materials required less area of steel to satisfy the design capacity. Thus, the serviceability limit states are more often the critical design consideration when using high strength materials in reinforced concrete beams. Therefore, reliable models for estimating the deflection at service level are essential. The elastic method of beams was used to predict the deflection at the service load level by utilizing the effective moment of inertia expressions of both Branson and Bischoff to account for the member stiffness. The midspan deflections using the elastic beam method and associated with the applied twopoint loading are calculated as:

$$
\Delta=\frac{M_{\text {service }}}{24 E_{c} I_{e}}\left(3 L^{2}-4 a^{2}\right),
$$

where $a=$ Distance between the support and the point load

As shown in Table 5-7, the use of both $I_{e}$ expressions gives a very close estimation for the deflection of the control beams, and for the beams with HSR type A615 that have a defined yield stress and yield plateau. For the beams made with HSR type A1035 of the roundhouse behavior, the use of the elastic method utilizing both $I_{e}$ expressions underestimated the deflection. For the beams reinforced with HSR type A1035, the comparison of measured initial deflections with predictions based on elastic method given in Table 5-7, indicated that the ratio of predicted to measured deflections ranged from 0.59 to 0.83 using Branson's expression and 0.7 to 0.85 using Bischoff's expression. Therefore, the use of Bischoff's expression of the effective moment of inertia resulted in better predictions for the initial deflection of beams. 
Moreover, for beams 8/A1035-120 (0.41\%) and 11/A1035-120 (0.41\%), which have very low reinforcement ratio $(\rho=0.41 \%$ ), use of Bischoff's expression gives better deflection predictions than Branson's, as illustrated in Table 5-7. Both expressions gave the same deflection predictions for beams 10/A1035-120 (0.74\%) and 10/A1035-120 (0.74\%) of higher reinforcement ratio $(\rho=0.74 \%)$.

The explanation for the underestimation for the deflection of the beams reinforced with HSR type A1035-120 of the roundhouse behavior is that the elastic method for deflection prediction works well only for the service load level that leads to a stress in the tension reinforcement within the linear elastic part of its stress-strain curve. In this study, the service load resulted in a stress in the reinforcement that exceeded the proportional limit (i.e. the linear part of the stress-strain curve) as shown in Figure 5-30.

For conventional steel, service load stress is normally estimated as about $.67 \mathrm{f}_{\mathrm{y}}$ because the design capacity is based on $f_{y}$. However, this was not the case with the beams made with HSR because their design was based on the ultimate stress $f_{u}$ not $f_{y}$. As a result, the service load stress the linear part of the stress-strain curve. 


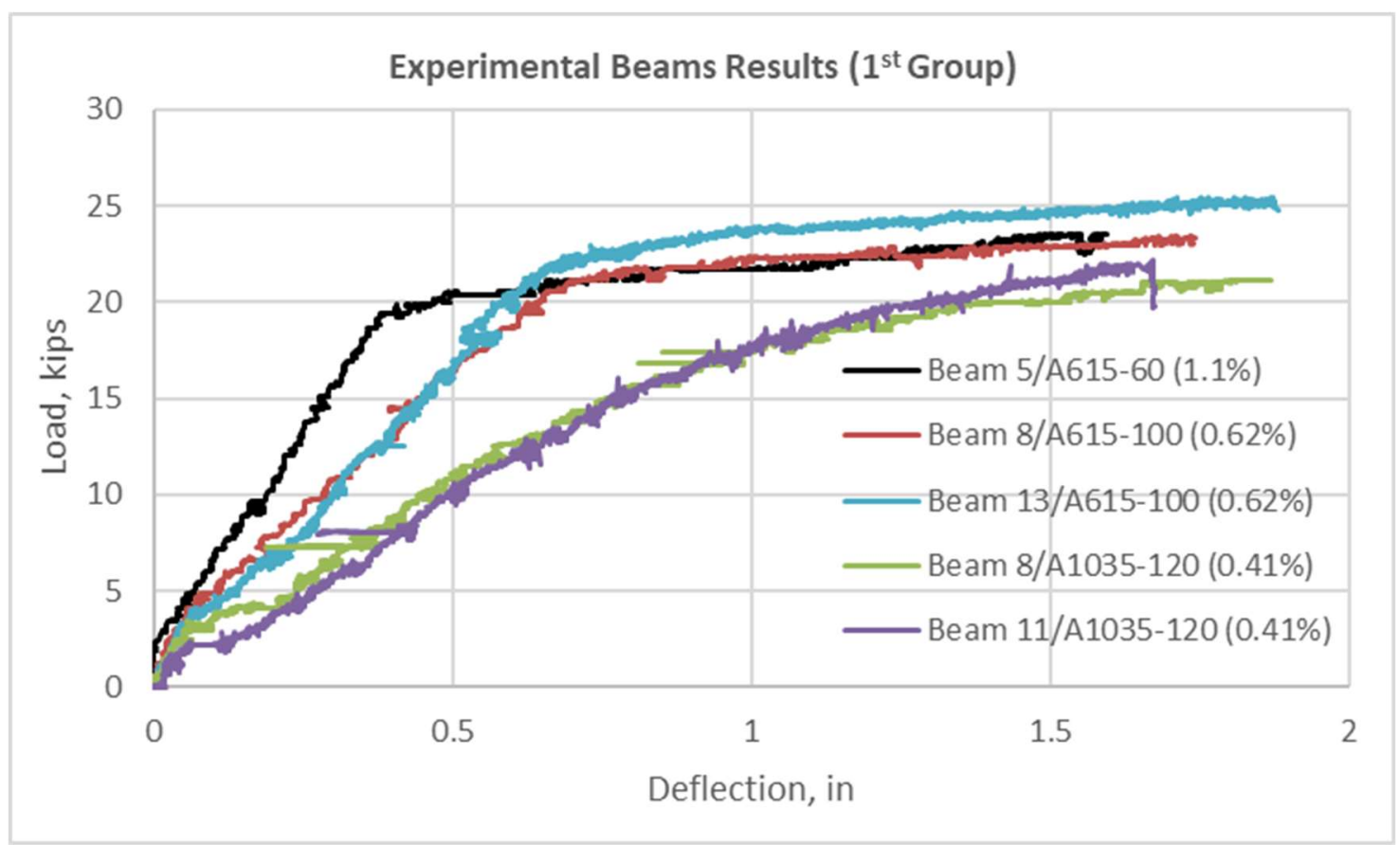

a) Experimental load-deflection results of the $1^{\text {st }}$ group

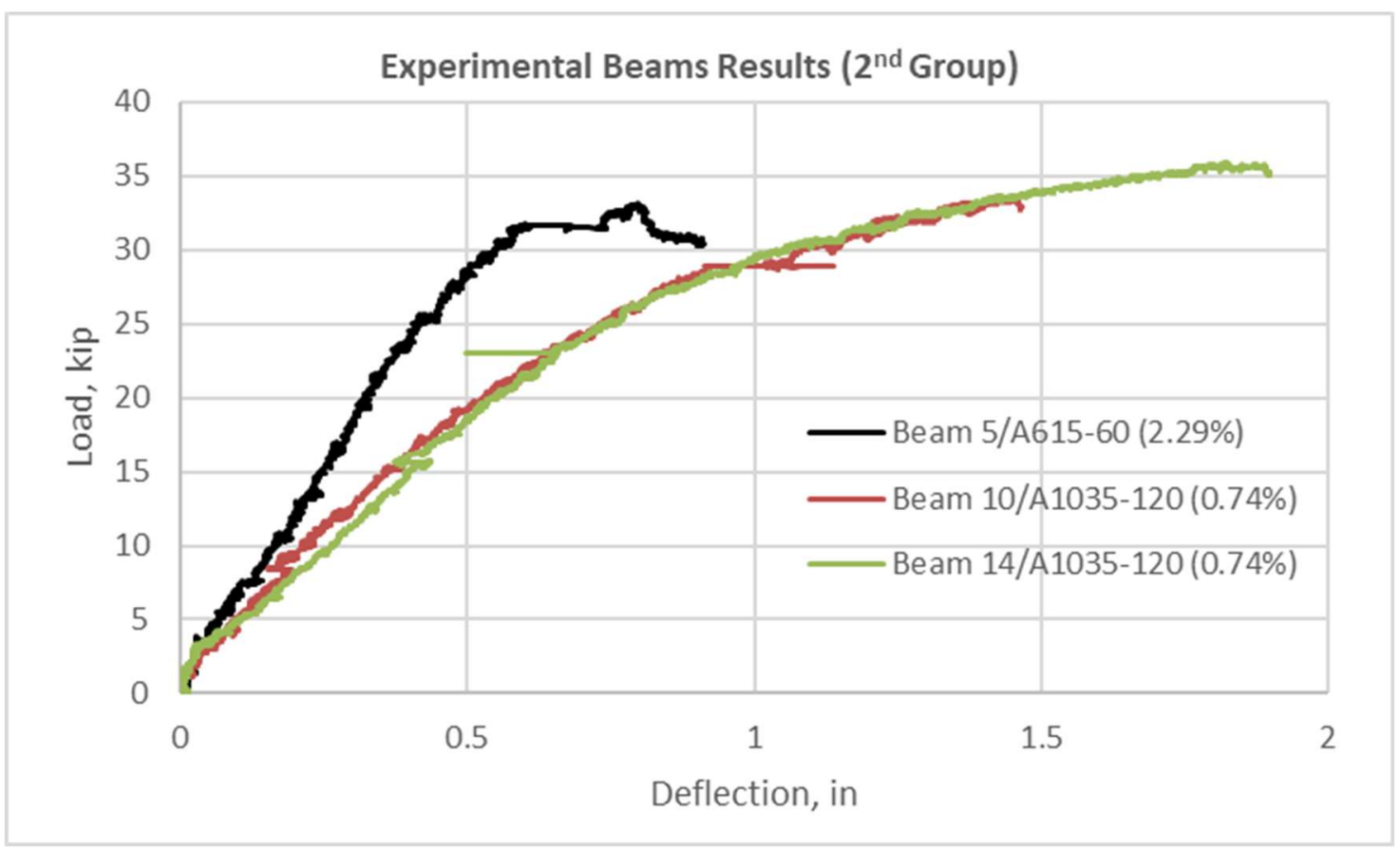

b) Experimental load-deflection results of the $2^{\text {nd }}$ group

Figure 5-29: Load-deflection response of tested beams 


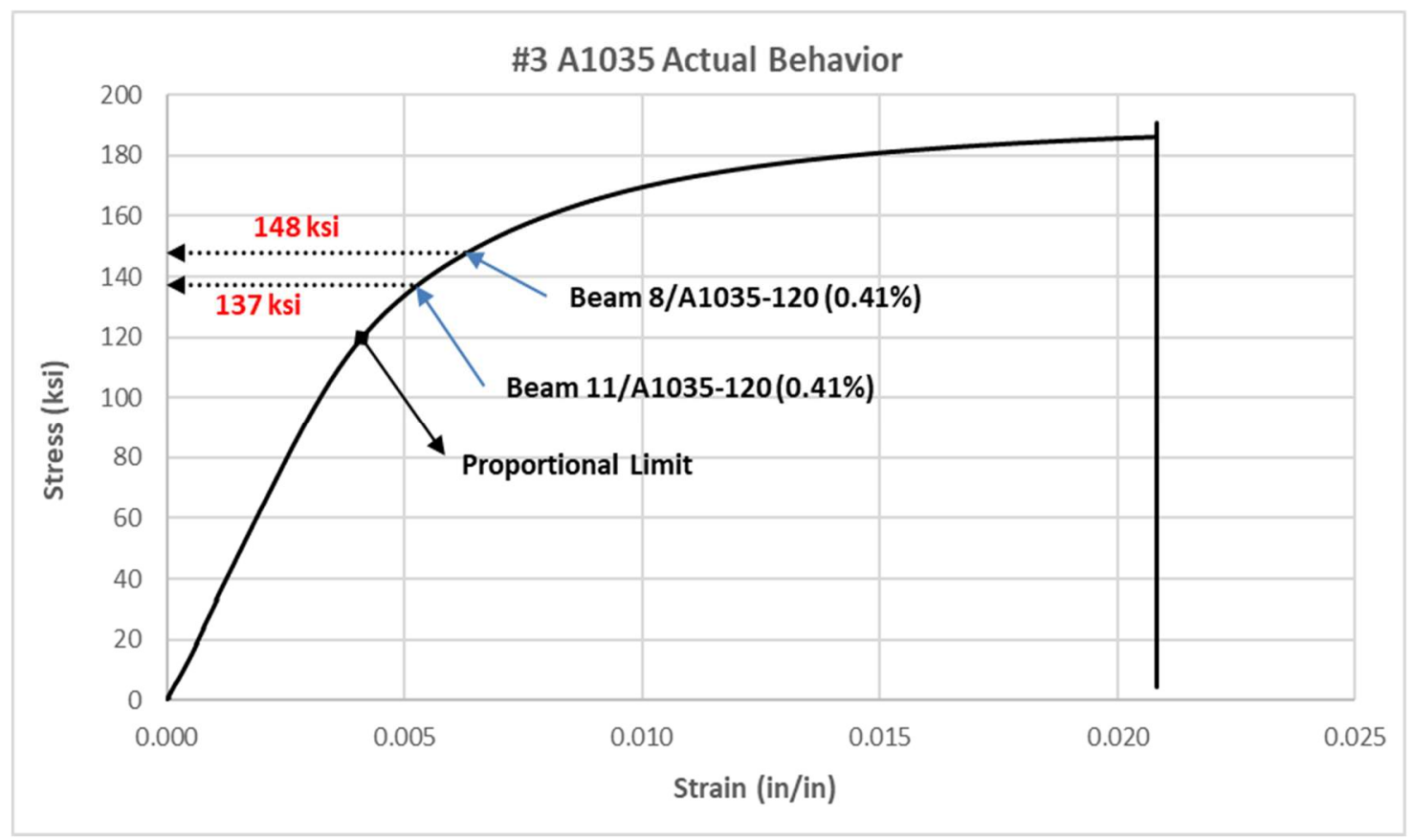

a) $\rho=0.41 \%$

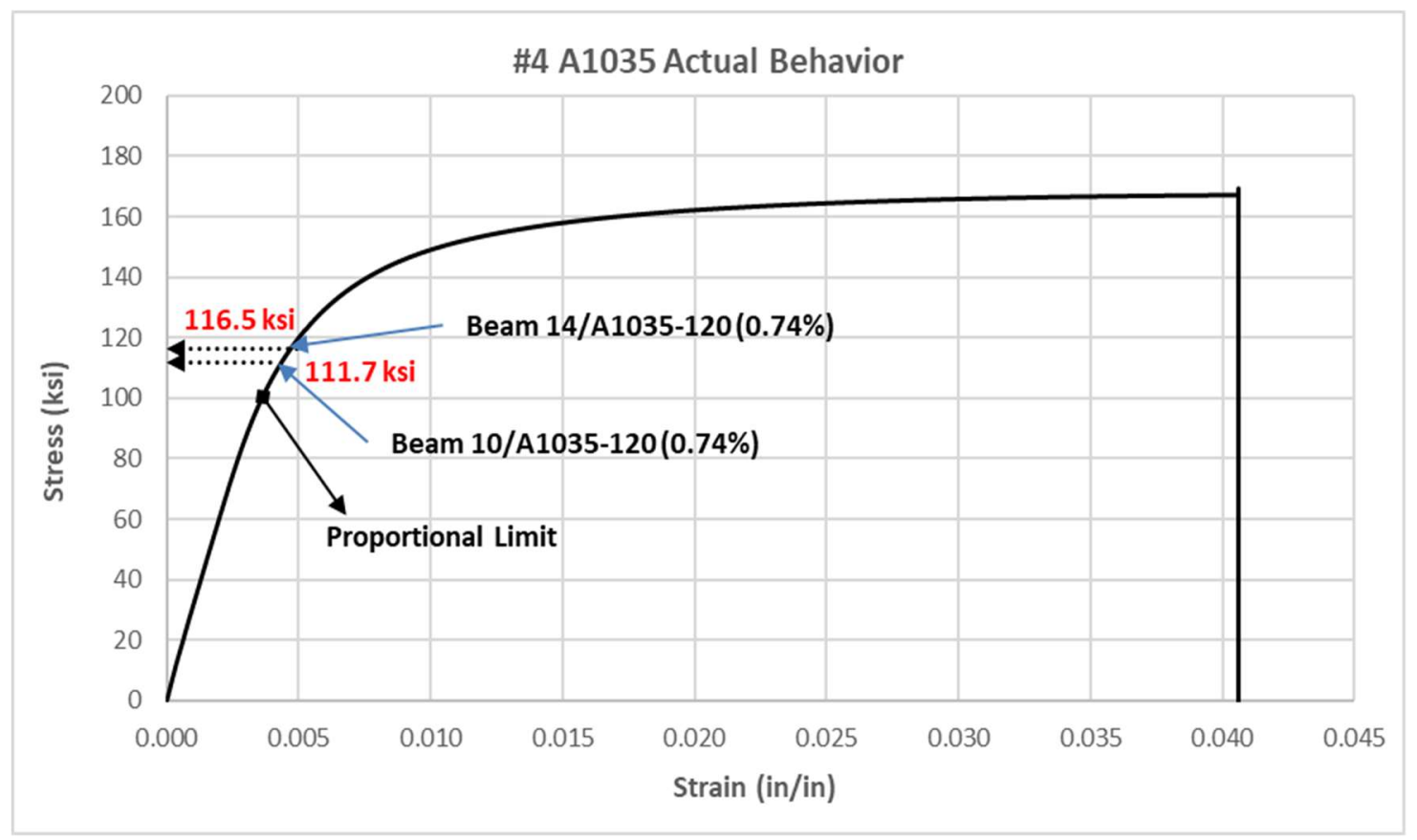

b) $\rho=0.74 \%$

Figure 5-30: Stress level in the tension reinforcement at service loading state for the tested beams reinforced with steel type A1035 Grade 120 


\subsection{Long-Term Deflection Test Results and Discussion}

As stated earlier, this study is intended to evaluate the long-term deflection behavior, and to check the validity of using the time-dependent multiplier $\lambda$ of the current ACI 318-14 (section 24.2.4.1.1) for beams made with HSC and HSR. Although only one beam was tested in this study, the results are considered as a starting point for more detailed future studies. The beam was subjected to a sustained load of 13.8 kips for twelve months. The load was applied using weights that were hung using a forklift. The initial immediate deflection reading of 0.756 in. was recorded immediately after applying the load. Then deflection reading was recorded every day for the first two weeks, every two days for the first three months, once a week for the first six months, and once every two to three weeks to the end of testing. The results of deflection vs. time are shown in Figure 5-31.

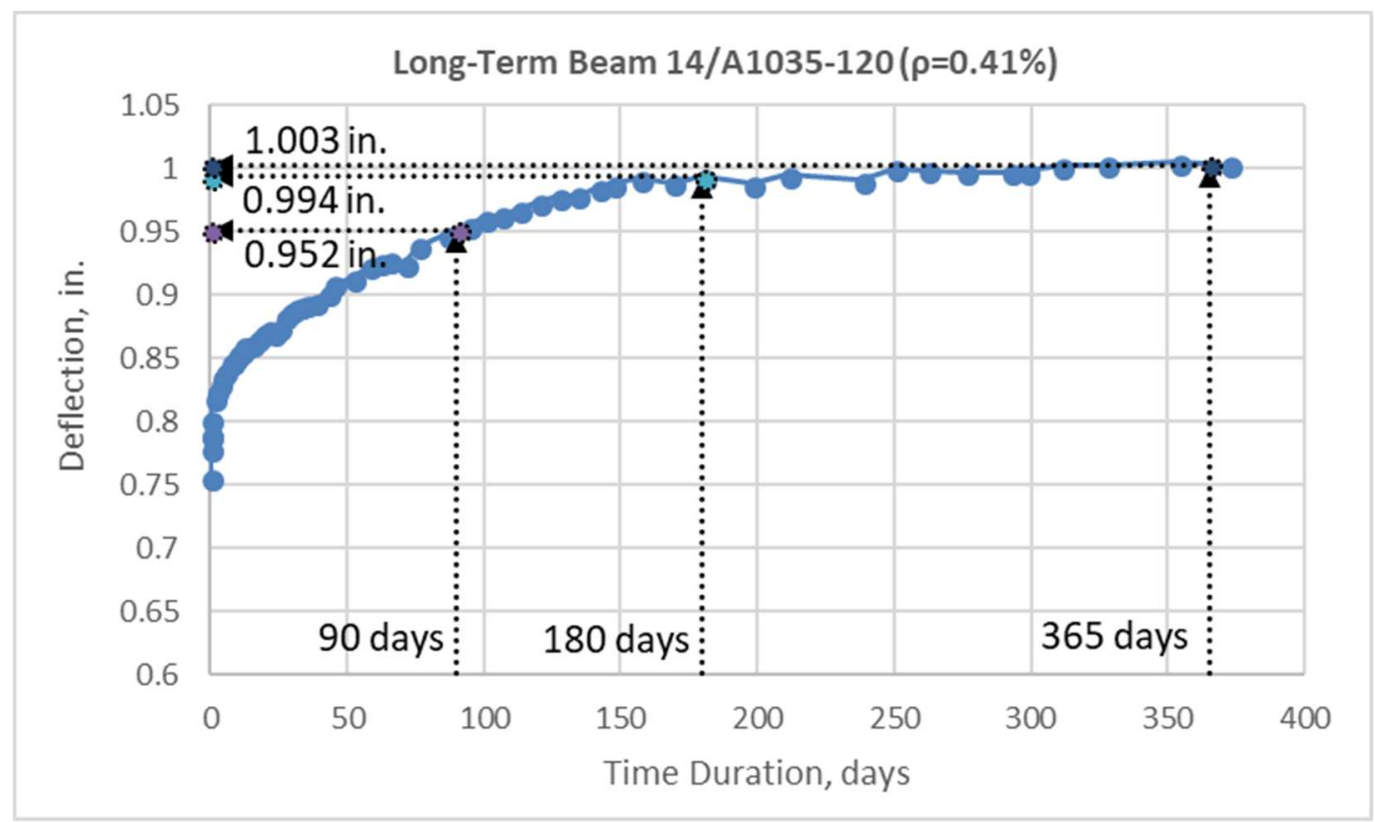

Figure 5-31: Time-dependent deflection of beam 14/A1035-120 (0.41\%) 
The long-term deflection was predicted using the ACI 318 long-term multiplier $\lambda$, which does not consider the concrete strength; the proposed multiplier by Paulson et al. (1991) that considers the lower creep of high-strength concrete; and the multiplier presented by Muhaisin (2012) to calculate the long-term deflection for reinforced concrete beams made with normal or high strength concrete, as summarized in Table 5-8.

Table 5-8: Comparison of predicted and measured time-dependent beam deflections

\begin{tabular}{|c|c|c|c|c|c|c|c|c|c|c|}
\hline \multicolumn{10}{|c|}{ Experimental immediate deflection $=\mathbf{0 . 7 5 6}$ in. } \\
\hline $\begin{array}{c}\text { Time } \\
\text { since } \\
\text { loading }\end{array}$ & $\begin{array}{c}\text { Experimental } \\
\text { long-term } \\
\text { deflection }\end{array}$ & \multicolumn{3}{|c|}{ ACI $318-14$} & \multicolumn{2}{|c|}{ Paulson et al. (1991) } & \multicolumn{4}{c|}{ Muhaisin (2012) } \\
\cline { 5 - 11 } & $\lambda$ & $\Delta_{\mathrm{L}-\mathrm{T}}$ & $\Delta_{\mathrm{L}-\mathrm{T}} / \Delta_{\text {exp. }}$ & $\lambda$ & $\Delta_{\mathrm{L}-\mathrm{T}}$ & $\Delta_{\mathrm{L}-\mathrm{T}} \Delta_{\text {exp. }}$ & $\lambda$ & $\Delta_{\mathrm{L}-\mathrm{T}}$ & $\Delta_{\mathrm{L}-\mathrm{T}} \Delta_{\text {exp. }}$ \\
\hline 3 months & 0.952 & 1.0 & 1.512 & $\mathbf{1 . 5 9}$ & 0.40 & 1.058 & $\mathbf{1 . 1 1}$ & 0.32 & 0.998 & $\mathbf{1 . 0 5}$ \\
\hline 6 months & 0.994 & 1.2 & 1.663 & $\mathbf{1 . 6 7}$ & 0.48 & 1.119 & $\mathbf{1 . 1 3}$ & 0.38 & 1.043 & $\mathbf{1 . 0 5}$ \\
\hline 12 months & 1.003 & 1.4 & 1.814 & $\mathbf{1 . 8 1}$ & 0.56 & 1.179 & $\mathbf{1 . 1 8}$ & 0.46 & 1.104 & $\mathbf{1 . 1 0}$ \\
\hline
\end{tabular}

Deflection measurements taken over a twelve month period allowed for the assessment of the ACI 318-14 time-dependent multiplier. As it can be seen from Table 5-8, ACI 318-14 overestimated the long-term deflection by about 1.6. The reason is because ACI 318 does not take into account the concrete strength. As shown by many researchers, high-strength concrete has lower creep over time than the normal strength concrete does. Therefore, the use of Paulson et al. (1991) and Muhaisin's (2012) long-term multipliers have shown improved predictions for the deflection as they considered the influence of the concrete strength in their modified multiplier. Based on the results of the tested beam, the 
modified multiplier proposed by Muhaisin (2012) showed the closest prediction for the long-term deflection.

The maximum crack width was also measured. All of the cracks formed once the load was applied, and the maximum crack width was $0.5 \mathrm{~mm}$ (0.02 in.) and remained the same until the end of the testing time. Figure 5-32 shows the crack pattern and the maximum crack width measurement.

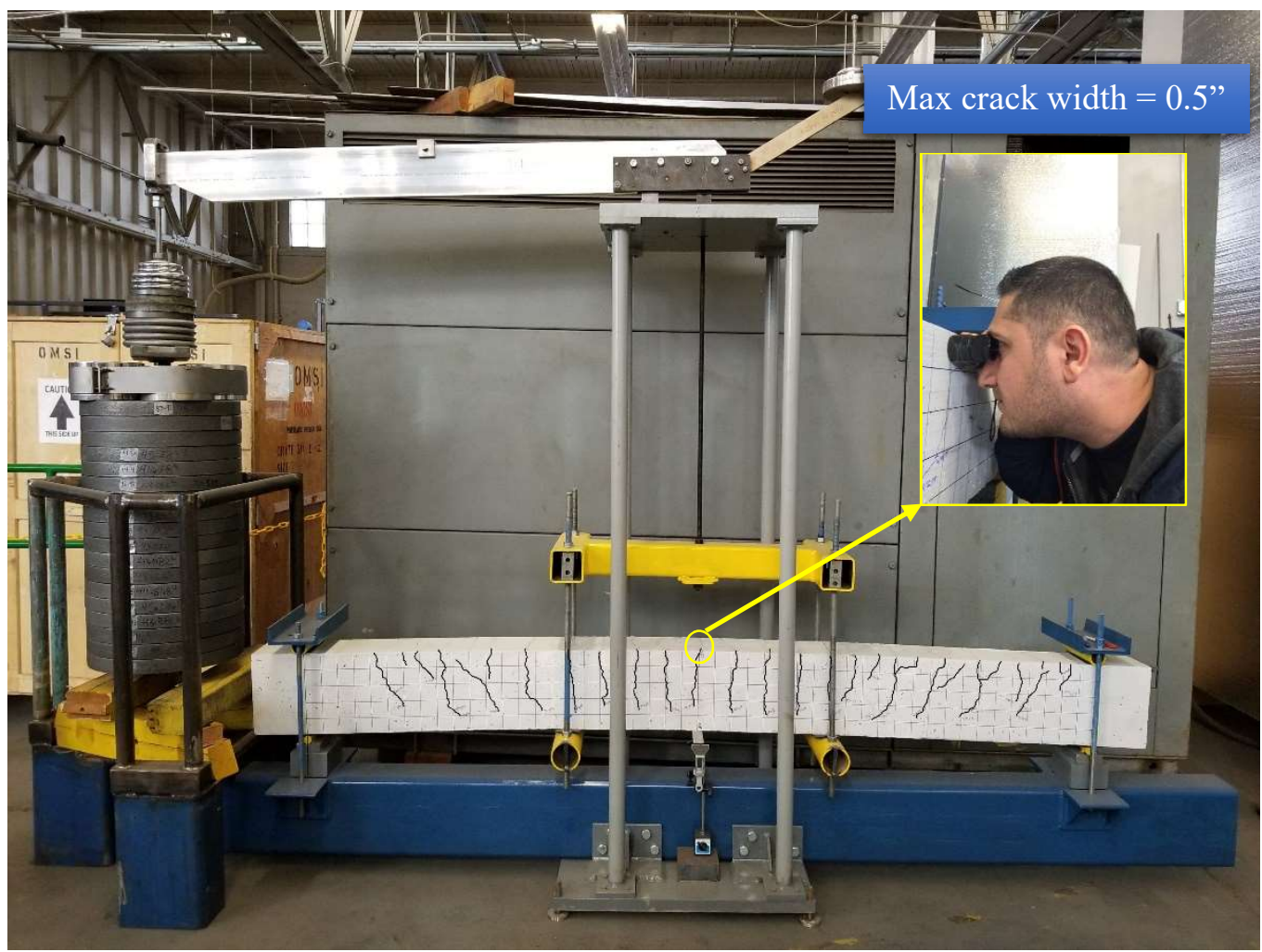

Figure 5-32: Crack pattern and maximum crack width measurement of the beam 14/A1035-120 (0.41\%) tested under long-term period 


\section{Chapter Six: A Parametric Study on the Key Design Issues with HSR and HSC}

\subsection{Introduction}

This chapter discusses the key design issues that are related to the flexural design of concrete beams of different concrete strengths ranging from normal to high strength (4 ksi to $12 \mathrm{ksi}$ ), and reinforced with high-strength bars of two different stress-strain behaviors (A615 Grade100 \& A1035 Grades 100 and 120). Different stress-strain relationships are expected to impact the force-displacement behavior of reinforced concrete beams in different ways including strain limits, flexural strength and the corresponding maximum deflection, and the spread of plasticity as the beam is loaded monotonically to failure. The key design issues discussed here include: Strength, ductility, strain limits and strength reduction factor, maximum and minimum reinforcement ratio, stiffness and immediate deflection prediction.

A parametric study is carried out using the verified MATLAB coding written by the author to address the issues related to the flexural design of concrete beams made with HSC and HSR, and to establish design guidelines related to maximum and minimum reinforcement ratio, strength reduction factor, service load level deflection prediction, and crack widths prediction.

It is well known that design of flexural members is based on achieving a ductile behavior to avoid the undesirable brittle failure. The term ductility is defined as the ability of the member to sustain deformation beyond its elastic limit while maintaining a reasonable load carrying capacity before total collapse. The ductility can be measured through strain, curvature, displacement, rotation, or energy absorption depending on the type of material 
or member. In this study, the curvature ductility and the energy absorption of beams reinforced with conventional Grade 60 steel are used as a reference for comparison. The curvature ductility can be defined as the ratio of the curvature at the ultimate load to the curvature at yielding of the reinforcement, $\mu=\varphi_{u} / \varphi_{\mathrm{y}}$. As a second measure of ductility, the energy absorption is determined by the area under the load-deflection response up to the ultimate load. The variables throughout the parametric study are:

- Concrete compression strength, $\mathrm{f}^{\prime}{ }_{\mathrm{c}}(4000,8000,12000 \mathrm{psi})$

- Reinforcement type and grade: A615-60, A615-100, A1035-100, and A1035-120

- Reinforcement ratio, $\rho$

\subsection{Flexural Strength and Ductility}

The current design provisions for computing flexural strength are applicable to conventional steel and need adjustment for application to the beams with high-strength reinforcement due to the difference in the stress-strain behavior, which impacts the loaddeflection response. In earlier editions of ACI 318 code, provisions for flexural members required a reinforcement ratio not greater than 75 percent of the balanced reinforcement ratio $\left(\rho_{\max } \leq 0.75 \rho_{b}\right)$. This criterion was in use and judged satisfactory for several decades until 1995 when a new approach based on tension reinforcement strain limits was introduced. The strain limits requirement was moved to the body of ACI 318 code in 2002, and replaced the former limit on the reinforcement ratio $\left(0.75 \rho_{b}\right)$. Both approaches are studied for the use of HSR in the following sections. 


\subsubsection{Reinforcement Ratio Limit}

In earlier ACI codes, for flexural members the maximum ratio of reinforcement was limited to $75 \%$ of the balance ratio $\left(\rho_{\max } \leq 0.75 \rho_{b}\right)$ so that the reinforcement yields before the concrete crushes to provide a minimum acceptable level of ductile behavior and to avoid sudden failure of members. The balance ratio is determined when the reinforcement reaches its yield strain at the same time the concrete reaches its maximum "permissible" strain of 0.003 . For the high-strength reinforcements that lack a welldefined yield strength, the $0.2 \%$ offset method was considered to define the yield stress and the corresponding yield strain in the reinforcement. Table 4-1 and Figure 4-2 show the typical stress-strain curves used in the analysis and their mechanical properties.

The concrete ultimate strain, $\varepsilon_{c u}$, was taken equal to 0.003 , as prescribed by ACI. An assumed simply supported beam of $10 \times 20$ inches cross-section and effective depth of 17.5 inches is used for the analysis with different concrete strengths and reinforcement type and grade. The beam is subjected to two-point loading at third points of its span of fifteen feet. The amount of steel was varied until the balanced condition is satisfied. Then, the $3 / 4$ fraction was applied to determine the maximum reinforcement ratio and the corresponding strain in the tension reinforcement for each case. Table 6-1 shows $\rho_{b}, \rho_{\max }$, and the strain in the tension steel when $\rho=\rho_{\max }$ for beams of various $f_{c}^{\prime}$ and steel type and grade. 
Table 6-1: Summary of reinforcement ratio limit based on $\rho=0.75 \rho_{b}$

\begin{tabular}{|c|c|c|c|c|c|c|}
\hline & $f_{y}$ & $\varepsilon_{y}$ & $f_{c}^{\prime}{ }_{c}$ & $\rho_{b}$ & $0.75 \rho_{b}$ & $\varepsilon_{\mathrm{s}}\left(\rho=0.75 \rho_{b}\right)$ \\
\hline \multirow{3}{*}{ A615-60 } & & & 4 & 0.0308 & 0.0231 & \\
\hline & 60 & 0.00207 & 8 & 0.0560 & 0.0420 & 0.0038 \\
\hline & & & 12 & 0.0787 & 0.0590 & \\
\hline \multirow{3}{*}{ A615-100 } & & & 4 & 0.0146 & 0.0110 & \\
\hline & 100 & 0.0034 & 8 & 0.0264 & 0.0198 & 0.0056 \\
\hline & & & 12 & 0.0370 & 0.0278 & \\
\hline \multirow{3}{*}{ A1035-100 } & & & 4 & 0.0117 & 0.0088 & \\
\hline & 100 & 0.005 & 8 & 0.0213 & 0.0160 & 0.0064 \\
\hline & & & 12 & 0.0299 & 0.0224 & \\
\hline \multirow{3}{*}{ A1035-120 } & & & 4 & 0.0087 & 0.0065 & \\
\hline & 120 & 0.006 & 8 & 0.0158 & 0.0118 & 0.0077 \\
\hline & & & 12 & 0.0221 & 0.0166 & \\
\hline
\end{tabular}

Figure 6-1 shows the moment-curvature responses for the maximum reinforcement ratio $\left(\rho_{\max } \leq 0.75 \rho_{b}\right)$ condition. It can be observed that for beams with the same $f^{\prime}$, the moment corresponding to $\rho_{\max }$ condition is less as the reinforcement yield stress increases. This is because the amount of steel required is less, which leads to a higher strain in steel and shallower depth of the compression zone of the section and therefore less moment. 

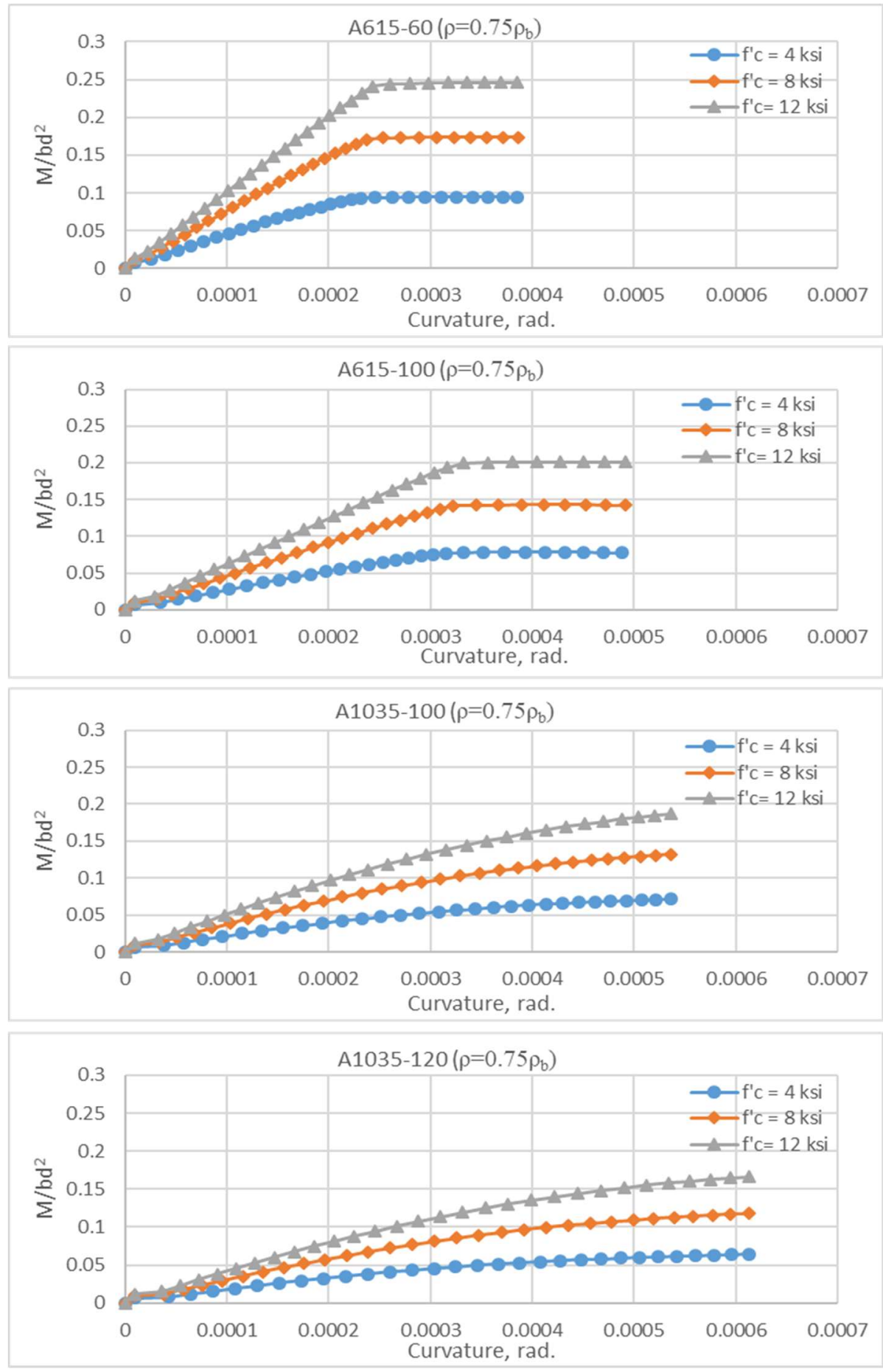

Figure 6-1: Moment-curvature responses for beams reinforced with conventional grade 60 steel and HSR based on $\rho=0.75 \rho_{b}$ 


\subsubsection{Tension Reinforcement Strain Limits}

In 1995, the ACI 318 code introduced a new requirement based on a minimum strain in the tension reinforcement at nominal strength rather than limiting the maximum reinforcement ratio for beams. Based on the new approach the member behavior is classified as tension-controlled, compression-controlled, or in the transition zone based on the strain in the tension reinforcement at nominal strength. Depending on the member classification, a strength reduction factor, $\phi$, is applied as a factor of safety to determine the design strength. For sections considered as tension-controlled, a minimum strain of 0.005 in the extreme tension steel at nominal moment is required to use a $\phi$ factor of 0.90 . Compression-controlled sections are defined as those sections having strain in extreme tension steel at or below the yield strain at nominal strength. The current steel strain limit of 0.002 (the simplification of Grade 60 yield strain of 0.00207) defining the upper bound of compression-controlled behavior. As these sections will not show a desirable ductile behavior, they are penalized with a lower $\phi$ factor of 0.65 . For sections in the transition region, the strength reduction factor varies linearly. Flexural members should normally be designed as tension-controlled members, however, ACI 318-02 proposed a minimum allowable strain in tension reinforcement equal to 0.004 , and that determines the maximum reinforcement ratio in this approach.

The above-mentioned strain limits $(0.002,0.004$ and 0.005$)$ were proposed for Grade 60 reinforcing steel. Therefore, an adjustment is required for the use of high-strength reinforcement. It seems reasonable to assume that the adjustment of the strain limits should be based on ductility requirements to obtain the same, or nearly the same, 
desirable ductile behavior of flexural members designed with Grade 60 reinforcement. Hence, in this study the ductility (curvature ductility and area under load-deflection curve) was determined for beams with Grade 60 when the strain at nominal strength is equal to $0.005,0.004$, and 0.00207 . Then the obtained ductility values were used as benchmarks to determine the corresponding comparable tension-controlled strain limits, minimum strains, and compression-strain limits for HSR.

As an example, the reinforcement ratio $(\rho)$ was varied for a beam $(10$ in. $\times 20$ in. and $L=$ $15 \mathrm{ft}$ ) made with $\mathrm{f}_{\mathrm{c}}$ of $4000 \mathrm{psi}$ and Grade 60 steel and subjected to a two-point loading at the third points of its span to determine $\rho$ corresponding to $\varepsilon_{\mathrm{s}}$ of 0.005 , as shown in Figure 6-3. Next, from the M- $\phi$ response, the curvature ductility that corresponds to $\varepsilon_{\mathrm{s}}=$ 0.005 was determined, shown in Figure 6-2. In Figure 6-3, the curvature ductility factor $\mu$ $=\varphi_{\mathrm{u}} / \varphi_{\mathrm{y}}=0.000457 / 0.000215=2.12$. The obtained curvature ductility (2.12) was used as a benchmark to determine the corresponding comparable tension-controlled strain limits for HSR. This approach was followed to determine the comparable strain limits for both types of HSR based on both curvature ductility and energy absorption (area under loaddeflection), as shown in Figure 6-4 to Figure 6-7. The determined comparable strain limits are summarized in Table 6-2 and Table 6-3. 


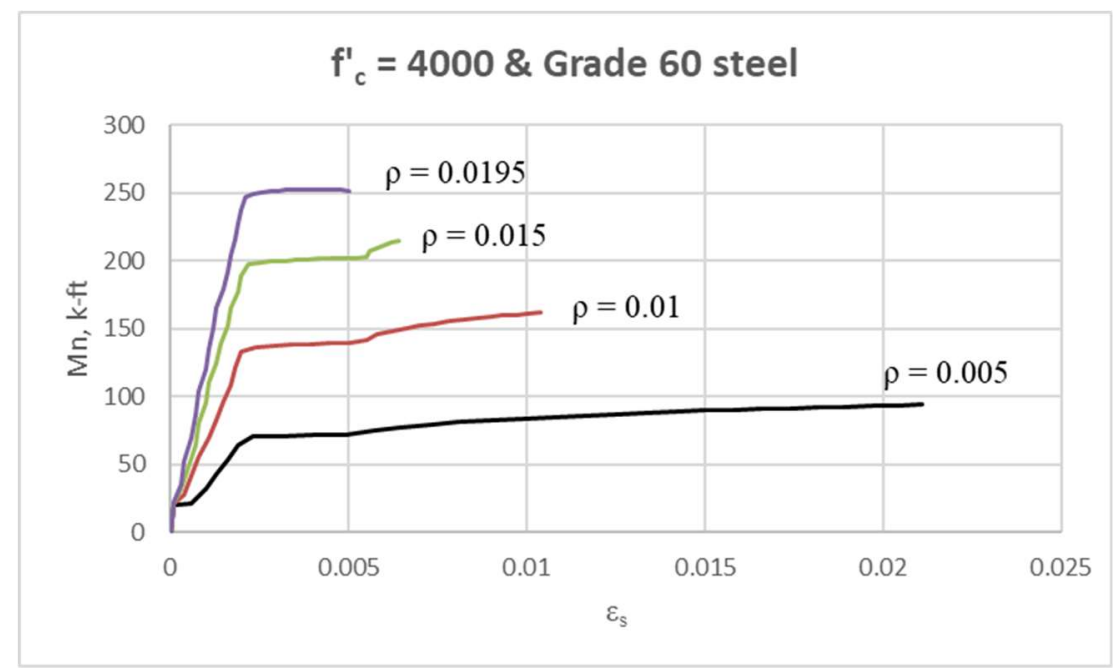

Figure 6-3: Effect of $\rho$ on the moment capacity and tension reinforcement strain

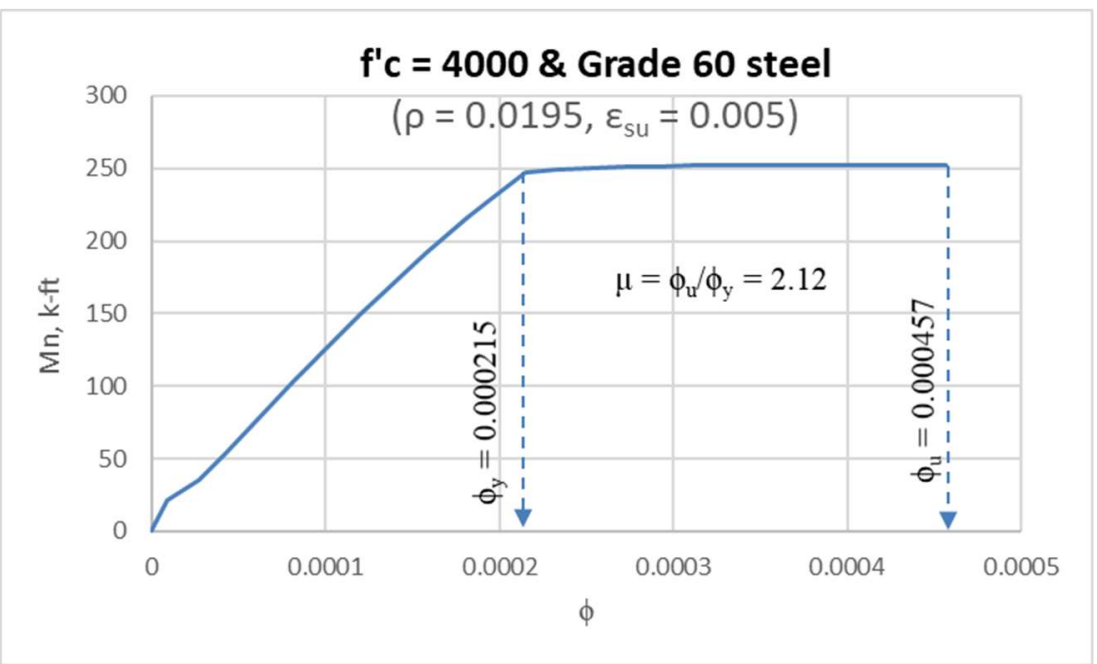

Figure 6-2: $\mathrm{M}-\phi$ response for a beam with $\mathrm{f}_{\mathrm{c}}=4000$ psi \& Grade 60 steel with $\rho=0.0195$ 

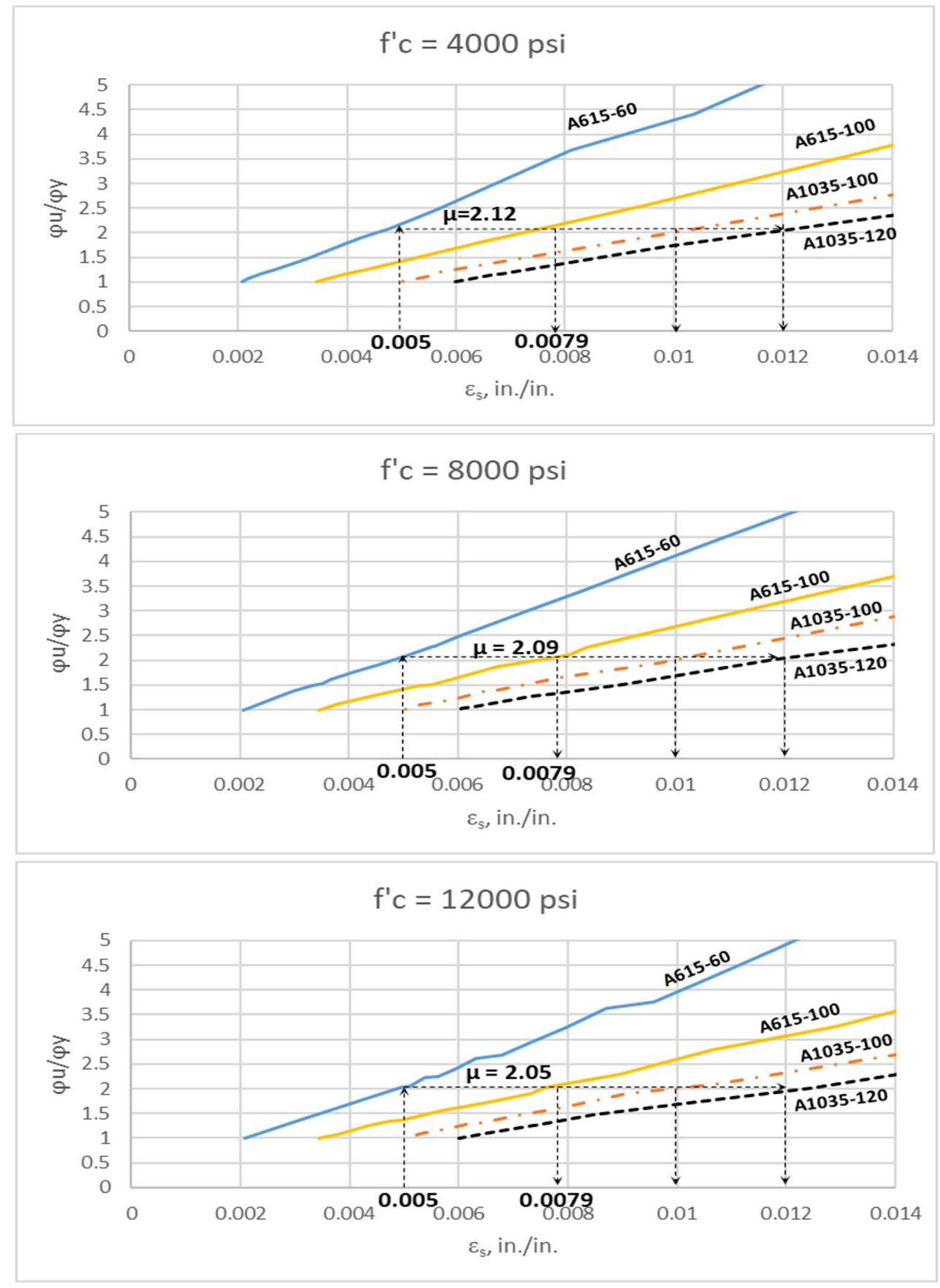

Figure 6-4: HSR comparable tension-control strain limits based on curvature ductility 


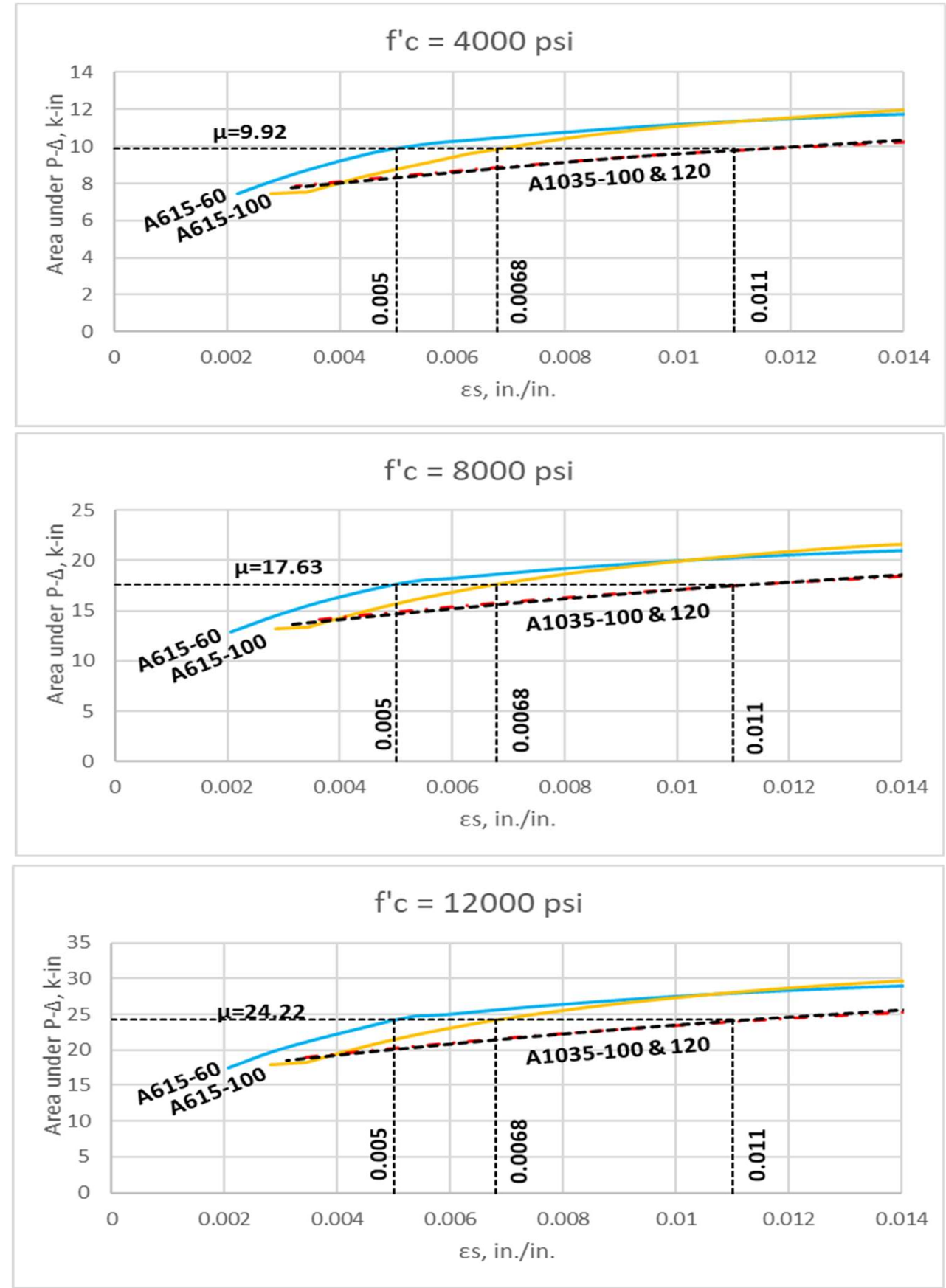

Figure 6-5: HSR comparable tension-control strain limits based on energy absorption (area under $\mathrm{P}-\Delta$ ) 


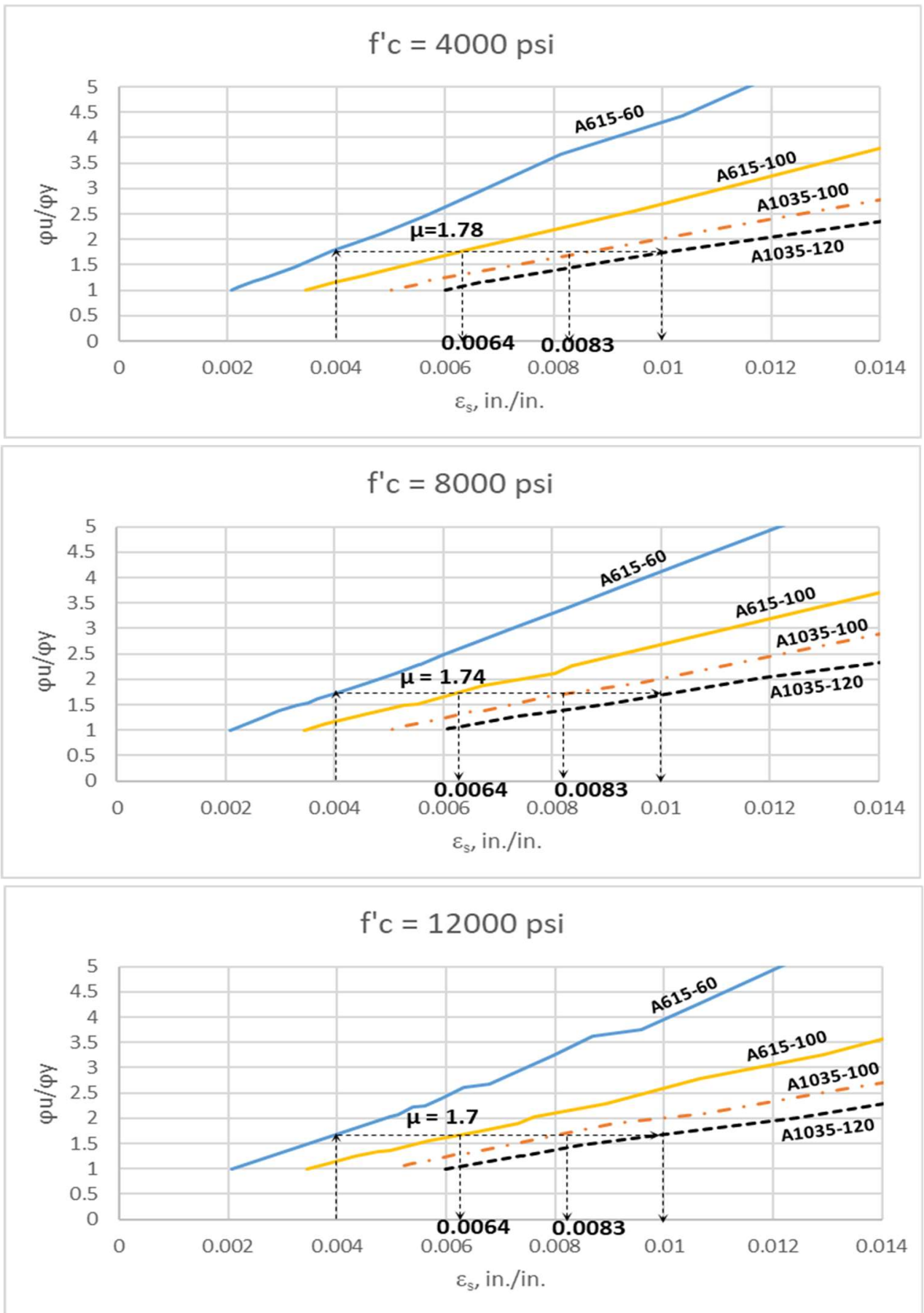

Figure 6-6: HSR comparable minimum strain limits based on curvature ductility 


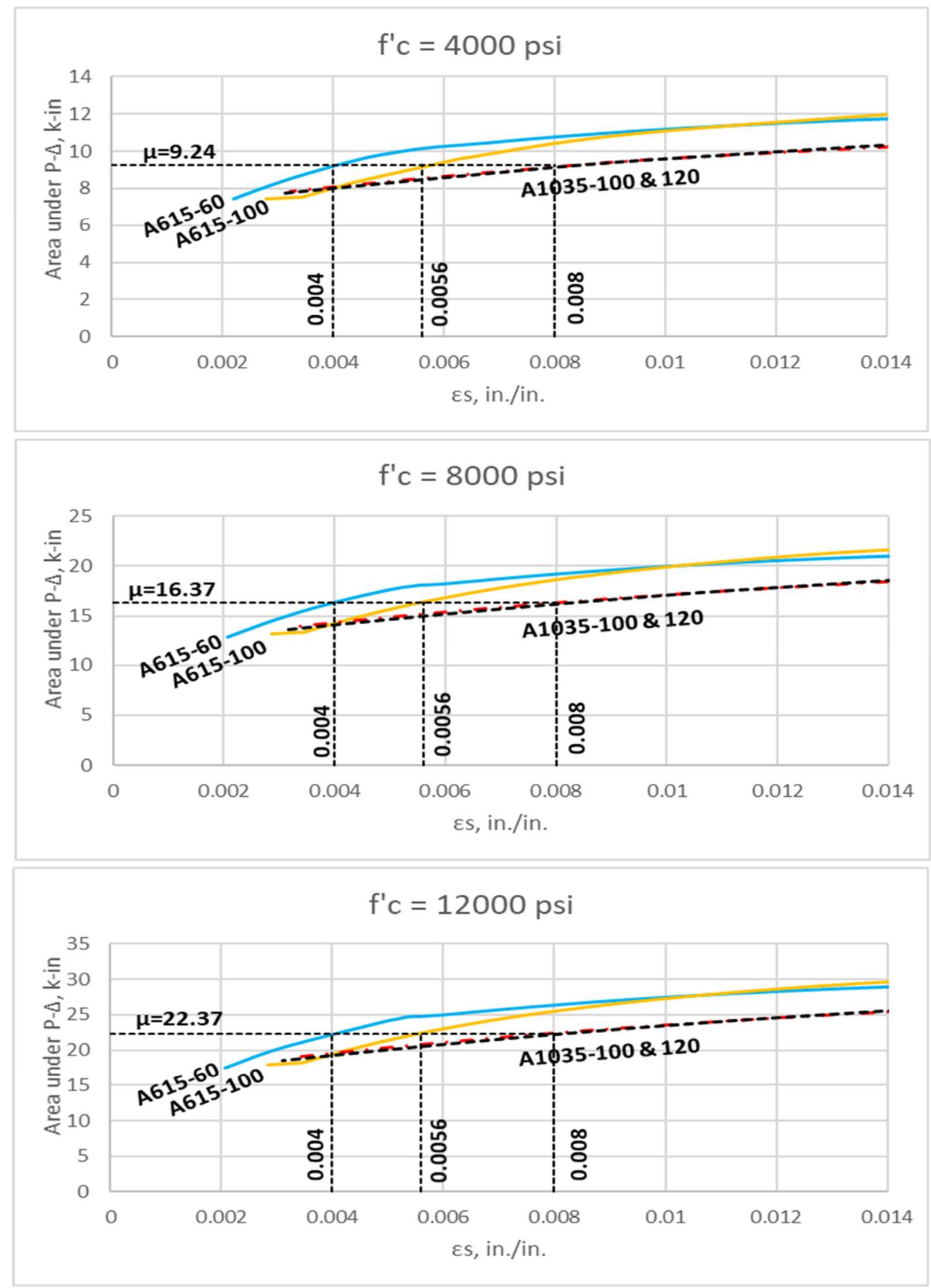

Figure 6-7: HSR comparable minimum strain limits based on energy absorption (area under P- $\Delta$ ) 
Table 6-2: Comparable strain limits based on curvature ductility $\left(\mu=\varphi_{\mathrm{u}} / \varphi_{\mathrm{y}}\right)$

\begin{tabular}{|c|c|c|c|c|}
\hline Strain limit & $\mathbf{A 6 1 5 - 6 0}$ & $\mathbf{A 6 1 5 - 1 0 0}$ & $\mathbf{A 1 0 3 5 - 1 0 0}$ & $\mathbf{A 1 0 3 5 - 1 2 0}$ \\
\hline Tension-Controlled & 0.005 & 0.0079 & 0.01 & 0.012 \\
\hline Minimum for flexural members & 0.004 & 0.0064 & 0.008 & 0.01 \\
\hline Compression-Controlled & 0.00207 & 0.00345 & 0.005 & 0.006 \\
\hline
\end{tabular}

Table 6-3: Comparable strain limits based on energy absorption $(\mu=$ Area under P- $\Delta)$

\begin{tabular}{|c|c|c|c|c|}
\hline Strain limit & $\mathbf{A 6 1 5 - 6 0}$ & $\mathbf{A 6 1 5 - 1 0 0}$ & $\mathbf{A 1 0 3 5 - 1 0 0}$ & $\mathbf{A 1 0 3 5 - 1 2 0}$ \\
\hline Tension-Controlled & 0.005 & 0.0068 & 0.011 & 0.011 \\
\hline Minimum for flexural members & 0.004 & 0.0056 & 0.008 & 0.008 \\
\hline Compression-Controlled & 0.00207 & 0.00206 & 0.0017 & 0.0018 \\
\hline
\end{tabular}

The results of minimum strain limits $\left(\varepsilon_{s}\right.$ min. $)$ in tension reinforcement resulted from the study in Section 6.2.1 and the current section are compared, as illustrated in Table 6-4.

Table 6-2 and Table 6-3 show that the comparable strain limits for HSR using curvature ductility are higher than those by using the area under the load-deflection curve to define the ductility. Also, the same observation can be made comparing the minimum strain limits in Table 6-4 using three different approaches. Therefore, using curvature ductility criterion requires a higher level of strain for design, which should result in more ductility for the member.

Table 6-4: Comparison of minimum strain limits for HSR from different approaches

\begin{tabular}{|c|c|c|c|}
\hline & $\varepsilon_{\text {s min. }}\left(\rho_{\max }=0.75 \rho_{b}\right)$ & $\varepsilon_{\text {s min. }}\left(\mu=\emptyset_{u} / \emptyset_{y}\right)$ & $\varepsilon_{\text {s min. }}(\mu=$ area under P- $\Delta)$ \\
\hline $\mathbf{A 6 1 5 - 1 0 0}$ & 0.0056 & 0.0064 & 0.0056 \\
\hline $\mathbf{A 1 0 3 5 - 1 0 0}$ & 0.0064 & 0.008 & 0.008 \\
\hline $\mathbf{A 1 0 3 5 - 1 2 0}$ & 0.0077 & 0.01 & 0.008 \\
\hline
\end{tabular}


For HSR to be consistence with ACI 318, the strength resistance factors of 0.9 and 0.65 are adopted when using tension-controlled and compression-controlled members respectively. The revised variation of the resistance factor, $\phi$, for each HSR based on curvature ductility are shown graphically in Figure 6-8.
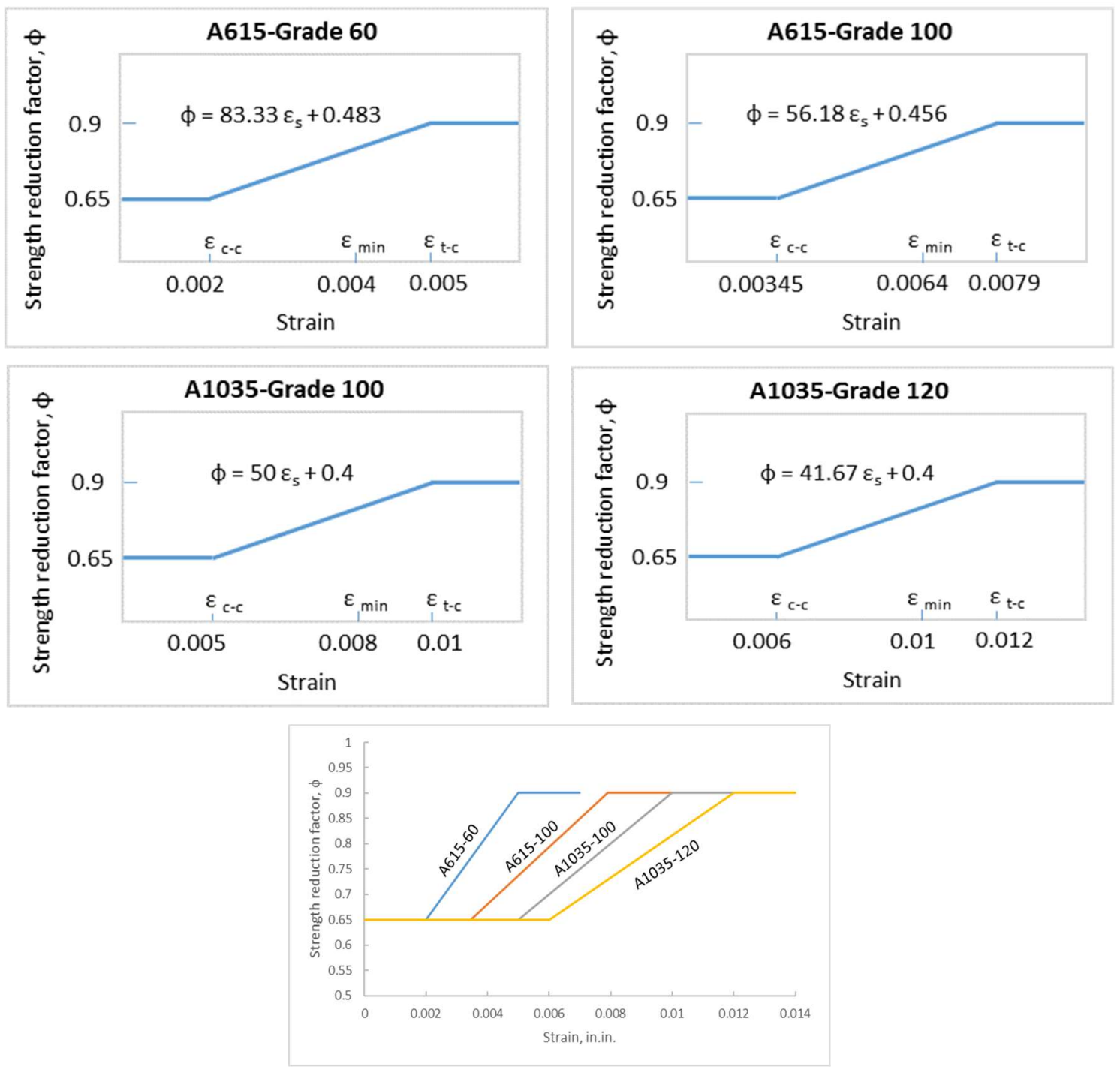

Figure 6-8: Relationship between strength reduction factor, $\phi$, and strain limits 
From this study, it is also evident that HSR type A615 Grade 100 with distinctive yield strength and yield plateau requires less strain in reinforcement to achieve ductility comparable to conventional steel than HSR type A1035 Grade 100, which has a roundhouse shape without a well-defined yield strength.

Moreover, Figure 6-4 to Figure 6-7 demonstrate that the concrete compressive strength has no apparent effect on the required strain limits in the reinforcement.

\subsection{Minimum Reinforcement Ratio}

The current minimum reinforcement ratio, $\rho_{\min }$, of the ACI 318 for reinforced concrete flexural members are intended to provide flexural moment capacity exceeds the cracking moment of the section to protect against the sudden collapse in cases of loading beyond cracking moment. The current equation considers concrete of different grades and reinforcement with variable yield strength $\left(\rho_{\min }=\max \left\{\frac{\sqrt[3]{f_{c}^{\prime}}}{f_{y}}, \frac{200}{f_{y}}\right\}\right)$. However, the applicability of this equation has not been verified for the use of high-strength reinforcement. The ATC-115 report in 2014 suggested that this equation could be eliminated, and $\rho_{\min }$ could be determined so that the design moment capacity is $120 \%$ of the cracked moment $\left(\varnothing M_{n}=1.2 M_{c r}\right)$.

This study consists of flexural section analyses with HSR to identify $\rho_{\min }$ corresponding to $\varnothing M_{n}=1.2 M_{c r}$. The results are compared with the current ACI 318 equation used to determine $\rho_{\min }$ for reinforced concrete flexural members, that is based on $\emptyset M_{n} \approx$ 
$1.5 M_{c r}$. The following variables were included in the study: (1) ratio of reinforcement depth to beam depth (d/h); (2) concrete compressive strength; and (3) HSR type and grade. With minimum amount of reinforcement in concrete sections, the strain in the reinforcement is expected to be large. HSR has a lower maximum tensile strain $\varepsilon_{u}$ compared to the conventional Grade 60 steel. A summary of the material properties of HSR steel type A1035 available in the literature given by National Cooperative Highway Research Program (NCHRP) report 679 (2011) shows the average $\varepsilon_{u}$ to be equal to 0.049 . Therefore, the maximum strain in the HSR when $\emptyset M_{n}=1.2 M_{c r}$ needs to be checked to make sure the steel doesn't reach a critical point that the reinforcement rupture may occur before the concrete fails.

As an example, a beam of 12 in. $x 24$ in. dimensions and span equal to $24 \mathrm{ft}$. was used in this study with varying $d / h$ ratio $(0.8-0.95)$ and varying $f^{\prime}{ }_{c}(4000-12000)$ and steel type. In order to compare the $\rho_{\min }$ using ACI318 equation with that using $\varnothing M_{n}=1.2 M_{c r}$, the stress in all types of the reinforcement investigated was limited to their yielding stress (i.e. elastic-plastic model was used). However, to check the strain in the steel, the actual representative stress-strain curves were used with the same $\rho$ determined from the previous step.

The resulting $\rho_{\min }$ values are given in Table 6-5 through Table 6-7 and shown graphically in Figure 6-9 through Figure 6-11. As shown in the tables and figures, the current ACI 318 equation gives higher results for $\rho_{\min }$ for all the investigated reinforcing steels because it is based on $\varnothing M_{n} \approx 1.5 M_{c r}$. More importantly, using $\varnothing M_{n}=1.2 M_{c r}$ to compute $\rho_{\min }$ results in high strains in the reinforcement (greater than $\varepsilon_{u}$ average $=$ 
0.049 in./in.) that may not be achieved by the HSR properties, as shown in Table 6-8 to

Table 6-9. The higher strains using $\varnothing M_{n}=1.2 M_{c r}$ are due to the reduced amount of steel than that using ACI 318 equation. Therefore, it is recommended to use the ACI 318 equation for HSR too as the resulted strain levels are less than 0.049 .

Table 6-5: Comparison of $\rho_{\min }$ for A615 Grade 60

\begin{tabular}{|c|c|c|c|c|c|}
\hline$d / h$ & 0.8 & 0.85 & 0.9 & 0.95 & $A C I 318$ \\
\hline$f^{\prime}{ }_{c}$ & \multicolumn{3}{|c|}{$\rho\left(\right.$ when $\left.\phi M_{n} / M_{c r}=1.2\right)$} & $\rho=\max \left(3 \mathrm{Vf}_{c}{ }_{c} / f_{y}, 200 / f_{y}\right)$ \\
\hline 4000 & 0.00281 & 0.00249 & 0.00221 & 0.00198 & 0.00333 \\
\hline 8000 & 0.00395 & 0.00349 & 0.00311 & 0.00279 & 0.00447 \\
\hline 12000 & 0.00482 & 0.00427 & 0.0038 & 0.00341 & 0.00548 \\
\hline
\end{tabular}

Table 6-6: Comparison of $\rho_{\min }$ for A615 \& A1035 Grade 100

\begin{tabular}{|c|c|c|c|c|c|}
\hline$d / h$ & 0.8 & 0.85 & 0.9 & 0.95 & $\mathrm{ACl} 318$ \\
\hline$f^{\prime}{ }_{c}$ & \multicolumn{4}{|c|}{$\rho$ (when $\left.\phi M_{n} / M_{c r}=1.2\right)$} & $\rho=\max \left(3 \mathrm{~V} f^{\prime} c / f_{y}, 200 / f_{y}\right)$ \\
\hline 4000 & 0.00169 & 0.00149 & 0.00133 & 0.00119 & 0.00200 \\
\hline 8000 & 0.00238 & 0.00210 & 0.00187 & 0.00168 & 0.00268 \\
\hline 12000 & 0.00290 & 0.00256 & 0.00229 & 0.00205 & 0.00329 \\
\hline
\end{tabular}

Table 6-7: Comparison of $\rho_{\text {min }}$ for A1035 Grade 120

\begin{tabular}{|c|c|c|c|c|c|}
\hline$d / h$ & 0.8 & 0.85 & 0.9 & 0.95 & ACI 318 \\
\hline$f_{c}^{\prime}$ & \multicolumn{4}{|c|}{$\rho\left(\right.$ when $\left.\phi M_{n} / M_{c r}=1.2\right)$} & $\rho=\max \left(3 \mathrm{~V} f_{c}^{\prime} / f_{y}, 200 / f_{y}\right)$ \\
\hline 4000 & 0.00141 & 0.00124 & 0.00111 & 0.00099 & 0.00167 \\
\hline 8000 & 0.00199 & 0.00175 & 0.00156 & 0.00140 & 0.00224 \\
\hline 12000 & 0.00241 & 0.00214 & 0.00190 & 0.00171 & 0.00274 \\
\hline
\end{tabular}




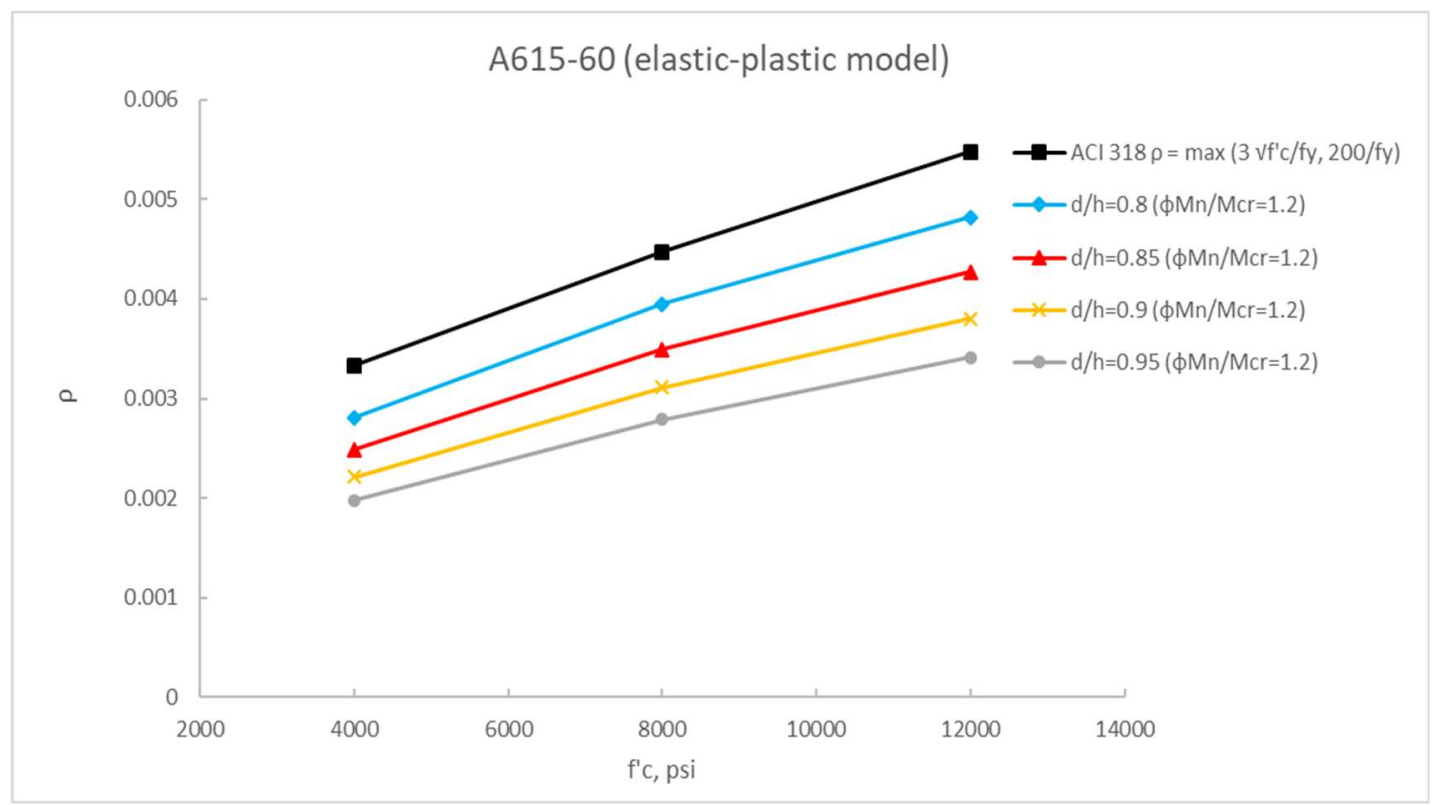

Figure 6-9: Comparison of $\rho_{\min }$ for A615 Grade 60

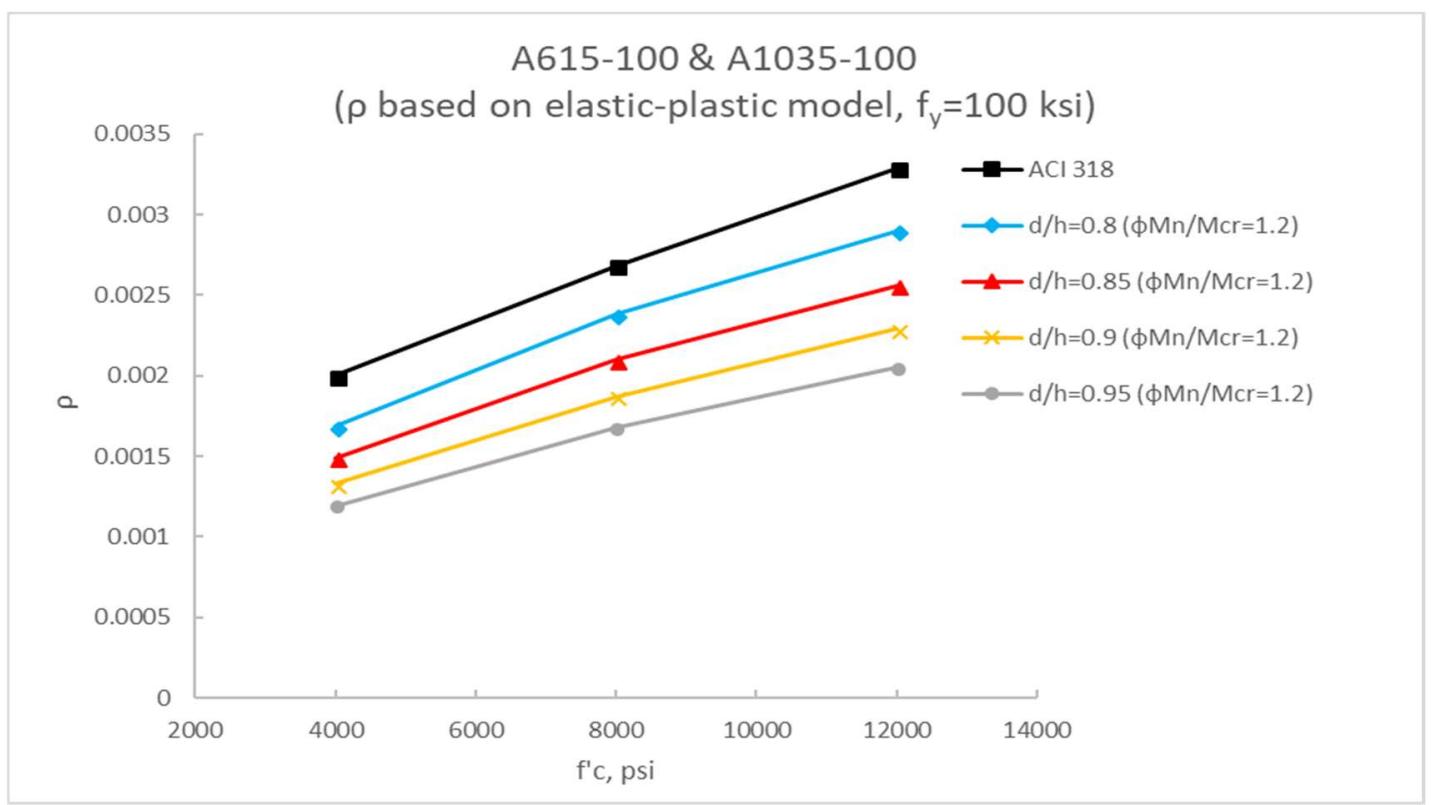

Figure 6-10: Comparison of $\rho_{\min }$ for A615 \& A1035 Grade 100 


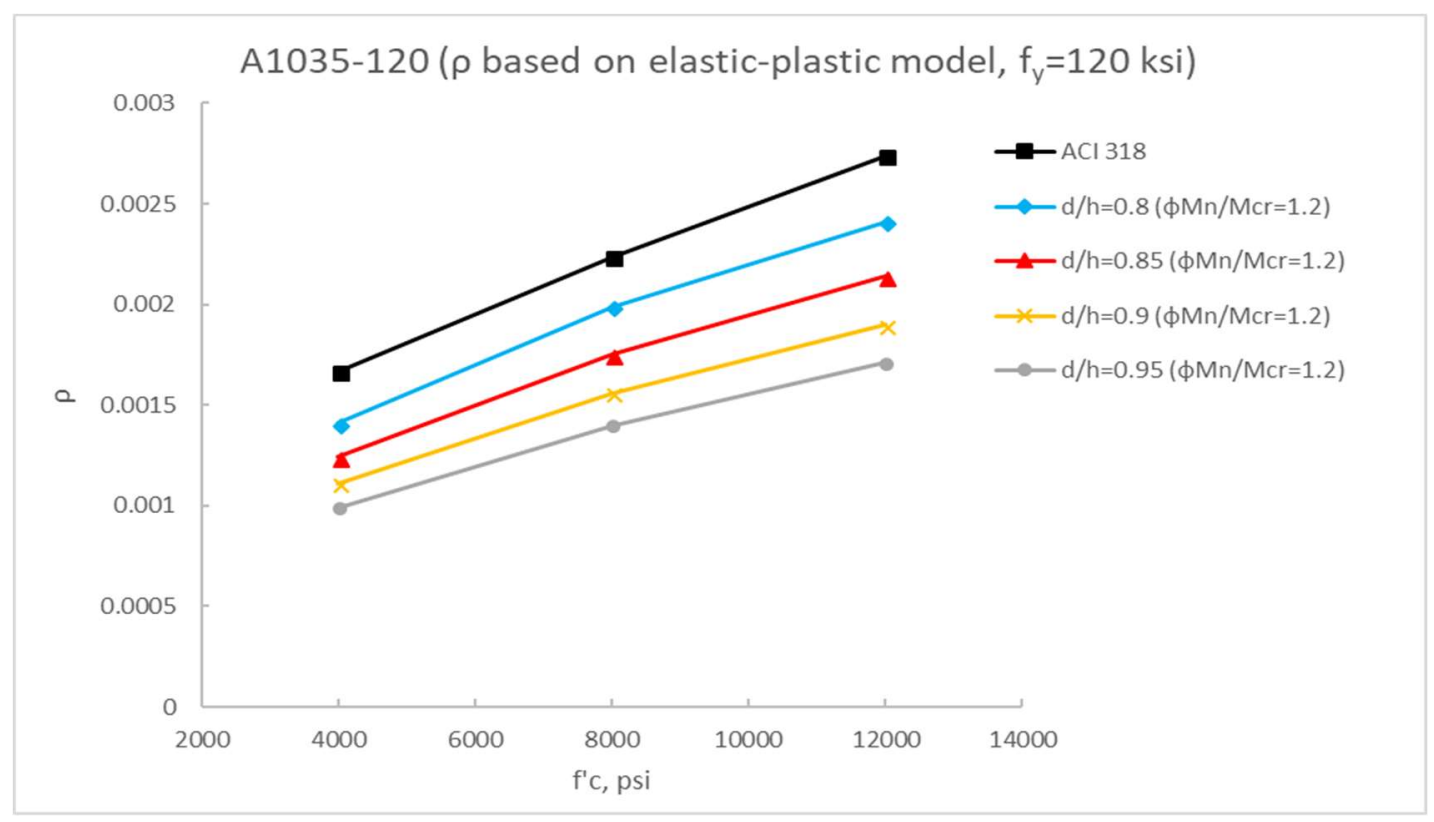

Figure 6-11: Comparison of $\rho_{\min }$ for A1035 Grade 120

Table 6-8: Comparison of $\varepsilon_{\mathrm{u}}$ at $\rho_{\text {min }}$ for A615 Grade 60

\begin{tabular}{|c|c|c|c|c|c|}
\hline$d / h$ & 0.8 & 0.85 & 0.9 & 0.95 & $A C l 318$ \\
\hline$f^{\prime}{ }_{c}$ & \multicolumn{4}{|c|}{$\varepsilon_{u}$ (when $\left.\phi M_{n} / M_{c r}=1.2\right)$} & $\varepsilon_{u}$ \\
\hline 4000 & 0.053 & 0.060 & 0.068 & 0.076 & 0.044 \\
\hline 8000 & 0.069 & 0.078 & 0.088 & 0.099 & 0.061 \\
\hline 12000 & 0.080 & 0.090 & 0.102 & 0.114 & 0.070 \\
\hline
\end{tabular}

Table 6-9: Comparison of $\varepsilon_{\mathrm{u}}$ at $\rho_{\min }$ for A615 Grade 100

\begin{tabular}{|c|c|c|c|c|c|}
\hline$d / h$ & 0.8 & 0.85 & 0.9 & 0.95 & $\mathrm{ACl} 318$ \\
\hline$f_{c}^{\prime}$ & \multicolumn{4}{|c|}{$\varepsilon_{\mathrm{u}}\left(\right.$ when $\left.\phi \mathrm{M}_{\mathrm{n}} / \mathrm{M}_{\mathrm{cr}}=1.2\right)$} & $\varepsilon_{\mathrm{u}}$ \\
\hline 4000 & 0.0431 & 0.0478 & 0.0526 & 0.0577 & 0.032 \\
\hline 8000 & 0.0534 & 0.0593 & 0.0652 & 0.0715 & 0.041 \\
\hline 12000 & 0.06 & 0.0665 & 0.0730 & 0.0801 & 0.046 \\
\hline
\end{tabular}


Table 6-10: Comparison of $\varepsilon_{\mathrm{u}}$ at $\rho_{\min }$ for A 1035 Grade 100

\begin{tabular}{|c|c|c|c|c|c|}
\hline$d / h$ & 0.8 & 0.85 & 0.9 & 0.95 & $A C l 318$ \\
\hline$f^{\prime}{ }_{c}$ & \multicolumn{4}{|c|}{$\varepsilon_{\mathrm{u}}$ (when $\left.\phi \mathrm{M}_{\mathrm{n}} / \mathrm{M}_{\mathrm{cr}}=1.2\right)$} & $\varepsilon_{\mathrm{u}}$ \\
\hline 4000 & 0.030 & 0.034 & 0.038 & 0.043 & 0.026 \\
\hline 8000 & 0.039 & 0.044 & 0.050 & 0.056 & 0.035 \\
\hline 12000 & 0.045 & 0.051 & 0.057 & 0.064 & 0.040 \\
\hline
\end{tabular}

Table 6-11: Comparison of $\varepsilon_{u}$ at $\rho_{\min }$ for A1035 Grade 120

\begin{tabular}{|c|c|c|c|c|c|}
\hline $\mathrm{d} / \mathrm{h}$ & 0.8 & 0.85 & 0.9 & 0.95 & $\mathrm{ACl} 318$ \\
\hline $\mathrm{f}_{\mathrm{c}}$ & \multicolumn{4}{|c|}{$\varepsilon_{\mathrm{u}}$ (when $\left.\phi \mathrm{M}_{\mathrm{n}} / \mathrm{M}_{\mathrm{cr}}=1.2\right)$} & $\varepsilon_{\mathrm{u}}$ \\
\hline 4000 & 0.036 & 0.041 & 0.046 & 0.051 & 0.030 \\
\hline 8000 & 0.046 & 0.053 & 0.060 & 0.067 & 0.041 \\
\hline 12000 & 0.054 & 0.061 & 0.069 & 0.077 & 0.047 \\
\hline
\end{tabular}




\subsection{Effect of Using Simplified Elastic-Plastic vs. Actual Roundhouse Stress-Strain for HSR Type A1035 on Flexural Design of Beams}

The use of the simplified elastic-plastic stress-strain in the analysis and the design of reinforced concrete beams is accepted for a reinforcement that has a well-defined yield stress and yield plateau. In order to evaluate the consequences on the flexural design, the simplified elastic-plastic stress-strain is used to idealize the behavior of high-strength reinforcement type A1035 that has a roundhouse stress-strain. An example beam with a 6 in. $\mathrm{x} 10$ in. cross-section with a concrete compressive strength of 8000 psi and reinforced with A1035 Grade 100 rebar is used to perform this evaluation.

The simplified elastic-plastic stress-strain curve has an elastic portion with a steel modulus $\left(E_{s}\right)$ of $29,000,000 \mathrm{psi}$, and perfectly plastic behavior after reaching $f_{y}$ equal to 100,000 psi. The actual behavior is represented by the equation that represents the typical behavior of A1035 Grade 100 reinforcement bars mentioned in section 4.2.2.

The values of the moment capacity $\left(\mathrm{M}_{\mathrm{n}} / \mathrm{bd}^{2}\right)$ and curvature ductility $\left(\phi_{\mathrm{u}} / \phi_{\mathrm{y}}\right)$ resulted from using both models are compared and given in Table 6-12, and shown graphically in Figure 6-12. For the example beam, the comparison indicates that using the simplified elastic-plastic model would result in underestimation for the moment capacity by $20 \%$ to $40 \%$ for the reinforcement ratio ranging from $\rho_{\max }$ to $\rho_{\min }$ respectively. Furthermore, the use of the simplified model would result in an inaccurate overestimation for the ductility by about two times the ductility when using the actual nonlinear model, and it will incorrectly suggest that the section exhibits sufficient warning prior to failure. Therefore, 
a representative actual stress-strain relationship for HSR type A1035 should be specified for optimum and safe design.

Table 6-12: Comparison of using elastic-plastic model vs. actual roundhouse to model A1035-100 reinforcement on moment capacity and curvature ductility

\begin{tabular}{|c|c|c|c|c|c|c|}
\hline & \multicolumn{2}{|c|}{$\begin{array}{c}\text { Simplified elastic-plastic } \\
\text { stress-strain }\end{array}$} & \multicolumn{2}{c|}{$\begin{array}{c}\text { Actual roundhouse stress- } \\
\text { strain }\end{array}$} & \\
\hline$\rho$ & $\begin{array}{c}\mathrm{R}_{\mathrm{s}}=\mathrm{M}_{\mathrm{n}} / \mathrm{bd}^{2} \\
(\mathrm{psi})\end{array}$ & $\mu_{\mathrm{S}}=\phi_{\mathrm{u}} / \phi_{\mathrm{y}}$ & $\begin{array}{c}\mathrm{R}_{\mathrm{A}}=\mathrm{M}_{\mathrm{n}} / \mathrm{bd}^{2} \\
(\mathrm{psi})\end{array}$ & $\mu_{\mathrm{A}}=\phi_{\mathrm{u}} / \phi_{\mathrm{y}}$ & $\mathrm{R}_{\mathrm{s}} / \mathrm{R}_{\mathrm{A}}$ & $\mu_{\mathrm{s}} / \mu_{\mathrm{A}}$ \\
\hline 0.00189 & 186.5 & 24.2 & 318.0 & 10.0 & $\mathbf{0 . 5 9}$ & $\mathbf{2 . 4}$ \\
\hline 0.003 & 293.7 & 15.7 & 483.7 & 6.0 & $\mathbf{0 . 6 1}$ & $\mathbf{2 . 6}$ \\
\hline 0.004 & 388.9 & 10.1 & 619.7 & 4.7 & $\mathbf{0 . 6 3}$ & $\mathbf{2 . 1}$ \\
\hline 0.005 & 482.6 & 7.9 & 743.6 & 3.9 & $\mathbf{0 . 6 5}$ & $\mathbf{2 . 0}$ \\
\hline 0.006 & 575.0 & 6.4 & 856.6 & 3.3 & $\mathbf{0 . 6 7}$ & $\mathbf{1 . 9}$ \\
\hline 0.007 & 666.0 & 5.4 & 959.5 & 2.6 & $\mathbf{0 . 6 9}$ & $\mathbf{2 . 0}$ \\
\hline 0.008 & 755.5 & 5.0 & 1053.7 & 2.3 & $\mathbf{0 . 7 2}$ & $\mathbf{2 . 1}$ \\
\hline 0.009 & 843.7 & 4.3 & 1139.9 & 2.1 & $\mathbf{0 . 7 4}$ & $\mathbf{2 . 0}$ \\
\hline 0.01 & 930.5 & 3.7 & 1219.2 & 1.9 & $\mathbf{0 . 7 6}$ & $\mathbf{1 . 9}$ \\
\hline 0.0117 & 1074.9 & 3.0 & 1340.4 & 1.8 & $\mathbf{0 . 8 0}$ & $\mathbf{1 . 7}$ \\
\hline
\end{tabular}



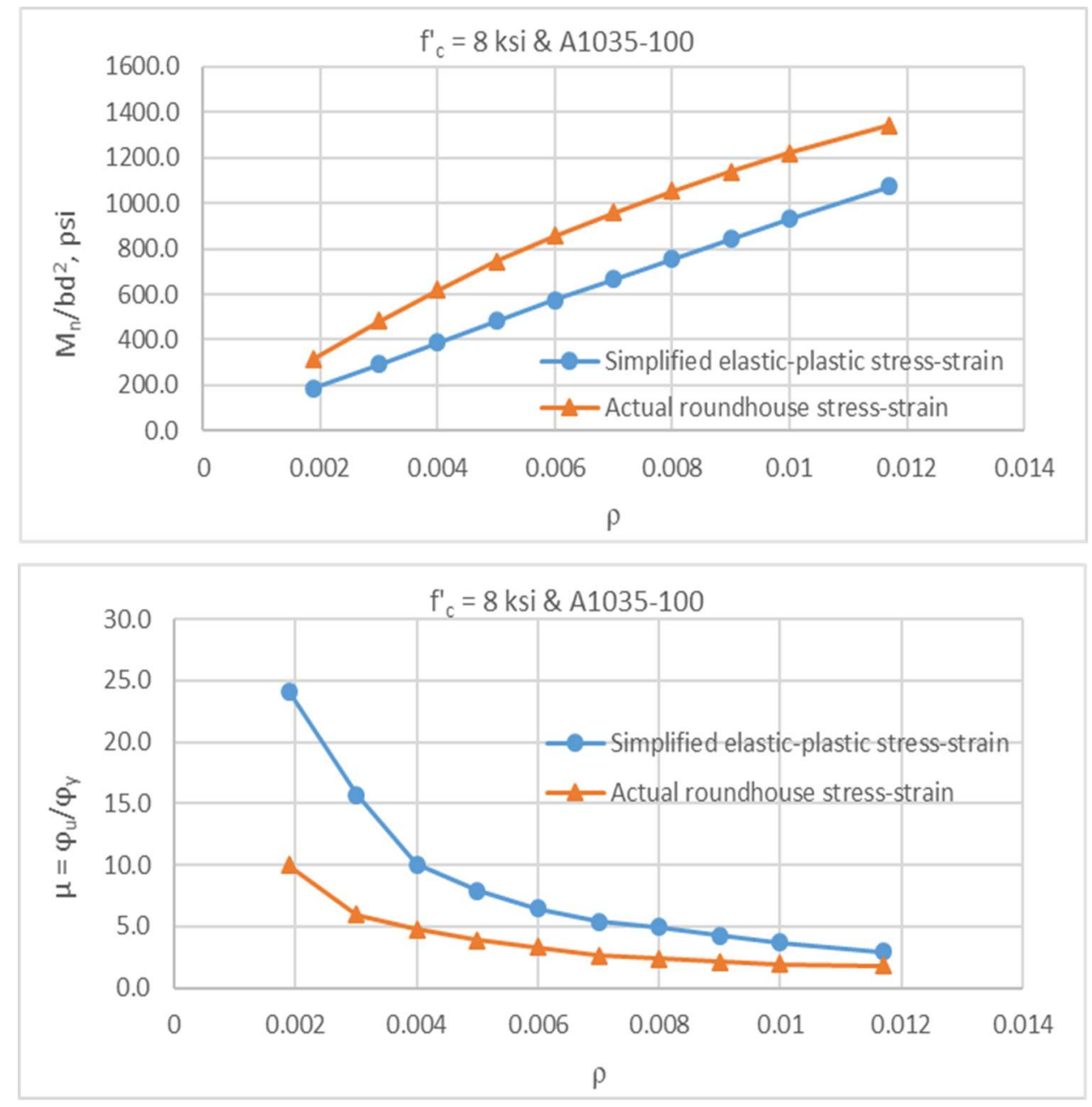

Figure 6-12: Effect of using simplified elastic-plastic model to idealize the behavior of A1035 reinforcement on moment capacity and curvature ductility 


\subsection{Flexural Design with HSR, Limiting the Maximum Stress}

In flexural design, the design strength should be greater than the LRFD factored load and is expressed as follows:

$\phi M_{n} \geq M_{u}$, where $M_{n}$ is the nominal flexural resistance; $M_{u}$ is the factored moment at the section.

In the current ACI 318 specifications, $\rho_{\max }$ can be derived based on the minimum strain limit. Moreover, there is a distinction of compression and tension-controlled section based on the strain in the extreme tension steel. To penalize for the undesirable behavior of compression-controlled sections, a lower value of strength reduction factor $(\phi)$ is assigned to "compression-controlled" sections compared to "tension-controlled" sections. Between these two strain limits (transition zone), the strength factor $\phi$ used for strength computation varies linearly with the strain in the extreme tension steel.

In this research for HSR, new comparable strain limits to that of Grade 60 steel were determined based on ductility, as described in Figure 6-8.

For HSR type A615 Grade 100 with distinct yield stress and yield plateau, a simplified elastic-plastic stress-strain curve can be used in design (with a yield stress, $f_{y}$, equal to $100 \mathrm{ksi}$ and modulus of elasticity, $E_{s}$, equal to $29000 \mathrm{ksi}$ ) so that the extra reserved capacity, represented by the strain hardening, is not accounted for in design to provide safety and to assure that the reinforcement will not rupture. This process would be comparable and similar to the current practice used for Grade 60 reinforcement. 
For HSR type A1035 Grades 100 \& 120 that have a roundhouse behavior, it was shown that using a simplified elastic-plastic stress-strain relationship in design is not recommended as it would overestimate the ductility by a factor of two. Therefore, in order to provide a reserved capacity with the use of the actual roundhouse curve, it seems reasonable to limit the stress, similar to what is commonly used in flexural design of prestressed concrete members. ACI 318 code prescribes the values for the maximum permissible stress in prestressed reinforcement, $f_{p s}$, using the following equation:

$f_{p s}=f_{p u}\left\{1-\frac{\gamma_{p}}{\beta_{1}}\left[\rho_{p} \frac{f_{p u}}{f_{c}^{\prime}}+\frac{d}{d_{p}} \frac{f_{y}}{f_{c}^{\prime}}\left(\rho-\rho^{\prime}\right)\right]\right\}$

Assuming only prestressed reinforcement is used, this equation reduces to:

$f_{p s}=f_{p u}\left\{1-\frac{\gamma_{p}}{\beta_{1}}\left[\rho_{p} \frac{f_{p u}}{f_{c}^{\prime}}\right]\right\}$, where:

$f_{p u}=$ is the specified tensile strength of prestressing reinforcement

$\rho_{p}=$ prestressed reinforcement ratio

$\beta_{1}=0.85-0.05\left(f_{c}^{\prime}-4000\right) \geq 0.65, \quad f_{c}^{\prime}$ in units of psi

$\gamma_{p}=$ factor used for type of prestressing reinforcement

\begin{tabular}{|c|c|}
\hline$f_{p y} / f_{p u}$ & $\gamma_{p}$ \\
\hline$\geq 0.80$ & 0.55 \\
\hline$\geq 0.85$ & 0.40 \\
\hline$\geq 0.90$ & 0.28 \\
\hline
\end{tabular}

This equation was applied for a range of $\rho_{p}$ of 0.0005 to 0.004 , and $f^{\prime} c$ of 4000 psi to 12000 psi. The results are summarized in Table 6-13 and Table 6-14. 
Table 6-13: Allowable stress in prestressed reinforcement for $\mathrm{f}_{\mathrm{c}}=4000 \mathrm{psi}$

\begin{tabular}{c|c|ccccc}
\multicolumn{1}{c}{$\boldsymbol{f}_{p u}$} & $\boldsymbol{f}_{c}^{\prime}$ & $\boldsymbol{\rho}_{\boldsymbol{p}}$ & $\boldsymbol{\gamma}_{\boldsymbol{p}}$ & $\boldsymbol{\beta}_{\boldsymbol{1}}$ & $\boldsymbol{f}_{p s}$ & $\boldsymbol{f}_{p s} / \boldsymbol{f}_{p u}$ \\
\hline \multirow{3}{*}{270} & 0.0005 & 0.55 & 0.85 & 264.1 & $\mathbf{0 . 9 8}$ \\
& & 0.001 & 0.55 & 0.85 & 258.2 & $\mathbf{0 . 9 6}$ \\
& & 0.002 & 0.55 & 0.85 & 246.4 & $\mathbf{0 . 9 1}$ \\
& \multirow{4}{*}{$\mathbf{4 0 0 0}$} & 0.003 & 0.55 & 0.85 & 234.6 & $\mathbf{0 . 8 7}$ \\
& & 0.004 & 0.55 & 0.85 & 222.8 & $\mathbf{0 . 8 3}$ \\
\cline { 3 - 7 } & & 0.0005 & 0.4 & 0.85 & 265.7 & $\mathbf{0 . 9 8}$ \\
& & 0.001 & 0.4 & 0.85 & 261.4 & $\mathbf{0 . 9 7}$ \\
& & 0.002 & 0.4 & 0.85 & 252.8 & $\mathbf{0 . 9 5}$ \\
& & 0.003 & 0.4 & 0.85 & 244.3 & $\mathbf{0 . 9 1}$ \\
& & 0.004 & 0.4 & 0.85 & 235.7 & $\mathbf{0 . 8 7}$ \\
\cline { 3 - 7 } & 0.0005 & 0.28 & 0.85 & 267.0 & $\mathbf{0 . 9 9}$ \\
& & 0.001 & 0.28 & 0.85 & 264.0 & $\mathbf{0 . 9 8}$ \\
& & 0.002 & 0.28 & 0.85 & 258.0 & $\mathbf{0 . 9 6}$ \\
& & 0.003 & 0.28 & 0.85 & 252.0 & $\mathbf{0 . 9 3}$ \\
& & 0.004 & 0.28 & 0.85 & 246.0 & $\mathbf{0 . 9 1}$ \\
& & & & & average & $\mathbf{0 . 9 3}$
\end{tabular}

Table 6-14: Allowable stress in prestressed reinforcement for $\mathrm{f}_{\mathrm{c}}=12000 \mathrm{psi}$

\begin{tabular}{|c|c|c|c|c|c|c|}
\hline$f_{p u}$ & $f_{c}^{\prime}$ & $\rho_{p}$ & $\gamma_{p}$ & $\boldsymbol{\beta}_{1}$ & fps & $f_{p s} / f_{p u}$ \\
\hline \multirow{15}{*}{270} & \multirow{15}{*}{12000} & 0.0005 & 0.55 & 0.65 & 267.4 & 0.990 \\
\hline & & 0.001 & 0.55 & 0.65 & 264.9 & 0.981 \\
\hline & & 0.002 & 0.55 & 0.65 & 259.7 & 0.962 \\
\hline & & 0.003 & 0.55 & 0.65 & 254.6 & 0.943 \\
\hline & & 0.004 & 0.55 & 0.65 & 249.4 & 0.924 \\
\hline & & 0.0005 & 0.4 & 0.65 & 268.1 & 0.993 \\
\hline & & 0.001 & 0.4 & 0.65 & 266.3 & 0.986 \\
\hline & & 0.002 & 0.4 & 0.65 & 262.5 & 0.972 \\
\hline & & 0.003 & 0.4 & 0.65 & 258.8 & 0.958 \\
\hline & & 0.004 & 0.4 & 0.65 & 255.0 & 0.945 \\
\hline & & 0.0005 & 0.28 & 0.65 & 268.7 & 0.995 \\
\hline & & 0.001 & 0.28 & 0.65 & 267.4 & 0.990 \\
\hline & & 0.002 & 0.28 & 0.65 & 264.8 & 0.981 \\
\hline & & 0.003 & 0.28 & 0.65 & 262.1 & 0.971 \\
\hline & & 0.004 & 0.28 & 0.65 & 259.5 & 0.961 \\
\hline & & & & & average & 0.97 \\
\hline
\end{tabular}


The average values of $\mathrm{f}_{\mathrm{ps}} / \mathrm{f}_{\mathrm{pu}}$ ratio are 0.93 and 0.97 for $\mathrm{f}_{\mathrm{c}}$ of $4000 \mathrm{psi}$ to $12000 \mathrm{psi}$ respectively.

Using the results of this study as a guide, for design purposes, it seems reasonable to limit the LRFD level design stress for HSR type A1035 to $0.90 \mathrm{f}_{\mathrm{u}}$.

\subsection{Design Flexural Strength vs. Reinforcement Ratio Charts for HSR}

To facilitate the design with high-strength reinforcement, nominal flexural strengths are determined for variable reinforcement ratios and variable concrete strengths, then the resistance factors (Figure 6-8) are applied to the nominal strength of sections reinforced with HSR to develop the design charts, as shown in Figure 6-14 through Figure 6-15. The minimum reinforcement ratios based on $\varepsilon_{u}=0.05$ as proposed in the previous section are presented in the charts for information purposes. The actual behavior of the materials is used for developing the design charts. The charts can be used to determine the reinforcement ratio for a given moment, $\mathrm{M}_{\mathrm{u}}$, and a selected section dimensions, $\mathrm{b}$ x d, or they can be used to account for the design strength for a given reinforced section. A set of design charts for beams with HSR and $f^{\prime}{ }_{c}$ range of 4000 psi to 12000 psi are shown in Appendix B. 


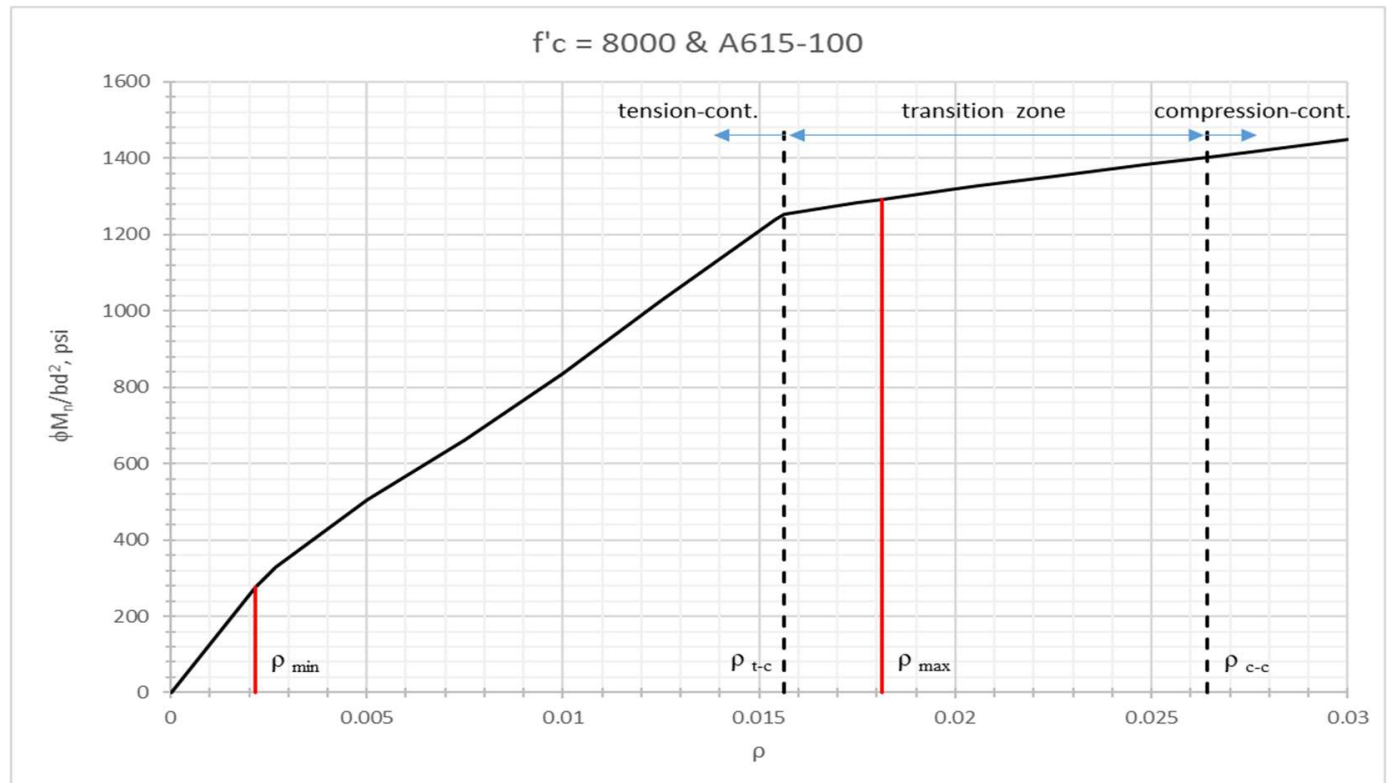

Figure 6-14: Flexural design chart for beams with $\mathrm{f}_{\mathrm{c}}=8000$ psi \& reinforced with A615 grade 100 rebar

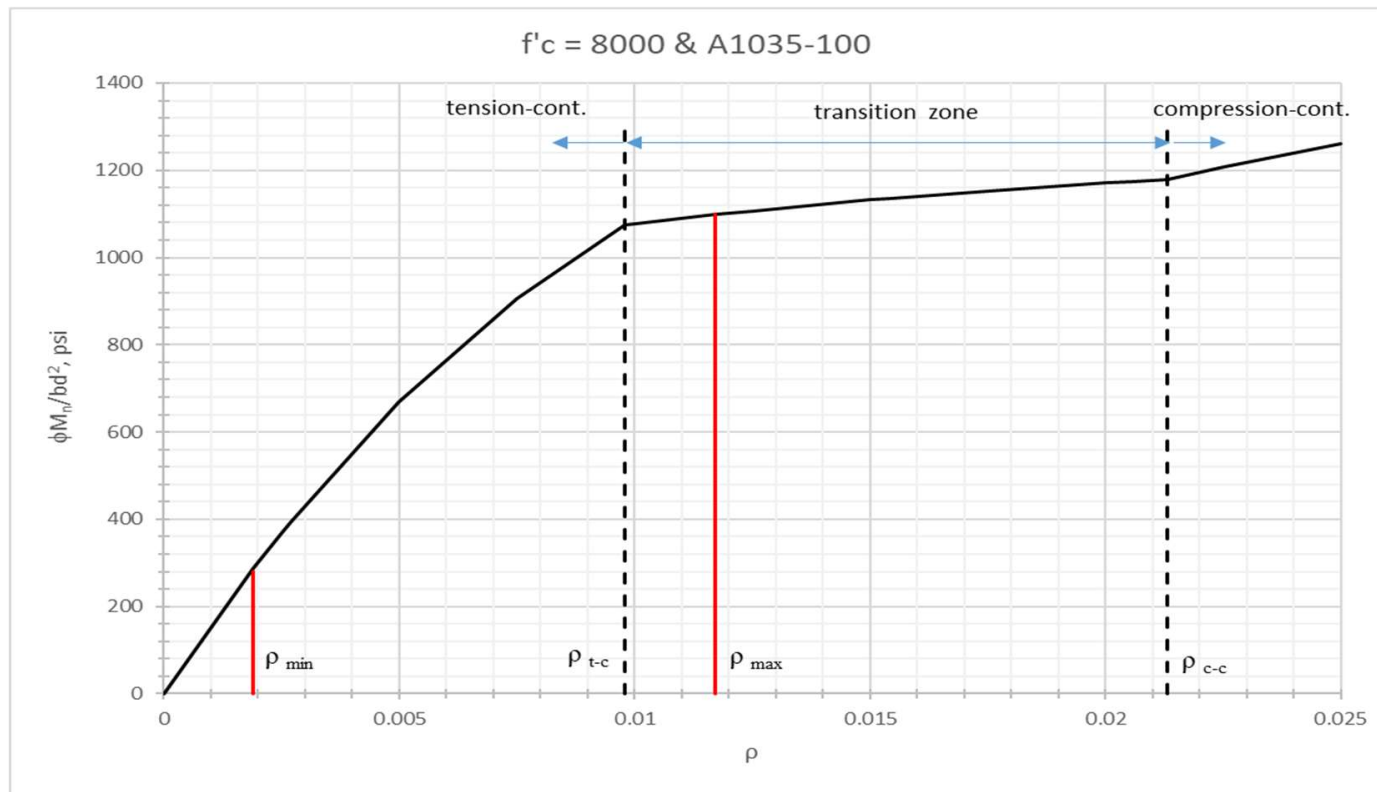

Figure 6-13: Flexural design chart for beams with $\mathrm{f}_{c}=8000$ psi \& reinforced with A1035 grade 100 rebar 


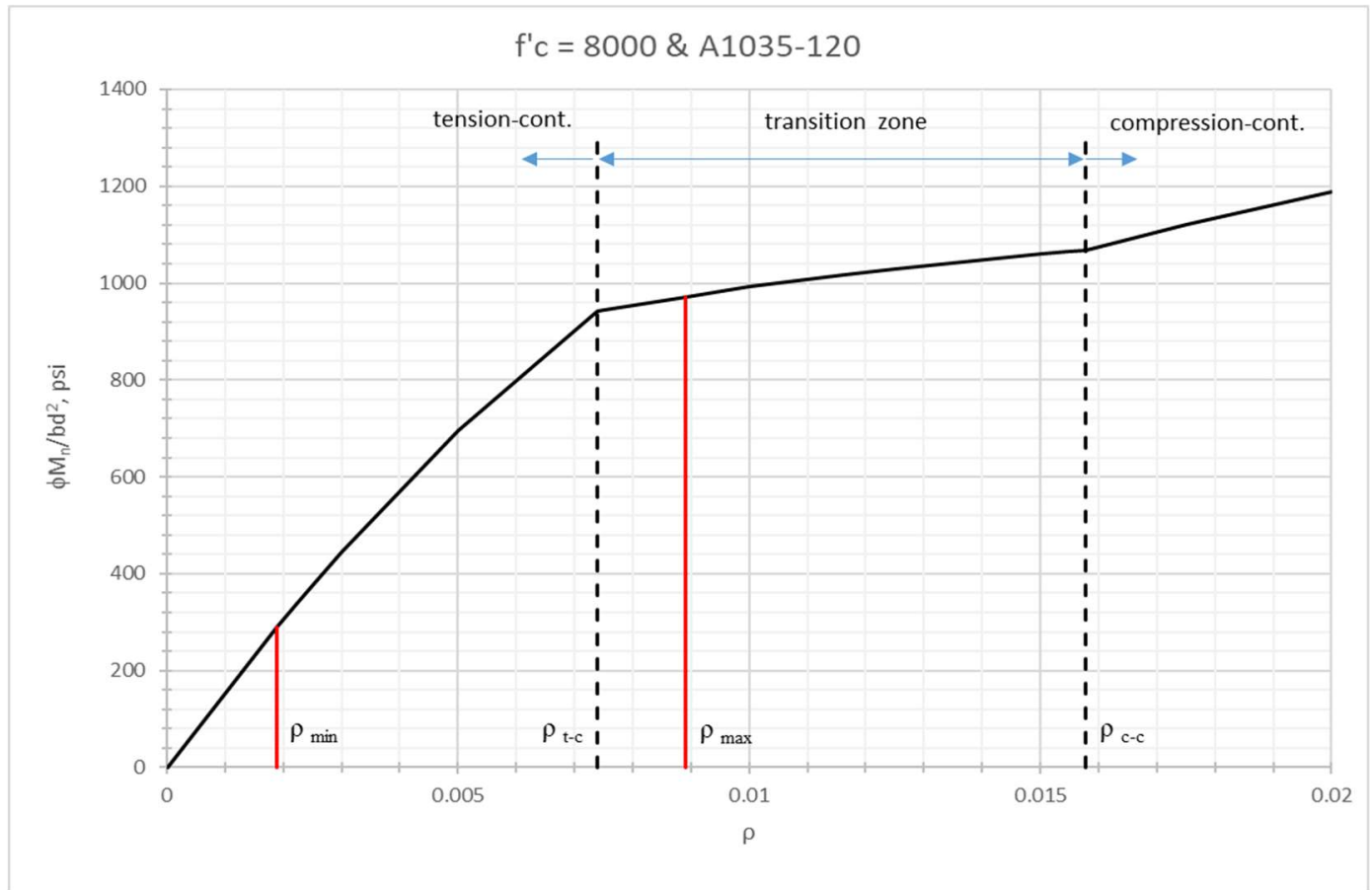

Figure 6-15: Flexural design chart for beams with $\mathrm{f}_{c}=8000$ psi \& reinforced with A1035 grade 120 rebar

\subsection{Short-Term Deflection at Service Load Level}

Deflection is an important performance criterion that needs to be checked to insure the structure remains serviceable under specified loading conditions. In load and resistance factor design (LRFD) approach, a deflection check follows the strength design. In this section, an analytical study is conducted to predict the deflections at service load level for flexural beams made with variable concrete strengths $(4,8$, and $12 \mathrm{ksi})$ and that are reinforced with high-strength reinforcement of two different types (A615-100, A1035$100 \& 120)$ to investigate the appropriateness of the current method used to predict deflection at service level for the use of HSR. Deflections are calculated using a momentcurvature analysis that considers the actual stress-strain relationships of the concrete and 
the reinforcement, and then are compared with the current approach to predict a deflection that utilizes the elastic beam deflection equations and the effective moment of inertia of the section. The effective moment of inertia is calculated using two formulas: Branson equation and Bischoff equation discussed in section 2.7.1. The beams are assumed simply supported and subjected to uniformly distributed load. Service load to LRFD level load is expressed as the following equation:

$$
\frac{w_{s}}{w_{n}}=\frac{D+L}{\left[\frac{(1.2 D+1.6 L)}{\emptyset}\right]}
$$

A parametric study of this ratio is shown in Appendix C. The study indicates that for reinforced concrete beams, $\mathrm{W}_{\mathrm{s}} / \mathrm{W}_{\mathrm{n}}$ is generally about $60 \%$ to $63 \%$ for common range of loads. For simplicity, the magnitude of service load used in this study was taken as $60 \%$ of the nominal LRFD level capacity. The deflection of simply supported reinforced concrete beams subjected to uniformly distributed load using the elastic method can be expressed as the following equation:

$$
\Delta=\frac{5 w L^{4}}{384 E_{c} I_{e}}
$$

Where,

$w=$ The applied service load

$L=$ Clear span length

$E_{c}=$ Concrete elastic modulus $\left(E_{c}=57000 \sqrt{f_{c}^{\prime}}\right.$, where $f_{c}^{\prime}$ is in psi unites $)$

$I_{e}=$ Effective moment of inertia of the section

$$
I_{e}=I_{c r}+\left(I_{g}-I_{c r}\right)\left(\frac{M_{c r}}{M_{a}}\right)^{3} \leq I_{g} \quad \ldots \ldots \ldots A C I 318-14 \text { Eq. }(24.2 .3 .5 a)
$$




$$
\begin{aligned}
& I_{e}=\frac{I_{c r}}{1-\left(1-\frac{I_{c r}}{I_{g}}\right)\left(\frac{M_{c r}}{M_{a}}\right)^{2}} \leq I_{g} \quad \ldots \ldots \ldots \text { Bischoff (2007)Eqaution } \\
& M_{c r}=\text { cracking moment }\left(M_{c r}=\frac{f_{r} \cdot I_{e}}{y_{t}}\right) \\
& y_{t}=\frac{h}{2} \\
& f_{r}=7.5 \sqrt{f_{c}^{\prime}} \\
& I_{g}=\frac{b \cdot h^{3}}{12} \\
& I_{c r}=\frac{b \cdot c^{3}}{3}+n \cdot A_{s}(d-c)^{2} \\
& \mathrm{c}=\text { depth of the neutral axis of the cracked section }\left(c=\frac{-n \cdot A_{s}+\sqrt{\left(n \cdot A_{s}\right)^{2}+2 . n \cdot A_{s} \cdot b \cdot d}}{b}\right) \\
& n=\frac{E_{s}}{E_{c}}
\end{aligned}
$$

From the moment-curvature analysis, the immediate deflection at service load is extracted from the load-deflection relationship when the load is equal to $60 \%$ of the maximum load. The cross section of the beams is assumed 6 in. x 10 in. with a simple span of $8 \mathrm{ft}$., and the reinforcement ratio is varied from $\rho_{\min }$ to $\rho_{\max }$. Figure 6-16 shows the relationship between $\rho$ and $\mathrm{M}_{\mathrm{cr}} / \mathrm{M}_{\mathrm{a}}$ ratio for the example beam. 


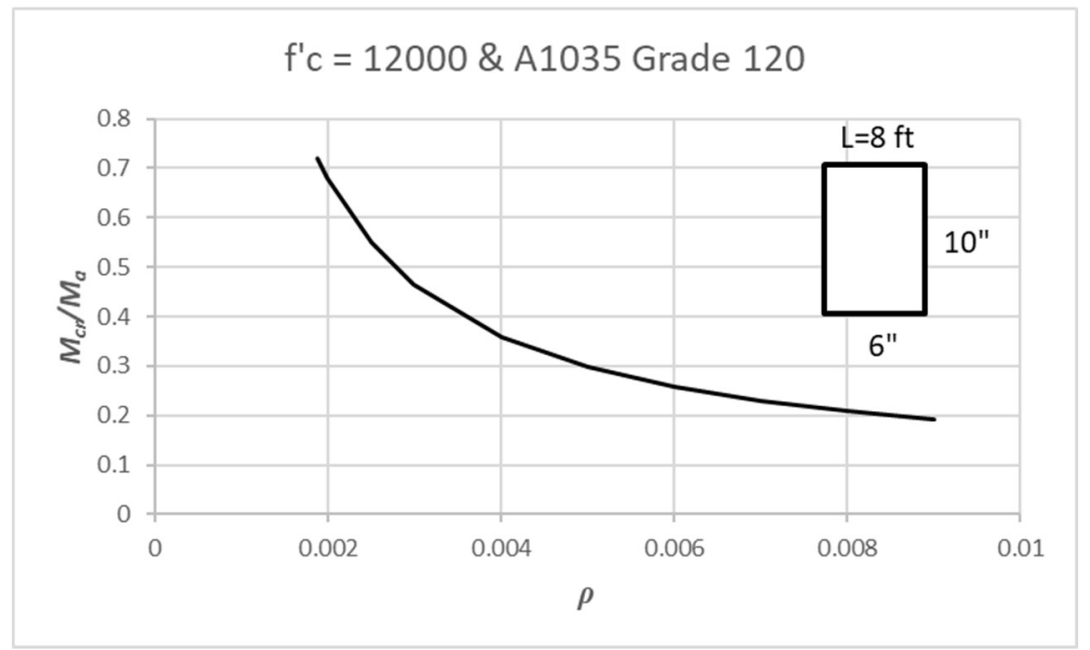

Figure 6-17: Relationship between $\rho$ and $\mathrm{M}_{\mathrm{cr}} / \mathrm{M}_{\mathrm{a}}$ ratio for an example beam

The results of comparing the immediate service load deflection using the momentcurvature analysis that represents the most accurate behavior with the elastic method using effective moment inertia for beams of different concrete capacities and reinforced with HSR are summarized in Table 6-15 through Table 6-17, and shown graphically in Figure 6-18 through Figure 6-20. 
Table 6-15: Comparison of analytical and calculated deflections at service load level for beams reinforced with A615 grade 100

\begin{tabular}{|c|c|c|c|c|c|c|c|c|c|}
\hline $\begin{array}{c}f^{\prime} c \\
\text { (ksi) }\end{array}$ & $\rho$ & $\begin{array}{l}\varepsilon_{s \text { (at }} \\
\text { failure) }\end{array}$ & $\begin{array}{c}\text { W service } \\
(\mathrm{k} / \mathrm{ft})\end{array}$ & $\begin{array}{c}\mathrm{f}_{\mathrm{s}} \\
\text { service } / \mathrm{fy}_{\mathrm{y}}\end{array}$ & $\begin{array}{r}\begin{array}{r}\Delta \mathrm{i}(\mathrm{M}-\phi \\
\text { analysis })\end{array} \\
\end{array}$ & $\begin{array}{c}\Delta_{\mathrm{i}} \\
\text { Branson } \\
\end{array}$ & $\begin{array}{c}\Delta_{\mathrm{i}} \\
\text { Bischoff } \\
\end{array}$ & $\begin{array}{l}\Delta \mathrm{i} \text { Branson } / \Delta \mathrm{i} \\
\text { ( } M-\varphi \text { analysis) }\end{array}$ & $\begin{array}{l}\Delta \mathrm{i}_{\text {Bischoff }} / \Delta \mathrm{i} \\
\text { (M- } \varphi \text { analysis) }\end{array}$ \\
\hline \multirow{11}{*}{4} & 0.0012 & 0.05 & 0.520 & 0.89 & 0.294 & 0.031 & 0.061 & 0.10 & 0.21 \\
\hline & 0.0015 & 0.0418 & 0.616 & 0.85 & 0.286 & 0.057 & 0.151 & 0.20 & 0.53 \\
\hline & 0.0017 & 0.0378 & 0.674 & 0.82 & 0.281 & 0.076 & 0.184 & 0.27 & 0.66 \\
\hline & 0.002 & 0.0333 & 0.755 & 0.79 & 0.273 & 0.107 & 0.215 & 0.39 & 0.79 \\
\hline & 0.0025 & 0.0280 & 0.879 & 0.74 & 0.262 & 0.156 & 0.241 & 0.59 & 0.92 \\
\hline & 0.003 & 0.0243 & 0.993 & 0.70 & 0.253 & 0.194 & 0.254 & 0.76 & 1.00 \\
\hline & 0.004 & 0.0194 & 1.199 & 0.64 & 0.241 & 0.237 & 0.262 & 0.99 & 1.09 \\
\hline & 0.005 & 0.0157 & 1.417 & 0.61 & 0.237 & 0.263 & 0.270 & 1.11 & 1.14 \\
\hline & 0.006 & 0.0126 & 1.676 & 0.61 & 0.243 & 0.285 & 0.285 & 1.17 & 1.17 \\
\hline & 0.008 & 0.0087 & 2.169 & 0.60 & 0.253 & 0.306 & 0.302 & 1.21 & 1.19 \\
\hline & 0.01 & 0.0064 & 2.630 & 0.59 & 0.261 & 0.317 & 0.313 & 1.21 & 1.20 \\
\hline \multirow{11}{*}{8} & 0.0022 & 0.05 & 0.953 & 0.90 & 0.308 & 0.077 & 0.198 & 0.25 & 0.64 \\
\hline & 0.003 & 0.0388 & 1.203 & 0.84 & 0.292 & 0.150 & 0.261 & 0.51 & 0.89 \\
\hline & 0.004 & 0.0310 & 1.470 & 0.77 & 0.279 & 0.220 & 0.285 & 0.79 & 1.02 \\
\hline & 0.005 & 0.0260 & 1.709 & 0.73 & 0.268 & 0.259 & 0.293 & 0.97 & 1.09 \\
\hline & 0.006 & 0.0226 & 1.929 & 0.69 & 0.260 & 0.279 & 0.294 & 1.07 & 1.13 \\
\hline & 0.008 & 0.0180 & 2.329 & 0.63 & 0.248 & 0.291 & 0.292 & 1.18 & 1.18 \\
\hline & 0.01 & 0.0140 & 2.826 & 0.62 & 0.252 & 0.308 & 0.304 & 1.22 & 1.21 \\
\hline & 0.012 & 0.0112 & 3.341 & 0.61 & 0.259 & 0.320 & 0.317 & 1.24 & 1.22 \\
\hline & 0.014 & 0.0092 & 3.839 & 0.61 & 0.264 & 0.330 & 0.326 & 1.25 & 1.23 \\
\hline & 0.016 & 0.0076 & 4.320 & 0.60 & 0.270 & 0.337 & 0.334 & 1.25 & 1.24 \\
\hline & 0.0181 & 0.0064 & 4.806 & 0.60 & 0.275 & 0.343 & 0.341 & 1.25 & 1.24 \\
\hline \multirow{11}{*}{12} & 0.003 & 0.05 & 1.308 & 0.91 & 0.310 & 0.110 & 0.242 & 0.36 & 0.78 \\
\hline & 0.004 & 0.0404 & 1.629 & 0.85 & 0.301 & 0.190 & 0.289 & 0.63 & 0.96 \\
\hline & 0.005 & 0.0339 & 1.908 & 0.80 & 0.291 & 0.245 & 0.305 & 0.84 & 1.05 \\
\hline & 0.006 & 0.0294 & 2.162 & 0.76 & 0.282 & 0.277 & 0.310 & 0.98 & 1.10 \\
\hline & 0.007 & 0.0261 & 2.398 & 0.73 & 0.275 & 0.295 & 0.312 & 1.07 & 1.13 \\
\hline & 0.008 & 0.0235 & 2.621 & 0.70 & 0.269 & 0.304 & 0.311 & 1.13 & 1.16 \\
\hline & 0.009 & 0.0214 & 2.833 & 0.68 & 0.264 & 0.308 & 0.310 & 1.17 & 1.18 \\
\hline & 0.01 & 0.0197 & 3.037 & 0.66 & 0.259 & 0.309 & 0.309 & 1.19 & 1.19 \\
\hline & 0.019 & 0.0096 & 5.253 & 0.62 & 0.273 & 0.342 & 0.339 & 1.25 & 1.24 \\
\hline & 0.021 & 0.0084 & 5.746 & 0.61 & 0.277 & 0.348 & 0.345 & 1.26 & 1.25 \\
\hline & 0.0255 & 0.0064 & 6.813 & 0.60 & 0.286 & 0.360 & 0.358 & 1.26 & 1.25 \\
\hline
\end{tabular}


Table 6-16: Comparison of analytical and calculated deflections at service load level for beams reinforced with A1035 grade 100

\begin{tabular}{|c|c|c|c|c|c|c|c|c|c|}
\hline $\begin{array}{c}f^{\prime} c \\
\text { (ksi) }\end{array}$ & $\rho$ & $\begin{array}{l}\varepsilon_{s} \text { (at } \\
\text { failure) }\end{array}$ & $\begin{array}{l}\text { Wervice } \\
(\mathrm{k} / \mathrm{ft})\end{array}$ & $\begin{array}{c}f_{s} \\
\text { service/ } f_{y}\end{array}$ & $\begin{array}{l}\Delta_{i}(\mathrm{M}-\phi \\
\text { analysis) }\end{array}$ & $\begin{array}{c}\Delta_{\mathrm{i}} \\
\text { Branson }\end{array}$ & $\begin{array}{c}\Delta_{\mathrm{i}} \\
\text { Bischoff }\end{array}$ & $\begin{array}{c}\Delta \mathrm{i}_{\text {Branson }} / \Delta \mathrm{i} \\
\text { (M- } \varphi \text { analysis) }\end{array}$ & $\begin{array}{l}\Delta \mathrm{i}_{\text {Bischoff }} / \Delta \mathrm{i} \\
\text { (M- } \varphi \text { analysis) }\end{array}$ \\
\hline \multirow{10}{*}{4} & 0.00103 & 0.05 & 0.526 & 1.04 & 0.480 & 0.032 & 0.075 & 0.07 & 0.16 \\
\hline & 0.00125 & 0.0409 & 0.628 & 1.03 & 0.478 & 0.061 & 0.188 & 0.13 & 0.39 \\
\hline & 0.0015 & 0.0340 & 0.741 & 1.02 & 0.473 & 0.106 & 0.261 & 0.22 & 0.55 \\
\hline & 0.002 & 0.0255 & 0.952 & 0.99 & 0.463 & 0.207 & 0.333 & 0.45 & 0.72 \\
\hline & 0.0025 & 0.0204 & 1.147 & 0.96 & 0.451 & 0.287 & 0.364 & 0.64 & 0.81 \\
\hline & 0.003 & 0.0171 & 1.325 & 0.93 & 0.437 & 0.335 & 0.377 & 0.77 & 0.86 \\
\hline & 0.004 & 0.0130 & 1.638 & 0.87 & 0.413 & 0.374 & 0.384 & 0.90 & 0.93 \\
\hline & 0.005 & 0.0105 & 1.905 & 0.82 & 0.390 & 0.379 & 0.380 & 0.97 & 0.97 \\
\hline & 0.006 & 0.0089 & 2.133 & 0.77 & 0.370 & 0.374 & 0.371 & 1.01 & 1.00 \\
\hline & 0.0067 & 0.008 & 2.274 & 0.74 & 0.357 & 0.368 & 0.365 & 1.03 & 1.02 \\
\hline \multirow{10}{*}{8} & 0.00187 & 0.05 & 0.956 & 1.05 & 0.490 & 0.079 & 0.228 & 0.16 & 0.47 \\
\hline & 0.0025 & 0.0372 & 1.248 & 1.03 & 0.486 & 0.175 & 0.325 & 0.36 & 0.67 \\
\hline & 0.003 & 0.0310 & 1.469 & 1.01 & 0.481 & 0.250 & 0.363 & 0.52 & 0.75 \\
\hline & 0.004 & 0.0233 & 1.882 & 0.98 & 0.469 & 0.351 & 0.399 & 0.75 & 0.85 \\
\hline & 0.005 & 0.0187 & 2.259 & 0.95 & 0.455 & 0.395 & 0.413 & 0.87 & 0.91 \\
\hline & 0.006 & 0.0156 & 2.602 & 0.92 & 0.441 & 0.413 & 0.418 & 0.94 & 0.95 \\
\hline & 0.007 & 0.0135 & 2.915 & 0.89 & 0.428 & 0.418 & 0.417 & 0.98 & 0.98 \\
\hline & 0.008 & 0.0119 & 3.200 & 0.86 & 0.415 & 0.418 & 0.415 & 1.01 & 1.00 \\
\hline & 0.009 & 0.0106 & 3.463 & 0.83 & 0.403 & 0.415 & 0.411 & 1.03 & 1.02 \\
\hline & 0.0123 & 0.008 & 4.190 & 0.74 & 0.368 & 0.397 & 0.394 & 1.08 & 1.07 \\
\hline \multirow{13}{*}{12} & 0.00262 & 0.05 & 1.342 & 1.05 & 0.498 & 0.122 & 0.287 & 0.25 & 0.58 \\
\hline & 0.003 & 0.0435 & 1.521 & 1.04 & 0.496 & 0.174 & 0.328 & 0.35 & 0.66 \\
\hline & 0.004 & 0.0326 & 1.973 & 1.02 & 0.490 & 0.295 & 0.386 & 0.60 & 0.79 \\
\hline & 0.005 & 0.0261 & 2.399 & 1.00 & 0.483 & 0.369 & 0.412 & 0.76 & 0.85 \\
\hline & 0.006 & 0.0217 & 2.798 & 0.98 & 0.474 & 0.408 & 0.426 & 0.86 & 0.90 \\
\hline & 0.007 & 0.0187 & 3.172 & 0.96 & 0.465 & 0.426 & 0.432 & 0.92 & 0.93 \\
\hline & 0.008 & 0.0164 & 3.522 & 0.93 & 0.455 & 0.435 & 0.435 & 0.95 & 0.96 \\
\hline & 0.009 & 0.0146 & 3.849 & 0.91 & 0.446 & 0.438 & 0.436 & 0.98 & 0.98 \\
\hline & 0.01 & 0.0132 & 4.157 & 0.89 & 0.436 & 0.438 & 0.434 & 1.00 & 1.00 \\
\hline & 0.012 & 0.0112 & 4.716 & 0.85 & 0.419 & 0.434 & 0.430 & 1.04 & 1.03 \\
\hline & 0.014 & 0.00968 & 5.212 & 0.81 & 0.402 & 0.427 & 0.423 & 1.06 & 1.05 \\
\hline & 0.016 & 0.00858 & 5.655 & 0.77 & 0.388 & 0.419 & 0.416 & 1.08 & 1.07 \\
\hline & 0.01728 & 0.0080 & 5.914 & 0.75 & 0.379 & 0.414 & 0.411 & 1.09 & 1.08 \\
\hline
\end{tabular}


Table 6-17: Comparison of analytical and calculated deflections at service load level for beams reinforced with A1035 grade 120

\begin{tabular}{|c|c|c|c|c|c|c|c|c|c|}
\hline $\begin{array}{c}f^{\prime} c \\
\text { (ksi) }\end{array}$ & $\rho$ & $\begin{array}{l}\varepsilon_{s} \text { (at } \\
\text { failure) }\end{array}$ & $\begin{array}{l}\text { W }_{\text {service }} \\
(\mathrm{k} / \mathrm{ft})\end{array}$ & $\begin{array}{c}\mathrm{f}_{\mathrm{s}} \\
\text { service/ } / \mathrm{f}_{\mathrm{y}}\end{array}$ & $\begin{array}{l}\Delta_{i}(\mathrm{M}-\phi \\
\text { analysis) }\end{array}$ & $\begin{array}{c}\Delta_{\mathrm{i}} \\
\text { Branson } \\
\end{array}$ & $\begin{array}{c}\begin{array}{c}\Delta_{\mathrm{i}} \\
\text { Bischoff }\end{array} \\
\text { Ben }\end{array}$ & $\begin{array}{l}\Delta \mathrm{i} \text { Branson } / \Delta \mathrm{i} \\
\text { (M- } \varphi \text { analysis) }\end{array}$ & $\begin{array}{l}\Delta \mathrm{i}_{\text {Bischoff }} / \Delta \mathrm{i} \\
\text { (M- } \varphi \text { analysis) }\end{array}$ \\
\hline \multirow{8}{*}{4} & 0.00102 & 0.05 & 0.526 & 0.88 & 0.431 & 0.032 & 0.075 & 0.07 & 0.17 \\
\hline & 0.00125 & 0.0403 & 0.637 & 0.87 & 0.433 & 0.065 & 0.198 & 0.15 & 0.46 \\
\hline & 0.0015 & 0.0333 & 0.755 & 0.87 & 0.435 & 0.113 & 0.273 & 0.26 & 0.63 \\
\hline & 0.002 & 0.0247 & 0.980 & 0.85 & 0.434 & 0.222 & 0.349 & 0.51 & 0.80 \\
\hline & 0.0025 & 0.0196 & 1.188 & 0.83 & 0.429 & 0.307 & 0.382 & 0.72 & 0.89 \\
\hline & 0.003 & 0.01625 & 1.380 & 0.81 & 0.421 & 0.358 & 0.397 & 0.85 & 0.94 \\
\hline & 0.004 & 0.0122 & 1.716 & 0.76 & 0.404 & 0.396 & 0.405 & 0.98 & 1.00 \\
\hline & 0.0049 & 0.01 & 1.972 & 0.72 & 0.387 & 0.401 & 0.401 & 1.04 & 1.04 \\
\hline \multirow{10}{*}{8} & 0.00188 & 0.05 & 0.970 & 0.88 & 0.442 & 0.083 & 0.237 & 0.19 & 0.54 \\
\hline & 0.002 & 0.0461 & 1.029 & 0.88 & 0.443 & 0.101 & 0.263 & 0.23 & 0.59 \\
\hline & 0.0025 & 0.0365 & 1.270 & 0.88 & 0.445 & 0.184 & 0.335 & 0.41 & 0.75 \\
\hline & 0.003 & 0.0302 & 1.503 & 0.87 & 0.445 & 0.264 & 0.375 & 0.59 & 0.84 \\
\hline & 0.004 & 0.0224 & 1.943 & 0.85 & 0.442 & 0.369 & 0.415 & 0.84 & 0.94 \\
\hline & 0.005 & 0.0178 & 2.347 & 0.82 & 0.436 & 0.416 & 0.432 & 0.96 & 0.99 \\
\hline & 0.006 & 0.0148 & 2.716 & 0.80 & 0.428 & 0.435 & 0.438 & 1.02 & 1.02 \\
\hline & 0.007 & 0.01268 & 3.051 & 0.78 & 0.418 & 0.440 & 0.439 & 1.05 & 1.05 \\
\hline & 0.008 & 0.0111 & 3.356 & 0.75 & 0.408 & 0.440 & 0.436 & 1.08 & 1.07 \\
\hline & 0.009 & 0.01 & 3.633 & 0.73 & 0.398 & 0.436 & 0.432 & 1.10 & 1.09 \\
\hline \multirow{12}{*}{12} & 0.0026 & 0.05 & 1.343 & 0.9 & 0.447 & 0.123 & 0.290 & 0.27 & 0.65 \\
\hline & 0.003 & 0.0430 & 1.540 & 0.9 & 0.451 & 0.180 & 0.335 & 0.40 & 0.74 \\
\hline & 0.0035 & 0.0366 & 1.780 & 0.9 & 0.452 & 0.249 & 0.372 & 0.55 & 0.82 \\
\hline & 0.004 & 0.0318 & 2.015 & 0.9 & 0.454 & 0.308 & 0.397 & 0.68 & 0.88 \\
\hline & 0.005 & 0.0252 & 2.467 & 0.9 & 0.453 & 0.386 & 0.427 & 0.85 & 0.94 \\
\hline & 0.006 & 0.0209 & 2.894 & 0.8 & 0.450 & 0.426 & 0.443 & 0.95 & 0.98 \\
\hline & 0.007 & 0.0178 & 3.296 & 0.8 & 0.446 & 0.446 & 0.451 & 1.00 & 1.01 \\
\hline & 0.008 & 0.0155 & 3.672 & 0.8 & 0.440 & 0.456 & 0.455 & 1.04 & 1.03 \\
\hline & 0.009 & 0.0138 & 4.025 & 0.8 & 0.434 & 0.460 & 0.457 & 1.06 & 1.05 \\
\hline & 0.01 & 0.0124 & 4.354 & 0.8 & 0.427 & 0.460 & 0.456 & 1.08 & 1.07 \\
\hline & 0.011 & 0.0113 & 4.661 & 0.8 & 0.420 & 0.459 & 0.455 & 1.09 & 1.08 \\
\hline & 0.012 & 0.01 & 4.949 & 0.7 & 0.413 & 0.456 & 0.452 & 1.11 & 1.09 \\
\hline
\end{tabular}




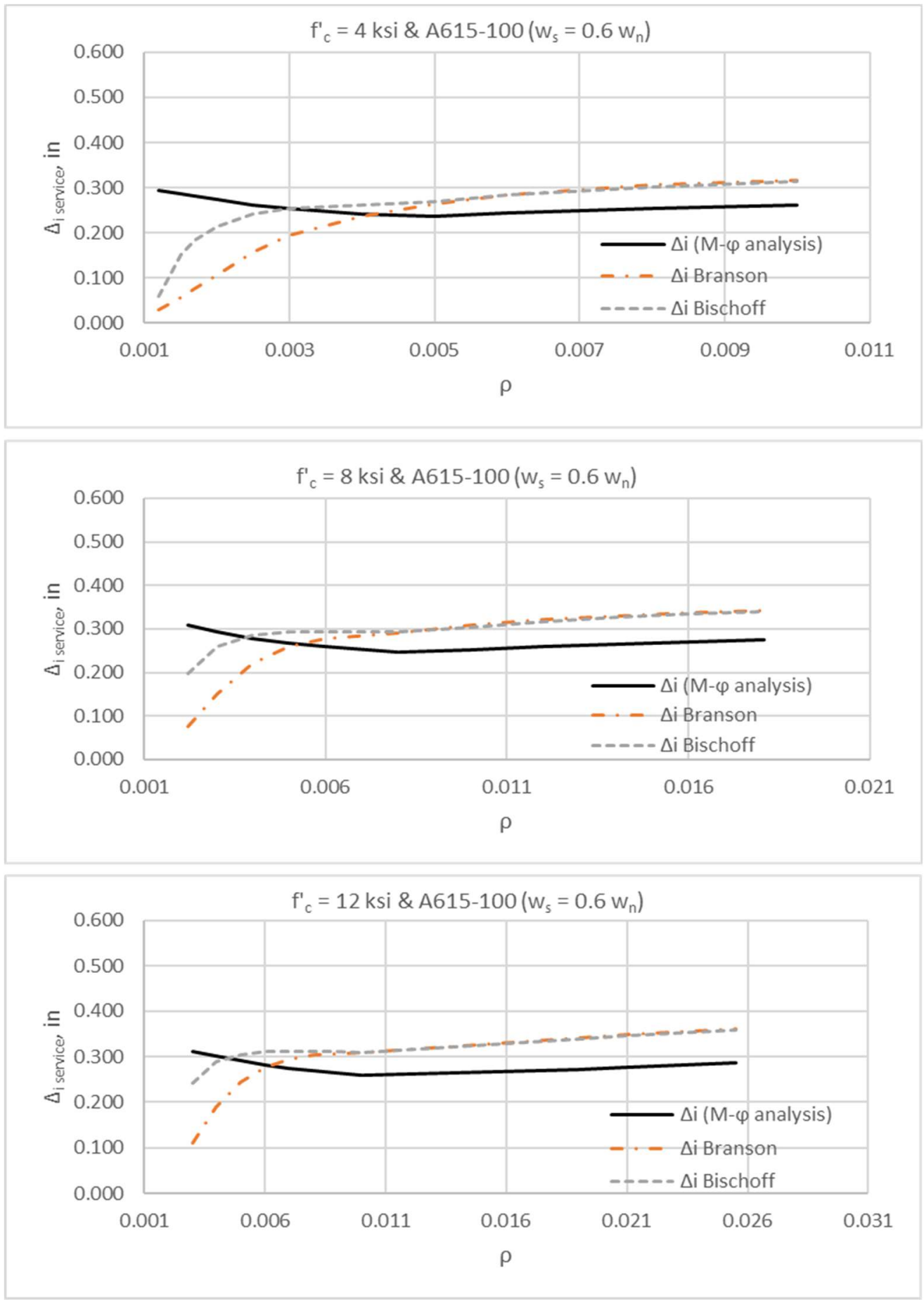

Figure 6-18: Immediate deflection prediction using M- $\phi$ analysis and $I_{e}$ method for beams reinforced with A615 grade 100 rebar 

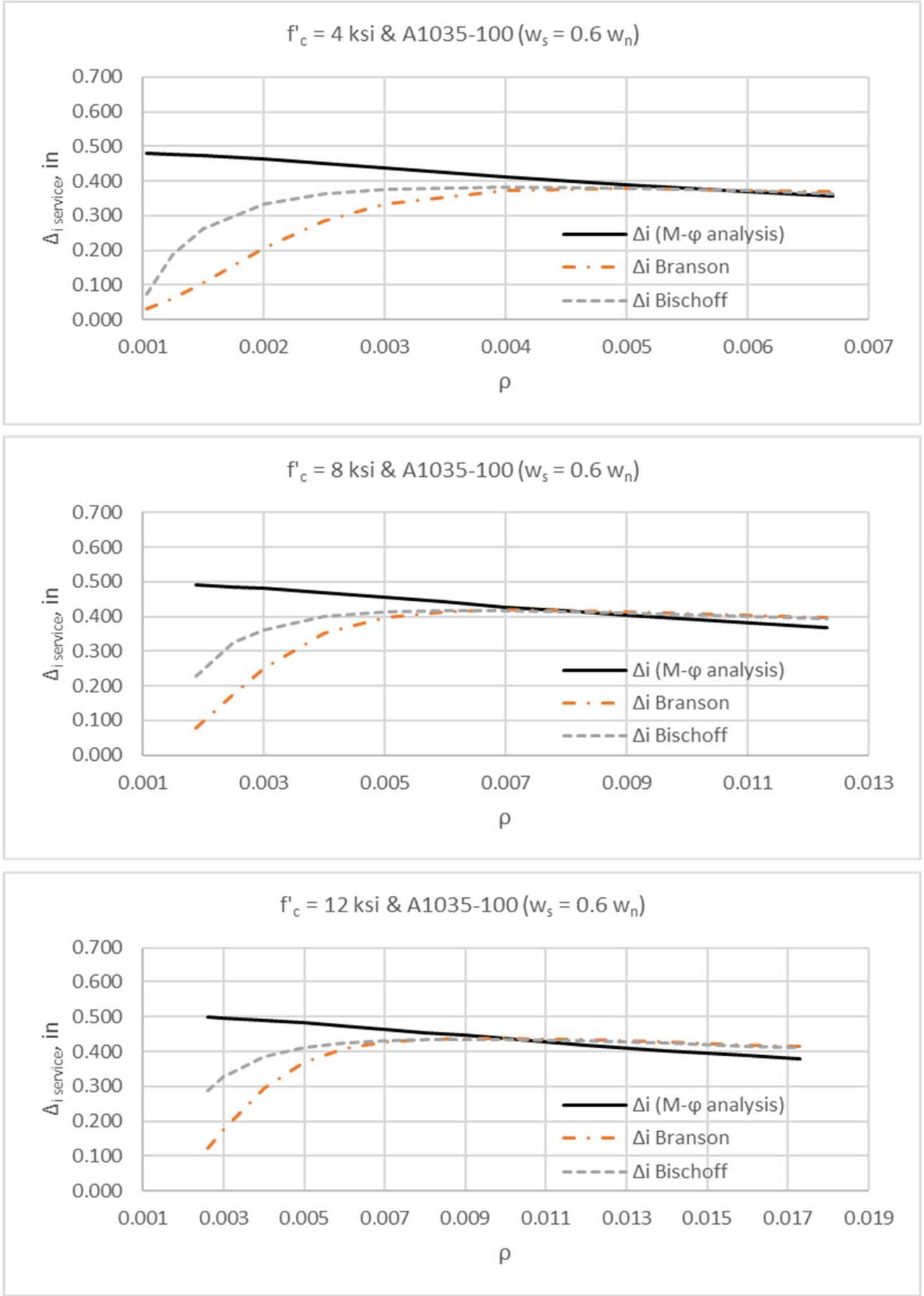

Figure 6-19: Immediate deflection prediction using M- $\phi$ analysis and $I_{e}$ method for beams reinforced with A1035 grade 100 rebar 


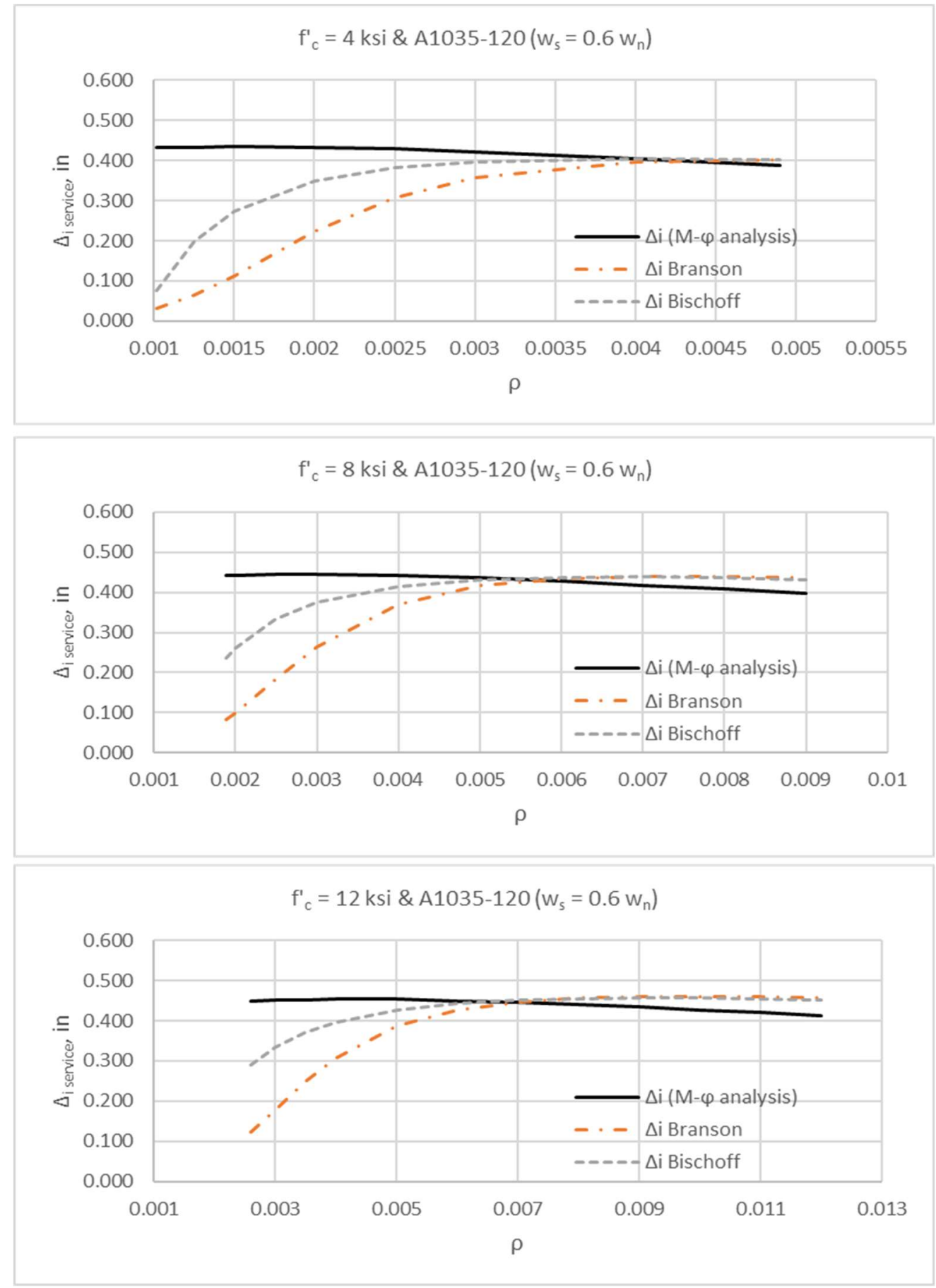

Figure 6-20: Immediate deflection prediction using M- $\phi$ analysis and $I_{e}$ method for beams reinforced with A1035 grade 120 rebar 
It is clear that from comparing the results of deflections from the moment-curvature analysis with the use of elastic method and effective moment of inertia that the elastic method resulted in either an underestimation for the deflection for very low reinforcement ratios or an overestimation for reinforcement ratios close to $\rho_{\max }$ of each HSR examined here. However, the use of Bischoff's equation to calculate $I_{e}$ gives better results than Branson's equation.

The elastic method is giving very low amount of deflections with very low reinforcement ratios because the $M_{c r} / M_{a}$ ratio is increasing when the reinforcement ratio is decreasing that leads to a high $I_{e}$ and as a result to a low deflection. The relationship between $\rho$ and $\mathrm{M}_{\mathrm{cr}} / \mathrm{M}_{\mathrm{a}}$ ratio is shown in Figure 6-17.

In this investigation, a modification factor, $\mathrm{K}$, based on a regression analysis for deflections using Bischoff's equation is suggested to be applied to Bischoff's effective moment of inertia to improve the prediction of deflections for beams reinforced with HSR.

The relationships between the immediate deflection calculated using M- $\phi$ analysis and $I_{e}$ of Bischoff method for different reinforcement ratios for beams with HSR and concrete strengths from 4000 psi to 12000 psi are shown in Figure 6-22 along with the best fit curves for each HSR type. However, the modification factor resulting from the Polynomial regression analysis using the least squares method led to a cumbersome equation, shown on the graphs. Therefore, it seemed reasonable to use a simpler Ramberg-Osgood equation to determine the modification factor $(\mathrm{K})$ to adjust the effective moment of inertia as following: 


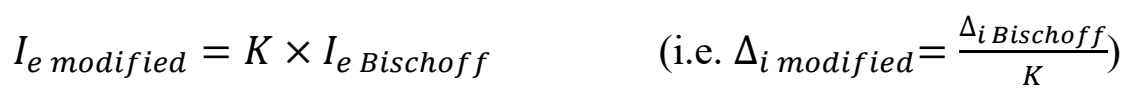

Where,

$K=\left\{A+\frac{1-A}{\left[1+(B \times \rho)^{C}\right]^{1 / C}}\right\} D \times \rho, \quad \rho=$ reinforcement ratio

Where the value of the coefficients A, B, C, and D for each reinforcement type were determined as follows:

\begin{tabular}{c|ccc} 
& $\mathbf{A 6 1 5 - 1 0 0}$ & $\mathbf{A 1 0 3 5}-\mathbf{1 0 0}$ & $\mathbf{A 1 0 3 5 - 1 2 0}$ \\
\hline $\mathbf{A}$ & 0.009 & 0.03 & 0.035 \\
B & 300 & 320 & 330 \\
C & 3 & 3 & 4 \\
D & 360 & 310 & 330
\end{tabular}

Figure 6-21 shows that the Polynomial regression analysis and K-factor modification equation give virtually the same results.

The comparison of the modified immediate deflections calculated using the modified Bischoff effective moment of inertia are given in Table 6-18 through Table 6-20. The results of modified deflections showed a very good agreement with the deflections resulted from the moment-curvature analysis with the average of ( $\left.\Delta \mathrm{i}_{\text {Bischoff modified }} / \Delta \mathrm{i}_{\mathrm{M}-\varphi \text { analysis }}\right)$ equal to 0.99. Thus, the use of the modification factor with Bischoff's expression of the effective moment of inertia will give a better prediction for the immediate deflections of the beams reinforced with HSR. 

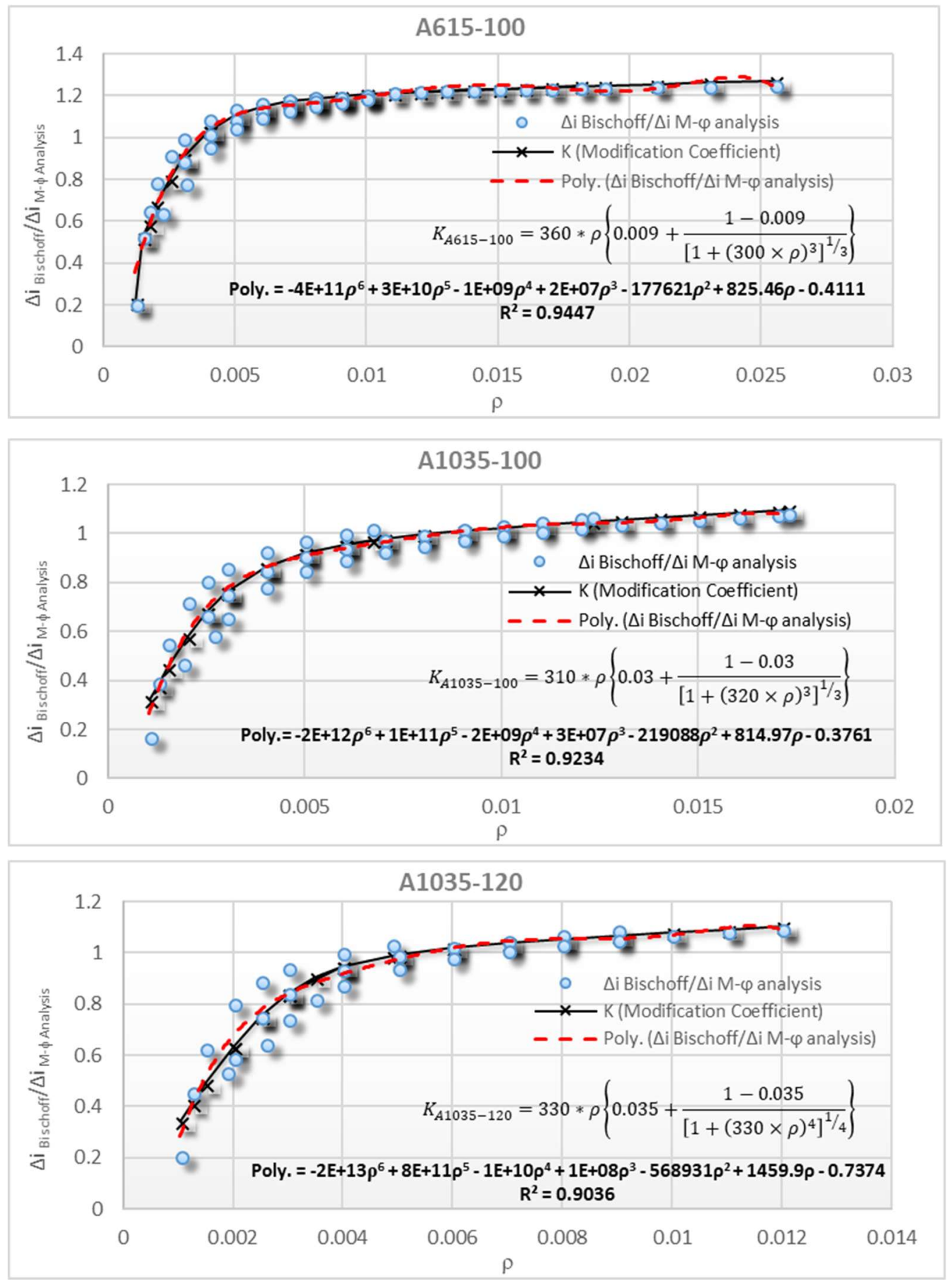

Figure 6-22: Relationship between immediate deflection calculated using M- $\phi$ analysis and $I_{e}$ of Bischoff method for beams reinforced with HSR 
Table 6-18: Modified immediate deflections calculated using the suggested modified Bischoff effective moment of inertia for beams reinforced with A615 grade 100

\begin{tabular}{|c|c|c|c|c|c|c|}
\hline $\mathrm{f}_{\mathrm{c}}^{\prime}(\mathrm{ksi})$ & $\rho$ & $\Delta \mathrm{i} M-\varphi$ analysis & $\begin{array}{c}\Delta \mathrm{i} \\
\text { Bischoff }\end{array}$ & K & $\Delta \mathrm{i}$ Bischoff modified & $\Delta \mathrm{i}_{\text {Bischoff modified }} / \Delta \mathrm{i} M-\varphi$ analysis \\
\hline \multirow{11}{*}{4} & 0.0012 & 0.294 & 0.061 & 0.43 & 0.142 & 0.48 \\
\hline & 0.0015 & 0.286 & 0.151 & 0.52 & 0.288 & 1.01 \\
\hline & 0.0017 & 0.281 & 0.184 & 0.59 & 0.314 & 1.12 \\
\hline & 0.002 & 0.273 & 0.215 & 0.67 & 0.319 & 1.17 \\
\hline & 0.0025 & 0.262 & 0.241 & 0.80 & 0.301 & 1.15 \\
\hline & 0.003 & 0.253 & 0.254 & 0.90 & 0.281 & 1.11 \\
\hline & 0.004 & 0.241 & 0.262 & 1.03 & 0.253 & 1.05 \\
\hline & 0.005 & 0.237 & 0.270 & 1.11 & 0.244 & 1.03 \\
\hline & 0.006 & 0.243 & 0.285 & 1.15 & 0.248 & 1.02 \\
\hline & 0.008 & 0.253 & 0.302 & 1.19 & 0.255 & 1.01 \\
\hline & 0.01 & 0.261 & 0.313 & 1.21 & 0.259 & 0.99 \\
\hline \multirow{11}{*}{8} & 0.0022 & 0.308 & 0.198 & 0.73 & 0.272 & 0.88 \\
\hline & 0.003 & 0.292 & 0.261 & 0.90 & 0.289 & 0.99 \\
\hline & 0.004 & 0.279 & 0.285 & 1.03 & 0.276 & 0.99 \\
\hline & 0.005 & 0.268 & 0.293 & 1.11 & 0.264 & 0.99 \\
\hline & 0.006 & 0.260 & 0.294 & 1.15 & 0.256 & 0.99 \\
\hline & 0.008 & 0.248 & 0.292 & 1.19 & 0.246 & 0.99 \\
\hline & 0.01 & 0.252 & 0.304 & 1.21 & 0.252 & 1.00 \\
\hline & 0.012 & 0.259 & 0.317 & 1.22 & 0.259 & 1.00 \\
\hline & 0.014 & 0.264 & 0.326 & 1.23 & 0.265 & 1.00 \\
\hline & 0.016 & 0.270 & 0.334 & 1.24 & 0.270 & 1.00 \\
\hline & 0.0181 & 0.275 & 0.341 & 1.25 & 0.273 & 1.00 \\
\hline \multirow{11}{*}{12} & 0.003 & 0.310 & 0.242 & 0.90 & 0.269 & 0.87 \\
\hline & 0.004 & 0.301 & 0.289 & 1.03 & 0.279 & 0.93 \\
\hline & 0.005 & 0.291 & 0.305 & 1.11 & 0.275 & 0.95 \\
\hline & 0.006 & 0.282 & 0.310 & 1.15 & 0.271 & 0.96 \\
\hline & 0.007 & 0.275 & 0.312 & 1.17 & 0.266 & 0.97 \\
\hline & 0.008 & 0.269 & 0.311 & 1.19 & 0.262 & 0.98 \\
\hline & 0.009 & 0.264 & 0.310 & 1.20 & 0.259 & 0.98 \\
\hline & 0.01 & 0.259 & 0.309 & 1.21 & 0.256 & 0.99 \\
\hline & 0.019 & 0.273 & 0.339 & 1.25 & 0.271 & 1.00 \\
\hline & 0.021 & 0.277 & 0.345 & 1.26 & 0.275 & 0.99 \\
\hline & 0.0255 & 0.286 & 0.358 & 1.27 & 0.281 & 0.99 \\
\hline
\end{tabular}


Table 6-19: Modified immediate deflections calculated using the suggested modified Bischoff effective moment of inertia for beams reinforced with A1035 grade 100

\begin{tabular}{|c|c|c|c|c|c|c|}
\hline $\mathrm{f}_{c}^{\prime}(\mathrm{ksi})$ & $\rho$ & $\begin{array}{c}\Delta_{\mathrm{i} M-\phi} \\
\text { analysis }\end{array}$ & $\Delta_{\mathrm{i} \text { Bischoff }}$ & K & $\Delta \mathrm{i}$ Bischoff modified & $\Delta \mathrm{i}_{\text {Bischoff modified }} / \Delta \mathrm{i} \mathrm{M}-\varphi$ analysis \\
\hline \multirow{10}{*}{4} & 0.00103 & 0.480 & 0.075 & 0.32 & 0.239 & 0.50 \\
\hline & 0.00125 & 0.478 & 0.188 & 0.38 & 0.495 & 1.04 \\
\hline & 0.0015 & 0.473 & 0.261 & 0.45 & 0.581 & 1.23 \\
\hline & 0.002 & 0.463 & 0.333 & 0.58 & 0.579 & 1.25 \\
\hline & 0.0025 & 0.451 & 0.364 & 0.68 & 0.536 & 1.19 \\
\hline & 0.003 & 0.437 & 0.377 & 0.76 & 0.498 & 1.14 \\
\hline & 0.004 & 0.413 & 0.384 & 0.86 & 0.445 & 1.08 \\
\hline & 0.005 & 0.390 & 0.380 & 0.92 & 0.413 & 1.06 \\
\hline & 0.006 & 0.370 & 0.371 & 0.95 & 0.389 & 1.05 \\
\hline & 0.0067 & 0.357 & 0.365 & 0.97 & 0.375 & 1.05 \\
\hline \multirow{10}{*}{8} & 0.00187 & 0.490 & 0.228 & 0.54 & 0.419 & 0.86 \\
\hline & 0.0025 & 0.486 & 0.325 & 0.68 & 0.479 & 0.99 \\
\hline & 0.003 & 0.481 & 0.363 & 0.76 & 0.478 & 1.00 \\
\hline & 0.004 & 0.469 & 0.399 & 0.86 & 0.463 & 0.99 \\
\hline & 0.005 & 0.455 & 0.413 & 0.92 & 0.449 & 0.99 \\
\hline & 0.006 & 0.441 & 0.418 & 0.95 & 0.437 & 0.99 \\
\hline & 0.007 & 0.428 & 0.417 & 0.98 & 0.427 & 1.00 \\
\hline & 0.008 & 0.415 & 0.415 & 1.00 & 0.416 & 1.00 \\
\hline & 0.009 & 0.403 & 0.411 & 1.01 & 0.406 & 1.01 \\
\hline & 0.0123 & 0.368 & 0.394 & 1.05 & 0.375 & 1.02 \\
\hline \multirow{13}{*}{12} & 0.00262 & 0.498 & 0.287 & 0.70 & 0.410 & 0.82 \\
\hline & 0.003 & 0.496 & 0.328 & 0.76 & 0.432 & 0.87 \\
\hline & 0.004 & 0.490 & 0.386 & 0.86 & 0.447 & 0.91 \\
\hline & 0.005 & 0.483 & 0.412 & 0.92 & 0.448 & 0.93 \\
\hline & 0.006 & 0.474 & 0.426 & 0.95 & 0.446 & 0.94 \\
\hline & 0.007 & 0.465 & 0.432 & 0.98 & 0.442 & 0.95 \\
\hline & 0.008 & 0.455 & 0.435 & 1.00 & 0.437 & 0.96 \\
\hline & 0.009 & 0.446 & 0.436 & 1.01 & 0.431 & 0.97 \\
\hline & 0.01 & 0.436 & 0.434 & 1.02 & 0.425 & 0.97 \\
\hline & 0.012 & 0.419 & 0.430 & 1.05 & 0.411 & 0.98 \\
\hline & 0.014 & 0.402 & 0.423 & 1.07 & 0.397 & 0.99 \\
\hline & 0.016 & 0.388 & 0.416 & 1.09 & 0.383 & 0.99 \\
\hline & 0.01728 & 0.379 & 0.411 & 1.10 & 0.374 & 0.99 \\
\hline
\end{tabular}


Table 6-20: Modified immediate deflections calculated using the suggested modified Bischoff effective moment of inertia for beams reinforced with A1035 grade 120

\begin{tabular}{|c|c|c|c|c|c|c|}
\hline $\mathrm{f}_{c}^{\prime}(\mathrm{ksi})$ & $P$ & $\begin{array}{c}\Delta_{\mathrm{i} M-\phi} \\
\text { analysis }\end{array}$ & $\begin{array}{c}\Delta_{\mathrm{i}} \\
\text { Bischoff }\end{array}$ & K & $\Delta \mathrm{i}$ Bischoff modified & $\Delta \mathrm{i}_{\text {Bischoff modified }} / \Delta \mathrm{i} M-\varphi$ analysis \\
\hline \multirow{8}{*}{4} & 0.00102 & 0.431 & 0.075 & 0.34 & 0.225 & 0.52 \\
\hline & 0.00125 & 0.433 & 0.198 & 0.41 & 0.483 & 1.12 \\
\hline & 0.0015 & 0.435 & 0.273 & 0.49 & 0.560 & 1.29 \\
\hline & 0.002 & 0.434 & 0.349 & 0.63 & 0.551 & 1.27 \\
\hline & 0.0025 & 0.429 & 0.382 & 0.75 & 0.507 & 1.18 \\
\hline & 0.003 & 0.421 & 0.397 & 0.84 & 0.472 & 1.12 \\
\hline & 0.004 & 0.404 & 0.405 & 0.94 & 0.429 & 1.06 \\
\hline & 0.0049 & 0.387 & 0.401 & 0.99 & 0.405 & 1.05 \\
\hline \multirow{10}{*}{8} & 0.00188 & 0.442 & 0.237 & 0.60 & 0.394 & 0.89 \\
\hline & 0.002 & 0.443 & 0.263 & 0.63 & 0.415 & 0.94 \\
\hline & 0.0025 & 0.445 & 0.335 & 0.75 & 0.445 & 1.00 \\
\hline & 0.003 & 0.445 & 0.375 & 0.84 & 0.446 & 1.00 \\
\hline & 0.004 & 0.442 & 0.415 & 0.94 & 0.439 & 0.99 \\
\hline & 0.005 & 0.436 & 0.432 & 0.99 & 0.435 & 1.00 \\
\hline & 0.006 & 0.428 & 0.438 & 1.02 & 0.430 & 1.00 \\
\hline & 0.007 & 0.418 & 0.439 & 1.04 & 0.423 & 1.01 \\
\hline & 0.008 & 0.408 & 0.436 & 1.05 & 0.415 & 1.02 \\
\hline & 0.009 & 0.398 & 0.432 & 1.07 & 0.405 & 1.02 \\
\hline \multirow{12}{*}{12} & 0.0026 & 0.447 & 0.290 & 0.77 & 0.375 & 0.84 \\
\hline & 0.003 & 0.451 & 0.335 & 0.84 & 0.398 & 0.88 \\
\hline & 0.0035 & 0.452 & 0.372 & 0.90 & 0.412 & 0.91 \\
\hline & 0.004 & 0.454 & 0.397 & 0.94 & 0.420 & 0.93 \\
\hline & 0.005 & 0.453 & 0.427 & 0.99 & 0.430 & 0.95 \\
\hline & 0.006 & 0.450 & 0.443 & 1.02 & 0.434 & 0.97 \\
\hline & 0.007 & 0.446 & 0.451 & 1.04 & 0.435 & 0.98 \\
\hline & 0.008 & 0.440 & 0.455 & 1.05 & 0.433 & 0.98 \\
\hline & 0.009 & 0.434 & 0.457 & 1.07 & 0.429 & 0.99 \\
\hline & 0.01 & 0.427 & 0.456 & 1.08 & 0.423 & 0.99 \\
\hline & 0.011 & 0.420 & 0.455 & 1.09 & 0.417 & 0.99 \\
\hline & 0.012 & 0.413 & 0.452 & 1.10 & 0.410 & 0.99 \\
\hline
\end{tabular}




\section{Chapter Seven: Summary, Conclusions, and Recommendations for Future Research}

\subsection{Summary and Conclusions}

Based on the results of the analytical and experimental studies of this research, the following observations and conclusions are made:

\subsubsection{Strength and Ductility}

1. For beams designed with HSR tension-controlled, minimum strain, and compression-controlled strain limits of the current ACI 318 code need to be modified so that these limits would provide ductility comparable to the members reinforced with Grade 60 steel. Curvature ductility and energy absorption, represented by the area under the load-deflection, were considered for comparisons of ductility. Curvature ductility index resulted in higher strain limits, which should lead to a higher ductility in the members. Therefore, the obtained strain limits based on curvature ductility (summarized in Table 6-2) are recommended for design with HSR.

2. Following the current approach of ACI 318 code for determining the strength reduction factor $\phi$, strength reduction factors for the investigated HSR are created based on comparable strain limits, as shown in Figure 6-8.

3. Different stress-strain shapes of the reinforced steels can lead to a different calibration for the strain limits needed for the design of flexural members. Therefore, a typical representative stress-strain relationship should be specified for each HSR for design purposes. 
4. Because HSR type A615 Grade 100 has a distinct yield point and yield plateau, a simplified elastic-plastic stress-strain comparable to Grade 60 steel is recommended for design with $f_{y}=100 \mathrm{ksi}$.

5. For HSR type A1035 Grades $100 \& 120$ that have a roundhouse stress-strain relationship, the use of elastic-plastic stress-strain underestimates the moment capacity and inaccurately predicts the ductility. For design purposes, using the representative stress-strain relationships are recommended, in conjunction with limiting the stress to about 0.90 of the ultimate stress.

6. For all the tested beams made with HSC and HSR, the maximum recorded strain in the tension reinforcement $\left(\varepsilon_{s}\right)$ satisfied and exceeded the target minimum strain ( $\varepsilon_{s \text { min }}$ ) for flexural members with HSR determined from the parametric study, which attests to ductile behavior. Moreover, near ultimate loads, all beams showed good crack distribution, visible crack openings and curvature. These are considered visual signs that attest to ductile behavior.

7. The analytical study and the experimental verification showed that HSRs studied in this investigation (A615-100, A1035-100, and A1035-120) are more efficient when coupled with the use of HSC. For each reinforcement type, for the same beam section and design moment capacity, the ductility of beams increased as the concrete strength increased up to the studied strength of 12000 psi (as shown in Table 4-3 and Table 5-5).

8. Beams reinforced with HSR A615 Grade 100 were more comparable in ductility and serviceability to beams made with Grade 60 steel, than beams reinforced with 
HSR A1035. However, in terms of cost saving, beams reinforced with HSR type A1035 required less steel to achieve the same design strength.

\subsubsection{Minimum Reinforcement Ratio}

The minimum reinforcement ratio $\left(\rho_{\min }\right)$ for the use of HSR was studied in this research for the goal of providing a minimum amount of steel with a reasonable margin of safety between first cracking and flexural failure $\left(\varnothing M_{n} / M_{c r}\right)$. The current ACI 318 equation was compared with the results of the approach suggested by the ATC-115, 2014 report $\left(\varnothing M_{n}=1.2 M_{c r}\right)$. ACI 318 equation for $\rho_{\min }$ resulted in higher amount of steel. However, $\varnothing M_{n}=1.2 M_{c r}$ approach resulted in higher strains in the reinforcement that may not be achievable by the properties of HSR. It is recommended to extend the use of ACI 318 equation to beams with HSR.

\subsubsection{Cracking Behavior}

1. Based on the results of flexural tests (Table 5-6), crack widths at service load levels were predictable using the current ACI 318 provisions and were found to be within presently acceptable limits.

2. Crack widths could be estimated accurately using Frosch's equation. This suggests that the current ACI 318 code approach for controlling crack width can be extended to beams with HSR. 


\subsubsection{Deflection Under Service Load}

1. A fundamental advantage in using HSR is that the amount of steel required for design is reduced considerably. However, this reduction results in higher stresses, and consequently higher strains in tension reinforcement at the service load level, as compared to conventional steel. Larger strains adversely affect deflection and crack width. Therefore, serviceability requirements are more likely to be the controlling limit states for design with HSR.

2. Moreover, a significant discrepancy between the actual deflection and the deflection predicted using the elastic method was observed when the stress in HSR exceeds the proportional limit, as shown in Table 5-7 for beams reinforced with HSR type A1035. Therefore, it is recommended to limit the stress for HSR in design to about 0.90 of the ultimate stress so that the service-level stresses will be within the elastic part.

3. Based on the analytical results for the prediction of the immediate deflection at service load level, use of Bischoff's equation to calculate $I_{e}$ showed better predictions with very low reinforcement ratios than Branson's equation. Bischoff's equation is recommended for deflection calculations with use of HSR. Additionally, the proposed modification factor $\mathrm{K}$ discussed in section 6.7 can be applied to Bischoff's $I_{e}$ for better results.

4. From the long-term deflection test results, it was observed that the current ACI 318 multiplier, $\lambda$, over predicted the long-term deflection for the tested beam made with HSC and HSR, as high-strength concrete has a lower creep factor. The 
modified multiplier proposed by Muhaisin (2012), which takes into account the concrete strength showed the closest prediction, hence is a likely potential for use with beams made with HSC and HSR.

\subsection{Recommendations for Future Research (Keep the sentence structure parallel)}

1. Test more beams made with HSC and HSR to provide additional data to fully validate and expand the findings of the current study.

2. Expand the current study to include beams made with concrete strength beyond 14000 psi to investigate ductility and serviceability of the beams with HSR.

3. Examine experimentally and theoretically the flexural behavior of beams made with HSC and HSR under cyclic loading.

4. Expand the experimental long-term deflection study for beams made with HSR (A615 Grade 100 and A1035 Grades 100 \& 120) with different concrete strengths and reinforcement ratios.

5. Explore the application of coupling HSC and HSR to other related topics, e.g. shear strength of beams and axial capacity of columns. 


\section{References}

ACI 211.1-91. (1991). Standard practice for selecting proportions for normal, heavyweight, and mass concrete. ACI Committee 211, American Concrete Institute, Farmington Hills, MI.

ACI 211.4R-08. (2008). Guide for selecting proportions for High-Strength Concrete using Portland cement and other cementitious materials. ACI Committee 211, American Concrete Institute, Farmington Hills, MI.

ACI 318-14. (2014). Building Code Requirements for Structural Concrete and Commentary. ACI Committee 318, American Concrete Institute, Farmington Hills, MI .

ACI 435R-95. (1995). Control of deflection in concrete structures. ACI Committee 435, American Concrete Institute, Farmington Hills, MI.

ACI ITG-6R-10. (2010). Design guide for the use of ASTM A1035/A1035M Grade 100 (690) steel bars for structural concrete. ACI Innovation Task Group 6, ACI Committee 93, American Concrete Institute, Farmington Hills, Michigan.

Ansley, M. H. (2002). Structures Design. Retrieved from Florida Department of Transportation: http://www.fdot.gov/structures/structuresresearchcenter/Final\%20Reports/200201\%20Investigation $\% 20$ Into $\% 20$ the $\% 20$ Structural $\% 20$ Performance $\% 20$ of $\% 20 \mathrm{M}$ MFX\%20Reinforcing.pdf

Ashour, S. A. (2000, May). Effect of compressive strength and tensile reinforcement ratio on flexural behavior of high-strength concrete beams. Engineering Structures, 22(5), 413-423. doi:https://doi.org/10.1016/S0141-0296(98)00135-7

ASTM A1035/A1035M - 15. (2015). Standard specification for deformed and plain, Low-Carbon, Chromium, steel bars for concrete reinforcement. West Conshohocken, PA: ASTM International. Retrieved from www.astm.org

ASTM A370 - 15. (2015). Standard test methods and definitions for mechanical testing of steel products. West Conshohocken, PA: ASTM International. Retrieved from www.astm.org

ASTM A615 / A615M - 15. (2015). Standard specification for deformed and plain Carbon-Steel bars for concrete reinforcement. West Conshohocken, PA: ASTM International. Retrieved from www.astm.org

ASTM C39 / C39M - 15. (2015). Standard test method for compressive strength of cylindrical concrete specimens. West Conshohocken, PA: ASTM International. Retrieved from www.astm.org 
ASTM C469 / C469M - 14. (2014). Standard test method for Static Modulus of Elasticity and Poisson's Ratio of concrete in compression. West Conshohocken, PA: ASTM International. Retrieved from www.astm.org

ASTM C78 / C78M - 15. (2015). Standard test method for flexural strength of concrete (using simple beam with third-point loading). West Conshohocken, PA: ASTM International. Retrieved from www.astm.org

ATC-115. (2014). Roadmap for the use of high-strength reinforcement in reinforced concrete design. Applied Technology Council. Redwood City, California: Charles Pankow Foundation.

Ayub, T., Shafiq, N., \& Nuruddin, M. (2014). Stress-strain response of high strength concrete and application of the existing models. Journal of Applied Sciences, Engineering and Technology, 8(10), 1174-1190.

Bischoff, P. H. (2005, May). Reevaluation of deflection prediction for concrete beams reinforced with steel and fiber reinforced polymer bars. Journal of structural engineering, 131(5), 752-767. doi:10.1061/(ASCE)0733-9445(2005)131:5(752)

Bischoff, P. H. (2007, January-Februay). Deflection calculation of FRP reinforced concrete beams based on modifications to the existing Branson equation. Journal of composites for construction, 11(1), 4-14. doi:10.1061/(ASCE)10900268(2007)11:1(4)

Branson, D. E. (1965). Instantaneous and time-dependent deflections of simple and continuous reinforced concrete beams. HPR Report No. 7, Part 1, Alabama Highway Department, Bureau of Public Roads (Dept. of Civil Engineering and Auburn Research Foundation, Auburn Univ., Aug. 1963), Alabama.

Brenkus, N. R., \& Hamilton, H. R. (2014, March-April). Proposed minimum steel provisions for prestressed and nonprestressed reinforced sections. ACI Structural Journal, 111(2), 431-440.

Carreira, D. J., \& Chu, K.-H. (1985). Stress-strain relationship for plain concrete in compression. ACI Journal, 82(6), 797-804.

Dawood, M., Seliem, H., Hassan, T., \& Rizkalla, S. (2004). Design guidelines for concrete beams reinforced with MMFX microcomposite reinforcing bars. International Conference on Future Vision and Challenges for Urban Development. Cairo.

Eltahawy, R., Hassan, T., Abd El-Wahed, O. H., \& Rizkalla, S. H. (2009). Flexural behavior of concrete beams reinforced with high strength steel reinforcing bars. Thirteen International Conference on Structural and Geotechnical Engineering. Cairo - Egypt. 
Frosch, R. J. (1999, May-June). Another look at cracking and crack control in reinforced concrete. ACI Structural Journal, 96(3), 437-442.

Frosch, R. J. (2001). Flexural crack control in reinforced concrete. Special Publication, 204, 135-153.

Gross, S. P., Yost, J. R., \& Kevgas, G. J. (2001). Time-Dependent Behavior of Normal and High Strength Concrete Beams Reinforced with GFRP Bars under Sustained Loads. International Conference on High Performance Materials in Bridges and Buildings, (pp. 451-462). Hawaii.

Harries, K. A., Shahrooz, B. M., \& Soltani, A. (2012, September-October). Flexural crack widths in concrete girders with high-strength reinforcement. Journal of bridge engineering, 17(5), 804-812.

Kalkan, I. (2013, January). Deflection prediction for reinforced concrete beams through different effective moment of inertia expressions. International Journal of Engineering Research and Development, 5(1).

Lu, Z.-H., \& Zhao, Y.-G. (2010, Nov.). Empirical stress-strain model for unconfined high-strength concrete under uniaxial compression. Journal of Materials in Civil Engineering, ASCE, 1181-1186.

Luebkaman, C. H., Nilson, A. H., \& Slate, F. O. (1985). Sustained load deflection of high strength concrete beams. Dept. of Structural Engineering, Cornell University.

Mast, R. F., Dawood, M., Rizkalla, S. H., \& Zia, P. (2008, September-October). Flexural strength design of concrete beams reinforced with high-strength steel bars. $A C I$ Structural Journal, 570-577.

Muhaisin, M. H. (2012). Long-term deflections for normal and high-strength reinforced concrete beams. Journal of Babylon University, Engineering Sciences, 20(1), 4662.

Nawy, E. G. (2010). Reinforced Concrete: A Fundamental Approach (6th ed.). New Jersey: Pearson Education, Inc.

NCHRP Report 679. (2011). Design of concrete structures using high-strength steel reinforcement. Washington, D.C.: National Cooperative Highway Research Program.

Nilson, A. (1985). Design implications of current research on high strength concrete. American Concrete Institute, Special Publication, 87, 85-117.

Nilson, A. H., Darwin, D., \& Dolan, C. W. (2010). Design of concrete structures (14th ed.). New York: McGraw Hill. 
NIST. (2014). Use of high-strength reinforcement in earthquake-resistant concrete structures. Prepared by NEHRP Consultants Joint Venture, a partnership of the Applied Technology Council and the Consortium of Universities for Research in Earthquake Engineering, for the National Institute of Standards and Technology, Gaithersburg, Maryland.

Orozco, C. E. (2015). Strain limits vs. reinforcement ratio limits - A collection of new and old formulas for the design of reinforced concrete sections. Case Studies in Structural Engineering, 4, 1-13.

Paulson, C., Rautenberg, J. M., Graham, S. K., \& Darwin, D. (2016, January-February). Defining yield strength for nonprestressed reinforcing steel. ACI Structural Journal, 113(1), 169-178.

Paulson, K. A., Nilson, A. H., \& Hover, K. C. (1991, March-April). Long-term deflection of high-strength concrete beams. ACI Materials Journal, 88(2), 197-206.

Rashid, M. A., \& Mansur, M. A. (2005, May-June). Reinforced high-strength concrete beams in flexure. ACI Structural Journal, 102(3), 462-471.

Seguirant, S. J., Brice, R., \& Khaleghi, B. (2010). Making sense of minimum flexural reinforcement requirements for reinforced concrete members. PCI Journal, 64-85.

Shafiq, N., Ayub, T., \& Nuruddin, M. (2014). Predictive stress-strain models for high strength concrete subjected to uniaxial compression. Applied Mechanics and Materials, 567, 476-481.

Shahrooz, B. M., Reis, J. M., Wells, E. L., Miller, R., Harries, K. A., \& Russell, H. G. (2010). Flexural behavior and design with high-strength bars and bars without a well-defined yield point. Transportation Research Record: Journal of the Transportation Research Board(2172), 103-111.

doi:http://dx.doi.org/10.3141/2172-12

Sharifi, Y., \& Maghsoudi, A. A. (2014, March 1). An experimental study on the flexural behavior of heavily steel reinforced beams with high-strength concrete. Frontiers of Structural and Civil Engineering, 8(1), 46-56. doi:10.1007/s11709-014-0237-y

Soltani, A. (2010). Deflection control for serviceability of reinforced concrete. In Bond and serviceability characterization of concrete reinforced with high strength steel (pp. 69-83). Doctoral dissertation, University of Pittsburgh.

Wee, T. H., Chin, M. S., \& Mansur, M. A. (1996, May). Stress-strain relationship of high-strength concrete in comression. Journal of Materials in Civil Engineering, 70-76. 
Whitney, C. S. (1937, March-April). Design of reinforced concrete members under flexure and combined flexure and direct compression. ACI Journal, 33, 483-498.

Yutakhong, P. (2003). Flexural performance of MMFX reinforcing bars in concrete structures. (Master's Thesis, North Carolina State University, 2003). 


\section{Appendix A: MATLAB Coding to Predict Load-Deflection Behavior}

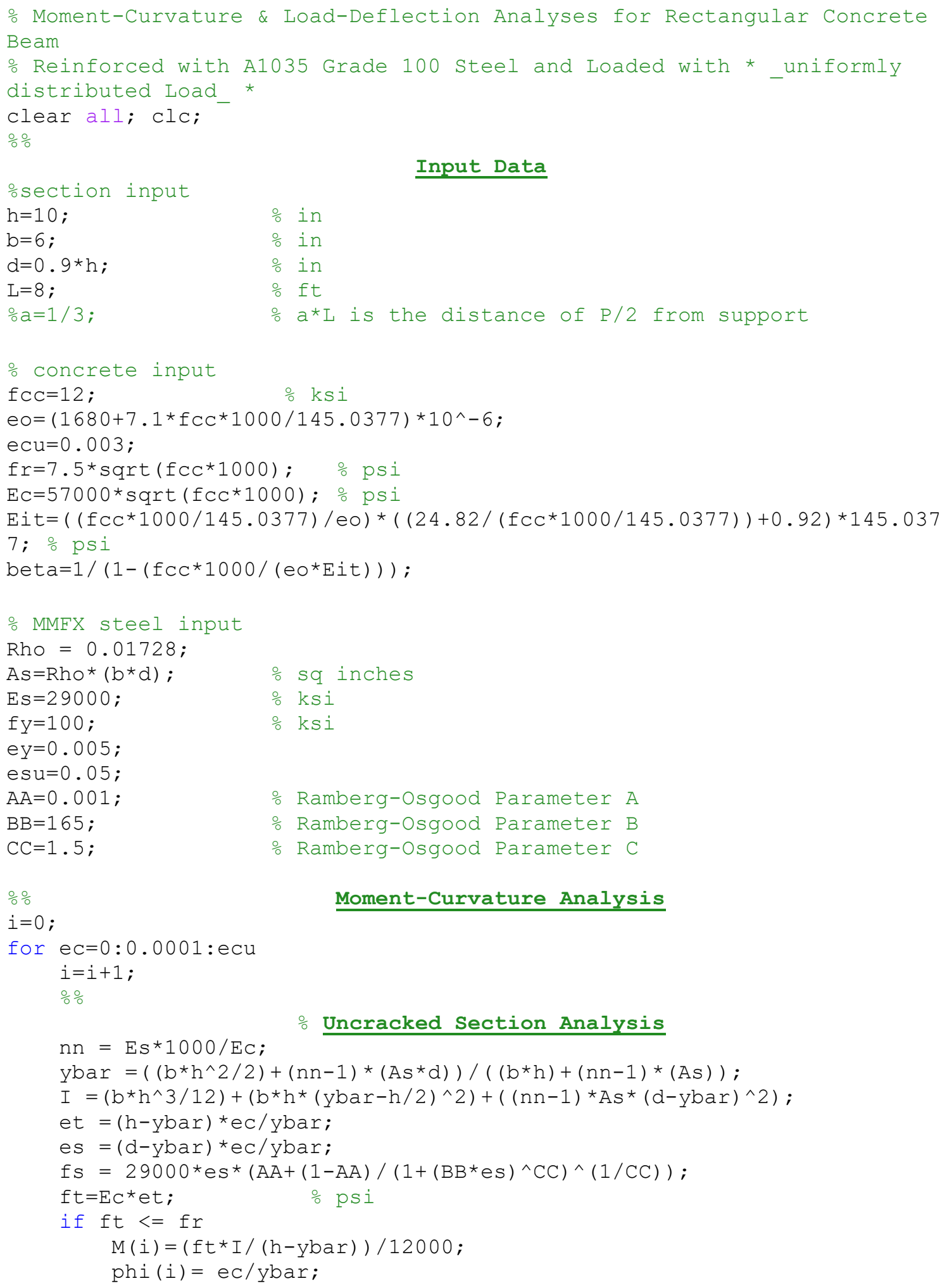




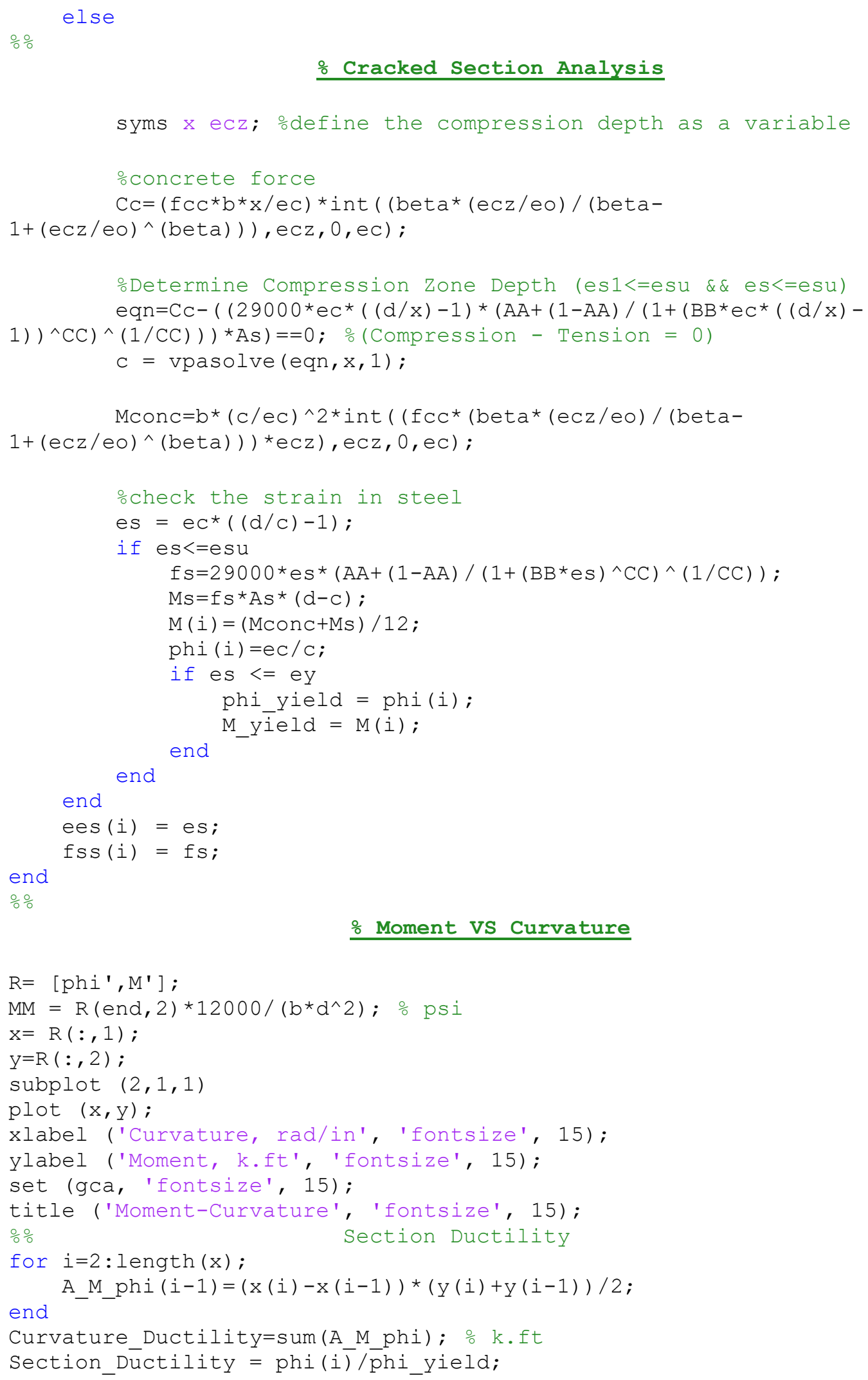

\% Moment VS Curvature 


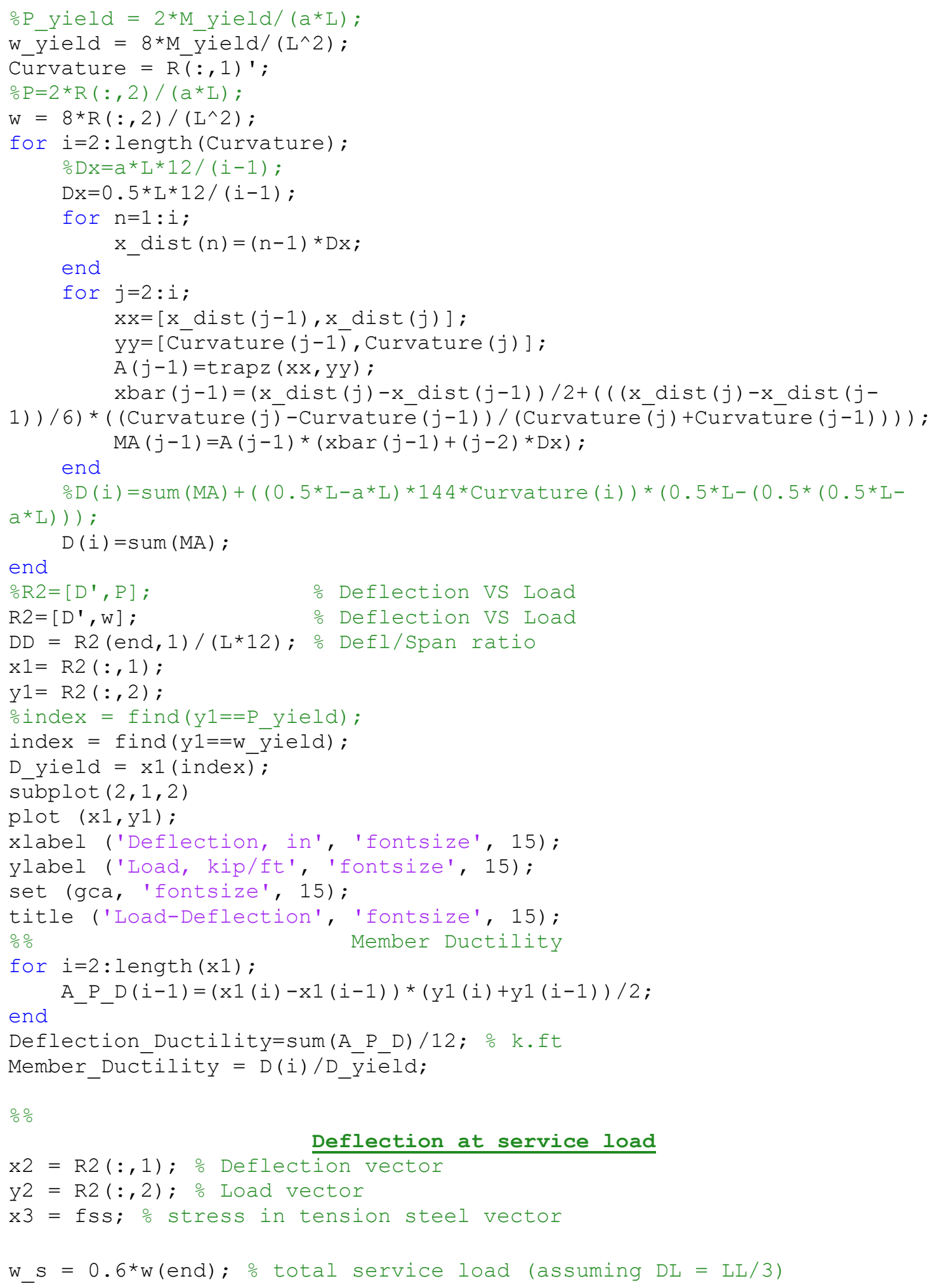




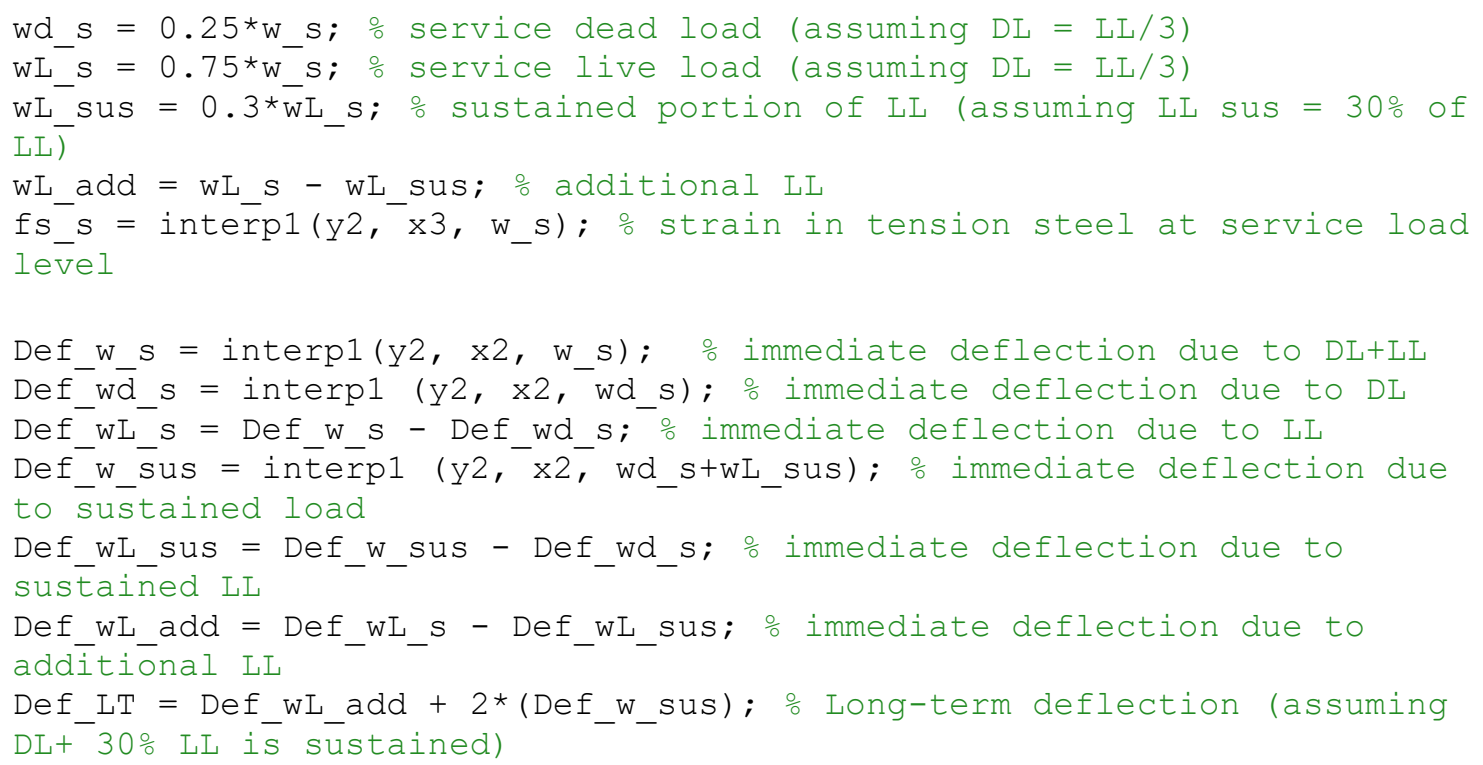




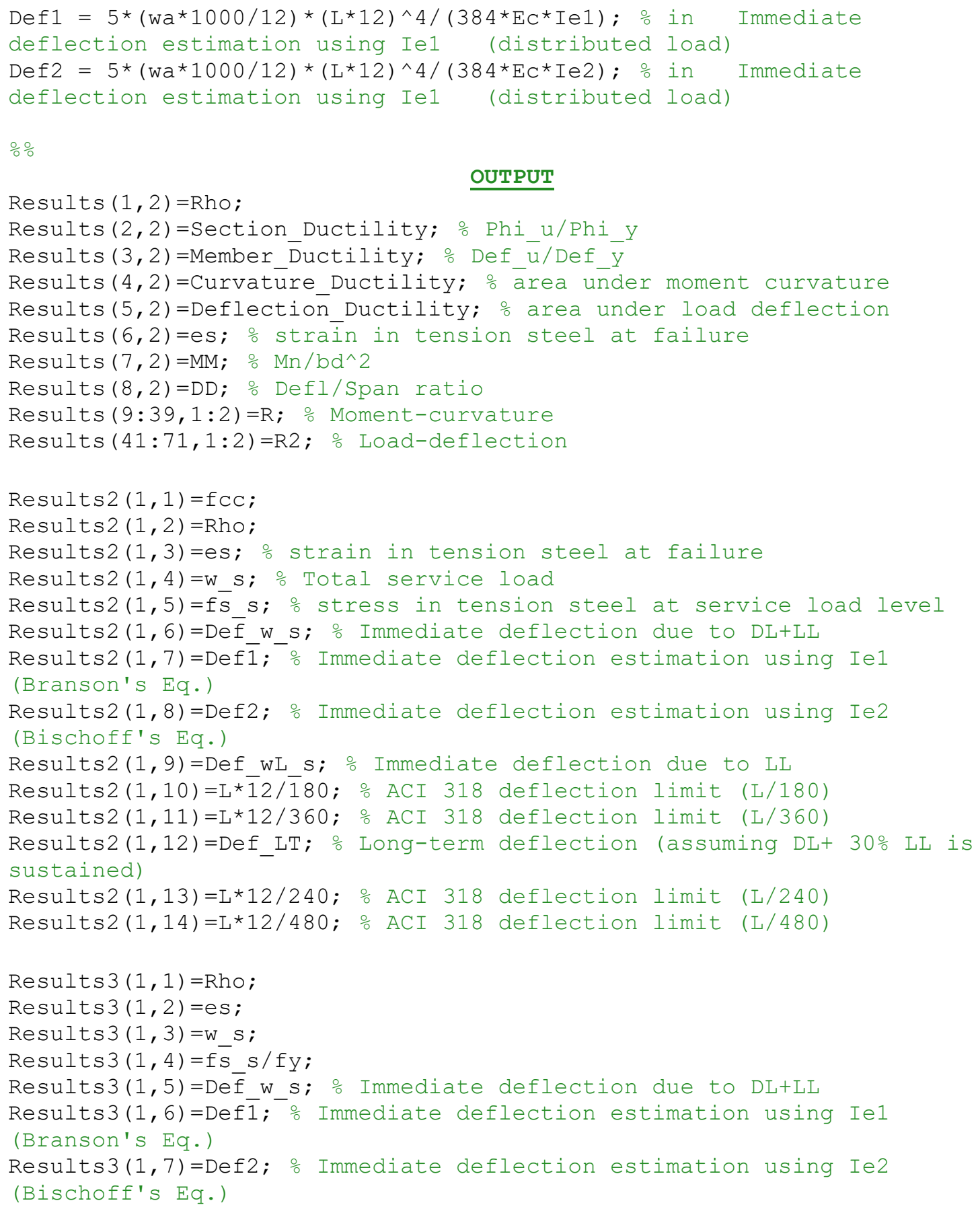


Appendix B: Design Charts for Beams Reinforced with HSR and Based on Materials Typical Stress-Strain Behavior
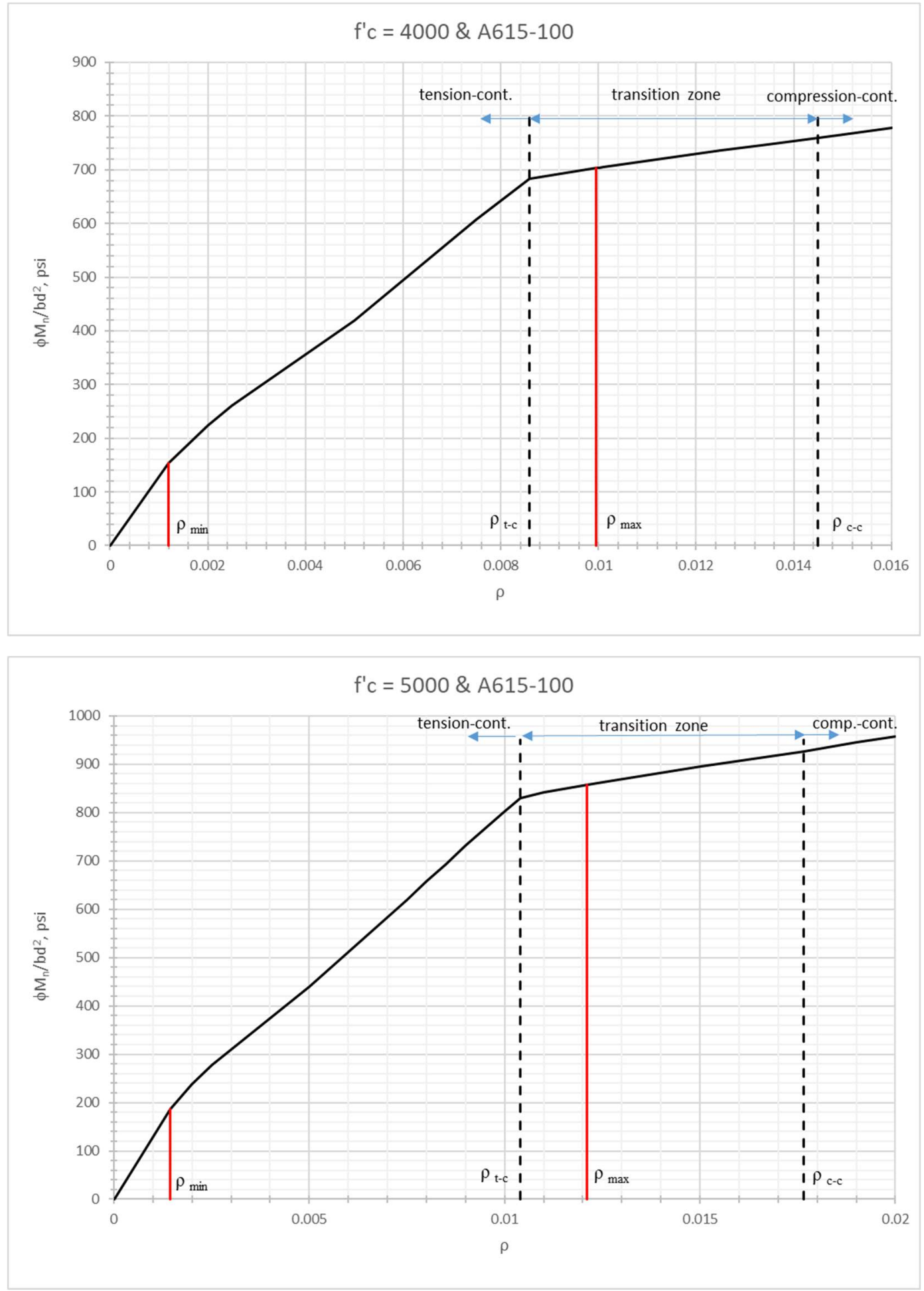

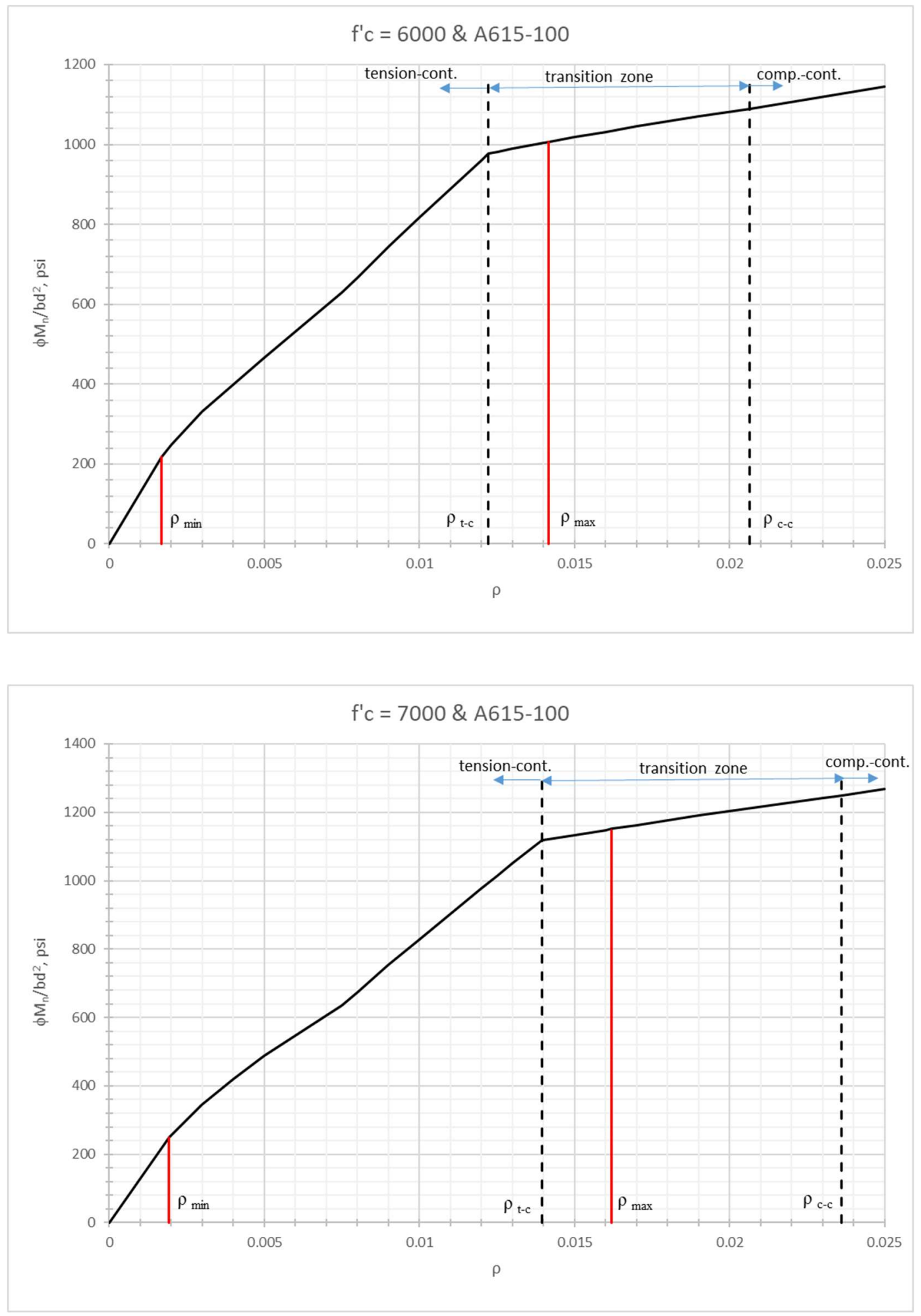

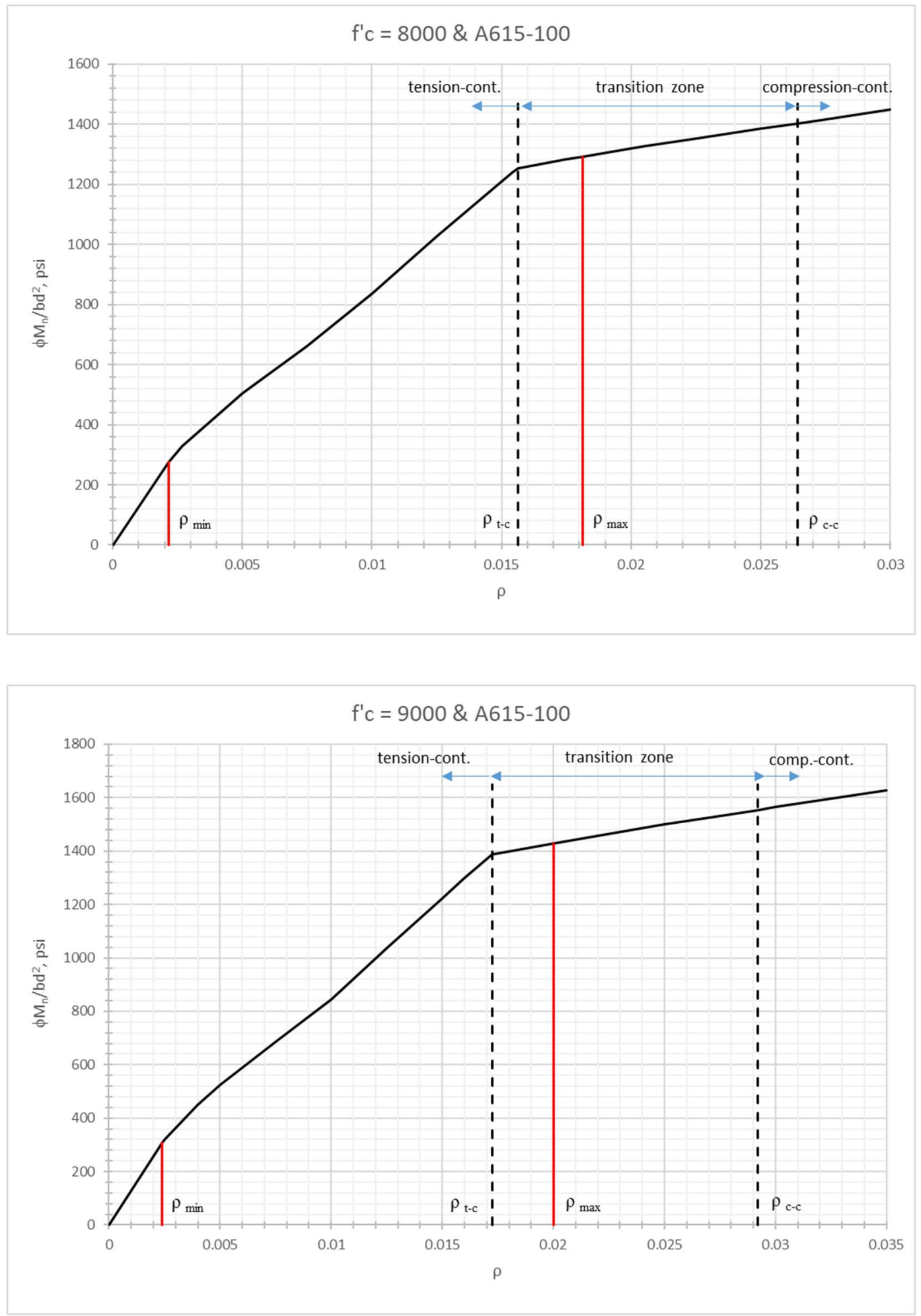

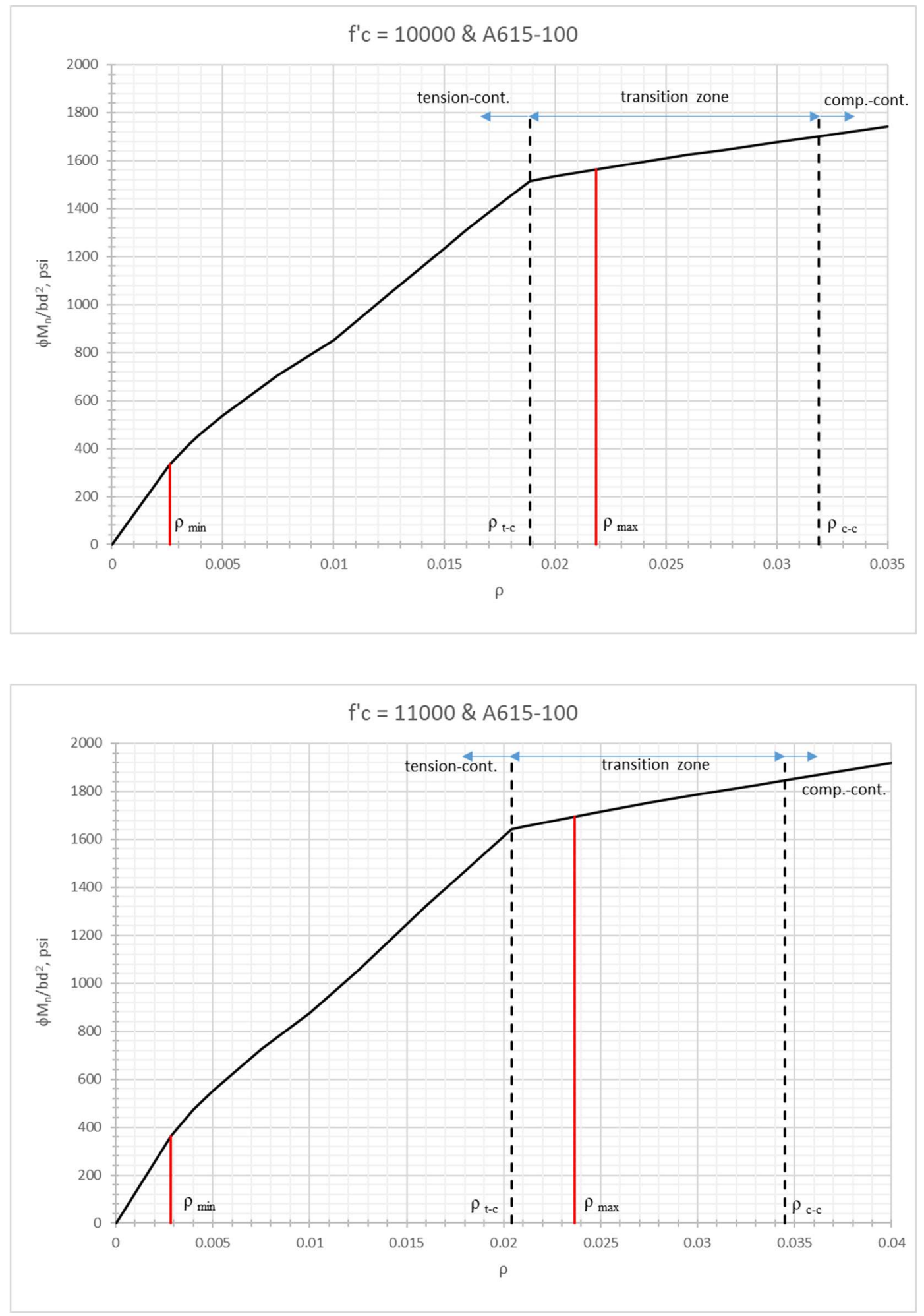

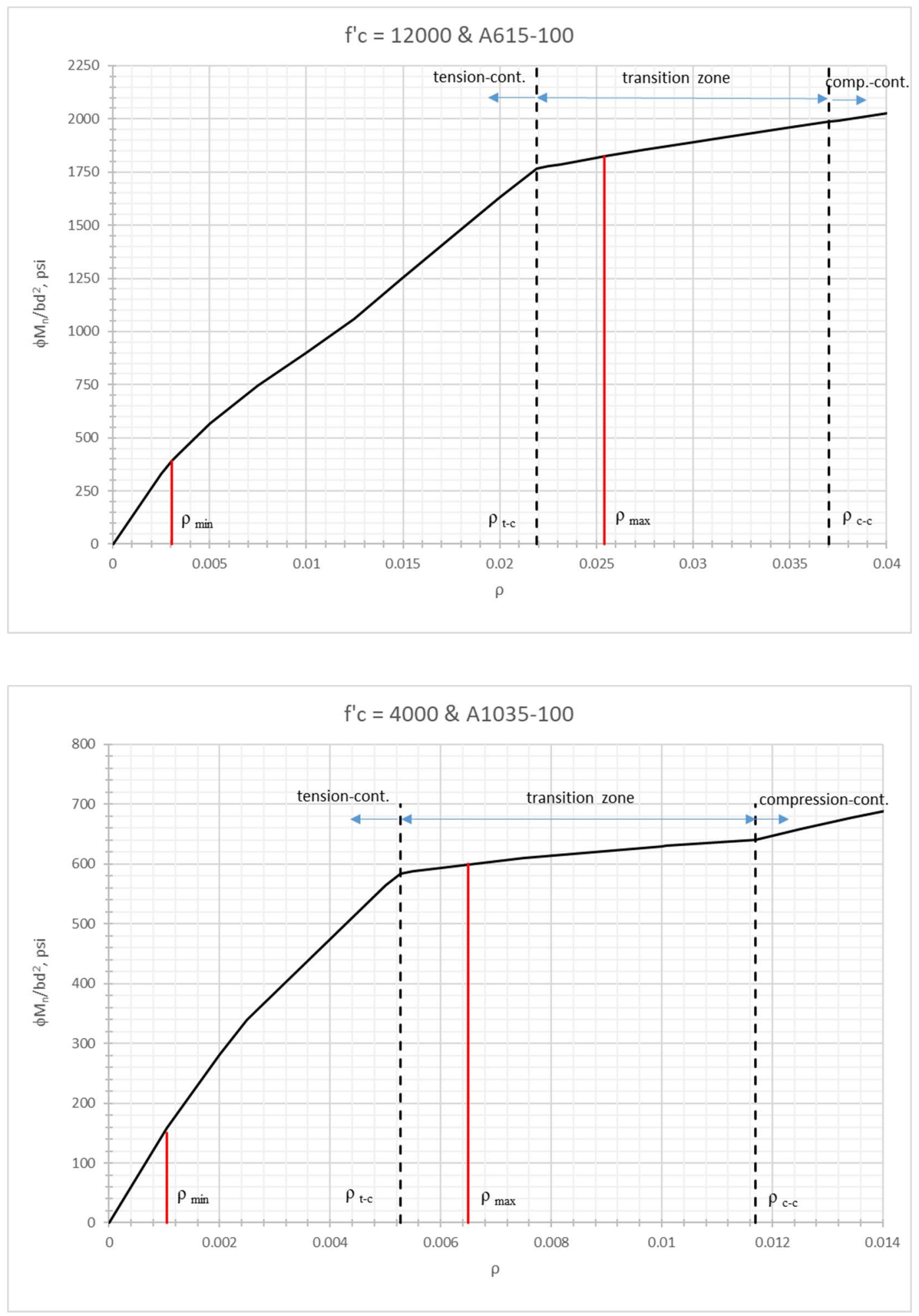

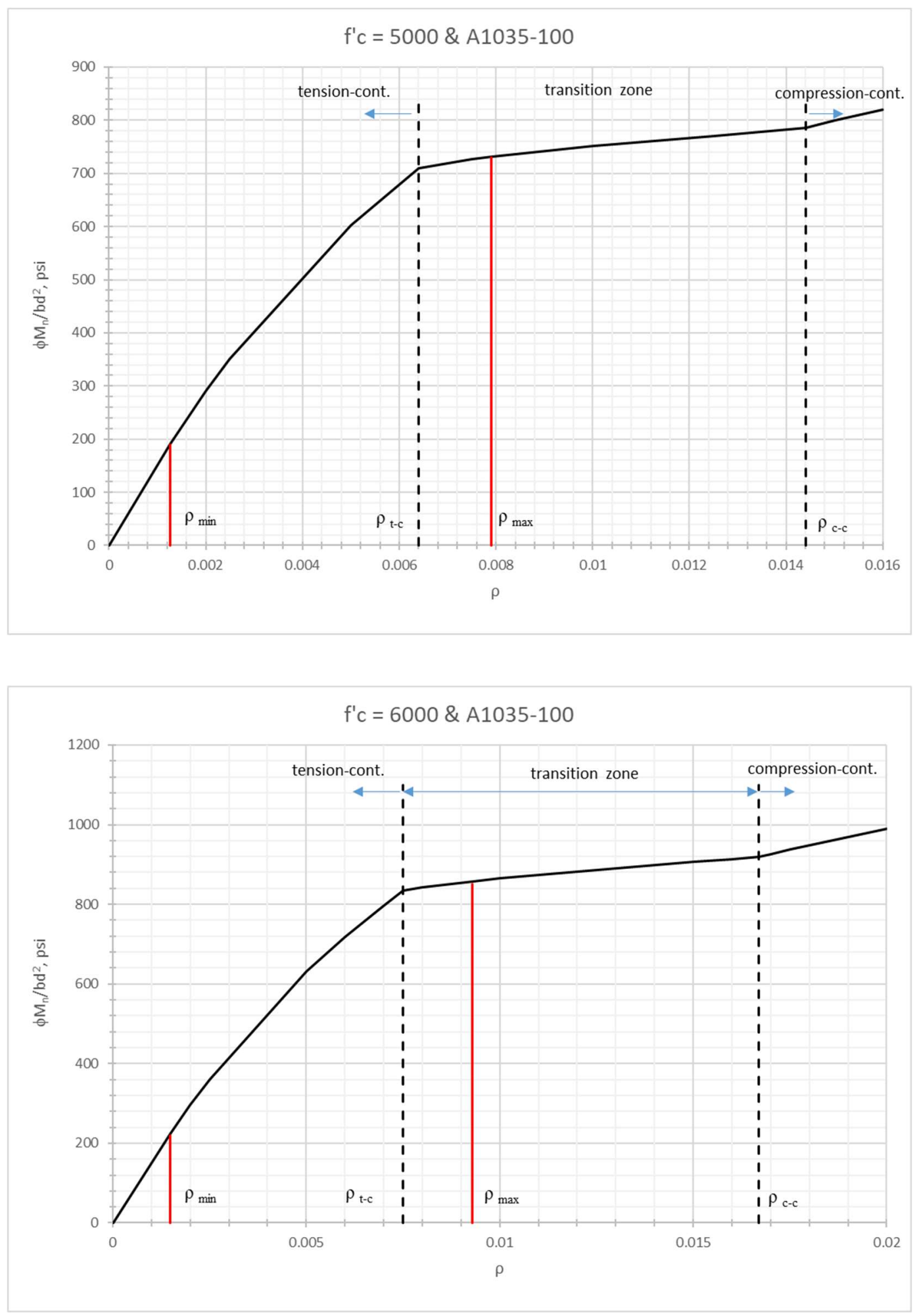

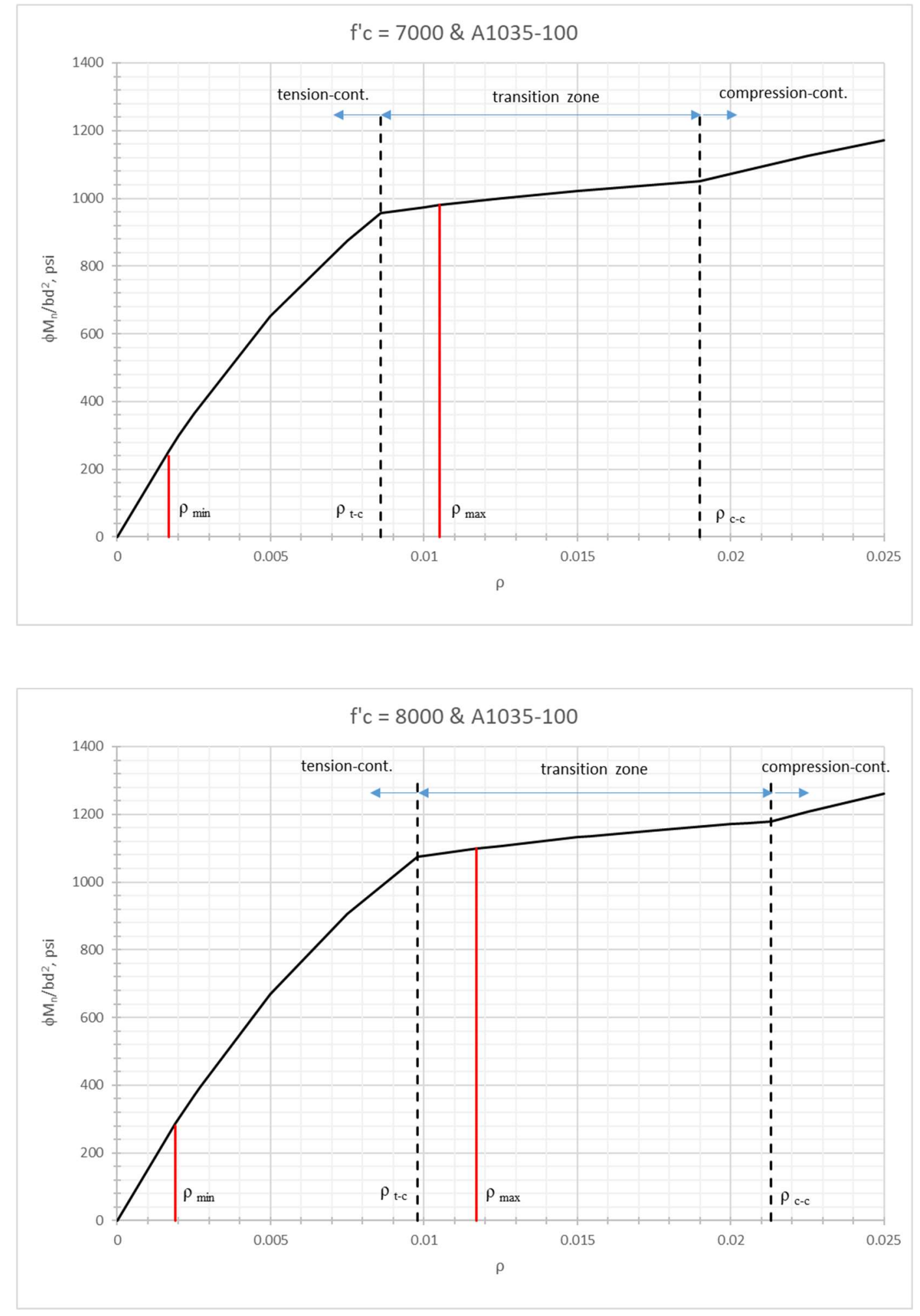

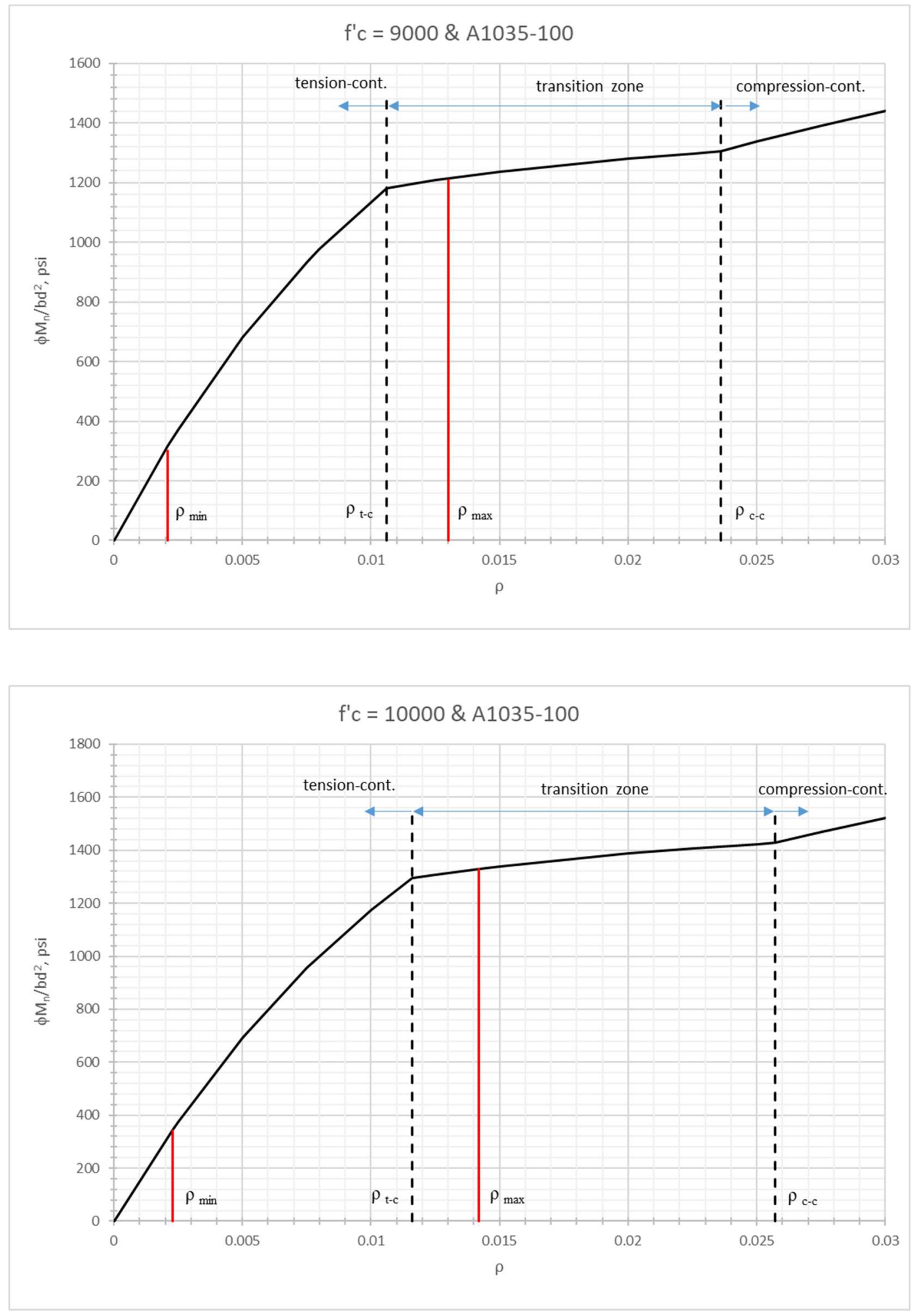

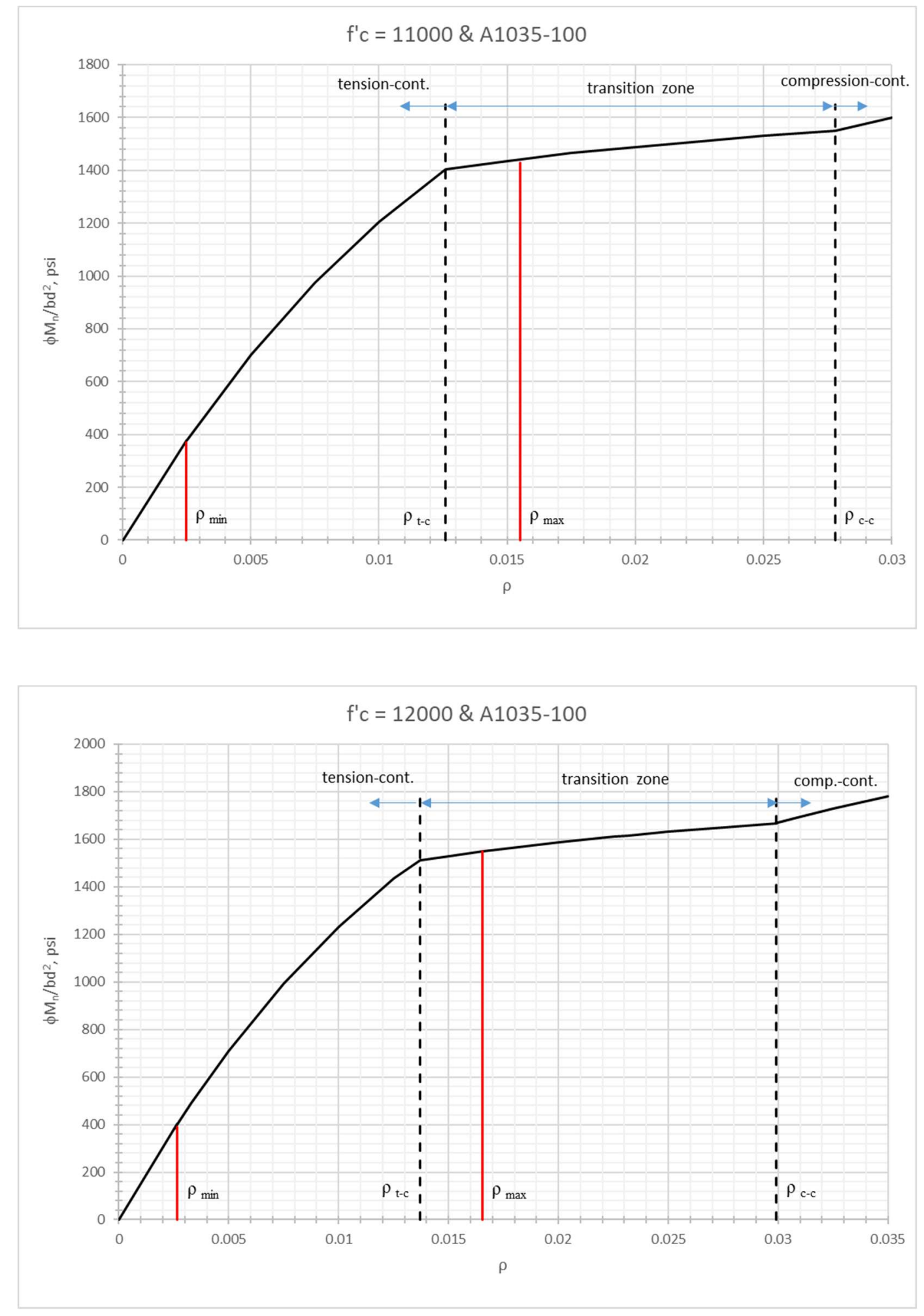

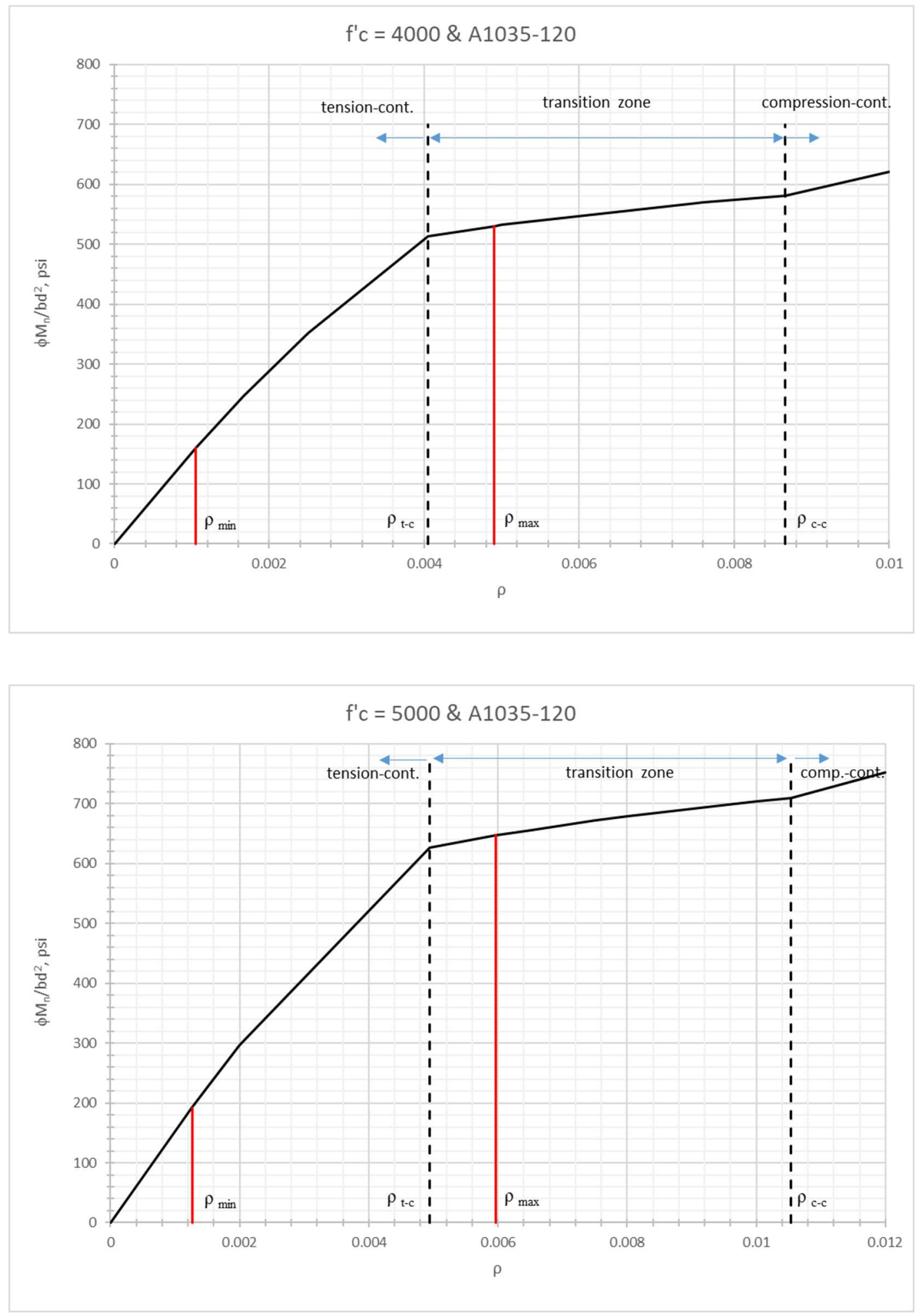

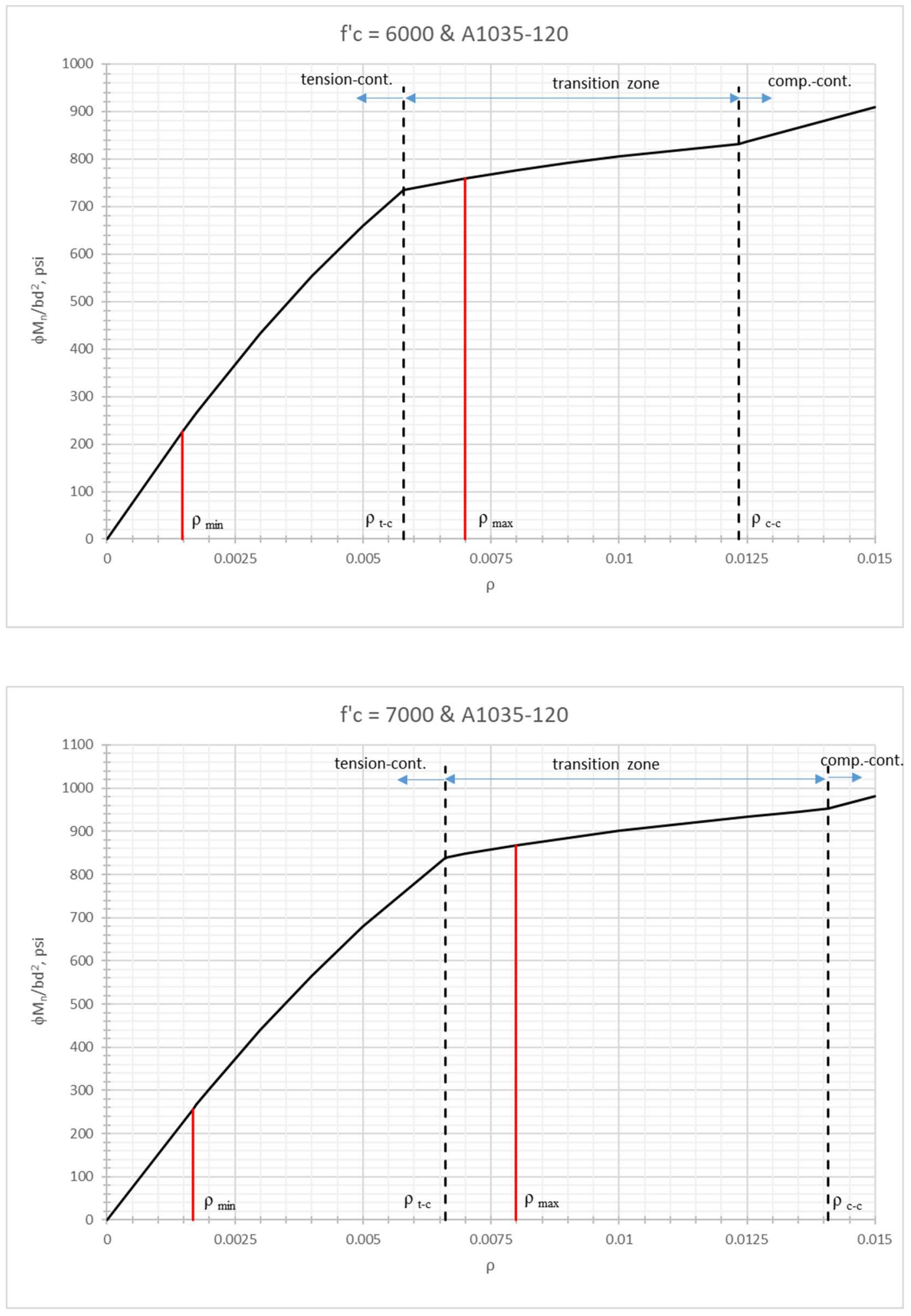

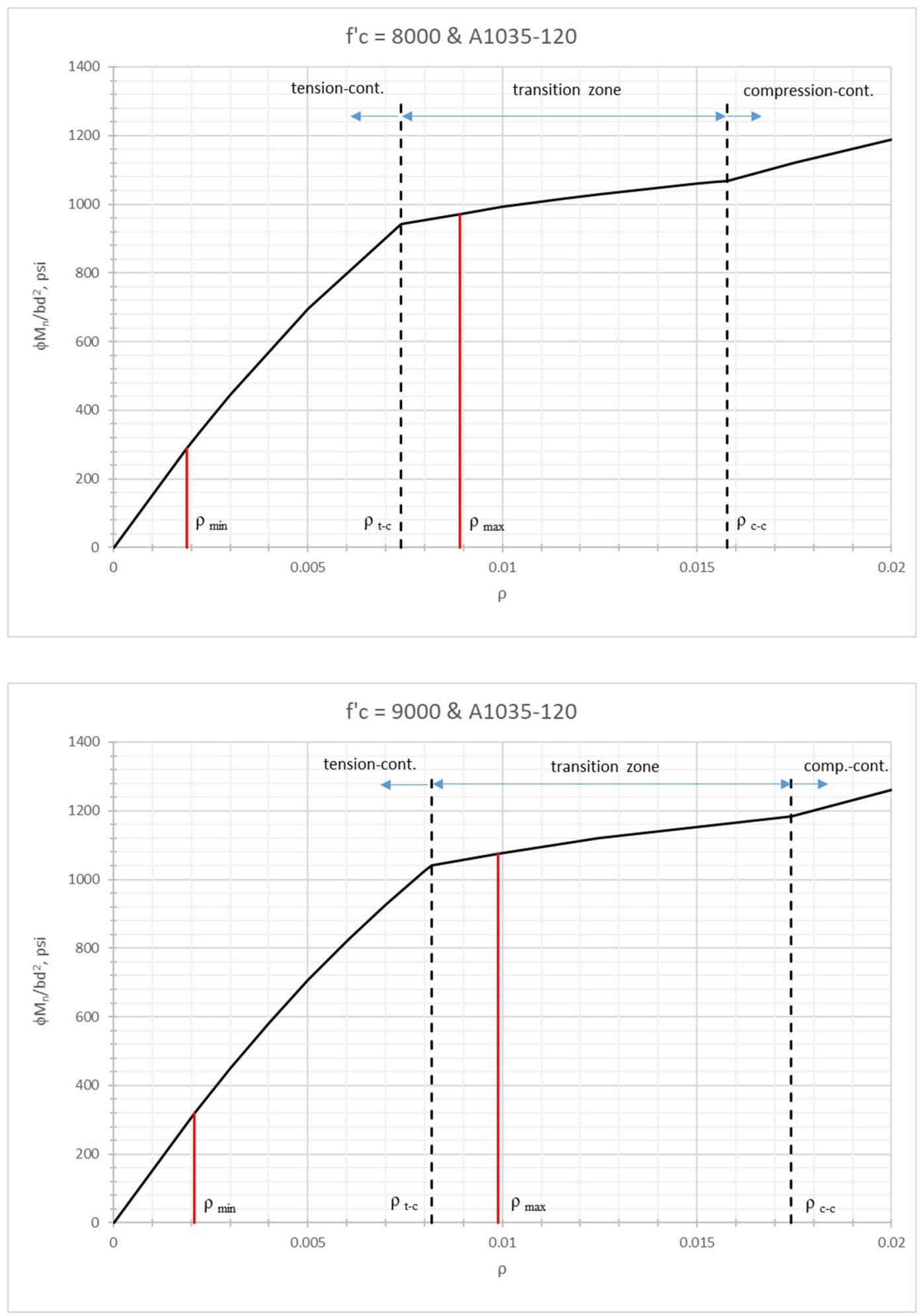

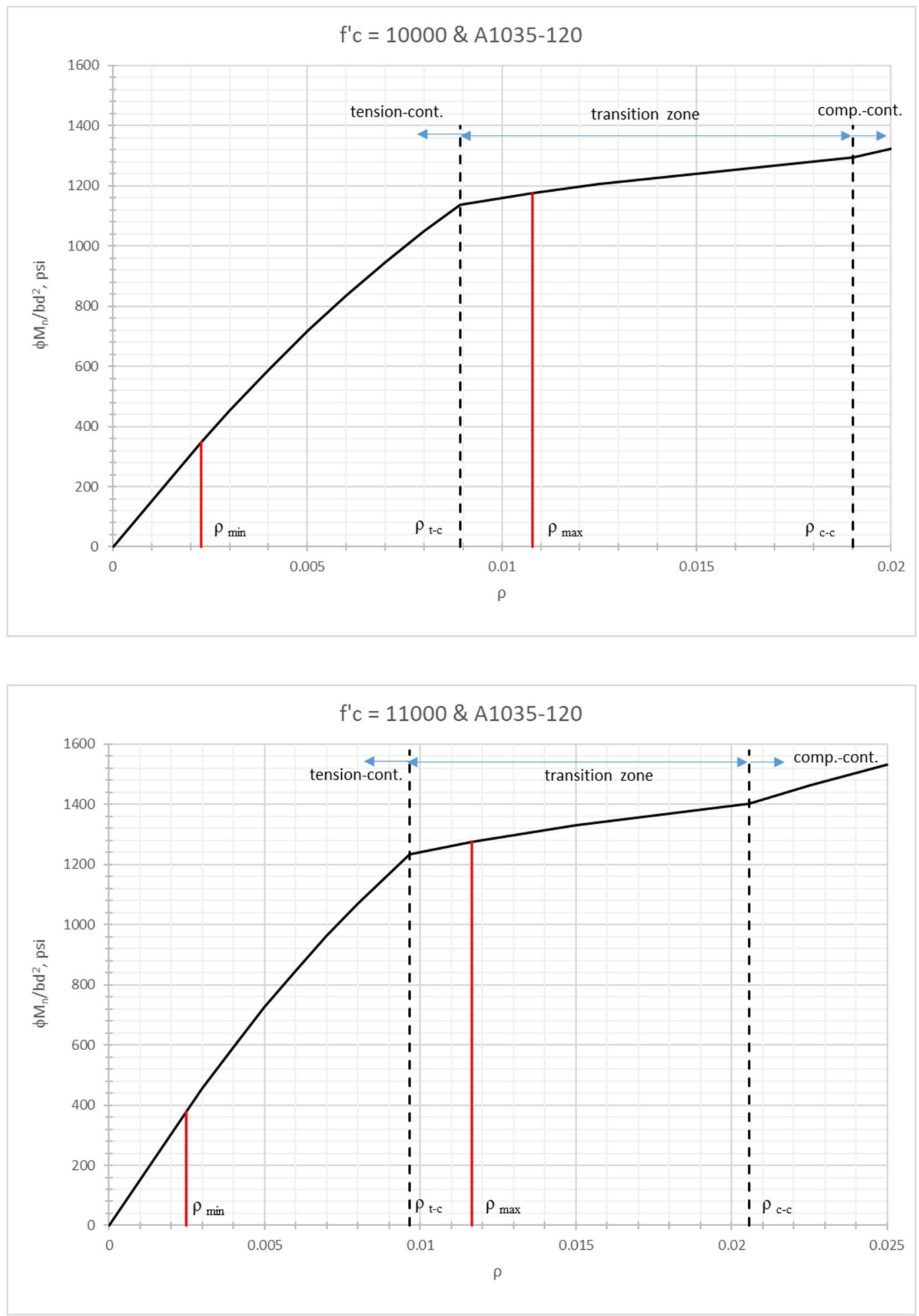


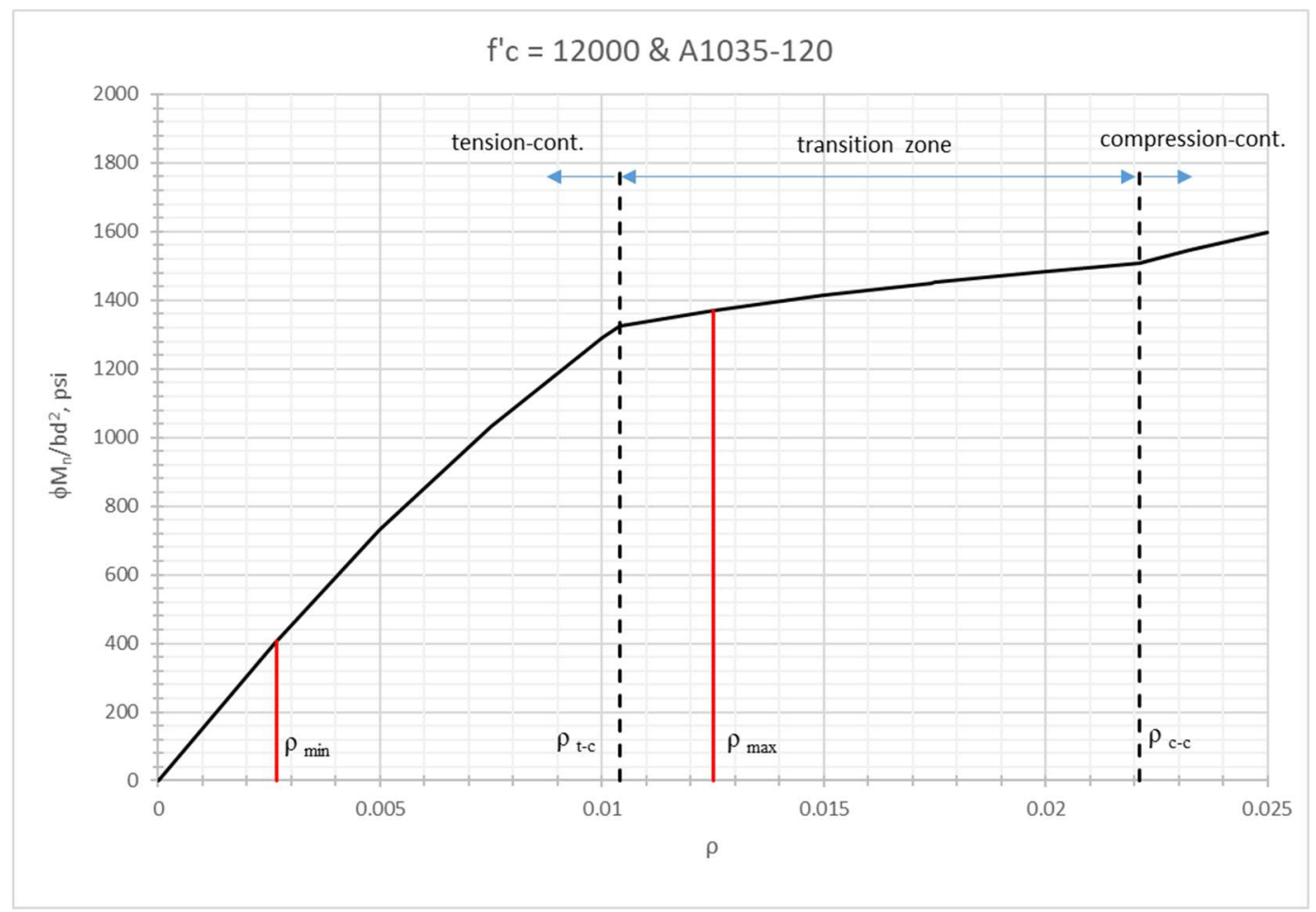




\section{Appendix C: Service Load Level Evaluation}

Service load level was evaluated as a ratio of the LRFD load level, i.e, $w_{u} / \varphi$. This ratio is denoted by $\left(\mathrm{w}_{\mathrm{s}} / \mathrm{w}_{\mathrm{n}}\right)$. In order to determine the ratio of $\mathrm{w}_{\mathrm{s}} / \mathrm{w}_{\mathrm{n}}$, the ratio of live load to dead load (L/D) was varied from 0.5 to 4.0. The following equation was applied to determine $\mathrm{w}_{\mathrm{s}} / \mathrm{w}_{\mathrm{n}}$ :

$\frac{w_{s}}{w_{n}}=\frac{D+L}{\frac{1}{\varphi}[1.2 D+1.6 k D]}=$ Service Load Level $/(1 / \varphi)$ LRFD Load Level

Where: $\mathrm{k}=\mathrm{L} / \mathrm{D}$ and $\varphi=0.9$

The two extreme $\mathrm{L} / \mathrm{D}$ ratios of 0.5 and 4.0 can be described as an example of 8 in. thick flat plate (self-weight $=100 \mathrm{psf}$ ) supporting a live load of $50 \mathrm{psf}$ and $400 \mathrm{psf}$ respectively. These combinations are very unlikely to occur in real practice. Ratio of L/D from 1.5 to 2.5 seem to have a higher probability of occurrence in practice, which lead to $\mathrm{w}_{\mathrm{s}} / \mathrm{w}_{\mathrm{n}}$ between 0.63 to 0.61 respectively, as shown in the figure below.

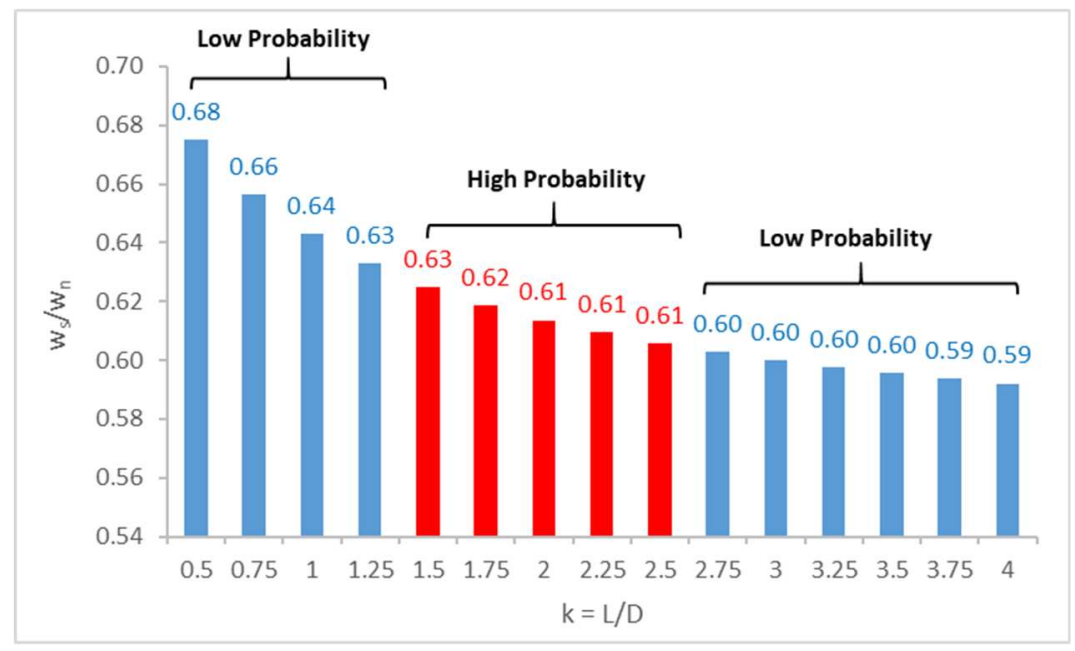

In this research, for simplicity, the service load level was assumed to be $60 \%$ of the nominal LRFD level load. 